Organisation de Coopération et de Développement Économiques

Organisation for Economic Co-operation and Development

23-Nov-2009

DIRECTORATE FOR EMPLOYMENT, LABOUR AND SOCIAL AFFAIRS

English text only HEALTH COMMITTEE

\title{
Health Working Papers
}

OECD HEALTH WORKING PAPERS No. 47

HEALTH CARE QUALITY INDICATORS PROJECT: PATIENT SAFETY INDICATORS REPORT 2009

Saskia Drösler, Patrick Romano, Lihan Wei

JEL Classifications: I19

Cross-country comparisons on patient safety are cautioned given that data presented in this working paper require further research and development.

This working paper has a separate annex with the code DELSA/HEA/WD/HWP(2009)5/ANN. 


\title{
DIRECTORATE FOR EMPLOYMENT, LABOUR AND SOCIAL AFFAIRS
}

\author{
www.oecd.org/els
}

\section{OECD HEALTH WORKING PAPERS}

\section{http://www.oecd.org/els/health/workingpapers}

This series is designed to make available to a wider readership health studies prepared for use within the OECD. Authorship is usually collective, but principal writers are named. The papers are generally available only in their original language - English or French - with a summary in the other.

Comment on the series is welcome, and should be sent to the Directorate for Employment, Labour and Social Affairs, 2, rue André-Pascal, 75775 PARIS CEDEX 16, France.

The opinions expressed and arguments employed here are the responsibility of the author(s) and do not necessarily reflect those of the OECD.

\section{Applications for permission to reproduce or translate all or part of this material should be made to:}

\author{
Head of Publications Service \\ OECD \\ 2, rue André-Pascal \\ 75775 Paris, CEDEX 16 \\ France
}

Copyright OECD 2009 


\section{ACKNOWLEDGEMENTS}

This paper presents the work of several years of research and development work by the HCQI Expert Group, particularly the members of the Patient Safety Subgroup and the data experts contributing data from the following countries: Australia, Belgium, Canada, Denmark, Finland, France, Germany, Iceland, Italy, Ireland, Latvia, Netherlands, New Zealand, Norway, Portugal, Singapore, Spain, Sweden, the United Kingdom and the United States. The authors would like to thank Daniel Tancreadi (University of California, Davis) for statistical analysis, Mark Pearson, Gaetan Lafortune, Ian Brownwood and Niek Klazinga for their contributions and Isabelle Vallard for editorial assistance.

The HCQI Project receives financial support from a grant provided by the Directorate General for Public Health and Consumer Affairs of the European Commission. 


\section{SUMMARY}

This paper reports on the progress in the research and development of the set of patient safety indicators developed by the Health Care Quality Indicators project. The indicators presented here have been recommended by an expert group for further consideration in international reporting on the quality of care on the key dimension of safety. The indicators have been selected by expert consensus, undergone validity testing and have been tested for comparability. While concern remains related to differences in coding and reporting from administrative hospital databases, the rigour with which the indicator work has been undertaken has resulted in the improved ability of countries to report on the quality of care. The work on the development of the patient safety indicators highlights the technical progress made in constructing measures and the ongoing need for methodological improvements. The indicators reported here should not be considered as making inferences on the state of patient safety in countries, but are intended to raise questions towards improving understanding of the reported differences.

\section{RÉSUMÉ}

Ce document présente l'état d'avancement de la recherche et du développement d'un ensemble d'indicateurs en matière de sécurité des patients dans le cadre du projet sur les indicateurs de la qualité des soins (HCQI). Un groupe d'experts a recommandé l'utilisation des indicateurs présentés ici pour les comparaisons internationales sur une dimension clé de la qualité des soins : la sécurité. Les indicateurs ont été sélectionnés par un consensus d'experts, leur validité et leur comparabilité ont été testées. Bien qu'il reste quelques problèmes quant aux différences de codage et de déclaration venant des bases de données administratives hospitalières, la rigueur du travail sur les indicateurs a permis d'améliorer la capacité des pays à rendre compte de la qualité des soins. Le développement des indicateurs de la sécurité des patients met l'accent sur les progrès techniques réalisés dans la construction de mesures et le besoin récurrent d'améliorer la méthodologie. Les indicateurs présentés ici ne doivent pas donner lieu à des conclusions quant à la situation de la sécurité des patients dans les pays, mais visent plutôt à poser des questions pour une meilleure compréhension des différences observées. 


\section{TABLE OF CONTENTS}

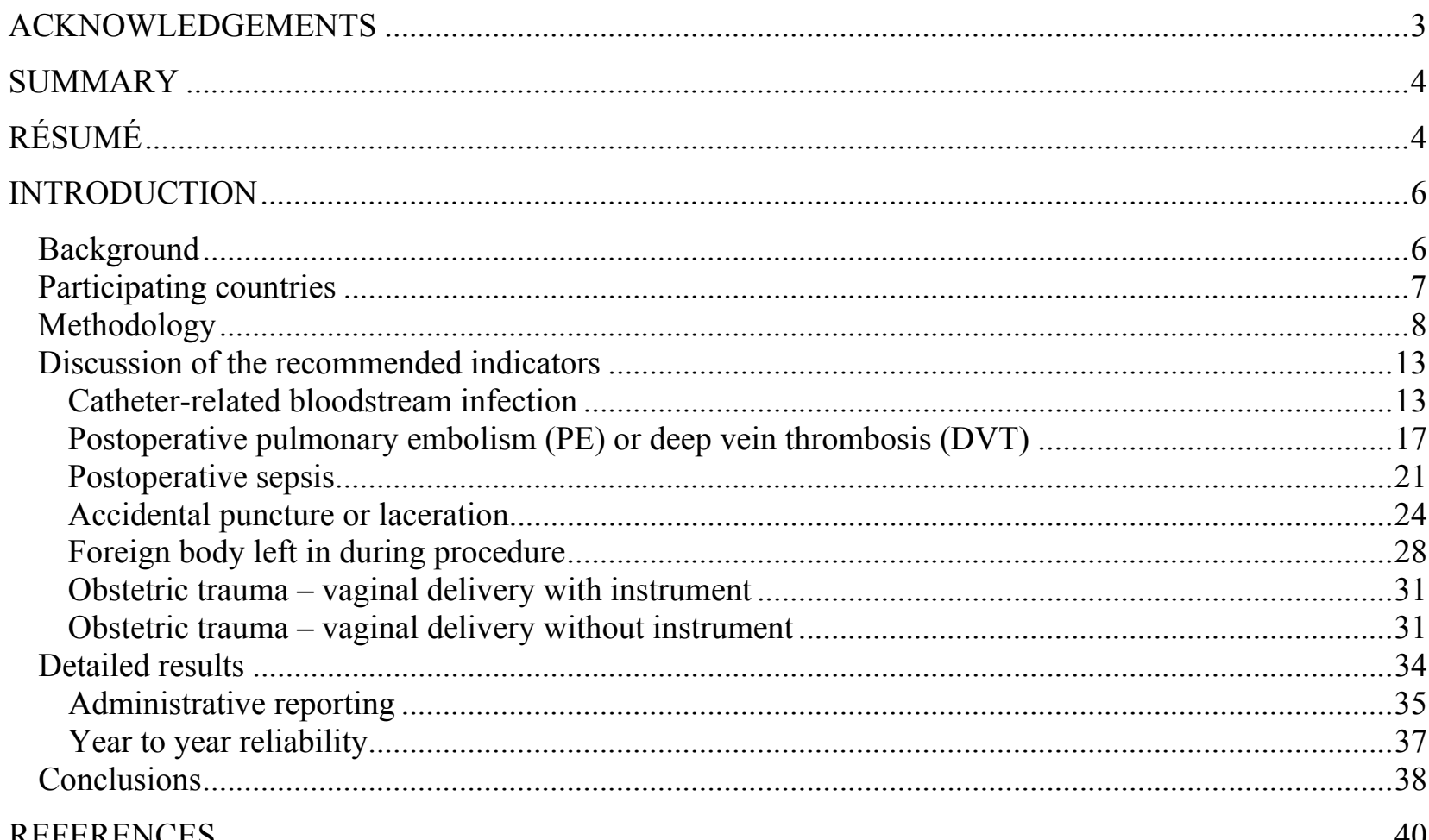

\section{Boxes}

Box 1. History of the patient safety indicators 


\section{INTRODUCTION}

\section{Background}

1. The OECD HCQI project identified patient safety as one of the priority areas for internationally comparable quality indicators. Government officials, national experts, academic researchers from participating countries, and the Secretariat have collaborated in the selection, data collection and validation of the recommended indicators. An extended discussion is presented here outlining the research and development for the seven proposed and agreed-upon indicators.

\section{Box 1. History of the patient safety indicators project}

In 2004, the OECD Health Care Quality Indicators Project identified patient safety as one of the five core priority areas for the development of quality indicators (along with cardiac care, primary care, mental health care and diabetes care). Using a structured review process, including a comprehensive literature review, clinician panel review, risk adjustment and empirical analysis, an expert panel selected, evaluated and recommended a set of patient safety indicators for comprehensiveness and cohesiveness across the five domains of patient safety: hospital-acquired infections; operative and postoperative complications; sentinel events ${ }^{1}$; obstetrics; and other care-related adverse events. From a total of 59 identified possible indicators, a group of 21 indicators was agreed upon based on their importance and scientific soundness (Millar et al, 2004).

In 2006, the first patient safety subgroup expert meeting met to discuss and evaluate the current state of patient safety data systems in OECD countries and potential areas of improvement in order to obtain reliable data for the proposed measures. Adverse events that occur rarely were identified as being somewhat outside the standardised data collection systems. National systems of coding patient safety were identified in OECD countries, although differing versions and adaptations employed in hospital administrative databases were recognised as a key area of development for international data comparability. One of the main outcomes of the meeting was the decision to develop an ICD crosswalk across versions of coding for international harmonisation of data comparability.

A comprehensive technical manual was developed to support the calculation of the 15 patient safety indicators to be collected in national hospital administrative databases. For each of the indicators, the manual provided detailed definitions of the indicators, coding and calculation processes, and a crosswalk from ICD 9 to ICD 10 coding (Drösler, 2008).

1

While all patient safety indicators refer to events that should occur rarely, sentinel events (including foreign body left in during procedure, transfusion reaction, wrong site surgery, etc.) are those that in theory and practice should never happen and thus whose occurrence should stand as a signal for immediate investigation. 
Three years of data collection, indicator development and methodology testing (2007-2009) have included a total participation from 21 countries (Table 1), with monthly teleconference meetings to refine definitions and methodology and yearly meetings of the patient safety expert subgroup to evaluate the validity of the methodology, data reliability and development of the data set. The 2009 data collection included a revised technical manual for the calculation of the indicators reflecting refinements and improvements in the methodology (see the Annex).

The long-term objective of the Health Care Quality Indicators project remains to develop a set of internationally comparable indicators that can then be used to raise questions for further exploration of the underlying reasons as to why these differences exist across and within countries. The patient safety indicators (as part of the larger set of quality indicators) represent measures selected for their importance - affect on health, policy relevance and susceptibility to influence by the health care system - and scientific soundness - face validity, content validity and reliability (Mattke et al., 2006).

2. Patient Safety Indicators (PSIs) originally published by the US Agency for Healthcare Research and Quality (AHRQ) have been evaluated to explore the potential of international comparison for patient safety and public reporting. Preliminary pilot studies among seven OECD member countries in 2007 (Drösler et al, 2009), and sixteen countries in 2008 showed the feasibility of the method. Countries were able to calculate most of the PSIs using their administrative hospital databases. Pilot results demonstrated that relative PSI rates appeared to be highly correlated across countries, although some countries had much lower rates for all PSIs than others.

3. The objectives of the PSI development work are:

1) To investigate the validity of the PSI rates of participating countries.

2) To evaluate the potential impacts on country-specific PSI rates of variation in the distribution of age and gender, length of hospital stay and diagnoses coding practices.

\section{Participating countries}

4. During the first three years of indicator development, the following countries (Table 1) participated in the data collection, validity testing and evaluation of the patient safety indicators. 
Table 1. Countries participating in the development of the patient safety indicators

\begin{tabular}{|c|c|c|c|}
\hline & 2007 & 2008 & 2009 \\
\hline Australia & $\mathrm{X}$ & & \\
\hline Belgium & & $x$ & $x$ \\
\hline Canada & 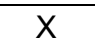 & $\mathrm{X}$ & $\mathrm{X}$ \\
\hline Denmark & & $\mathrm{X}$ & $x$ \\
\hline Finland & & $x$ & $x$ \\
\hline France & & $x$ & $x$ \\
\hline Germany & $x$ & $x$ & $x$ \\
\hline Iceland & & & $x$ \\
\hline Italy & & $x$ & $x$ \\
\hline Ireland & & & $\mathrm{X}$ \\
\hline Latvia & & & $\mathrm{X}$ \\
\hline Netherlands & & $x$ & \\
\hline New Zealand & & $x$ & $x$ \\
\hline Norway & & $x$ & $x$ \\
\hline Portugal & & $x$ & $\mathrm{X}$ \\
\hline Singapore & & $x$ & $x$ \\
\hline Spain & $x$ & $x$ & $x$ \\
\hline Sweden & $x$ & $x$ & $x$ \\
\hline Switzerland & & & $x$ \\
\hline United Kingdom & $x$ & $x$ & $x$ \\
\hline United States & $X$ & $x$ & $\mathrm{X}$ \\
\hline
\end{tabular}

\section{Methodology}

5. A set of 15 patient safety indicators was initially selected for development in 2007. Of these, seven were determined to be ready for data collection and analysis, based on the decision of the OECD's Patient Safety Expert Subgroup in October 2008 (Table 2). The other eight indicators either rely on procedure codes that proved difficult to map across countries (e.g., postoperative respiratory failure, iatrogenic pneumothorax), or they were found to have limited validity in North American studies that distinguished conditions present on admission from hospital-acquired complications (e.g., complications of anaesthesia, decubitus ulcer, postoperative hip fracture). 
Table 2: List of patient safety indicators evaluated

\begin{tabular}{|c|c|c|c|}
\hline Area & Indicator name & $\begin{array}{c}\text { AHRQ } \\
\text { PSI }\end{array}$ & $\begin{array}{c}\text { Recommended } \\
\text { for ongoing } \\
\text { evaluation }\end{array}$ \\
\hline \multirow{2}{*}{$\begin{array}{l}\text { Hospital-acquired } \\
\text { infections }\end{array}$} & Catheter-related bloodstream infection & PSI 7 & $\mathrm{X}$ \\
\hline & Decubitus ulcer & PSI 3 & \\
\hline \multirow{7}{*}{$\begin{array}{l}\text { Operative and post- } \\
\text { operative } \\
\text { complications }\end{array}$} & Complications of anaesthesia & PSI 1 & \\
\hline & Postoperative hip fracture & PSI 8 & \\
\hline & $\begin{array}{l}\text { Postoperative pulmonary embolism (PE) or deep vein } \\
\text { thrombosis (DVT) }\end{array}$ & PSI 12 & $\mathrm{X}$ \\
\hline & Postoperative sepsis & PSI 13 & $\mathrm{X}$ \\
\hline & Accidental puncture or laceration & PSI 15 & $\mathrm{X}$ \\
\hline & Postoperative respiratory failure & PSI 11 & \\
\hline & latrogenic pneumothorax & PSI 6 & \\
\hline \multirow{2}{*}{ Sentinel events } & Transfusion reaction & PSI 16 & \\
\hline & Foreign body left in during procedure & PSI 5 & $\mathrm{X}$ \\
\hline \multirow{4}{*}{ Obstetrics } & Birth trauma - injury to neonate & PSI 17 & \\
\hline & Obstetric trauma - vaginal delivery with instrument & PSI 18 & $\mathrm{X}$ \\
\hline & Obstetric trauma - vaginal delivery without instrument & PSI 19 & $\mathrm{X}$ \\
\hline & Obstetric trauma - caesarean section & PSI 20 & \\
\hline
\end{tabular}

6. An OECD calculation manual was provided (Annex), which adopted the PSI definitions as published by AHRQ (AHRQ, 2007) for most of the indicators. In addition, the manual provided internationally harmonised code lists in ICD-10 (Quan, 2008) as more than half of the participating countries use ICD-10 (Table 3). Countries were asked to complete an accompanying questionnaire to provide information on the databases and related data collection procedures.

7. Patent safety indicators are largely constructed from secondary diagnoses. The calculation of the numerator builds on secondary diagnosis for most of the indicators. The indicator definitions refer to conditions produced post admission.

8. $\quad$ Nineteen countries performed PSI calculations and delivered their results between February and June 2009. Table 3 shows some key country-related information derived from the questionnaires. Most of the participating countries use a hospital reimbursement system based on Diagnosis Related Groups (DRGs). This information is important as DRGs are based on coded health information. The use of coded health data for reimbursement creates incentives for accurate and complete documentation. However, although many countries use a DRG-based reimbursement system, the mean number of secondary diagnoses among eligible cases varied substantially between 0.87 (Italy, postoperative sepsis - PSI 15) and 7.02 (Belgium, accidental puncture or laceration - PSI 13). Finland reported relatively few secondary diagnoses (0.47) in the 2008 PSI calculation pilot but did not provide any information on the number of secondary diagnoses in 2009. Iceland and Latvia provided only obstetric indicators from registry data, so the number of secondary diagnoses is not relevant for these countries. 
Table 3. Country-related key information on medical classifications, documentation and reimbursement

\begin{tabular}{|c|c|c|c|c|c|}
\hline Country & Year & $\begin{array}{l}\text { Diagnosis } \\
\text { classification }\end{array}$ & $\begin{array}{l}\text { Procedure } \\
\text { classification }\end{array}$ & $\begin{array}{c}\text { Mean number of } \\
\text { secondary } \\
\text { diagnoses, } \\
\text { derived from } \\
\text { PSI } 5\end{array}$ & $\begin{array}{c}\text { DRG } \\
\text { reimbursement }\end{array}$ \\
\hline Belgium & 2006 & ICD-9 CM & ICD-9 CM & 6.72 & Yes \\
\hline Canada & 2007 & ICD-10 CA & $\mathrm{CCl}$ & 3.11 & Yes \\
\hline Denmark & 2008 & ICD-10 & NOMESCO & 2.41 & Yes \\
\hline Finland & 2007 & ICD-10 & NOMESCO & $\overline{\mathrm{NA}}$ & Yes \\
\hline France & 2007 & ICD-10 & CCAM & NA & Yes \\
\hline Germany & 2007 & ICD-10 GM (2007) & OPS 2007 & 5.31 & Yes \\
\hline Iceland & 2007 & ICD-10 & NOMESCO & $\overline{N A}$ & Yes \\
\hline Ireland & 2007 & $\begin{array}{l}\text { ICD-10 AM 4th } \\
\text { Edition }\end{array}$ & $\mathrm{ACHI}$ & 2.57 & Yes \\
\hline Italy & 2007 & ICD-9 CM (1997) & ICD-9 CM & 1.50 & Yes \\
\hline Latvia & 2007 & $\mathrm{NA}$ & NA & $\overline{N A}$ & NA \\
\hline New Zealand & 2007 & ICD-10 AM & $\mathrm{ACHI}$ & 3.93 & Yes \\
\hline Norway & 2007 & ICD-10 & NOMESCO & 1.90 & Yes \\
\hline Portugal & 2007 & ICD-9 CM & ICD-9 CM & $\mathrm{NA}$ & Yes \\
\hline Singapore & 2007 & ICD-9-AM & ICD-9-AM & 3.89 & Yes \\
\hline Spain & 2007 & $\begin{array}{l}\text { ICD-9 CM V22 } \\
(2004)\end{array}$ & ICD-9 CM & 3.71 & $\mathrm{No}^{1}$ \\
\hline Sweden $^{2}$ & 2007 & NA & $\mathrm{NA}$ & 2.50 & $\overline{N A}$ \\
\hline Switzerland & 2007 & ICD-10 WHO 1.3 & CHOP (ICD-9-CM) & 3.03 & Yes (partially) \\
\hline United Kingdom & 2007 & ICD-10 & OPCS 4.3 & 2.72 & Yes \\
\hline United States & 2006 & ICD-9 CM & ICD-9 CM & 6.02 & Yes \\
\hline
\end{tabular}

1. Reported that a DRG hospital payment system was in use for 2008 pilot.

2. From earlier data collections in 2007 and 2008, Sweden uses ICD-10, NOMESCO and a DRG system in some parts of the country. 
9. The number of cases included from each participating country can be approximated by the denominator of PSI 5 (foreign body left in during procedure). The eligible population for this indicator includes nearly all adult medical and surgical cases (Table 4). A comparison to the hospital discharge numbers reported by the OECD (2009) suggests that most countries used their complete administrative database for PSI calculation with the observed differences largely due to the exclusion of paediatric and obstetric patients from the denominator of PSI 5. Three countries (e.g. Germany, USA, and Sweden) used a sample for calculating their PSI rates. Only Denmark reported a slightly higher count in the PSI denominator than the total number of hospital discharges, presumably because these data come from 2008 and 2007 , respectively.

Table 4. Country-related information on discharge numbers and average length of stay

\begin{tabular}{|c|c|c|c|c|}
\hline Country & $\begin{array}{c}\text { Denominator } \\
\text { population PSI } 5 \text { (in } \\
\text { millions) }\end{array}$ & $\begin{array}{l}\text { Estimated annual } \\
\text { hospital discharges } \\
\text { (in millions, 2007) }\end{array}$ & $\begin{array}{l}\text { Average length of } \\
\text { stay (denominator } \\
\text { PSI 5) }\end{array}$ & $\begin{array}{l}\text { Average length of } \\
\text { stay (2007) }\end{array}$ \\
\hline Belgium & 1.52 & $1.83^{1}$ & 8.55 & $7.2^{1}$ \\
\hline Canada & 1.52 & $2.75^{1}$ & 8.14 & 7.3 \\
\hline Denmark & 1.00 & 0.93 & 4.49 & $3.5^{2}$ \\
\hline \begin{tabular}{|l} 
Finland \\
\end{tabular} & 0.94 & 1.00 & 3.60 & 4.6 \\
\hline Germany & $1.27^{3}$ & 18.67 & 8.76 & 7.8 \\
\hline Ireland & 0.46 & 0.60 & 7.30 & $5.9^{1}$ \\
\hline Italy & 7.25 & $8.11^{1}$ & 8.34 & $6.7^{1}$ \\
\hline New Zealand & 0.43 & 0.59 & 5.51 & NA \\
\hline Norway & 0.62 & 0.82 & 5.30 & 5.0 \\
\hline \begin{tabular}{|l} 
Portugal \\
\end{tabular} & NA & 1.15 & NA & 6.8 \\
\hline Singapore & 0.24 & $0.43^{5}$ & 5.91 & NA \\
\hline Spain & 3.29 & 4.78 & 7.73 & $6.6^{1}$ \\
\hline Sweden & $1.26^{3}$ & 1.51 & 5.05 & 4.5 \\
\hline \begin{tabular}{|l|} 
Switzerland \\
\end{tabular} & 0.93 & 1.26 & 8.25 & 7.8 \\
\hline United Kingdom & 6.68 & 7.32 & NA & 7.2 \\
\hline United States & $32.81^{4}$ & $37.74^{2}$ & 4.79 & $5.5^{6}$ \\
\hline
\end{tabular}

1. 2006.

2. 2005 .

3. PSI calculations are based on a $10 \%$ representative sample of the entire population of hospital discharges.

4. PSI calculations are based on a $20 \%$ representative sample of US hospital discharges, extrapolated to the total population.

5. www.moh.gov.sg

6. When the same data set (Nationwide Inpatient Sample) from which PSI rates were derived was also used to estimate mean length of stay in the USA, the value was 4.6 days.

Source: OECD Health Data 2009 (for estimated annual hospital discharges and average length of stay) 
10. A comparison of mean length of stay between the PSI calculation data and annually reported OECD data on health care activities shows concordance for most countries. It is expected that the average length of stay is longer among the denominator cases of PSI 5 than the corresponding average extracted from OECD Health Data, as children are excluded from the denominator population of PSI 5. Only Finland and USA report a shorter average length of stay in their PSI 5 data than the data they have submitted for OECD Health Data. This discrepancy for the USA is likely due to the use of a different data source for annual reporting to OECD on average length of stay (i.e. the American Hospital Associations voluntary annual survey of hospitals).

\section{Validity}

11. Applying general concepts of validation to the field of patient safety measurement, several potential domains of validity can be identified. Some of these domains are easier to evaluate than others; unfortunately, the most challenging domains to evaluate are often the most useful for those who wish to understand the meaning of the data.

12. Content validity addresses the extent to which the content of a measure is consistent with professional knowledge about health care quality and the outcomes of high-quality care. Consensual validation is the most rigorous approach for assessing the content validity of health care quality indicators, because it requires agreement or near-consensus among professionals from different disciplines, different regions, and different practice environments. Ideally, the expert panels convened for consensual validation represent all of the disciplines involved in treating the condition(s) of interest, include at least 8-10 members, and discuss all of the relevant evidence supporting use of the quality indicator.

13. Construct validity addresses the extent to which one purported measure of quality is correlated with other measures with which a high correlation would be expected, according to the conceptual framework underlying quality improvement research. The most common application of this approach, known as convergent validity, is to estimate correlations between measures of the process of care and measures of the outcomes of that care. Process measures include both implicit assessments, in which health professionals review available documents or other evidence to formulate a global assessment of quality, and explicit assessments, which focus on specific evidence-based diagnostic tests or treatments. Explicit process measures are typically preferred, because they are often (but not always) based on randomised controlled trials, which are relatively immune to bias from unmeasured confounders. Another approach to construct validation is to study associations between outcome measures and structural indicators, such as nurse staffing levels and skill mix, which have previously been shown to represent markers of quality. Finally, some authors test the construct that any meaningful adverse outcome should be associated with other adverse outcomes. Applied to patient safety measurement, this construct suggests that in-hospital adverse events should be associated with subsequent mortality, re-admissions, prolonged length of stay, and long-term disability.

14. Criterion validity addresses the extent to which one purported measure of quality is correlated with other, better measures of the same phenomenon. It implies the existence of a "gold standard" that can be used to evaluate less costly - and presumably less accurate - measurement methods. Applied to patient safety measurement, this approach typically involves comparing indicators based on routinely collected administrative data with indicators of the same outcomes based on more complex linked data, in-depth medical record review, physician/nurse interview, patient interview, or even direct observation. Criterion validity may represent the strongest validation approach, but its applicability is often limited by the lack of an accepted "gold standard". 
DELSA/HEA/WD/HWP(2009)5

\section{Discussion of the recommended indicators}

15. Charts in the following sections do not contain all data displayed in Table 6 (detailed results section below) due to validity concerns. Analysis of data quality revealed documentation patterns with the data that may indicate that some rates from some countries may not have been appropriate for PSI calculation. Even for rare events, zero rates are considered implausible for patient safety events (except sentinel events).

\section{Catheter-related bloodstream infection}

\section{Validity}

16. Rationale and concerns. As nosocomial infections are often preventable (Eggimann et al., 2000), the occurrence of infections in the course of medical care is an important measure of the quality of care. The indicator catheter-related bloodstream infection is supposed to flag cases with a hospital-acquired infection caused by intravenous lines or catheters. Infections related to medical care can be a very serious problem, leading to death in some cases. Often patients experience pain and others discomfort. Currently, WHO Patient Safety promotes the campaign "Clean Care is Safer Care" as it is proven that proper hand hygiene reduces the incidence of catheter-related bloodstream infections (WHO, 2009).

17. Content (consensual) validity. Content validity was addressed in the technical report accompanying the original release of the AHRQ PSIs (AHRQ, 2007). Although panellists' ratings of the "usefulness" of each candidate indicator were used to select the final PSI set, panellists were also asked to rate each indicator on its preventability and its likelihood of being due to medical error. The median rating of this indicator was 7, with indeterminate agreement, on the former dimension, leading to a classification of "acceptable". The median rating was 6 , with indeterminate agreement, on the latter dimension, leading to a classification of "unclear". Through similar processes, this PSI was endorsed by the OECD Patient Safety Panel (Millar et al., 2004), but rejected by the SimPatIE (Safety Improvement for Patients in Europe) project as "not suitable for implementation" due to potential casemix bias (Kristensen et al., 2009). A 47-member Delphi panel convened by RAND rated this indicator "low" in importance, although an otherwise identical indicator based on clinical data was rated "moderate" in importance and "close to ready for use" (Farley et al., 2008).

18. Construct (convergent, predictive) validity. This indicator rates very highly on predictive validity. Cases from the US Nationwide Inpatient Sample (NIS) that were flagged by this PSI in 2000 had $4.3 \%$ excess mortality, 9.6 days of excess hospitalisation, and $\$ 38700$ in excess hospital charges, relative to carefully matched controls that were not flagged (Zhan and Miller, 2003). This finding was confirmed in the Veterans Affairs (VA) hospital system, where cases that were flagged by this PSI in 2001 had 2.7\% excess mortality, 4.5-9.5 days of excess hospitalisation, and \$7 292-13 816 in excess hospital costs, relative to carefully matched controls that were not flagged (Rivard et al., 2008). A more recent replication using 2007 data, corrected for infections that were reported as "present on admission", estimated 16.1 attributable hospital days and \$33 118 in attributable hospital costs for the average case (Foster et al., 2009). In a commercial claims database from 45 large employers in the USA, each event (aggregating this PSI with postoperative sepsis) was associated not just with $3.1 \%$ excess mortality, but also with $7.7 \%$ excess readmissions, which added \$2 594 to the total attributable cost per event (Encinosa and Hellinger, 2008). A case control analysis from England estimated excess mortality of 5.7\% and 11.4 days of excess hospitalisation (Raleigh et al., 2008). Finally, the largest reported estimates of these impacts came from a study of children at 38 freestanding paediatric hospitals in the USA in 2006 (i.e., 22.4 hospital days, $\$ 172484$ in hospital charges) (Kronman et al., 2008). 
19. In a study testing construct validity using an implicit process measure of quality (Miller et al., 2005), smoothed rates of this PSI among 2116 hospitals surveyed by the Joint Commission in 1997-1999 were not associated with summary evaluation scores (although a later study of 115 hospitals surveyed in 2002 found a significant association with one patient safety practice subscore on "assessing patient needs") (Thornlow and Merwin, 2009). Indeed, the occurrence of one or more events flagged by this indicator, among 3594 hospitals that treated Medicare patients in the USA in 2003, was associated with better performance on process-of-care measures for three medical conditions and lower risk-adjusted mortality for five of six high-risk categories of patients (Isaac and Jha, 2008). Rates of this PSI were inversely associated with adoption of strategic information technology applications among 98 Florida hospitals (Menachemi et al., 2007), and with adoption of electronic medical record (EMR) systems among Medicare patients (Parente and McCullough 2009), but not among 66 Georgia hospitals (Culler et al., 2007).

20. A correlational study based on the 1997-2002 Nationwide Inpatient Sample (USA) labelled this indicator as a "canary measure" because it was significantly and consistently associated with at least nine other AHRQ Patient Safety Indicators at the hospital level (Yao et al., 2009). For both Medicare and Veterans Health Administration patients, this indicator loaded strongly with two other PSIs (iatrogenic pneumothorax and postoperative DVT/PE) on a common factor (Rosen et al., 2009). Finally, this indicator was significantly associated with re-admission within three months (risk ratio=1.29), but not within one month (risk ratio $=1.00$ ), after adjusting for patient characteristics using 2004 surgical data from seven US states (Friedman et al., 2009). Unadjusted data from England confirm the association between this PSI and re-admission (Bottle and Aylin, 2009).

21. Although children aged less than 15 years were excluded from OECD analyses, data on the validity of this indicator in paediatric populations may still be relevant. Physicians participating in the National Association of Children's Hospitals and Related Institutions' (NACHRI) Pediatric PSI Collaborative reviewed 145 flagged events from 14 hospitals in 2003, using an online tool to assess implicit process of care, and judged $39 \%$ to be preventable and only $31 \%$ to be clearly non-preventable (Sedman et al., 2005; Scanlon et al., 2006). In a follow-up study of 2003-2005 data from 28 children's hospitals $(\mathrm{N}=285$ events), $11 \%$ were incorrectly coded and $43 \%$ of the remainder were present on admission; only $20-41 \%$ of all flagged events were judged to be preventable (Scanlon et al., 2008).

22. Criterion validity. No evidence about the criterion validity of this indicator was available before its original release as an AHRQ indicator. It is now known that this indicator has a minor problem due to missing data about timing. Some US data sets now include a "flag" variable denoting whether each diagnosis was present at admission. The percentage of cases flagged by this PSI for whom the event was reported to be a complication of the hospital stay was $65 \%$ in California, $65 \%$ in New York, $60 \%$ in the Rochester, Minnesota area, and 36-44\% at the University of Michigan (Houchens et al., 2008; Naessens et al., 2007; Bahl et al., 2008). Hospital-specific rates including infections reported as present on admission were moderately correlated with hospital-specific rates excluding such infections ( $\mathrm{r}=0.91$ in California, $\mathrm{r}=0.88$ in New York), especially among coronary artery bypass surgery patients ( $\mathrm{r}=0.99$ in California) (Glance et al., 2008).

23. The best recent evidence about the positive predictive value (PPV) of this indicator comes from the 47 hospitals participating in the AHRQ PSI Validation Pilot Project $(\mathrm{N}=191)$. In this study, 20\% of the flagged events were present at admission, 21\% lacked clear documentation of an eligible infection, and 4\% had an unreported disqualifying comorbid condition (i.e., cancer, severe malnutrition, immunodeficiencies), leaving 55\% that were confirmed as iatrogenic complications (Zrelak et al., 2009). All of the confirmed events were attributable to a vascular device, including central venous catheters (74\%), peripheral venous catheters, and arterial catheters. 
24. A similar review of medical records of 168 cases from 18 English NHS (National Health Service) trusts found that $6 \%$ of the flagged events were present at admission and $12 \%$ were miscoded, leaving $79 \%$ that were confirmed (Bottle and Aylin 2008). Finally, evidence from New York and New Zealand suggests that a significant number of true events may not be ascertained because they occur after hospital discharge; linking 30-day re-admissions in New York increased the overall rate of this PSI from 2.02 to 2.52 per 1000 eligible discharges; $56 \%$ of the post-discharge events were complications of haemodialysis (Gallagher et al., 2005a; Stevanovic 2009). One study from 24 US hospitals participating in a patient safety collaborative reported the sensitivity of this PSI as only 9\% relative to case ascertainment using National Healthcare Safety Network protocols ( $\mathrm{N}=89$ ); PPV could not be evaluated due to the study design (Stone et al., 2007).

25. In summary, recent evidence on construct validity and criterion validity is moderately supportive of this indicator. A recent change to the ICD-9-CM coding of catheter-associated infections $(999.31=$ "infection due to central venous catheter") should enhance its criterion validity in countries that use ICD-9$\mathrm{CM}$, by excluding most of the false positive cases captured by the previous definition. Based on limited information, underreporting is a serious concern. Risk adjustment is recommended for inter-provider comparisons (AHRQ, 2007) to ensure that variation due to different patient populations across institutions is removed.

\section{Findings}

26. Reported catheter-related bloodstream infection rates vary across participating OECD countries between 0.01 and $0.4 \%$ (Chart 1). Hospital-acquired infections occur far more often in male patients than in females in all countries. Direct adjustment for 5-year age-gender strata did not affect indicator rates or rankings across countries. A correlation between indicator rate and amount of documentation can be found for the indicator (Chart 2, Spearman $\mathrm{r}=0.912, \mathrm{p}<0.0001$ ). In Belgium and USA the mean number of secondary diagnoses is more than two times greater than in Denmark and Switzerland, which might explain elevated infection rates reported by these countries. Underreporting is likely for countries with low infection rates. The rates represented in the charts below have not been age-sex standardised or adjusted for secondary diagnoses or length of stay. 


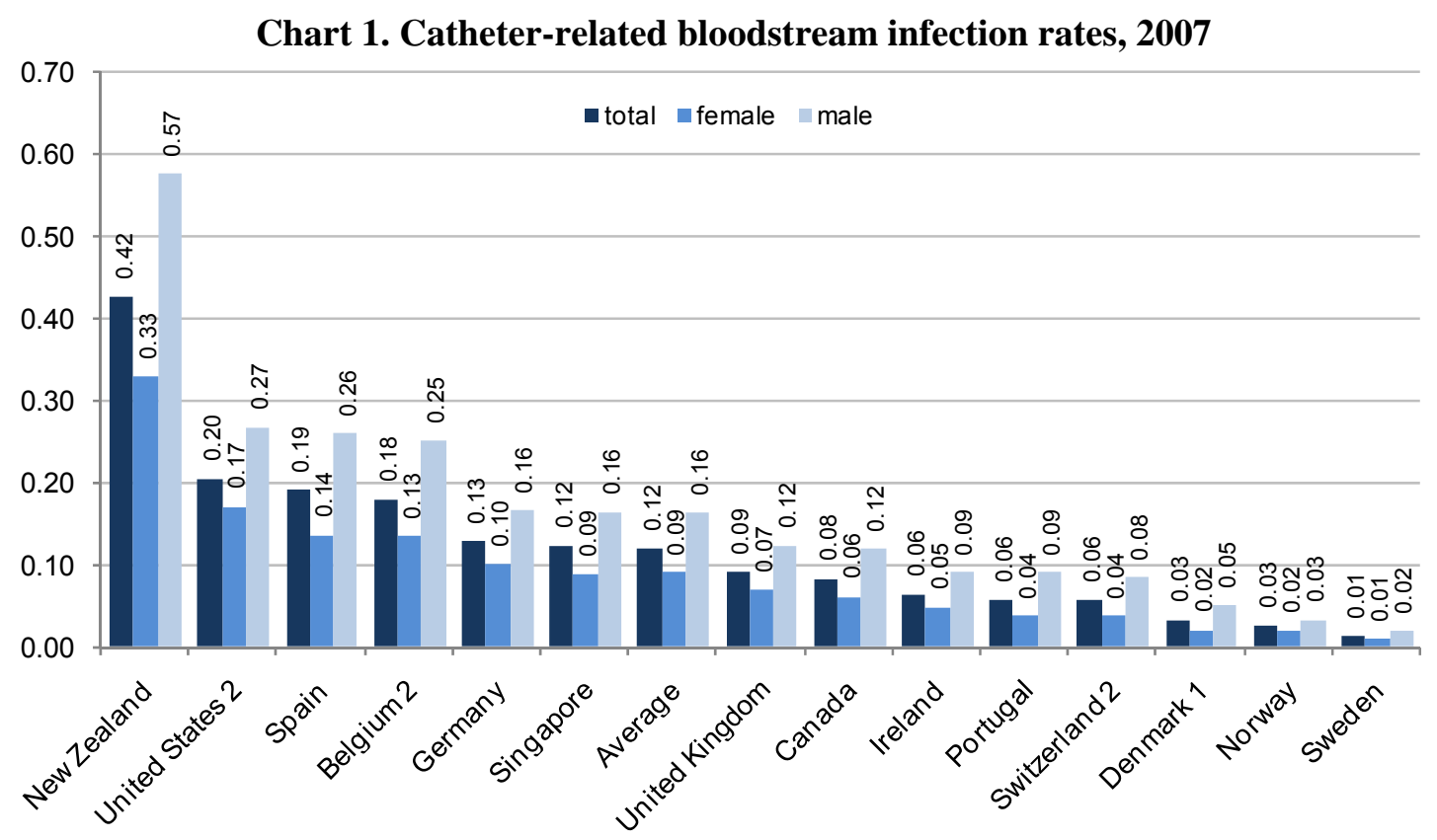

1. 2008. 2. 2006

Note: Rates based on hospital administrative databases as reported by countries for the research and development work of the HCQI project.

Chart 2. Catheter-related bloodstream infection rates and mean number of secondary diagnoses, 2007

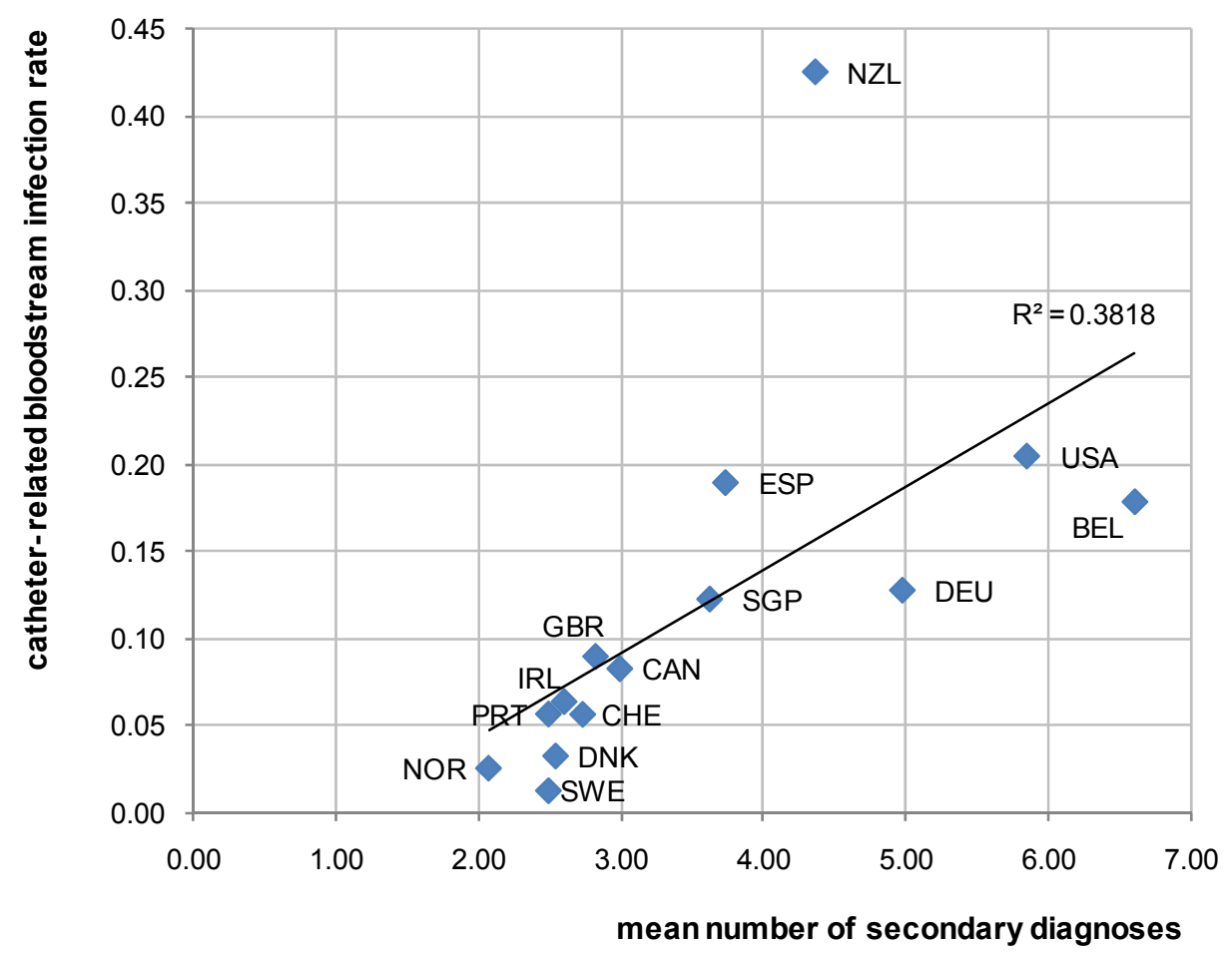

Note: Rates based on hospital administrative databases as reported by countries for the research and development work of the HCQI project. 


\title{
Postoperative pulmonary embolism (PE) or deep vein thrombosis (DVT)
}

\author{
Validity
}

27. Rationale and concerns. The occurrence of postoperative PE/DVT can range from mild symptoms to devastating clinical consequences including pain, respiratory distress, and death. Regarding pulmonary embolism, the mortality rate is less than $8 \%$ when detected and correctly treated but about $30 \%$ when the condition is unrecognised and not treated (Olin, 2002). Because PE/DVT can cause unnecessary prolongation of hospital stays as well as unnecessary pain, suffering and death, this indicator has important financial and quality improvement implications. This adverse event can be prevented through the appropriate use of anticoagulants and other preventive measures; evidence based guidelines are available (Geerts et al., 2004). This indicator based on administrative hospital data was proposed in 1994 (Iezzoni et al., 1994) and subsequently further investigated (Miller et al., 2001).

28. Content (consensual) validity. Content validity was addressed in the technical report accompanying the original release of the AHRQ PSIs. Although panellists' ratings of the "usefulness" of each candidate indicator were used to select the final PSI set, panellists were also asked to rate each indicator on its preventability and its likelihood of being due to medical error. The median ratings of this indicator on the former dimension from two independent panels were 7 and 6 , with indeterminate agreement and disagreement, respectively, leading to classifications of "acceptable" and "unclear", respectively. The median ratings of this indicator on the latter dimension were 6 and 3 , with indeterminate agreement, leading to classifications of "unclear" and "unacceptable", respectively.

29. Through similar processes, this PSI was endorsed by the OECD Patient Safety Panel (Millar et al., 2004) and the National Quality Forum (time-limited due to ICD-9-CM changes), but rejected by the SimPatIE (Safety Improvement for Patients in Europe) project as "not suitable for implementation" due to potential casemix bias (Kristensen et al., 2009). A 47-member Delphi panel convened by RAND rated this indicator "moderate" in importance, but lower on validity (i.e., median ratings 8 and 6, respectively) (Farley et al., 2008). Over diagnosis through increased ultrasound screening of high-risk but asymptomatic postoperative patients is an emerging concern (Haut et al., 2007).

30. Construct (convergent, predictive) validity. This indicator rates very highly on predictive validity. Cases from the NIS that were flagged by this PSI had 6.6\% excess mortality, 5.4 days of excess hospitalisation, and \$21 700 in excess hospital charges, relative to carefully matched controls that were not flagged (Zhan and Miller, 2003). This finding was confirmed in the Veterans Affairs hospital system, where cases that were flagged by this PSI had 6.1\% excess mortality, 4.5-5.5 days of excess hospitalisation, and \$7 205-9 064 in excess hospital costs, relative to carefully matched controls that were not flagged (Rivard et al., 2008). A more recent replication using 2007 data, corrected for thromboses that were reported as "present on admission", estimated 7.8 attributable hospital days and \$18 331 in attributable hospital costs for the average case (Foster et al., 2009).

31. In a study testing construct validity using an implicit process measure of quality (Miller et al., 2005), smoothed rates of this PSI among 2116 hospitals surveyed by the Joint Commission in 1997-1999 were marginally $(\mathrm{p}=0.06)$ associated with summary evaluation scores, in the expected direction. In addition, hospitals with high smoothed rates of this PSI were less likely to receive favourable accreditation decisions than hospitals with lower rates. For both Medicare and Veterans Health Administration patients, this indicator loaded strongly with two other PSIs (iatrogenic pneumothorax and selected infections due to medical care) on a common factor (Rosen et al., 2009). Finally, this indicator was significantly associated with re-admission within either three months (risk ratio=1.28) or one month (risk ratio=1.25), after adjusting for patient characteristics using 2004 surgical data from seven US states (Friedman et al., 2009). 
32. Although children aged less than 15 years were excluded from OECD analyses, data on the validity of this indicator in paediatric populations may still be relevant. Physicians participating in the NACHRI Pediatric PSI Collaborative reviewed 120 flagged events from 14 hospitals, using an online tool to assess implicit process of care, and judged only $28 \%$ to be preventable and $49 \%$ to be clearly nonpreventable (Sedman et al., 2005; Scanlon et al., 2006). As a result, this indicator was dropped from the AHRQ Pediatric Quality Indicator module.

33. Historically, this indicator evolved from one of the "flags" in Iezzoni's Complications Screening Program (CSP). Explicit process of care failures in the CSP validation study were relatively frequent among cases flagged on this indicator ( $72 \%$ of major surgery patients, $69 \%$ of medical patients), after excluding patients who had DVT/PE at admission, but unflagged controls were not evaluated on the same criteria (Iezzoni ., 1999). Major surgical cases flagged on this indicator and unflagged controls differed marginally $(11 \%$ versus $4 \%, p=0.09)$ on a composite of 17 generic process criteria. Physician reviewers identified potential quality problems in $50 \%$ of major surgery patients and $20 \%$ of medical patients flagged on this indicator, versus $2 \%$ of unflagged controls for each risk group (Weingart et al., 2000).

34. At least two older studies assessed the construct validity of the ICD-9-CM codes mapped to this PSI through correlation with structural measures of nurse staffing. Needleman and Buerhaus (Needleman et al., 2002) found that nurse staffing was independent of the occurrence of DVT/PE among both major surgical and medical patients from 799 hospitals in 11 states in 1997. However, Kovner and Gergen reported that among 506 community hospitals in the 1993 NIS, having more registered nurse hours and non-RN hours per adjusted patient day were both associated with a lower rate of DVT/PE after major surgery (Kovner and Gergen, 1998). Nurse staffing was not associated with the rate of DVT/PE after invasive vascular procedures. Rates of this PSI were marginally $(\mathrm{p}=0.06)$ associated with adoption of clinical information technology applications among 98 Florida hospitals (Menachemi et al., 2007), but were not associated with adoption of EMR systems among Medicare patients (Parente and McCullough, 2009) or among 66 Georgia hospitals (Culler et al., 2007).

35. Criterion validity. The original CSP definition of this PSI, which differed slightly from the current AHRQ definition, had an adequate confirmation rate among major surgical cases sampled from FY1994 Medicare inpatient claims from California and Connecticut (i.e., 59\% according to coders, 70\% according to physicians, $68 \%$ according to nurses who relied on physician documentation) (Lawthers et al., 2000; Weingart et al., 2000; McCarthy et al., 2000). Several smaller, older studies also suggested adequate sensitivity and PPV of PE codes among surgical patients, although the sensitivity of DVT codes was notably poorer (Keeler et al., 1992; Romano et al., 2002; Hawker et al., 1997; Best et al., 2002). Based on these findings, AHRQ limited this PSI to surgical cases (defined using DRGs).

36. One weakness of this indicator is its inability to distinguish thromboses that were present at admission from thromboses that developed during a hospital stay. Some US data sets now include a "flag" variable denoting whether each diagnosis was present at admission. The percentage of cases flagged by this PSI for whom the event was reported to be a complication of the hospital stay was only $46 \%$ in California, 43\% in New York, $40 \%$ in the Rochester, Minnesota area, and 51-67\% at the University of Michigan (Houchens et al., 2008; Naessens et al., 2007; Bahl et al., 2008). Hospital-specific rates including thromboses reported as present on admission were variably correlated with hospital-specific rates excluding such thromboses ( $\mathrm{r}=0.80$ in California, $\mathrm{r}=0.41$ in New York), even among coronary artery bypass surgery patients ( $\mathrm{r}=0.63$ in California) (Glance et al., 2008).

37. The best recent evidence about the PPV of this indicator comes from the 47 hospitals participating in the AHRQ PSI Validation Pilot project $(\mathrm{N}=155)$ and the 33 hospitals participating in a parallel benchmarking initiative by the University Health System Consortium (UHC, N=505). In this study, only $13 \%$ of the flagged events were present at admission and $8 \%$ lacked clear documentation of an 
acute venous thrombosis, leaving $79 \%$ that were confirmed as iatrogenic complications (White et al., 2009). However, $29 \%$ of the confirmed events involved upper extremity, thoracic, or superficial veins (which are not the target for prevention), reducing the overall PPV for clinical purposes to $56 \%$ (95\% CI, $52-60 \%)$. In the 33 teaching hospitals, abstractors also reviewed 517 cases that were not flagged as having this PSI, and found zero false-negatives (sensitivity $=100 \%$; 95\% CI, 53-100\%). A single US teaching hospital (not in the UHC study) separately reported $87 \%$ sensitivity and $50 \%$ PPV, using the same clinical definition (Henderson et al., 2009), and eight Belgian hospitals reported 54-59\% PPV with only one false negative case among 1,392 records reviewed (Gillet et al., 2008). These estimates significantly exceed the sensitivity and PPV estimates of 68\% and 29\%, respectively, based on 2002-2004 data from the Medicare Patient Safety Monitoring System (Zhan et al., 2007), suggesting that the validity of this indicator may depend on the number of available diagnosis fields (as Medicare data are limited to nine secondary diagnoses).

38. Comparing hospital administrative data from the Department of Veterans Affairs against the National Surgical Quality Improvement Program's clinically abstracted data from 2001, Romano et al., (2009) reported a sensitivity of $56 \%$ and a PPV of $22 \%$, although the PPV in a more recent review of 112 randomly selected cases from 2004-2007 was 56\% (Borzecki et al., 2009). As in the AHRQ PSI Validation Pilot, most of the false positives in the VA were attributable to chronic thromboses that were present at admission, upper extremity thromboses, or superficial lower extremity thromboses that did not require anticoagulation.

39. Finally, evidence from New York, Denmark, and New Zealand suggests that a significant number of true events may not be ascertained because they occur after hospital discharge; linking 30-day readmissions in New York increased the overall rate of this PSI from 9.3 to 11.3 per 1,000; $45 \%$ of the postdischarge events were pulmonary emboli (Weller et al., 2004; Stevanovic 2009).

40. In summary, recent evidence suggests that this indicator should be used very cautiously for comparing hospital performance unless validated information is available about the timing of the diagnosis and/or the specific veins involved. Recent changes to the ICD-9-CM coding of deep vein thromboses, including new codes specifying superficial, upper extremity, and thoracic thromboses, should enhance criterion validity in countries that use ICD-9-CM, by excluding most of the false positive cases captured by the previous definition. Underreporting does NOT appear to be a problem, based on studies from the USA and Belgium. Over diagnosis through screening of high-risk but asymptomatic postoperative patients is an emerging concern, and may explain the markedly elevated risk of this event at major teaching hospitals and large hospitals (Vartak et al., 2008). Risk adjustment is recommended for inter-provider comparisons (AHRQ, 2007) to ensure that variation due to different patient populations across institutions is removed.

\section{Findings}

41. Reported postoperative PE/DVT rates vary across participating OECD countries between 0.1 and $1.4 \%$ (Chart 3). Most countries report slightly higher rates in females, but the U.S. and Ireland have higher rates in men and a larger gender discrepancy. As expected, rates are higher in patients aged 70 years and older than in younger age groups in all countries (Chart 3). Direct adjustment for 5-year age-gender strata did not materially affect indicator rates across countries, although two countries moved up one rank (and two others moved down one rank to compensate). A statistically significant dependency between indicator rates and amount of administrative documentation, expressed as the mean number of secondary diagnoses, was found and is shown in Chart 4 (Spearman $r=0.670, p=0.009$ ). Countries with more coded diagnoses reported higher rates. The rates represented in the charts below have not been age-sex standardised or adjusted for secondary diagnoses or length of stay. 
Chart 3. Postoperative pulmonary embolism or deep vein thrombosis, 2007
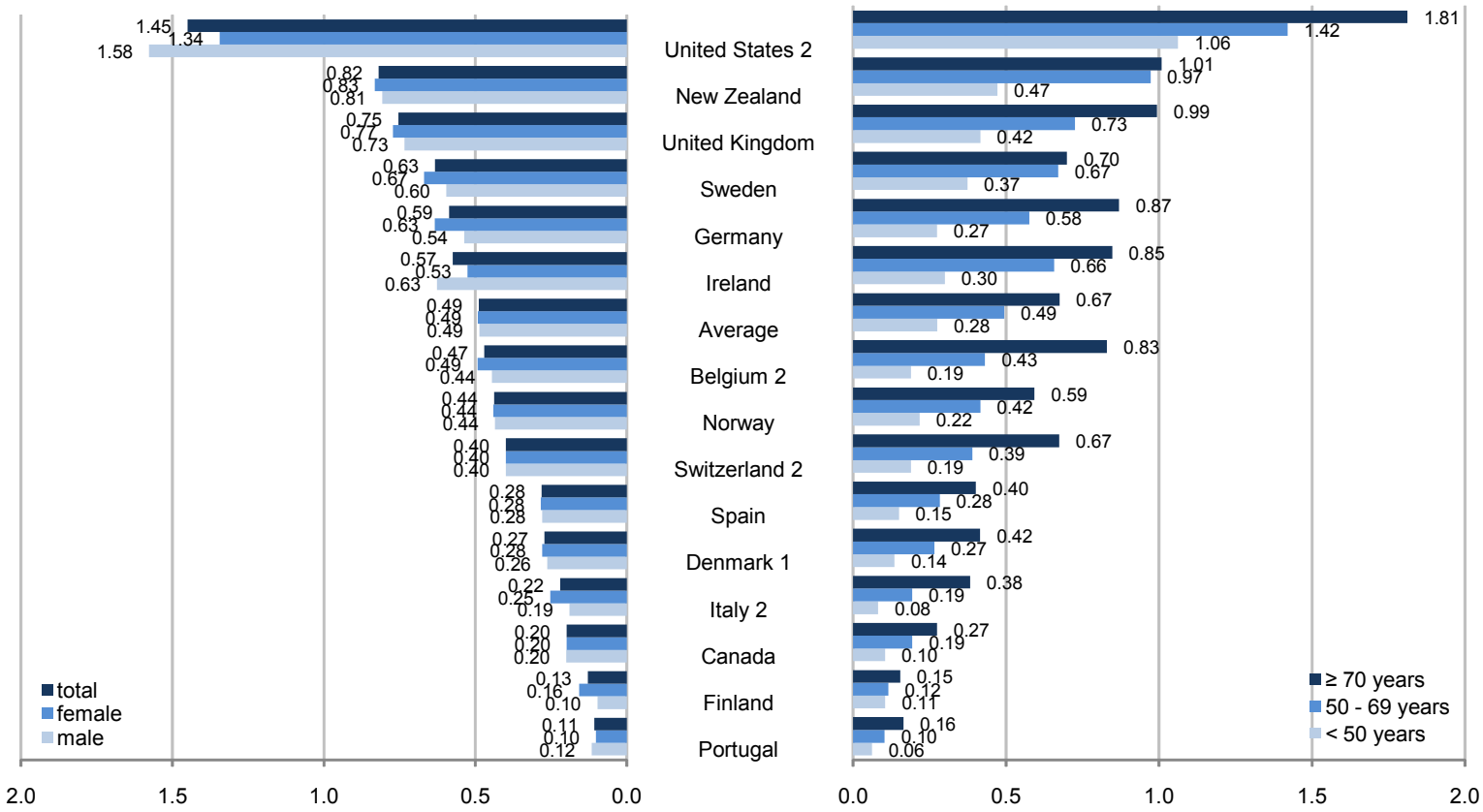

1. 2008. 2. 2006.

Note: Rates based on hospital administrative databases as reported by countries for the research and development work of the HCQI project.

Chart 4. Postoperative pulmonary embolism and mean number of secondary diagnoses

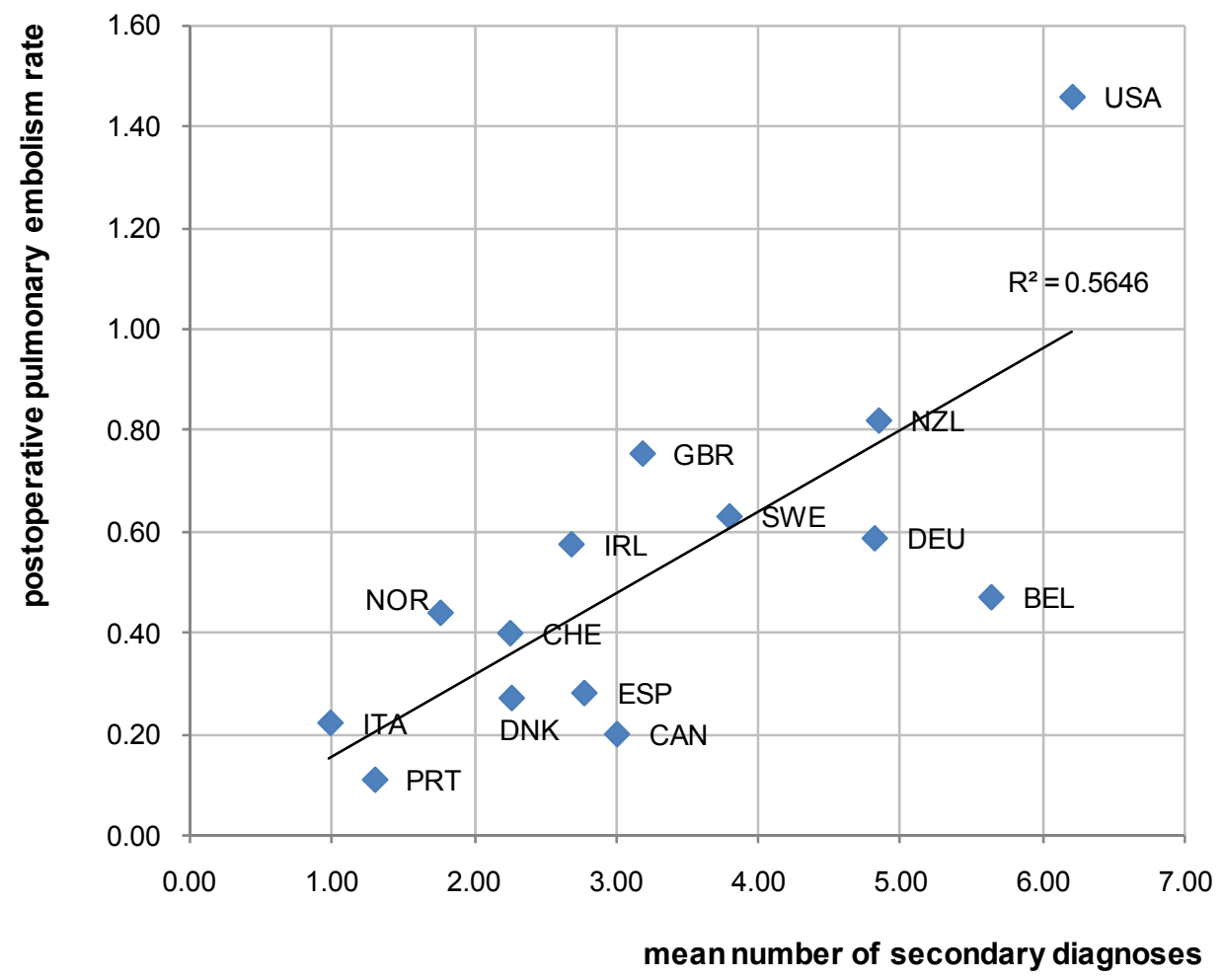

Note: Rates based on hospital administrative databases as reported by countries for the research and development work of the HCQI project. 


\section{Postoperative sepsis}

Validity

42. Rationale and concerns. The occurrence of sepsis following surgery is a severe complication with a mortality rate of up to $30 \%$. Many cases of postoperative sepsis can be prevented through the appropriate use of prophylactic antibiotics, good surgical site preparation, careful and sterile surgical techniques and good postoperative care. Sepsis after elective surgery is considered a severe complication. It usually results from less severe infective complications, such as urinary tract infections, pneumonia and wound infection, which should be avoided and/or properly treated. Consequently, this indicator is a plausible patient safety measure. Given the dramatic nature of this complication, it is likely to be reliably coded in administrative data sources, relative to less serious complications (Miller et al., 2004).

43. Content (consensual) validity. Content validity was addressed in a technical report accompanying the original release of the AHRQ PSIs. Although panellists' ratings of the "usefulness" of each candidate indicator were used to select the final PSI set, panellists were also asked to rate each indicator on its preventability and its likelihood of being due to medical error. The median rating of this indicator was 6.5 (with agreement) on the former dimension, and 6 (with indeterminate agreement) on the latter dimension, leading to a classification of "unclear" on both dimensions. Through similar processes, this PSI was endorsed by both the OECD Patient Safety Panel (Millar et al., 2004) and the SimPatIE (Safety Improvement for Patients in Europe) project (Kristensen et al., 2009). A 47-member Delphi panel convened by RAND rated this indicator "moderate" in importance, but lower on validity (i.e., median ratings 8 and 5, respectively) (Farley et al., 2008).

44. Construct (convergent, predictive) validity. This indicator rates very highly on predictive validity. Cases from the NIS that were flagged by this PSI had 21.9\% excess mortality, 10.9 days of excess hospitalisation, and $\$ 57700$ in excess hospital charges, relative to carefully matched controls that were not flagged (Zhan and Miller, 2003). This finding was confirmed in the Veterans Affairs hospital system, where cases that were flagged by this PSI had 30.2\% excess mortality, 5.7-18.8 days of excess hospitalisation, and \$13 395-31 262 in excess hospital costs, relative to carefully matched controls that were not flagged (Rivard et al., 2008). A more recent replication using 2007 data, corrected for sepsis that was reported as "present on admission", estimated 13.7 attributable hospital days and \$39117 in attributable hospital costs for the average case (Foster et al., 2009). In a commercial claims database from 45 large employers in the USA, each event (aggregating this PSI with catheter-related bloodstream infections) was associated not just with $3.1 \%$ excess mortality, but also with $7.7 \%$ excess readmissions, which added \$2 594 to the total attributable cost per event (Encinosa and Hellinger, 2008). A case control analysis from England estimated excess mortality of $27.1 \%$ and 15.9 days of excess hospitalisation (Raleigh et al., 2008). Finally, the largest reported estimates of these impacts came from a study of children at 38 freestanding paediatric hospitals in the USA in 2006 (i.e., 23.5 hospital days, \$261 173 in hospital charges) (Kronman et al., 2008). In a study testing construct validity using an implicit process measure of quality (Miller et al., 2005), smoothed rates of this PSI among 2116 hospitals surveyed by the Joint Commission in 1997-1999 were marginally $(\mathrm{p}=0.10)$ associated with summary evaluation scores, in the expected direction. For both Medicare and Veterans Health Administration patients, this indicator loaded strongly with two other PSIs (postoperative sepsis and respiratory failure) on a common factor representing perioperative continuity of care (Rosen et al., 2009). Finally, this indicator was significantly associated with re-admission within three months (risk ratio=1.26), but not within one month (risk ratio $=0.99$ ), after adjusting for patient characteristics using 2004 surgical data from seven US states (Friedman et al., 2009). Unadjusted data from England confirm the association between this PSI and readmission (Bottle and Aylin, 2009). 
Although children aged less than 15 years were excluded from OECD analyses, data on the validity of this indicators in paediatric populations may still be relevant. In a study of 2003-2005 data from 28 children's hospitals ( $\mathrm{N}=279$ events), $20 \%$ were incorrectly coded and $40 \%$ of the remainder were present on admission; only $12-32 \%$ of all flagged events were judged to be preventable (Scanlon et al., 2008).

45. At least one older study assessed the construct validity of the ICD-9-CM codes mapped to this PSI through correlation with structural measures of nurse staffing. Needleman and Buerhaus (Needleman et al., 2002) found that nurse staffing was independent of the occurrence of sepsis among both major surgical and medical patients from 799 hospitals in 11 states in 1997. Rates of this PSI were inversely associated with adoption of clinical information technology applications among 98 Florida hospitals (Menachemi et al., 2007), but not among 66 Georgia hospitals (Culler et al., 2007).

46. Criterion validity. Several small studies provided limited data about the criterion validity of the ICD-9-CM codes mapped to this indicator before its release. Unfortunately, several of these studies either did not clearly document their ICD-9 definitions (Massanari et al., 1987; Belio-Blasco et al., 2000) or did not stratify the subgroup of patients with a secondary diagnosis of DVT/PE (Barbour, 1993). In comparison with the VA's National Surgical Quality Improvement Program database from 123 hospitals in 1994-95, in which "systemic sepsis" was defined by a positive blood culture with systemic manifestations of sepsis within 30 days after surgery, ICD-9-CM diagnoses had a sensitivity of $37 \%$ and a PPV of $30 \%$ (Best et al., 2002).

47. This indicator has a minor problem due to missing data about timing. Some US data sets now include a "flag" variable denoting whether each diagnosis was present at admission. The percentage of cases flagged by this PSI for whom the event was reported to be a complication of the hospital stay was $73 \%$ in California, 70\% in New York, 76\% in the Rochester, Minnesota area, and 59-60\% at the University of Michigan (Houchens et al., 2008; Naessens et al., 2007; Bahl et al., 2008). Hospital-specific rates including sepsis reported as present on admission were moderately correlated with hospital-specific rates excluding such infections ( $\mathrm{r}=0.72$ in California, $\mathrm{r}=0.82$ in New York), especially among coronary artery bypass surgery patients ( $\mathrm{r}=0.93$ in California) (Glance et al., 2008).

48. The best recent evidence about the PPV of this indicator comes from the 47 hospitals participating in the AHRQ PSI Validation Pilot Project ( $\mathrm{N}=164)$. In this study, $17 \%$ of the flagged events (or precursor infections) were present at admission, and 17\% lacked clear documentation of sepsis, bacteraemia, or SIRS (systematic inflammatory response syndrome) with infection, leaving $66 \%$ that were confirmed as complications. (However, an additional $25 \%$ of flagged cases may have been ineligible because the reviewer perceived the "index" surgery as being non-elective.) The primary site of infection was catheter-related in $24 \%$, lungs in $39 \%$, surgical site in $9 \%$, and urinary tract in $19 \%$. Comparing hospital administrative data from the Department of Veterans Affairs against the National Surgical Quality Improvement Program's clinically abstracted data from 2001, Romano et al., (2009) reported a sensitivity of $37 \%$, PPV of $45 \%$, and positive likelihood ratio of 131 . Most of the "false positives" were patients with clinical evidence of sepsis, who were treated for presumptive sepsis, but lacked "definitive evidence of infection". A similar review of medical records of 53 cases from 18 English NHS trusts found that $6 \%$ of the flagged events were present at admission and $21 \%$ were miscoded, leaving $70 \%$ that were confirmed (Bottle and Aylin, 2008). Eight Belgian hospitals reported 45\% PPV (largely due to overreporting or failure to satisfy clinical criteria for sepsis), with 25 false negative cases among 1396 records reviewed (98.2\% negative predictive value) (Gillet et al., 2008).

49. In summary, recent evidence on construct validity and criterion validity is somewhat supportive of this indicator, but raises questions about the ability to accurately identify patients for elective surgery. Very little evidence is available on potential underreporting. Risk adjustment is recommended for inter- 
provider comparisons (AHRQ, 2007) to ensure that variation due to different patient populations across institutions is removed.

\section{Findings}

50. Reported postoperative sepsis rates vary across participating countries between 0.2 and $1.7 \%$ (Chart 5); the average is $0.61 \%$. Three countries (Belgium, Portugal, and USA) reported markedly higher sepsis rates than the others. Postoperative sepsis occurs far more often in male patients than in females in all countries. This finding corresponds to the literature (Angus et al., 2001). Direct adjustment for 5-year age-gender strata did not materially affect indicator rates across countries, although three countries moved up one rank (and three others moved down one rank to compensate). A non-significant correlation between indicator rates and amount of documentation was found (Chart 6 , Spearman $r=0.414, p=0.142$ ), based on the mean number of secondary diagnoses in denominator cases. In Belgium and USA, the mean number of secondary diagnoses is more than two times greater than in Singapore, which might explain elevated infection rates in the first two countries. Underreporting is likely for countries with low infection rates. The rates represented in the charts below have not been age-sex standardised or adjusted for secondary diagnoses or length of stay.

Chart 5. Postoperative sepsis rates, 2007

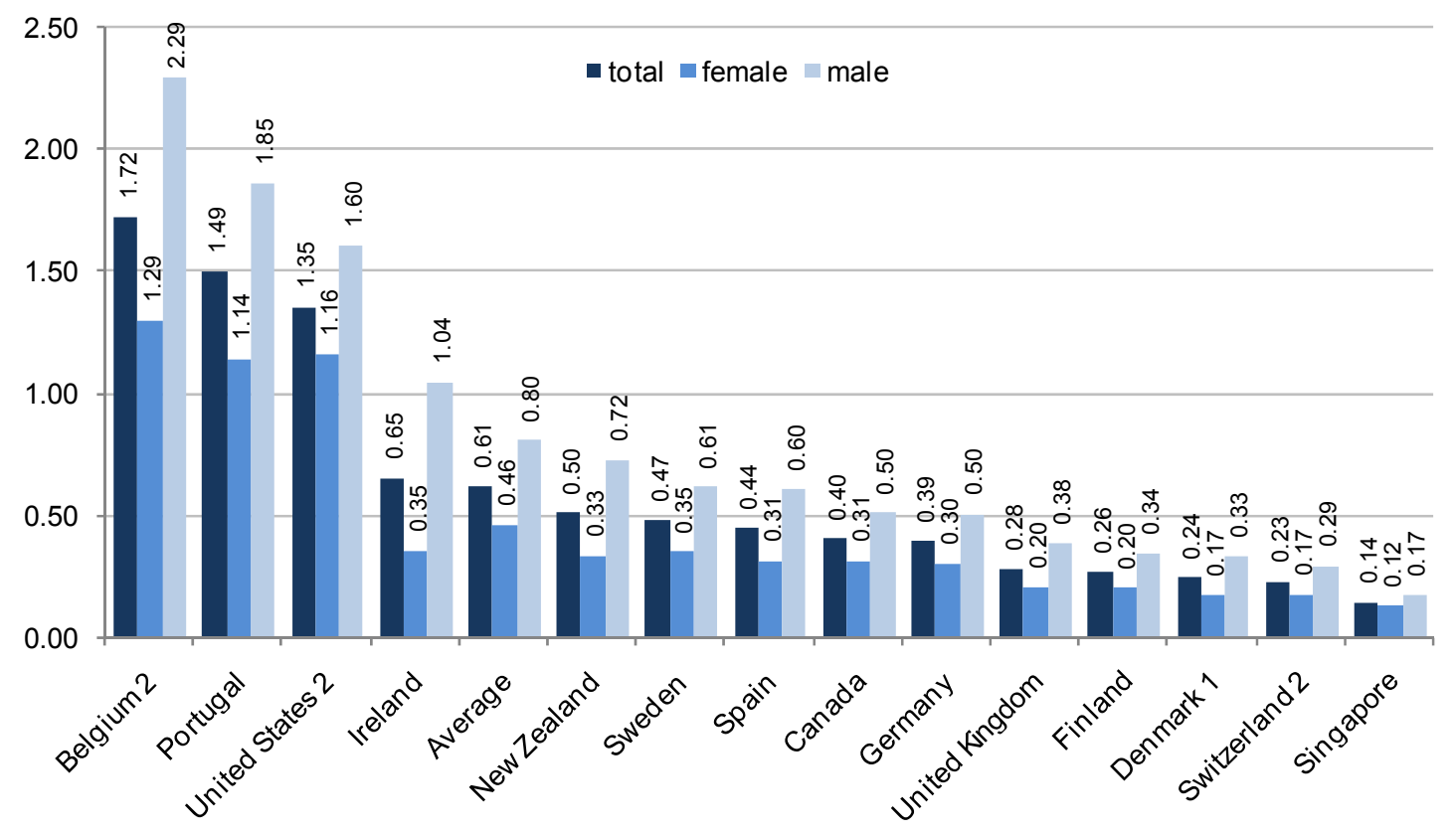

1. 2008. 2. 2006.

Note: Rates based on hospital administrative databases as reported by countries for the research and development work of the HCQI project. 
Chart 6. Postoperative sepsis rates and mean number of secondary diagnoses, 2007

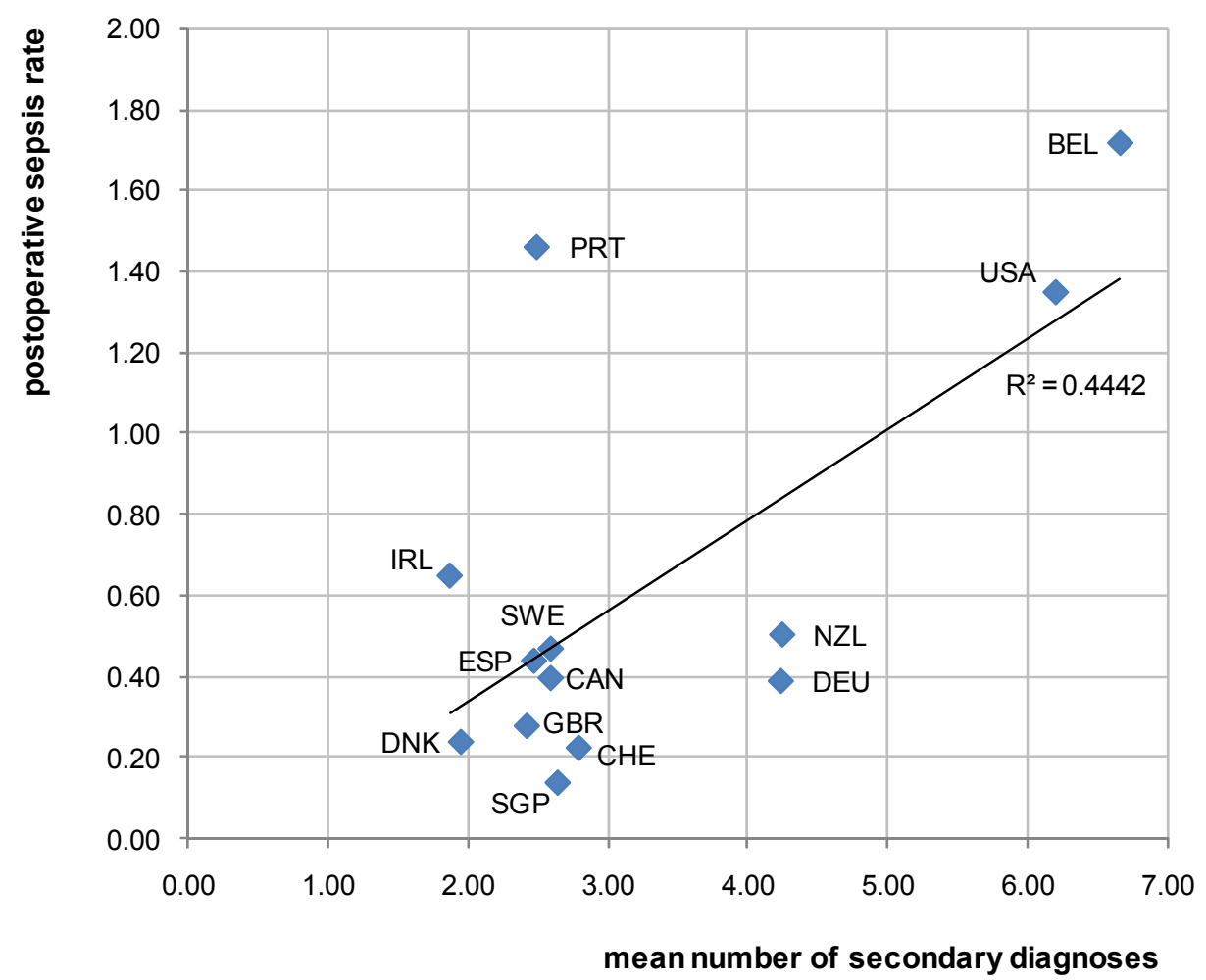

Note: Rates based on hospital administrative databases as reported by countries for the research and development work of the HCQI project.

\section{Accidental puncture or laceration}

Validity

51. Rationale and concerns. This indicator captures events related to technical and process limitations of hospital care. While accidental cut, puncture, perforation or laceration during a surgical procedure is a recognised risk, for example of abdominal surgery, elevated rates of such complications may indicate systems problems, such as inadequate training or fatigued health staff. Experts involved in the selection of this indicator stated that some incidents might not be preventable (AHRQ, 2007). The indicator captures surgical as well as medical discharges based on administrative hospital data. They were proposed in 1994 (Iezzoni et al., 1994) and subsequently further investigated (Miller et al., 2001).

52. Content (consensual) validity. Content validity was addressed in the technical report accompanying the original release of the AHRQ PSIs. Although panellists' ratings of the "usefulness" of each candidate indicator were used to select the final PSI set, panellists were also asked to rate each indicator on its preventability and its likelihood of being due to medical error. The median rating of this indicator was 7, with agreement, on the former dimension, leading to a classification of "acceptable". The median rating was 6 , with indeterminate agreement, on the latter dimension, leading to a classification of "unclear". Through similar processes, this PSI was endorsed by the OECD Patient Safety Panel (Millar et al., 2004) and the US National Quality Forum, but rejected by the SimPatIE (Safety Improvement for Patients in Europe) project as "not workable for implementation in Europe". A 47-member Delphi panel convened by RAND rated this indicator "low" in importance, although the median rating of 7 would have qualified for endorsement in the AHRQ panel process (Farley et al., 2008). 
53. Construct (convergent, predictive) validity. This indicator rates highly on predictive validity. Cases from the NIS that were flagged by this PSI had $2.2 \%$ excess mortality, 1.3 days of excess hospitalisation, and $\$ 8300$ in excess hospital charges, relative to carefully matched controls that were not flagged (Zhan and Miller, 2003). This finding was confirmed in the Veterans Affairs hospital system, where cases that were flagged by this PSI had 3.2\% excess mortality, 1.4-3.1 days of excess hospitalisation, and \$3 359-6 880 in excess hospital costs, relative to carefully matched controls that were not flagged (Rivard et al., 2008). A more recent replication using 2007 data, corrected for injuries that were reported as "present on admission", estimated 3.7 attributable hospital days and $\$ 12087$ in attributable hospital costs for the average case (Foster et al., 2009). In a commercial claims database from 45 large employers in the USA, these events (aggregated with four rarer PSIs) were not associated with either excess mortality or excess readmissions (Encinosa and Hellinger,2008). Finally, the largest reported estimates of these impacts came from a study of children at 38 freestanding paediatric hospitals in the USA in 2006 (i.e., 2.8 hospital days, $\$ 34884$ in hospital charges) (Kronman et al., 2008).

54. In a study testing construct validity using an implicit process measure of quality (Miller et al., 2005), smoothed rates of this PSI among 2,116 hospitals surveyed by the Joint Commission in 1997-1999 were significantly $(\mathrm{p}<0.01)$ associated with summary evaluation scores, in the expected direction. For both Medicare and Veterans Health Administration patients, this indicator loaded strongly with three other PSIs (foreign body left in, postoperative haemorrhage or hematoma, and wound dehiscence) on a common factor representing technical complications of care (Rosen et al., 2009). Finally, this indicator was significantly associated with re-admission within either three months (risk ratio $=1.29$ ) or one month (risk ratio=1.00), after adjusting for patient characteristics using 2004 surgical data from seven US states (Friedman et al., 2009). Unadjusted data from England confirm the association between this PSI and readmission (Bottle and Aylin, 2009).

55. Rates of this PSI were inversely associated with adoption of strategic information technology applications among 98 Florida hospitals (Menachemi et al., 2007), but not among 66 Georgia hospitals (Culler et al., 2007).

56. Although children aged less than 15 years were excluded from OECD analyses, data on the validity of this indicator in paediatric populations may still be relevant. Physicians participating in the NACHRI Pediatric PSI Collaborative reviewed 119 flagged events from 14 hospitals, using an online tool to assess implicit process of care, and judged $64 \%$ to be preventable and only $14 \%$ to be clearly nonpreventable (Sedman et al., 2005; Scanlon et al., 2006). In a follow-up study of 2003-2005 data from 28 children's hospitals ( $\mathrm{N}=285$ events), $9 \%$ were incorrectly coded and $7 \%$ of the remainder were present on admission; $27-57 \%$ of all flagged events were judged to be preventable (Scanlon et al., 2008).

57. Criterion validity. . Several studies that were published before the release of this indicator offered conflicting conclusions about the criterion validity of the underlying ICD-9 codes. For example, a study of laparoscopic cholecystectomy in 18 Ontario hospitals in 1991-95 (Taylor, 1998) found that 95\% (99/104) of patients with an ICD-9 code of 998.2 or E870.0 had a confirmed injury to the bile duct or gallbladder (although only $27 \%$ were "clinically significant"). A similar study of all cholecystectomies performed in Western Australia between 1988 and 1994 reported that these two codes had a sensitivity of 40\% (19/48) and a PPV of 23\% (19/84) in identifying bile duct injuries (Valinsky et al., 1999). Among 185 total knee replacement patients from 5 Ontario hospitals in 1984-90, Hawker et al., (1997) found that the sensitivity and PPV of codes describing "miscellaneous mishaps during or as a direct result of surgery" were $86 \%$ (6/7) and 55\% (6/11), respectively. Romano et al., (2002) identified 19 of 45 chart-confirmed episodes of accidental puncture or laceration using discharge abstracts of diskectomy patients at 30 California hospitals in 1990-91, with only one false positive. 
58. This indicator does not appear to have a significant problem due to missing data about timing. Some US data sets now include a "flag" variable denoting whether each diagnosis was present at admission. The percentage of cases flagged by this PSI for whom the event was reported to be a complication of the hospital stay was $87 \%$ in California, $87 \%$ in New York, $85 \%$ in the Rochester, Minnesota area, and 84-91\% at the University of Michigan (Houchens et al., 2008; Naessens et al., 2007; Bahl et al., 2008). Hospital-specific rates including injuries reported as present on admission were highly correlated with hospital-specific rates excluding such injuries $(r=0.97$ in California, $r=0.96$ in New York, $\mathrm{r}=0.95$ for $\mathrm{CABG}$ patients).

59. The best recent evidence about the PPV of this indicator comes from the 47 hospitals participating in the AHRQ PSI Validation Pilot Project ( $\mathrm{N}=249)$. In this study, $2 \%$ of the flagged events were present at admission, and 7\% lacked clear documentation of an accidental puncture or laceration, leaving about $91 \%(95 \% \mathrm{CI}, 88-94 \%)$ that were confirmed as complications. Of these events, $71 \%$ occurred in the abdomen or pelvis, $10 \%$ in the chest, and $16 \%$ in the spine (Utter et al., 2009). About $75 \%$ of the confirmed injuries were categorised as "potentially consequential", meaning that they would generally require surgical repair. Similarly, the PPV in a recent review of 112 randomly selected cases from the Department of Veterans Affairs in 2004-2007 was 86\% (95\% CI, 78-92\%) (Borzecki et al., 2009).

60. There is very limited evidence about the sensitivity of this indicator. Investigators in New York systematically searched their hospital administrative data for procedure codes suggesting repair of iatrogenic injuries, and reported that this PSI may have missed $27 \%$ of bladder injuries from hysterectomy, $21 \%$ of bowel injuries from cholecystectomy, $47 \%$ of abdominal injuries from lysis of adhesions, $54 \%$ of abdominal injuries from nephroureterectomy, and $20 \%$ of spinal injuries from lumbar surgery (Gallagher et al., 2005b). AHRQ is currently evaluating whether these procedure codes can be added to the PSI definition to improve its sensitivity, without compromising its PPV.

61. In summary, recent evidence on construct validity and criterion validity is moderately supportive of this indicator. Based on limited information, underreporting is a valid concern. Risk adjustment is recommended for inter-provider comparisons (AHRQ, 2007) to ensure that variation due to different patient populations across institutions is removed.

\section{Findings}

62. Reported accidental puncture or laceration rates vary across participating OECD countries between 0.01 and $0.4 \%$ (Chart 7). Gender subgroups show a slight female predominance of rates in all countries. Direct adjustment for 5-year age-gender strata did not materially affect indicator rates across countries, although two countries switched ranks. Underreporting is assumed for countries reporting low rates. Chart 8 supports this assumption and demonstrates how rates of this indicator are correlated with the amount of administrative documentation (Spearman $\mathrm{r}=0.714, \mathrm{p}=0.006$ ); however, not all participating countries provided this additional information. The rates represented in the charts below have not been age-sex standardised or adjusted for secondary diagnoses or length of stay. 
Chart 7. Accidental puncture or laceration rates, 2007

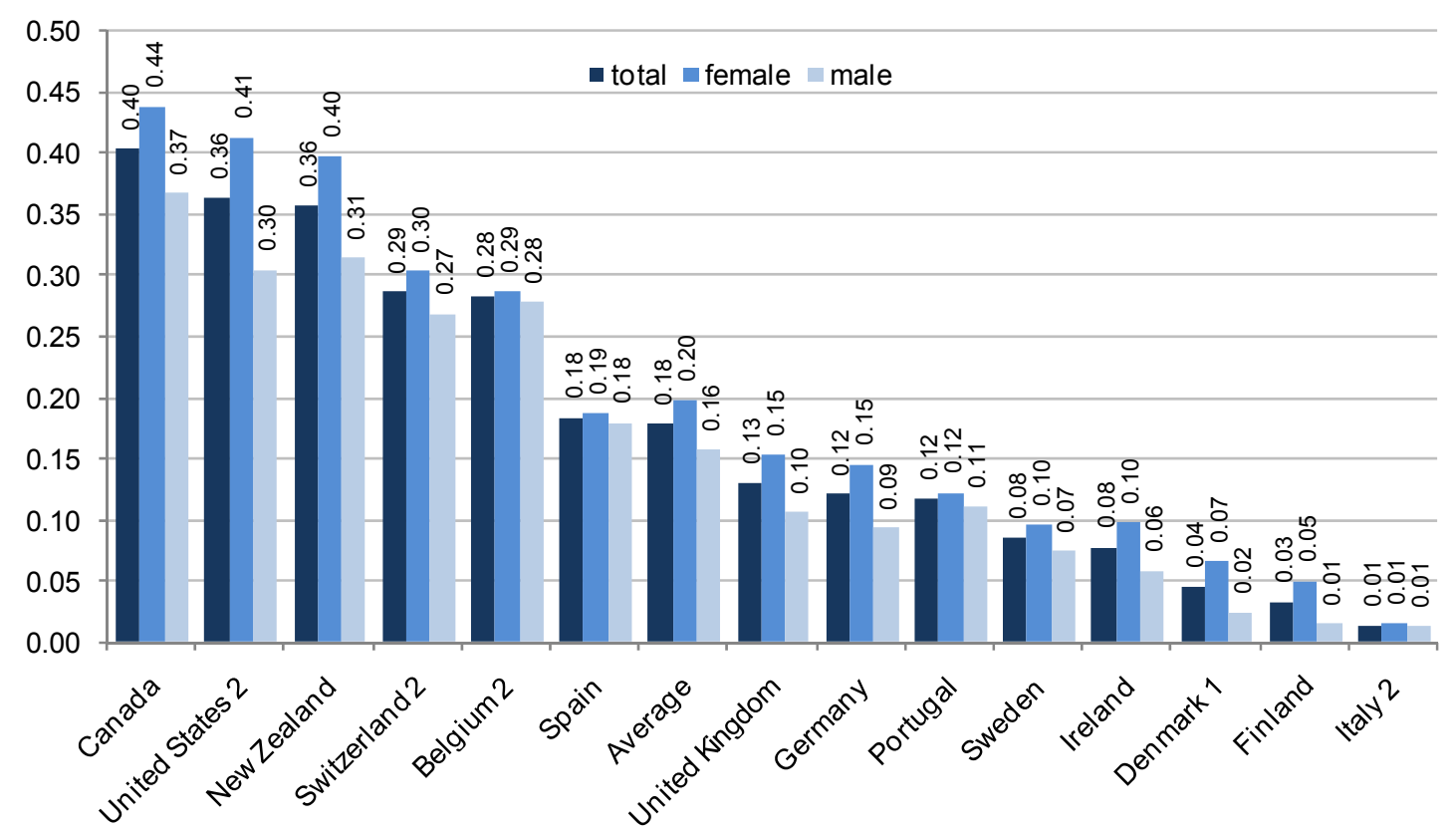

1. 2008. 2. 2006 .

Note: Rates based on hospital administrative databases as reported by countries for the research and development work of the HCQI project.

Chart 8. Accidental puncture or laceration rates and mean number of secondary diagnoses

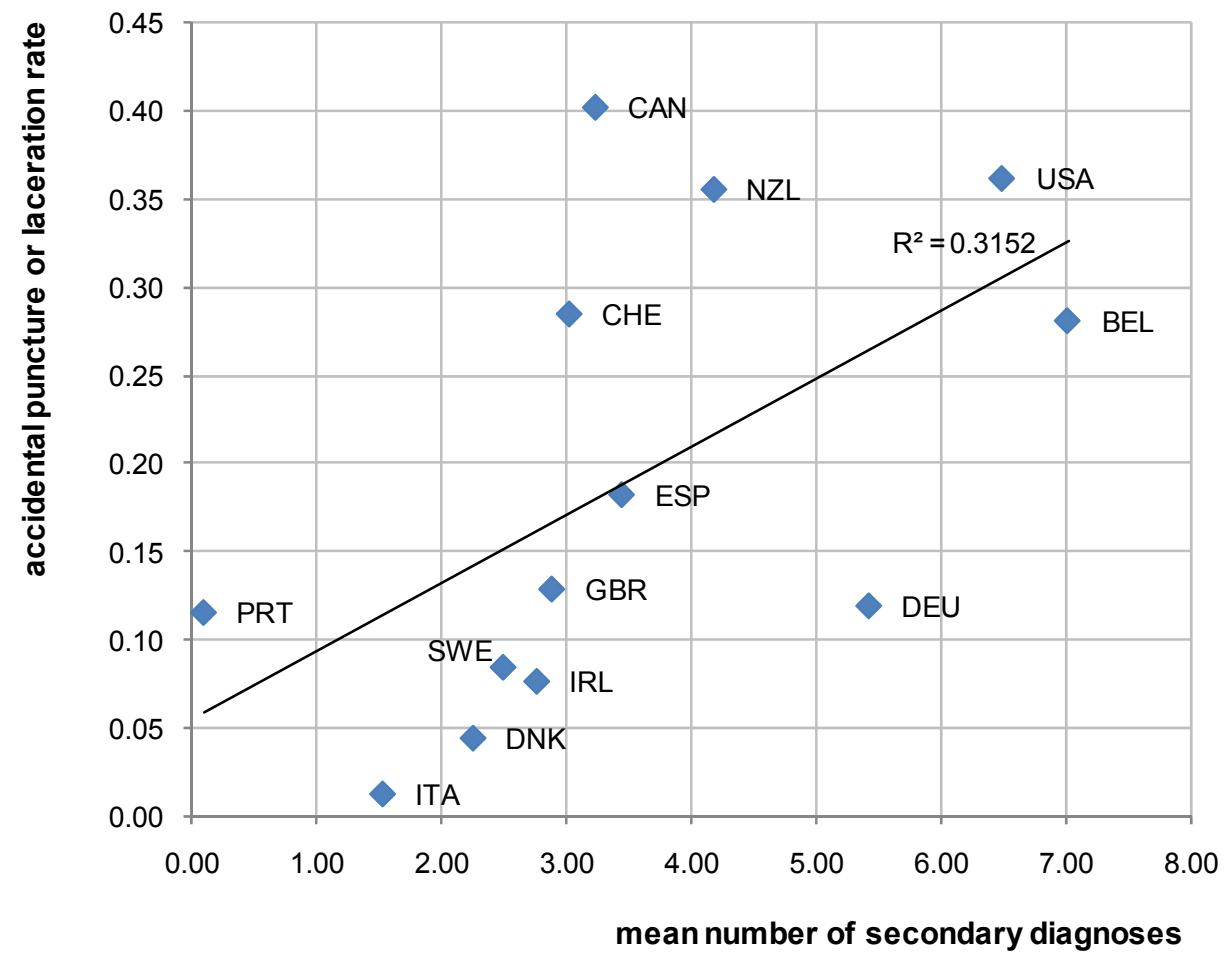

Note: Rates based on hospital administrative databases as reported by countries for the research and development work of the HCQI project. 


\section{Foreign body left in during procedure}

Validity

63. Rationale and concerns. This indicator captures events related to technical and process limitations of hospital care. Errors relating to the failure to remove surgical instruments at the end of a procedure (i.e. needles, knife blades, electrosurgical adaptors, safety pins or sponges) are clinically significant in about $50 \%$ of all patients with a $10 \%$ mortality following intra-abdominal surgery (Gonzalez-Ojeda et al., 1999). The true frequency of this adverse event remains unclear as underreporting is assumed. Although this indicator captures a rather infrequent complication, it should be addressed after happening. So called sentinel events might reflect serious process problems. This complication is susceptible to be influenced by the health care system: one study identified risk factors for retained instruments and sponges after surgery, namely emergencies, unplanned changes in procedure and obesity (Gawande et al., 2003). The Joint Commission assesses these events as "reviewable" even when the outcome is not death or major permanent loss of function.

64. The indicator captures surgical as well as medical discharges, based on administrative hospital data. It was proposed in 1994 (Iezzoni et al., 1994) and subsequently further investigated (Miller et al.,2001).

65. Content (consensual) validity. Content validity was addressed in the technical report accompanying the original release of the AHRQ PSIs. Although panellists' ratings of the "usefulness" of each candidate indicator were used to select the final PSI set, panellists were also asked to rate each indicator on its preventability and its likelihood of being due to medical error. The median ratings of this indicator on the former dimension from two independent panels were 8 and 7.5, with agreement, leading to classifications of "acceptable" from both panels. The median ratings of this indicator on the latter dimension were 8 and 7, with agreement and indeterminate agreement, respectively, leading to classifications of "acceptable" from both panels. Through similar processes, this PSI was endorsed by the OECD Patient Safety Panel (Millar et al. 2004) and the US National Quality Forum, but rejected by the SimPatIE (Safety Improvement for Patients in Europe) project as "not suitable for implementation" due to potential casemix bias (Kristensen et al., 2009). A 47-member Delphi panel convened by RAND rated this indicator "high" in importance, but lower on validity (i.e., median ratings 8 and 6, respectively) (Farley et al., 2008).

66. Construct (convergent, predictive) validity. This indicator rates highly on predictive validity. Cases from the NIS that were flagged by this PSI had 2.1\% excess mortality, 2.1 days of excess hospitalisation, and $\$ 13300$ in excess hospital charges, relative to carefully matched controls that were not flagged (Zhan and Miller, 2003). A more recent replication using 2007 data, corrected for foreign bodies that were reported as "present on admission", estimated 4.5 attributable hospital days and \$13 202 in attributable hospital costs for the average case (Foster et al., 2009). Finally, the largest reported estimates of these impacts came from a study of children at 38 freestanding paediatric hospitals in the USA in 2006 (i.e., 14.3 hospital days, $\$ 144889$ in hospital charges) (Kronman et al., 2008).

67. In a study testing construct validity using an implicit process measure of quality (Miller et al., 2005), smoothed rates of this PSI among 2116 hospitals surveyed by the Joint Commission in 1997-1999 were not associated with summary evaluation scores. For both Medicare and Veterans Health Administration patients, this indicator loaded strongly with three other PSIs (accidental puncture or laceration, postoperative haemorrhage or hematoma, and wound dehiscence) on a common factor representing technical complications of care (Rosen et al., 2009). However, unadjusted data from England showed no association between this PSI and readmission (Bottle and Aylin, 2009). 
68. Although children aged less than 15 years were excluded from OECD analyses, data on the validity of this indicators in paediatric populations may still be relevant. Physicians participating in the NACHRI Pediatric PSI Collaborative reviewed 45 flagged events from 14 hospitals, using an online tool to assess implicit process of care, and judged $51 \%$ to be preventable and only $27 \%$ to be clearly nonpreventable (Sedman et al., 2005; Scanlon et al., 2006). In a follow-up study of 2003-2005 data from 28 children's hospitals ( $\mathrm{N}=72$ events), $22 \%$ were incorrectly coded and $20 \%$ of the remainder were present on admission; 28-50\% of all flagged events were judged to be preventable (Scanlon et al., 2008).

69. Criterion validity. No evidence about the criterion validity of this indicator was available before its original release as an AHRQ indicator. This indicator may have a problem due to missing data about timing. Some US data sets now include a "flag" variable denoting whether each diagnosis was present at admission. The percentage of cases flagged by this PSI for whom the event was reported to be a complication of the hospital stay was $64 \%$ in California, $76 \%$ in New York, 54\% in the Rochester, Minnesota area, and 33-80\% at the University of Michigan (Houchens et al., 2008; Naessens et al., 2007; Bahl et al., 2008). Hospital-specific rates including foreign bodies reported as present on admission were highly correlated with hospital-specific rates excluding such foreign bodies ( $\mathrm{r}=0.89$ in California, $\mathrm{r}=0.94$ in New York).

70. A review of medical records of 29 cases from 18 English NHS (National Health Service) trusts found that $10 \%$ of the flagged events were present at admission and $38 \%$ were miscoded, leaving $52 \%$ that were confirmed (Bottle and Aylin, 2008). A validation study in the USA is currently underway. However, recent evidence from New Zealand suggests that a significant number of true events may not be ascertained because they occur after hospital discharge (Stevanovic, 2009).

71. In summary, recent evidence on construct validity and criterion validity is moderately supportive of this indicator. No information on underreporting is currently available. Risk adjustment is not recommended, based on the rarity and sentinel nature of this outcome (AHRQ, 2007).

\section{Findings}

72. Reported rates of foreign body left in during procedure vary across participating OECD countries from 2 to 11 cases per 100000 hospital admissions (Chart 9). Regarding inter-country variability, this indicator varies least across countries among all patient safety indicators. Rather low rates in general reflect the nature of a sentinel event indicator and make scientifically sound interpretations of age or gender subgroup data difficult. Direct adjustment for 5-year age-gender strata did not materially affect indicator rates across countries, although one country moved up two ranks (and two others moved down one rank to compensate). Underreporting is suspected for countries reporting low rates. Chart 10 supports this hypothesis and demonstrates how indicator rates are dependent on the amount of administrative documentation (Spearman $\mathrm{r}=0.621, \mathrm{p}=0.024$ ); however, the relationship is less consistent than for other PSIs. The rates represented in the charts below have not been age-sex standardised or adjusted for secondary diagnoses or length of stay. 
Chart 9. Foreign body left in during procedure rates, 2007

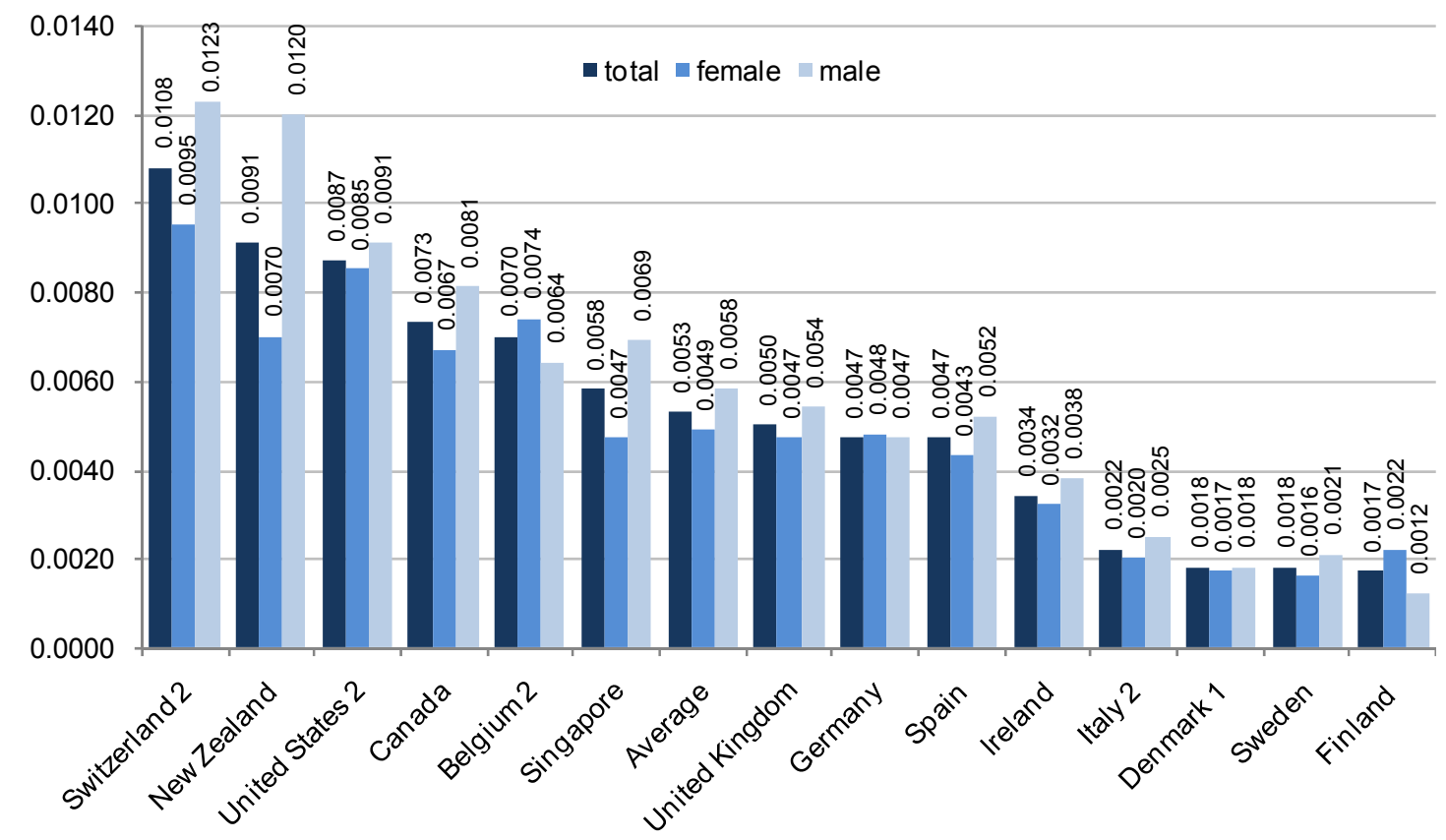

1. 2008. 2. 2006.

Note: Rates based on hospital administrative databases as reported by countries for the research and development work of the HCQI project.

Chart 10. Foreign body left in during procedure and mean number of secondary diagnoses

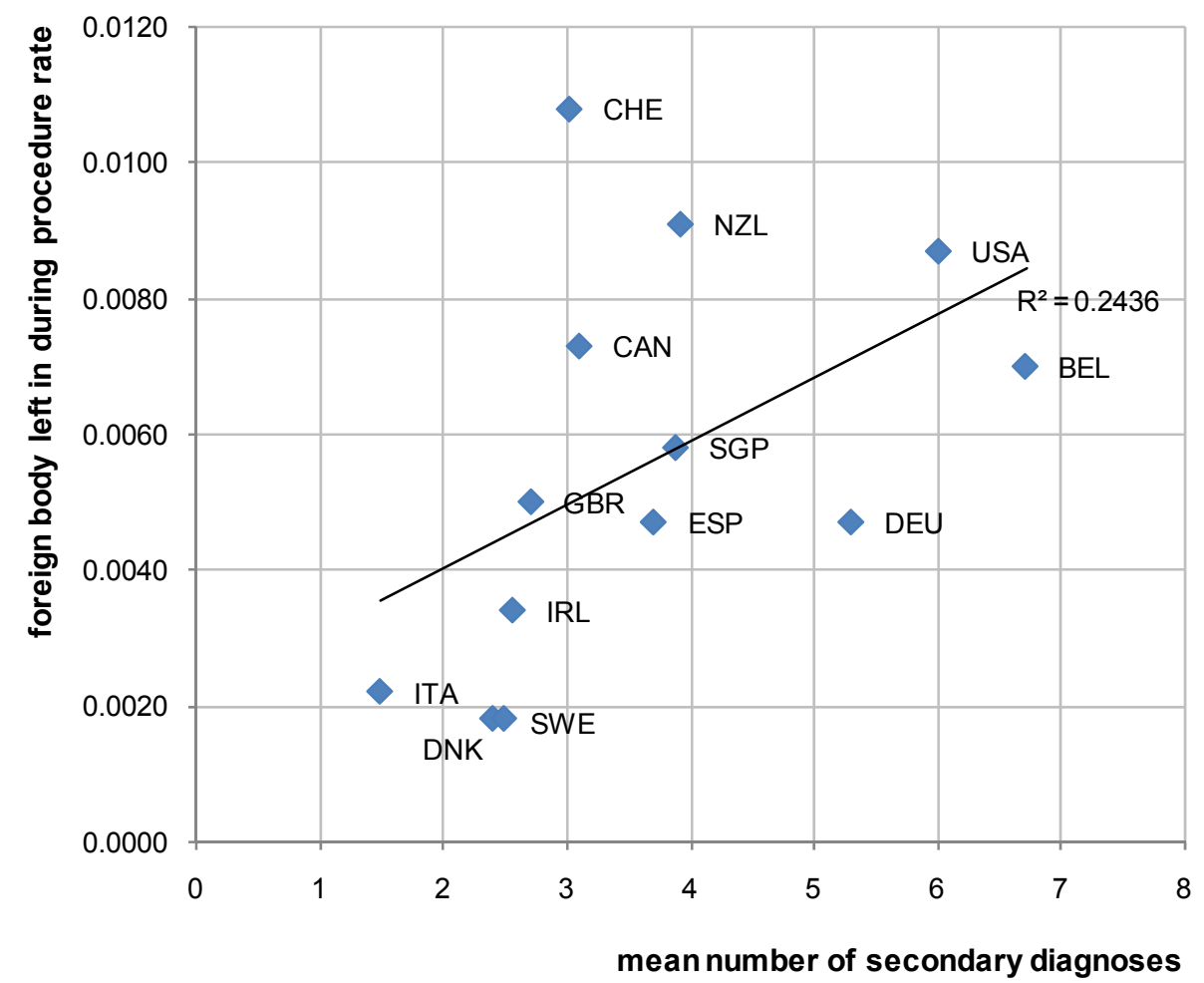

Note: Rates based on hospital administrative databases as reported by countries for the research and development work of the HCQI project. 


\title{
Obstetric trauma - vaginal delivery with instrument
}

\section{Obstetric trauma - vaginal delivery without instrument}

\author{
Validity
}

73. Rationale and concerns. These indicators are intended to flag cases of potentially preventable trauma $\left(3^{\text {rd }}\right.$ and $4^{\text {th }}$ degree perineal tears) during vaginal delivery. It is estimated that in about $11 \%$ of all deliveries perineal trauma associated with subsequent faecal incontinence occurs (Dudding et al., 2008). Although risk factors as prolonged labour and no previous deliveries have been identified, precise recommendations for labour management in order to prevent obstetric lacerations remain unclear (Wheeler and Richter, 2007) resulting in an unclear preventability of these indicators. However, the percentage of deliveries involving higher degree lacerations is a useful monitor for the quality of obstetrical care and can assist in reducing the morbidity. Obstetric trauma indicators have been used by the US Joint Commission as well as by different international quality initiatives analysing obstetric data such as "BQS" the German statutory external quality assurance programme. As the risk of a perineal laceration is significantly increased in instrument-assisted labour (vacuum, forceps), rates for this patient population are reported separately.

74. Content (consensual) validity. Content validity was addressed in the technical report accompanying the original release of the AHRQ PSIs. Although panellists' ratings of the "usefulness" of each candidate indicator were used to select the final PSI set, panellists were also asked to rate each indicator on its preventability and its likelihood of being due to medical error. The median rating of this indicator was 7, with agreement, on the former dimension, leading to a classification of "acceptable". The median rating was 5, with disagreement, on the latter dimension, leading to a classification of "unclear". Through similar processes, this PSI was endorsed by both the OECD Patient Safety Panel (Millar et al., 2004) and the SimPatIE (Safety Improvement for Patients in Europe) project (Kristensen et al., 2009). A 47-member Delphi panel convened by RAND rated this indicator "moderate" in importance, but lower on validity (i.e., median ratings 8 and 5, respectively) (Farley et al., 2008). A similar indicator was initially implemented by the Joint Commission, which accredits health care organisations in the US, but subsequently withdrawn. The obstetric indicator was withdrawn because of clinical controversy about how often these lacerations are preventable, and whether use of the indicator could inadvertently promote caesarean delivery for questionable clinical indications. Empirically, we found no association between risk-adjusted laceration rates and caesarean rates at the hospital level (unpublished data) in California.

75. Construct (convergent, predictive) validity. This indicator rates moderately on predictive validity. Cases from the NIS that were flagged by this PSI had no excess mortality, but they did have 0.05-0.07 excess hospital days and up to $\$ 220$ in excess hospital charges, relative to carefully matched controls that were not flagged (Zhan and Miller, 2003). The reported differences in hospital length-of-stay and total charges were small, but statistically significant given the large number of events. A more recent replication using 2007 data, corrected for lacerations that were reported as "present on admission", estimated 0.130.14 attributable hospital days and \$210-243 in attributable hospital costs for the average case (Foster et al., 2009). Finally, a case control analysis from England estimated 0.48-0.56 days of excess hospitalisation (Raleigh et al., 2008).

76. In a study testing construct validity using an implicit process measure of quality (Miller et al., 2005), smoothed rates of this PSI among 2,116 hospitals surveyed by the Joint Commission in 1997-1999 were positively (counter intuitively) associated $(\mathrm{p}=0.04)$ with summary evaluation scores, but only in the subset of women with forceps or vacuum deliveries. Similarly, unadjusted data from England showed no association between this PSI and readmission (Bottle and Aylin, 2009). 
77. Criterion validity. No evidence about the criterion validity of this indicator was available before its release. This indicator is not likely to have a significant problem due to missing data about timing, because the indicator is inherently limited to women who have an in-hospital delivery. The best data about criterion validity come from the California Obstetric Validation Study (Romano et al., 2005), which involved a stratified random cluster sample of 1662 records from 52 hospitals (51\% vaginal), of which over $97 \%$ were reviewed by an "expert" coder and obstetric nurse abstractor. This PSI demonstrated a sensitivity of $90 \%$ (95\% CI, 82-96\%) and a PPV of 90-95\%; adjusting for the complex stratified sampling design increased the sensitivity to $93 \%$ (95\% CI, 82-97\%) but decreased the PPV to $73 \%$. A subsequent study based on a clinical research data set with 393 indicator-positive (3rd/4th degree tears) and 383 indicator-negative vaginal deliveries (Brubaker et al., 2007) reported a sensitivity of $77 \%$ (95\% CI, $72-$ $81 \%)$ and a specificity of $99.7 \%$ (95\% CI, 98.5-99.4\%). PPV could not be estimated due to the sampling design, but should be approximately $93 \%$ given a typical prevalence of $5 \%$. A similar review of medical records of 955 cases from 18 English NHS (National Health Service) trusts found that none of the flagged events was present at admission and $15 \%$ were miscoded, leaving $85 \%$ that were confirmed (Bottle and Aylin, 2008).

78. In summary, recent evidence on construct validity of this indicator is inconclusive, but the evidence on criterion validity is quite supportive. Risk adjustment for maternal age and comorbidity is recommended for these indicators (AHRQ, 2007; Grobman et al., 2006). To take the individual birth weight of the newborn into account when calculating these indicators would be a desirable risk adjustment approach. As maternal and neonatal data are stored separately in many administrative hospital databases, this methodological improvement is not feasible in most countries.

\section{Findings}

79. The rate of obstetric trauma after vaginal delivery with instrument shows rather high variability among countries (Chart 11). Reported rates vary from below 3\% (France, Italy, Spain, Belgium) to more than $10 \%$ (Sweden, Canada, USA), and the rate of the USA is ten-fold higher than the rate of France. Rates of obstetric trauma after vaginal delivery without instrument (Chart 12 ) range from $0.2 \%$ to $3.8 \%$. Charts 11 and 12 display corresponding rates by age categories. In most countries, obstetric trauma rates are lower at age 40 years and older, probably due to the fact that in higher age groups, the risk factor of a first delivery is not as frequent as in younger age groups. As two countries (Finland and Sweden) use probably more reliable register data instead of administrative hospital data to report these indicators, validity concerns regarding the obstetric indicators are not as marked as compared to the other patient safety indicators. Direct adjustment for 5-year age-gender strata did not materially affect indicator rates across countries, although two countries moved up one rank (and two others moved down one rank to compensate). Rates of these obstetric indicators were not associated with the mean number of secondary diagnoses at the country level $\left(\mathrm{R}^{2}<2 \%, \mathrm{p}>0.5\right)$. Ongoing projects on comparisons of obstetric trauma rates drawn from different data sources will provide information on the validity of these indicators in the near future. The rates represented in the charts below have not been age standardised or adjusted for secondary diagnoses or length of stay. 


\section{Chart 11. Obstetric trauma after vaginal delivery with instrument}
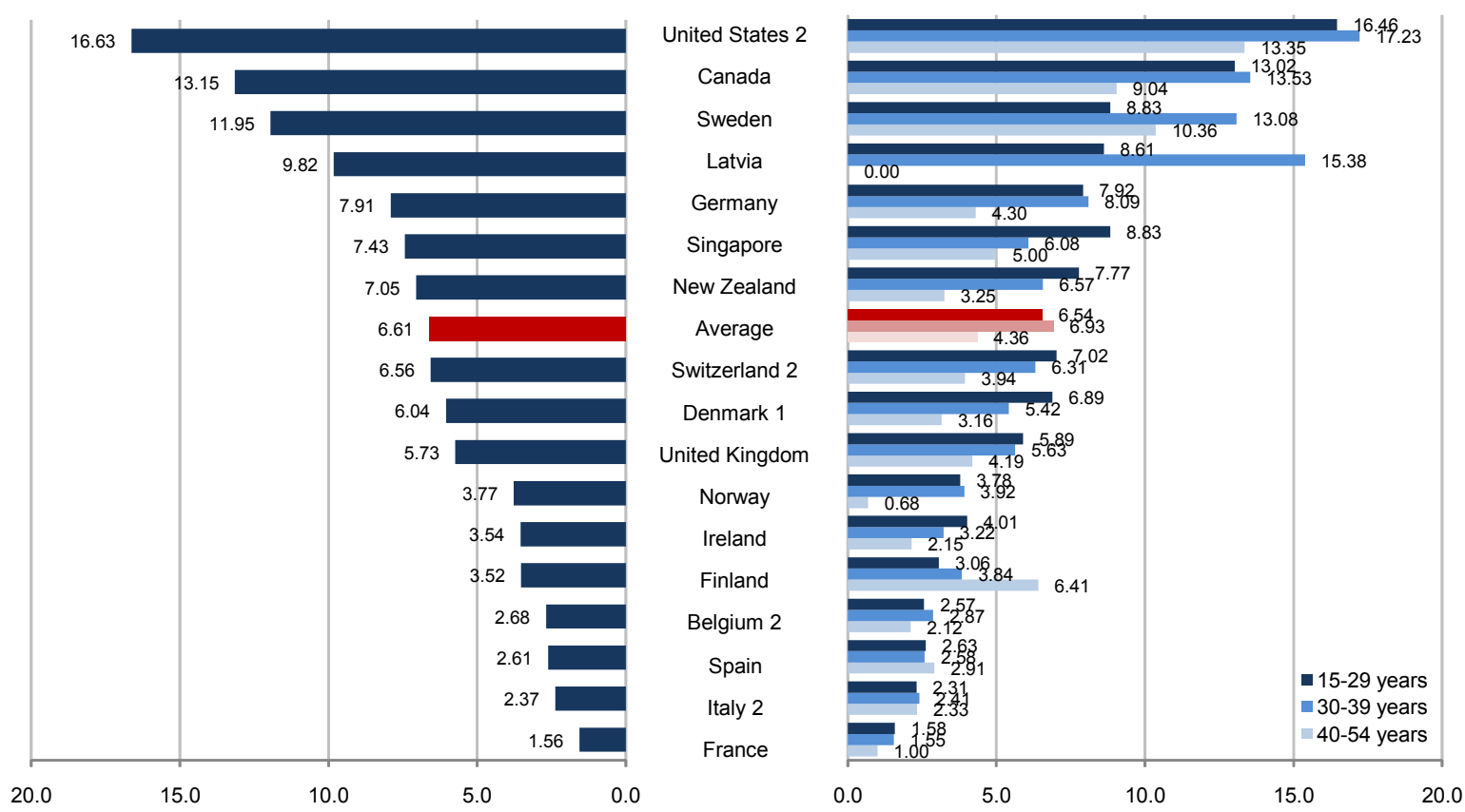

1. 2008. 2. 2006.

Note: Rates based on hospital administrative databases as reported by countries for the research and development work of the HCQI project.

\section{Chart 12. Obstetric trauma after vaginal delivery without instrument}
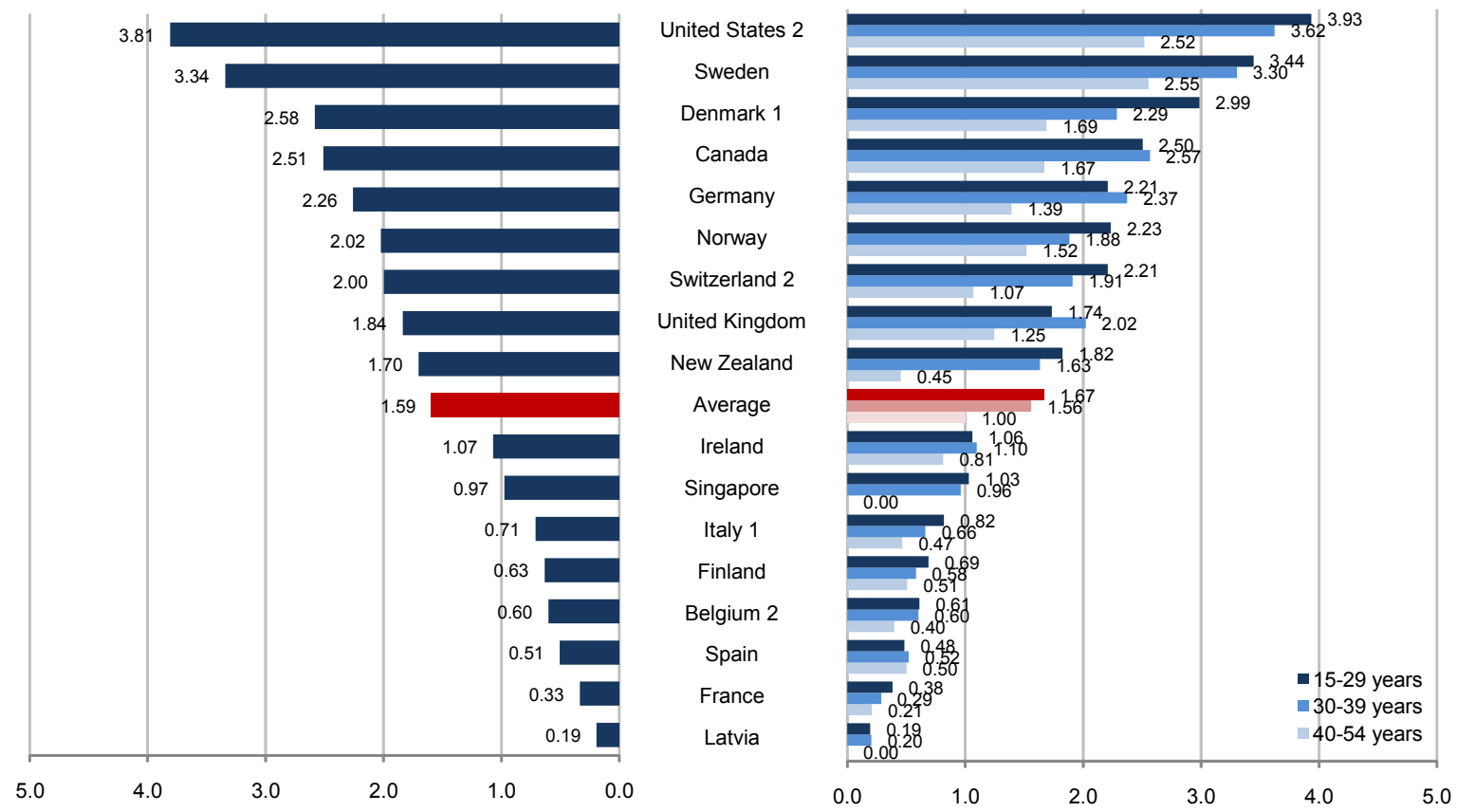

1. 2008. 2. 2006

Note: Rates based on hospital administrative databases as reported by countries for the research and development work of the HCQI project. 


\section{Detailed results}

80. Table 6 depicts all reported PSI rates from each country. Empty cells represent missing rates. In one country (Norway), rates of zero (no numerator cases) occurred. PSI rates of zero are suspicious and might reflect under-coding. Table 7 shows minimal and maximal rates for each PSI across all reporting countries, replacing zero rates with the lowest nonzero rate of another country in Table 6 to permit calculation of ratios between the highest and lowest PSI rate. Portugal and Norway contributed most of the minimal values. The ratios between the highest and the lowest rates, representing inter-country variability, were rather high for some PSIs; for example, the ratio was 106 for PSI 7 (catheter-related bloodstream infection). The least variability was found for PSI 5 (foreign body left in during procedure) and obstetric trauma - vaginal delivery with instrument (9.8). Regarding PSI 13 (postoperative sepsis), the reported rates varied between 0.1 and $8.8 \%$.

Table 6. PSI rates (\%) reported by 19 countries in 2009

\begin{tabular}{|c|c|c|c|c|c|c|c|}
\hline & $\begin{array}{l}\text { Foreign } \\
\text { body left in } \\
\text { during } \\
\text { procedure } \\
\text { (PSI 5) }\end{array}$ & $\begin{array}{l}\text { Catheter- } \\
\text { related } \\
\text { blood- } \\
\text { stream } \\
\text { infection } \\
\text { (PSI 7) }\end{array}$ & $\begin{array}{c}\text { Post } \\
\text { operative } \\
\text { pulmonary } \\
\text { embolism } \\
\text { or deep } \\
\text { vein } \\
\text { thrombosis } \\
\text { (PSI 12) }\end{array}$ & $\begin{array}{c}\text { Post } \\
\text { operative } \\
\text { sepsis (PSI } \\
\text { 13) }\end{array}$ & $\begin{array}{l}\text { Accidental } \\
\text { Puncture or } \\
\text { Laceration } \\
\text { (PSI 15) }\end{array}$ & $\begin{array}{c}\text { Obstetric } \\
\text { trauma - } \\
\text { vaginal } \\
\text { delivery } \\
\text { with } \\
\text { instrument } \\
\text { (PSI 18) }\end{array}$ & $\begin{array}{c}\text { Obstetric } \\
\text { trauma - } \\
\text { vaginal } \\
\text { delivery } \\
\text { without } \\
\text { instrument } \\
\text { (PSI 19) }\end{array}$ \\
\hline Belgium & 0.007 & 0.178 & 0.470 & 1.717 & 0.281 & 2.682 & 0.602 \\
\hline Canada & 0.007 & 0.083 & 0.199 & 0.398 & 0.402 & 13.147 & 2.511 \\
\hline Denmark & 0.002 & 0.033 & 0.271 & 0.240 & 0.045 & 6.043 & 2.582 \\
\hline Finland & 0.002 & 0.004 & 0.128 & 0.264 & 0.033 & 3.521 & 0.633 \\
\hline France & & & & & & 1.556 & 0.338 \\
\hline Germany & 0.005 & 0.128 & 0.587 & 0.391 & 0.120 & 7.905 & 2.257 \\
\hline Iceland & & & & & & & 6.681 \\
\hline Ireland & 0.003 & 0.064 & 0.575 & 0.650 & 0.077 & 3.537 & 1.070 \\
\hline Italy & 0.002 & 0.006 & 0.220 & 0.144 & 0.013 & 2.370 & 0.710 \\
\hline Latvia & & & & & & 9.821 & 0.193 \\
\hline New Zealand & 0.009 & 0.425 & 0.819 & 0.505 & 0.356 & 7.055 & 1.704 \\
\hline Norway & 0.000 & 0.026 & 0.438 & 8.081 & 0.000 & 3.768 & 2.021 \\
\hline Portugal & & 0.057 & 0.108 & 1.493 & 0.116 & 1.698 & 0.632 \\
\hline Singapore & 0.006 & 0.123 & & 0.140 & & 7.434 & 0.975 \\
\hline Spain & 0.005 & 0.189 & 0.281 & 0.440 & 0.183 & 2.611 & 0.505 \\
\hline Sweden & 0.002 & 0.013 & 0.170 & 0.474 & 0.085 & 11.950 & 3.342 \\
\hline Switzerland & 0.011 & 0.056 & 0.399 & 0.226 & 0.285 & 6.564 & 1.997 \\
\hline United Kingdom & 0.005 & 0.090 & 0.754 & 0.276 & 0.129 & 5.731 & 1.837 \\
\hline United States & 0.009 & 0.205 & 1.450 & 1.349 & 0.362 & 16.626 & 3.811 \\
\hline
\end{tabular}

Note: Rates based on hospital administrative databases as reported by countries for the research and development work of the HCQI project. Minimal and maximal rates printed in bold. 
Table 7. Minimum and maximum PSI rates (\%) reported by all 18 countries

\begin{tabular}{|l|c|c|c|c|}
\hline & $\begin{array}{c}\mathbf{N} \\
\text { (countries) }\end{array}$ & $\begin{array}{c}\text { Min Rate } \\
\text { (\%) }\end{array}$ & $\begin{array}{c}\text { Max Rate } \\
\text { (\%) }\end{array}$ & $\begin{array}{c}\text { Ratio between } \\
\text { highest and lowest } \\
\text { PSI rate, 16 } \\
\text { countries }\end{array}$ \\
\hline $\begin{array}{l}\text { Foreign body left in during procedure } \\
\text { (PSI 5) }\end{array}$ & 15 & 0.002 & 0.011 & 6.0 \\
\hline $\begin{array}{l}\text { Catheter-related bloodstream infection } \\
\text { (PSI 7) }\end{array}$ & 16 & 0.004 & 0.425 & 106.25 \\
\hline $\begin{array}{l}\text { Postoperative pulmonary embolism (PE) } \\
\text { or deep vein thrombosis (DVT) (PSI 12) }\end{array}$ & 15 & 0.108 & 1.450 & 13.50 \\
\hline Postoperative sepsis (PSI 13) & 16 & 0.140 & 8.081 & 57.73 \\
\hline $\begin{array}{l}\text { Accidental Puncture or Laceration (PSI } \\
\text { 15) }\end{array}$ & 15 & 0.013 & 0.402 & 31.15 \\
\hline $\begin{array}{l}\text { Obstetric trauma - vaginal delivery with } \\
\text { instrument (PSI 18) }\end{array}$ & 17 & 1.556 & 16.626 & 10.69 \\
\hline $\begin{array}{l}\text { Obstetric trauma - vaginal delivery } \\
\text { without instrument (PSI 19) }\end{array}$ & 18 & 0.193 & 6.681 & 34.62 \\
\hline
\end{tabular}

Note: Rates based on hospital administrative databases as reported by countries for the research and development work of the HCQI project.

\section{Administrative reporting}

Age and sex adjustment

81. Direct adjustment for age and gender did not materially affect the rates across countries for most indicators.

Secondary diagnoses

82. Thirteen countries reported the average number of secondary diagnoses calculated from the denominator-eligible cases for each PSI; Table 8 shows the corresponding data. 
Table 8. Reported averages of secondary diagnoses per PSI

\begin{tabular}{|c|c|c|c|c|c|c|c|}
\hline & $\begin{array}{l}\text { Foreign body } \\
\text { left in during } \\
\text { procedure } \\
\text { (PSI 5) }\end{array}$ & $\begin{array}{l}\text { Catheter- } \\
\text { related } \\
\text { bloodstrea } \\
\text { m infection } \\
\text { (PSI 7) }\end{array}$ & $\begin{array}{c}\text { Post } \\
\text { operative } \\
\text { pulmonary } \\
\text { embolism } \\
\text { (PE) or } \\
\text { deep vein } \\
\text { thrombosis } \\
\text { (DVT) (PSI } \\
12)\end{array}$ & $\begin{array}{c}\text { Post } \\
\text { operative } \\
\text { sepsis (PSI } \\
13)\end{array}$ & $\begin{array}{l}\text { Accidental } \\
\text { Puncture or } \\
\text { Laceration } \\
\text { (PSI 15) }\end{array}$ & $\begin{array}{l}\text { Obstetric } \\
\text { trauma - } \\
\text { vaginal } \\
\text { delivery } \\
\text { with } \\
\text { instrument } \\
\text { (PSI 18) }\end{array}$ & $\begin{array}{c}\text { Obstetric } \\
\text { trauma - } \\
\text { vaginal } \\
\text { delivery w/o } \\
\text { instrument } \\
\text { (PSI 19) }\end{array}$ \\
\hline Belgium & 6.72 & 6.61 & 5.63 & 6.66 & 7.02 & 4.89 & 3.75 \\
\hline Canada & 3.11 & 3.00 & 3.00 & 2.60 & 3.24 & 3.59 & 2.00 \\
\hline Denmark & 2.41 & 2.55 & 2.26 & 1.96 & 2.26 & 6.88 & 6.62 \\
\hline Germany & 5.31 & 4.98 & 4.81 & 4.24 & 5.43 & 5.30 & 3.32 \\
\hline Ireland & 2.57 & 2.61 & 2.68 & 1.88 & 2.77 & 2.67 & 1.83 \\
\hline Italy & 1.50 & & 0.99 & 0.87 & 1.54 & 1.79 & 1.50 \\
\hline New Zealand & 3.93 & 4.37 & 4.84 & 4.25 & 4.19 & 3.77 & 2.20 \\
\hline Norway & 1.90 & 2.08 & 1.76 & 7.00 & 1.90 & 2.30 & 2.00 \\
\hline Portugal & & 2.50 & 1.30 & 2.50 & 0.10 & & \\
\hline Singapore & 3.89 & 3.63 & & 2.65 & & 3.85 & 2.21 \\
\hline Spain & 3.71 & 3.74 & 2.77 & 2.48 & 3.45 & 3.32 & 2.79 \\
\hline Sweden & 2.50 & 2.50 & 3.79 & 2.60 & 2.50 & 2.60 & 1.40 \\
\hline Switzerland & 3.03 & 2.74 & 2.25 & 2.80 & 3.03 & 4.07 & 3.09 \\
\hline United Kingdom $^{1}$ & 2.72 & 2.83 & 3.18 & 2.43 & 2.89 & 2.83 & 1.90 \\
\hline United States & 6.02 & 5.85 & 6.20 & 6.20 & 6.50 & 3.77 & 2.83 \\
\hline
\end{tabular}

1. Data for the United Kingdom refers to England only.

83. There is currently no valid information on the mean number of secondary diagnoses from Finland, Portugal and Sweden. The United Kingdom reported this information only for England, which contributed most of the cases to the denominator. Age-sex standardised PSI rates were significantly correlated with the mean number of secondary diagnoses across countries for all of the non-obstetric indicators. Among 12 countries that reported the mean number of secondary diagnoses for PSI 15 (accidental puncture or laceration), the Spearman rank correlation coefficient was $0.706(\mathrm{p}=0.010)$. Among 13 countries that reported the mean number of secondary diagnoses for PSI 5 (foreign body left in during procedure), the rank correlation was $0.643(\mathrm{p}=0.018)$. Among 12 countries that reported the mean number of secondary diagnoses for PSI 12 (postoperative PE or DVT), the rank correlation was $0.657(\mathrm{p}=0.020)$. Among 13 countries that reported the mean number of secondary diagnoses for PSI 13 (postoperative sepsis), the rank correlation was $0.643(\mathrm{p}=0.018)$. Among 13 countries that reported the mean number of secondary diagnoses for PSI 7 (catheter-related bloodstream infection), the rank correlation was 0.918 $(\mathrm{p}<0.0001)$. The corresponding R-squared statistics (proportion of variance explained) ranged from $28 \%$ to $52 \%$. Italy, followed by Norway (except PSI 13), reported the lowest mean number of secondary diagnoses among eligible cases, which explains some rather low PSI rates reported by these countries.

84. Based on the consistent country-level association between the mean number of secondary diagnoses (among denominator cases) and rates of all non-obstetric PSIs, it is possible to adjust country- 
specific PSI rates for variation in coding intensity. Specifically, an ordinary least squares unweighted regression model was estimated for each PSI using data from all countries that reported both the mean number of secondary diagnoses and the corresponding rate for that PSI. Data from Norway were excluded from the analyses of accidental puncture or laceration, foreign body, and postoperative sepsis, because Norway reported implausibly low (zero) or high rates on these three indicators. The outcome variable in these regression models was a country's age-sex standardised PSI rate; the predictor variable was the mean number of secondary diagnoses among denominator cases. Parameter estimates from these models were used to estimate country-specific residuals, which were then linearly transformed into adjusted PSI rates with the same mean value as the unadjusted but standardised rates. The resulting adjusted PSI rates demonstrate far less variation (measured by the range, maximum-minimum ratio, standard deviation, and coefficient of variation) than unadjusted rates, for all non-obstetric PSIs. Based on the $\mathrm{R}^{2}$ statistic, $28 \%$ to $52 \%$ of the observed variation at the country level in PSI rates is attributable to variation in diagnostic coding. Removing this portion of the variation appears to yield more valid country-specific PSI rates.

\section{Length of stay}

85. Mean length of stay data among denominator-eligible cases for each indicator were reported by 14 countries. In no case was there a statistically significant association between mean length of stay and the age-sex standardised PSI rate. This finding suggests that international variation in length of stay does not meaningfully contribute to the variation in PSI rates, probably because all participating countries attempted to remove same-day hospital cases in the 2009 cycle of data submission

\section{Year to year reliability}

86. To estimate divergence across years, PSI rates reported in the current calculation cycle were compared to rates reported in the 2008 OECD cycle. Most indicators did not significantly change in definition and were used for this analysis. Thirteen of seventeen countries participating in 2008 also participated in 2009 and completely recalculated their PSI rates: Belgium, Canada, Denmark, Finland, Germany, Italy, New Zealand, Norway, Portugal, Singapore, Spain, Sweden, the United Kingdom, and the United States.

87. To assess the reliability of country-specific PSI rates across years, correlation analyses were performed using the 2008 and 2009 rates reported by each country for each PSI. The correlation analyses show high reliability both within countries (Table 9) and within PSIs (Table 10).

88. The year-to-year reliability of PSI rates, based on Pearson's correlation coefficient, was greater than $\mathrm{r}=0.94$ ( $\mathrm{p} \leq 0.01)$ for all countries except Portugal. However, the correlation coefficient between Portuguese and US data improved, suggesting that year-to-year reliability was poor simply because of an improvement of the Portuguese data or calculation methods. The correlation coefficient is slightly lower for the United Kingdom than for other countries, probably due to the fact that only data from England were included in last year's calculation. 
Table 9. Pearson's correlation coefficients of PSI rates between 2008 and 2009, by participating country

\begin{tabular}{|l|c|c|c|c|}
\hline & $\begin{array}{c}\text { n (number of } \\
\text { PSI rates [\%]) }\end{array}$ & $\begin{array}{c}\text { Pearson's } \\
\text { correlation } \\
\text { coefficient }\end{array}$ & $\begin{array}{c}\text { Year of data collection } \\
\text { (2008 calculation) }\end{array}$ & $\begin{array}{c}\text { Year of data collection } \\
\text { (2009 calculation) }\end{array}$ \\
\hline Belgium & 7 & 0.999 & 2004 & 2006 \\
\hline Canada & 7 & 1 & $2006-2007$ & 2007 \\
\hline Denmark & 7 & 1 & 2007 & 2008 \\
\hline Finland & 7 & 0.997 & 2006 & 2007 \\
\hline Germany & 7 & 0.999 & 2006 & 2007 \\
\hline Italy & 7 & 1 & 2005 & 2007 \\
\hline New Zealand & 7 & 0.998 & $2006-2007$ & 2007 \\
\hline Norway & 7 & 0.941 & 2006 & 2007 \\
\hline Portugal & 6 & 0.546 & 2006 & 2007 \\
\hline Singapore & 5 & $1^{2}$ & 2007 & 2007 \\
\hline Spain & 7 & 0.996 & 2006 & 2007 \\
\hline Sweden & 7 & 0.999 & 2006 & 2007 \\
\hline United Kingdom & 7 & 0.994 & $2006-2007$ & 2007 \\
\hline United States & 7 & $1^{1}$ & 2006 & 2006 \\
\hline
\end{tabular}

1.The year-to-year correlation for the USA is close to one, because 2007 data were not yet available from all participating states at the time of this data submission.

2. Singapore used data from the same year of data collection in both calculations and shows a year-to-year correlation close to one.

Table 10. Pearson's correlation coefficients of PSI rates between 2008 and 2009 calculations, by PSI

\begin{tabular}{|l|c|c|}
\hline \multicolumn{1}{|c|}{ Indicator name } & n (countries) & $\begin{array}{c}\text { Pearson's } \\
\text { correlation } \\
\text { coefficient } \\
\text { (ps0.01) }\end{array}$ \\
\hline Foreign body left in during procedure (PSI 5) & 13 & 0.920 \\
\hline Catheter-related bloodstream infection (PSI 7) & 14 & 0.994 \\
\hline $\begin{array}{l}\text { Postoperative pulmonary embolism (PE) or deep vein thrombosis } \\
\text { (DVT) (PSI 12) }\end{array}$ & 13 & 0.821 \\
\hline Postoperative sepsis (PSI 13) & 14 & 0.970 \\
\hline Accidental Puncture or Laceration (PSI 15) & 13 & 0.916 \\
\hline Obstetric trauma - vaginal delivery with instrument (PSI 18) & 14 & 0.996 \\
\hline Obstetric trauma - vaginal delivery without instrument (PSI 19) & 14 & 0.981 \\
\hline
\end{tabular}

89. The year-to-year reliability of PSI 12 (postoperative pulmonary embolism or deep vein thrombosis) was $0.892(\mathrm{p} \leq 0.01)$, which was less than that of the other indicators listed in Table 10.

\section{Conclusions}

90. All participating countries performed PSI calculations and contributed data; however, validity concerns arose in the analysis of data from several countries, as discussed above. Criteria to ensure data quality proposed in the last year's project are partially applied: rates of indicators of zero are regarded as invalid (except for the sentinel event indicator transfusion reaction which was not investigated this year) and should not be publicly reported. 
91. As several countries did not report average counts of secondary diagnoses, it was not feasible to implement a quality criterion based on the "mean number of secondary diagnoses among denominator cases". As the PSI methodology is based on analyses of secondary diagnoses reported in administrative hospital databases, thorough reporting of the average number of secondary diagnoses together with the corresponding PSI rate will be required in future projects envisaging public reporting.

92. The test-retest analyses suggest excellent reliability for eleven of twelve countries participating in 2008 and 2009 and using data from different collection periods. One country (Portugal) showed poorer year-to-year reliability, probably due to reported difficulties in the data collection and analysis during 2008, with subsequent improvement this year. Similarly, there was good test-to-retest reliability for all tested PSIs except for the postoperative pulmonary embolism or deep vein thrombosis indicator.

93. Standardisation of PSI rates using relatively narrow, five-year age strata proved that international variation in hospitalisation practices and population age structure explains very little of the observed variation in PSI rates. For all of the non obstetric PSIs, the consistent relationship between a country's standardised PSI rate and its mean number of secondary diagnoses is a cause for concern. This finding suggests that some countries have more thorough reporting of secondary diagnoses than others, and that variation in reporting may account for $28-52 \%$ of the observed variation in PSI rates. Further analyses are underway to model the impact of underreporting on PSI rates, and to impute corrected PSI rates after adjusting for underreporting. Underreporting does not appear to be an issue for postoperative DVT/PE and obstetric trauma, based on both published literature and empirical analyses of OECD data, although overdiagnosis due to widespread ultrasound screening in some hospitals or areas is an emerging concern for the former PSI.

94. Research and development work on patient safety indicators over the past four years has provided encouraging evidence that system-level patient safety indicators can be calculated from administrative databases by a majority of OECD countries. Although significant advancement in methodology and international comparability has been achieved during this period the requirement remains for ongoing research and development. During 2010-2011, work in this domain will focus on the technical specifications of the existing indicators, impact of different coding practices and classification systems on indicator rates and the potential use of data adjustment methods. 


\section{REFERENCES}

AHRQ (Agency for Health Care Research and Quality) (2007), PSI Technical Specifications. Version 3.1, Revision 3 http://www.qualityindicators.ahrq.gov/archives/psi/psi_technical_specs_v30a.pdf.

Angus DC, Linde-Zwirble WT, Lidicker J, Clermont G, Carcillo J, Pinsky MR. "Epidemiology of severe sepsis in the United States: analysis of incidence, outcome, and associated costs of care." Crit Care Med. $2001 \mathrm{Jul} ; 29(7): 1303-10$.

Bahl V, Thompson MA, Kau TY, Hu HM, Campbell DA. (2008), "Do the AHRQ Patient Safety Indicators flag conditions that are present at the time of hospital admission?" Medical Care, Vol. 46, No. 5, pp. 516-522.

Barbour GL. (1993), "Usefulness of a discharge diagnosis of sepsis in detecting iatrogenic infection and quality of care problems", American Journal of Medical Quality, Vol. 8, No. 1, pp. 2-5.

Belío-Blasco C, Torres-Fernández-Gil MA, Echeverría-Echarri JL, Gómez-López LI. (2000), “Evaluation of two retrospective active surveillance methods for the detection of nosocomial infection in surgical patients", Infection Control and Hospital Epidemiology, Vol. 21, No. 1, pp 24-27.

Best WR, Khuri SF, Phelan M, Hur K, Henderson WG, Demakis JG, Daley J. (2002), "Identifying patient preoperative risk factors and postoperative adverse events in administrative databases: results from the Department of Veterans Affairs National Surgical Quality Improvement Program”, Journal of the American College of Surgeons, Vol. 194, No. 3, pp.257-266.

Borzecki A, Kaafarani H, Hanchate A, Loveland S, Mull H, Shin M, Rosen A. (2009), "Validating the Patient Safety Indicators (PSI) in the Veterans Health Administration", abstract presented at AcademyHealth Annual Research Meeting, http://www.academyhealth.org/files/2009/tuesday/borzecki.pdf

Bottle A, Aylin P. (2008), "How NHS trusts could use patient safety indicators to help improve care", HealthCareRiskReport, May 2008, pp. 12-14.

Bottle A, Aylin P. (2009), "Application of AHRQ Patient Safety Indicators to English hospital data", Quality and Safety in Health Care, Vol. 18, pp. 303-308.

Brubaker L, Bradley CS, Handa VL, Richter HE, Visco A, Brown MB, Weber AM. (2007), “Anal sphincter laceration at vaginal delivery: is this event coded accurately?", Obstetrics and Gynecology, Vol. 109, No.5, pp.1141-1145.

Culler SD, Hawley JN, Naylor V, Rask KJ. (2007), "Is the availability of hospital IT applications associated with a hospital's risk adjusted incidence rate for Patient Safety Indicators: Results from 66 Georgia hospitals", Journal of Medical Systems, Vol. 31, pp. 319-327.

Drösler SE, (2008), "Facilitating Cross-National Comparisons of Indicators for Patient Safety at the Health-System Level in OECD Countries", OECD Health Technical Papers, No. 19, OECD, Paris. 
Drösler SE, Klazinga NS, Romano PS, Tancredi DJ, Gogorcena Aoiz MA, Hewitt MC, Scobie S, Soop M, Wen E, Quan H, Ghali WA, Mattke S, Kelley E., (2009), "Application of patient safety indicators internationally: a pilot study among seven countries", International Journal for Quality in Health Care, Vol.21, No.4, pp.272-278.

Dudding TC, Vaizey CJ, Kamm MA. (2008), "Obstetric anal sphincter injury: incidence, risk factors, and management", Annals of Surgery, Vol. 247, No.2, pp.224-237.

Eggimann P, Harbarth S, Constantin MN, Touveneau S, Chevrolet JC, Pittet D. (2000), "Impact of a prevention strategy targeted at vascular-access care on incidence of infections acquired in intensive care", Lancet, Vol. 355, No.9218, pp.1864-1868.

Encinosa WE, Hellinger FJ. (2008), "The impact of medical errors on ninety-day costs and outcomes: An examination of surgical patients", Health Services Research, Vol. 43, No. 6, pp. 2067-2085.

Farley DO, Greenberg MD, Haviland AM, Lovejoy S. (2008), "Prioritizing Patient Safety Outcomes Measures: Results of an Expert Consensus Process", prepared for the Agency for Healthcare Research and Quality, http://192.5.14.110/pubs/working_papers/2008/RAND_WR601.pdf .

Foster D, Young J, Heller S. (2009), "US national estimates of mortality, length of stay, and costs attributable to inpatient complications of care", abstract presented at AcademyHealth 2009 Annual Research Meeting (http://www.academyhealth.org/files/arm/ARM-2009-Posters.pdf).

Friedman B, Encinosa W, Jiang HJ, Mutter R. (2009), "Do patient safety events increase readmissions?" Medical Care, Vol. 47, No. 5, pp. 583-590.

Gallagher B, Cen L, Hannan EL. (2005a), "Readmissions for Selected Infections Due to Medical Care: Expanding the definition of a Patient Safety Indicator", In "Advances in Patient Safety: from Research to Implementation", Agency for Health Care Research and Quality 2005.

Gallagher B, Cen L, Hannan EL. (2005b), "Validation of AHRQ's Patient Safety Indicator for Accidental Puncture or Laceration." In "Advances in Patient Safety: from Research to Implementation", Agency for Health Care Research and Quality 2005.

Gawande AA, Studdert DM, Orav EJ, Brennan TA, Zinner MJ. (2003), "Risk factors for retained instruments and sponges after surgery", New England Journal of Medicine, Vol. 348, No.3, pp.229235.

Gonzalez-Ojeda A, Rodriguez-Alcantar DA, Arenas-Marquez H, Sanchez Perez-Verdia E, Chavez-Perez R, Alvarez-Quintero R, Perea-Sanchez A. (1999), "Retained foreign bodies following intraabdominal surgery", Hepatogastroenterology, Vol.46, No.26, pp.808-812.

Geerts WH, Pineo GF, Heit JA, Bergqvist D, Lassen MR, Colwell CW, Ray JG. (2004), "Prevention of venous thromboembolism: the Seventh ACCP Conference on Antithrombotic and Thrombolytic Therapy”, Chest, Vol.126, No.3 Suppl., pp.338S-400S.

Gillet P, Kolh P, Sermeus W, Vleugels A, Jacques J, Van Den Heede K, Devriese S, Vrijens F, Verelst S. (2008), "Détection des événements indésirables dans les bases de données administratives", KCE reports 93B, http://www.kce.fgov.be/index_fr.aspx?SGREF=3439\&CREF=11889 . 
Glance LG, Li Y, Osler TM, Mukamel DB, Dick AW. (2008), "Impact of date stamping on patient safety measurement in patients undergoing CABG: Experience with the AHRQ Patient Safety Indicators", BMC Health Services Research, Vol. 8, pp. 176.

Grobman WA, Feinglass J, Murthy S. (2006), "Are the Agency for Healthcare Research and Quality obstetric trauma indicators valid measures of hospital safety?" American Journal of Obstetrics and Gynecology, Vol. 195, pp. 868-874.

Haut ER, Noll K, Efron DT, Berenholz SM, Haider A, Cornwell EE, Pronovost PJ. (2007), "Can increased incidence of deep vein thrombosis (DVT) be used as a marker of quality of care in the absence of standardized screening? The potential effect of surveillance bias on reported DVT rates after trauma", Journal of Trauma, Vol. 63, No. 5, pp. 1132-1137.

Hawker GA, Coyte PC, Wright JG, Paul JE, Bombardier C. (1997), “Accuracy of administrative data for assessing outcomes after knee replacement surgery", Journal of Clinical Epidemiology, Vol.50, No.3, pp.265-273.

Henderson KE, Recktenwald AJ, Reichley RM, Bailey TC, Waterman BM, Diekemper RL, Storey PE, Ireland BK, Dunagan WC. (2009), "Clinical validation of the AHRQ Postoperative Venous Thromboembolism Patient Safety Indicator", Joint Commission Journal on Quality and Patient Safety, Vol. 35, No. 7, pp. 370-376.

Houchens RL, Elixhauser A, Romano PS. (2008), "How often are potential patient safety events present on admission?" Joint Commission Journal on Quality and Patient Safety, Vol.34, No.3, pp.154-163.

Iezzoni LI, Daley J, Heeren T, Foley SM, Hughes JS, Fisher ES, Duncan CC, Coffman GA. (1994a), "Using administrative data to screen hospitals for high complication rates", Inquiry, Vol.31, No.1, pp.40-55.

Iezzoni LI, Shwartz M, Ash AS, Mackiernan Y, Hotchkin EK. (1994b), "Risk adjustment methods can affect perceptions of outcomes", American Journal of Medical Quality, Vol.9, No.2, pp.43-48.

Iezzoni LI, Davis RB, Palmer RH, Cahalane M, Hamel MB, Mukamal K, Phillips RS, Banks NJ, Davis DT Jr. (1999), "Does the Complications Screening Program flag cases with process of care problems? Using explicit criteria to judge processes", International Journal of Quality in Health Care, Vol.11, No.2, pp.107-118.

Isaac T, Jha AK. (2008), "Are Patient Safety Indicators related to widely used measures of hospital quality?" Journal of General Internal Medicine, Vol. 23, No. 9, pp. 1373-1378.

Keeler EB, Kahn KL, Bentow SS. (1992), Assessing quality of care for hospitalized Medicare patients with hip fracture using coded diagnoses from the Medicare Provider Analysis and Review File (Prepared for the Health Care Financing Adminstration, US Department HHS) RAND 1992

Kovner C, Gergen PJ. (1998), "Nurse staffing levels and adverse events following surgery in U.S. hospitals", Image - the Journal of Nursing Scholarship, Vol.30, No.4, pp.315-321.

Kristensen S, Mainz J, Bartels P. (2009), "Selection of indicators for continuous monitoring of patient safety: recommendations of the project 'Safety Improvement for Patients in Europe'”, International Journal for Quality in Health Care, Vol. 21, No. 3, pp. 169-175. 
Kronman MP, Hall M, Slonim AD, Shah SS. (2008), "Charges and length of stay attributable to adverse patient-care events using pediatric-specific quality indicators: A multicenter study of freestanding children's hospitals", Pediatrics, Vol. 121, No. 6, pp. e1653-e1659.

Lawthers AG, McCarthy EP, Davis RB, Peterson LE, Palmer RH, Iezzoni LI. (2000), "Identification of inhospital complications from claims data. Is it valid?”, Medical Care, Vol.38, No.8, pp785-795.

Massanari RM, Wilkerson K, Streed SA, Hierholzer WJ Jr. (1987), "Reliability of reporting nosocomial infections in the discharge abstract and implications for receipt of revenues under prospective reimbursement", American Journal of Public Health, Vol.77, No.5, pp.561-564.

McCarthy EP, Iezzoni LI, Davis RB, Palmer RH, Cahalane M, Hamel MB, Mukamal K, Phillips RS, Davies DT Jr. (2000), "Does clinical evidence support ICD-9-CM diagnosis coding of complications?”, Medical Care, Vol.38, No.8, pp.868-876.

Mattke S, et al. (2006), "Health Care Quality Indicators Project Initial Indicators Report", OECD Health Working Papers, No. 22, OECD, Paris

Menachemi N, Saunders C, Chukmaitov A, Matthews MC, Brooks RG. (2007), "Hospital adoption of information technologies and improved patient safety: A study of 98 hospitals in Florida", Journal of Healthcare Management, Vol. 52, No. 6, pp. 398-409.

Millar J, Mattke S and the members of the OECD Patient Safety Panel (2004), "Selecting Indicators for Patient Safety at the Health Systems Level in OECD Countries", OECD Health Technical Papers, No. 18, OECD, Paris.

Miller MR, Elixhauser A, Zhan C, Meyer GS. (2001), "Patient Safety Indicators: using administrative data to identify potential patient safety concerns", Health Services Research, Vol.36, No.6 (part 2), pp.110-132.

Miller MR, Pronovost P, Donithan M, Zeger S, Zhan C, Morlock L, Meyer GS. (2005), "Relationship between performance measurement and accreditation: implications for quality of care and patient safety", American Journal of Medical Quality, Vol.20, No.5, pp.239-252.

Naessens JM, Campbell CR, Berg B, Williams AR, Culbertson R. (20007), "Impact of diagnosis-timing indicators on measures of safety, comorbidity, and case mix groupings from administrative data sources", Medical Care, Vol.45, No.12, pp.1234.

Needleman J, Buerhaus P, Mattke S, Stewart M, Zelevinsky K. (2002), "Nurse-staffing levels and the quality of care in hospitals", New England Journal of Medicine, Vol.346, No.22, pp.1715-1722.

OECD Health Data 2008, June 2008, Frequently Requested Data.

Olin JW. (2002), "Pulmonary embolism”, Reviews in Cardiovascular Medicine, Vol.3, No.Suppl 2, pp.S68-75.

Parente ST, McCullough JS. (2009), "Health information technology and patient safety: Evidence from panel data", Health Affairs, Vol. 28, No. 2, pp. 357-360.

Quan, H et al.(2008) for the IMECCHI Investigators. Adaptation of AHRQ Patient Safety Indicators for Use in ICD-10 Administrative Data by an International Consortium. 2008.

http://www.ahrq.gov/downloads/pub/advances2/vol1/advances-quan_52.pdf. 
Raleigh VS, Cooper J, Bremner SA, Scobie S. (2008), "Patient safety indicators for England from hospital administrative data: case-control analysis and comparison with US data", BMJ, Vol.337, No.a, pp.1702.

Rivard PE, Luther SL, Christiansen CL, Shibei Zhao, Loveland S, Elixhauser A, Romano PS, Rosen AK. (2008), "Using patient safety indicators to estimate the impact of potential adverse events on outcomes", Medical Care Research and Review, Vol.65, No.1, pp.67-87.

Romano PS, Schembri ME, Rainwater JA. (2002), "Can administrative data be used to ascertain clinically significant postoperative complications?”, American Journal of Medical Quality, Vol. 17, No.4, pp.145-154.

Romano PS, Yasmeen S, Schembri ME, Keyzer JM, Gilbert WM. (2005), "Coding of perineal lacerations and other complications of obstetric care in hospital discharge data", Obstetrics and Gynecology, Vol.106, No.4, pp.717-725.

Romano PS, Mull HJ, Rivard PE, Zhao S, Henderson WG, Loveland S, Tsilimingras D, Christiansen CL, Rosen AK. (2009), "Validity of selected AHRQ patient safety indicators based on VA National Surgical Quality Improvement Program data”, Health Services Research, Vol.44, No.1, pp.182-204.

Rosen AK, Loveland SA, Romano PS, Itani KMF, Silber JH, Even-Shoshan OO, Halenar MJ, Teng Y, Zhu J, Volpp KG. (2009), "Effects of resident duty hour reform on surgical and procedural Patient Safety Indicators among hospitalized Veterans Health Administration and Medicare patients", Medical Care, Vol. 47, No. 7, pp. 723-731.

Scanlon MC, Miller M, Harris JM, Schulz K, Sedman A. (2006), "Targeted chart review of pediatric patient safety events identified by the Agency for Healthcare Research and Quality's Patient Safety Indicators methodology", Journal of Patient Safety, Vol. 2, No. 4, pp. 191-197.

Scanlon MC, Harris JM, Levy F, Sedman A. (2008), "Evaluation of the Agency for Healthcare Research and Quality Pediatric Quality Indicators", Pediatrics, Vol. 121, No. 6, pp. e1723-1731.

Sedman A, Harris JM 2nd, Schulz K, Schwalenstocker E, Remus D, Scanlon M, Bahl V. (2005), "Relevance of the Agency for Healthcare Research and Quality Patient Safety Indicators for children's hospitals", Pediatrics, Vol.115, No.1, pp.135-145.

Stevanovic V. (2009), "Technical Analysis of the Validity and Comparability of the Patient Safety Indicators: Impact of the AHRQ Exclusions", presented at the Patient Safety Experts Subgroup of the HCQI Project, OECD, Paris, 23 October.

Stone PW, Horan TC, Shih HC, Mooney-Kane C, Larson E. (2007), "Comparisons of health careassociated infections identification using two mechanisms for public reporting", American Journal of Infection Control, Vol. 35, No. 3, pp. 145-149.

Taylor B. (1998), "Common bile duct injury during laparoscopic cholecystectomy in Ontario: does ICD-9 coding indicate true incidence?, CMAJ, Vol.158, No.4, pp.481-485.

Thornlow DK, Merwin E. (2009), "Managing to improve quality: The relationship between accreditation standards, safety practices, and patient outcomes", Health Care Management Review, Vol. 34, No. 3, pp. 267-272. 
Utter GH, Zrelak PA, Baron R, Tancredi DJ, Sadeghi B, Geppert JJ, Romano PS. (2009), "Positive predictive value of the AHRQ Accidental Puncture or Laceration Patient Safety Indicator", Medical Care, epub ahead of print.

Valinsky LJ, Hockey RL, Hobbs MS, Fletcher DR, Pikora TJ, Parsons RW, Tan P. (1999), "Finding bile duct injuries using record linkage: a validated study of complications following cholecystectomy", Journal of Clinical Epidemiology, Vol.52, No.9, pp.893-901.

Vartak S, Ward MM, Vaughn TE. (2008), "Do postoperative complications vary by hospital teaching status", Medical Care, Vol. 46, No. 1, pp. 25-32.

Weingart SN, Iezzoni LI, Davis RB, Palmer RH, Cahalane M, Hamel MB, Mukamal K, Phillips RS, Davies DT Jr, Banks NJ. (2000), "Use of administrative data to find substandard care: validation of the complications screening program", Medical Care, Vol.38, No.8, pp.796-806.

Weller WE, Gallagher BK, Cen L, Hannan EL. (2004), "Readmissions for venous thromboembolism: Expanding the definition of Patient Safety Indicators", Joint Commission Journal on Quality and Safety, Vol. 30, No. 9, pp. 497-504.

Wheeler TL 2nd, Richter HE. Delivery method, anal sphincter tears and fecal incontinence: new information on a persistent problem. Curr Opin Obstet Gynecol. 2007 Oct;19(5):474-9.

White RH, Sadeghi B, Tancredi DJ, Zrelak P, Cuny J, Sama P, Utter GH, Geppert JJ, Romano PS. (2009), "How valid is the ICD-9-CM based AHRQ Patient Safety Indicator for Postoperative Venous Thromboembolism?" Medical Care, Vol. 47, epub ahead of print.

WHO (2009), "WHO Guidelines on Hand Hygiene in Health Care: First Global Patient Safety Challenge Clean Care is Safer Care", WHO, Geneva.

Yao H, Greenberg MD, Haviland AM, Farley DO. (2009), “'Canary measures' among the AHRQ Patient Safety Indicators", American Journal of Medical Quality, Vol. 24, epub ahead of print.

Zhan C, Miller MR. (2003), "Excess length of stay, charges, and mortality attributable to medical injuries during hospitalization”, JAMA, Vol.290, No.14, pp.1868-1874.

Zhan C, Battles J, Chiang Y, Hunt D. (2007), "The validity of ICD-9-CM codes in identifying postoperative deep vein thrombosis and pulmonary embolism", Joint Commission Journal on Quality and Patient Safety, Vol. 33, No. 6, pp. 326-331.

Zrelak PA, Sadeghi B, Utter GH, Baron R, Tancredi DJ, Geppert JJ, Romano PS. (2009), "Positive predictive value of the AHRQ Patient Safety Indicator for Central Line Associated Bloodstream Infection (Selected Infections Due to Medical Care)", under review. 


\section{OECD HEALTH WORKING PAPERS}

A full list of the papers in this series can be found on the OECD website: www.oecd.org/els/health/workingpapers

No. 47 HEALTH CARE QUALITY INDICATORS PROJECT: PATIENT SAFETY INDICATORS REPORT 2009 (2009) Saskia Drösler, Patrick Romano, Lihan Wei

No. 46 EDUCATION AND OBESITY IN FOUR OECD COUNTRIES (2009) Franco Sassi, Marion Devaux, Jody Church, Michele Cecchini and Francesca Borgonovi

No. 45 THE OBESITY EPIDEMIC: ANALYSIS OF PAST AND PROJECTED FUTURE TRENDS IN SELECTED OECD COUNTRIES (2009) Franco Sassi, Marion Devaux, Michele Cecchini and Elena Rusticelli

No. 44 THE LONG-TERM CARE WORKFORCE: OVERVIEW AND STRATEGIES TO ADAPT SUPPLY TO A GROWING DEMAND (2009) Rie Fujisawa and Francesca Colombo

No. 43 MEASURING DISPARITIES IN HEALTH STATUS AND IN ACCESS AND USE OF HEALTH CARE IN OECD COUNTRIES (2009) Michael de Looper and Gaetan Lafortune

No. 42 POLICIES FOR HEALTHY AGEING: AN OVERVIEW (2009) Howard Oxley

No. 41 THE REMUNERATION OF GENERAL PRACTITIONERS AND SPECIALISTS IN 14 OECD COUNTRIES: WHAT ARE THE FACTORS EXPLAINING VARIATIONS ACROSS COUNTRIES? (2008) Rie Fujisawa and Gaetan Lafortune

No. 40 INTERNATIONAL MOBILITY OF HEALTH PROFESSIONALS AND HEALTH WORKFORCE MANAGEMENT IN CANADA: MYTHS AND REALITIES (2008) Jean-Christophe Dumont, Pascal Zurn, Jody Church and Christine Le Thi

No. 39 PHARMACEUTICAL PRICING \& REIMBURSEMENT POLICIES IN GERMANY (2008) Valérie Paris and Elizabeth Docteur

No. 38 MIGRATION OF HEALTH WORKERS: THE UK PERSPECTIVE TO 2006 (2008) James Buchan, Susanna Baldwin and Miranda Munro

No. 37 THE US PHYSICIAN WORKFORCE: WHERE DO WE STAND? (2008) Richard A. Cooper

No. 36 MIGRATION POLICIES OF HEALTH PROFESSIONALS IN FRANCE (2008) Roland Cash and Philippe Ulmann

No. 35 NURSE WORKFORCE CHALLENGES IN THE UNITED STATES: IMPLICATIONS FOR POLICY (2008) Linda H. Aiken and Robyn Cheung

No. 34 MISMATCHES IN THE FORMAL SECTOR, EXPANSION OF THE INFORMAL SECTOR: IMMIGRATION OF HEALTH PROFESSIONALS TO ITALY (2008) Jonathan Chaloff

No. 33 HEALTH WORKFORCE AND INTERNATIONAL MIGRATION: CAN NEW ZEALAND COMPETE? (2008) Pascal Zurn and Jean-Christophe Dumont

No. 32 THE PREVENTION OF LIFESTYLE-RELATED CHRONIC DISEASES: AN ECONOMIC FRAMEWORK (2008) Franco Sassi and Jeremy Hurst 


\section{RECENT RELATED OECD PUBLICATIONS}

HEALTH AT A GLANCE 2009: OECD INDICATORS (2009).

See http://www. oecd.org/health/healthataglance for more information

ACHIEVING BETTER VALUE FOR MONEY IN HEALTH CARE (2009), OECD HEALTH POLICY STUDIES

OECD HEALTH DATA 2009 (2009), available on CD-ROM (in single-user or network installations). The database can be queried in English, French, German, Spanish and Italian. Japanese and Russian are also available but exclusively in the online version. www. oecd.org/health/healthdata

OECD REVIEWS OF HEALTH SYSTEMS - TURKEY (2009)

THE LOOMING CRISIS IN THE HEALTH WORKFORCE: CAN OECD COUNTRIES RESPOND? (2008)

PHARMACEUTICAL PRICING POLICIES IN A GLOBAL MARKET (2008)

OECD REVIEWS OF HEALTH SYSTEMS - SWITZERLAND (2006)

LONG-TERM CARE FOR OLDER PEOPLE (2005), OECD HEALTH PROJECT SERIES

HEALTH TECHNOLOGIES AND DECISION MAKING (2005), OECD HEALTH PROJECT SERIES

OECD REVIEWS OF HEALTH CARE SYSTEMS - FINLAND (2005)

OECD REVIEWS OF HEALTH CARE SYSTEMS - MEXICO (2005)

PRIVATE HEALTH INSURANCE IN OECD COUNTRIES (2004), OECD HEALTH PROJECT SERIES

TOWARDS HIGH-PERFORMING HEALTH SYSTEMS - POLICY STUDIES (2004), OECD HEALTH PROJECT SERIES

TOWARDS HIGH-PERFORMING HEALTH SYSTEMS (2004), OECD HEALTH PROJECT SERIES

OECD REVIEWS OF HEALTH CARE SYSTEMS - KOREA (2003)

A DISEASE-BASED COMPARISON OF HEALTH SYSTEMS: WHAT IS BEST AND AT WHAT COST? (2003)

MEASURING UP: IMPROVING HEALTH SYSTEMS PERFORMANCE IN OECD COUNTRIES (2002)

A SYSTEM OF HEALTH ACCOUNTS (2000)

SHA Revision information and proposals at http://www.oecd.org/health/sha/revision

For a full list, consult the OECD On-Line Bookstore at www.oecd.org, or write for a free written catalogue to the following address:

OECD Publications Service

2, rue André-Pascal, 75775 PARIS CEDEX 16 
Organisation de Coopération et de Développement Économiques

Organisation for Economic Co-operation and Development

23-Nov-2009

DIRECTORATE FOR EMPLOYMENT, LABOUR AND SOCIAL AFFAIRS

English text only HEALTH COMMITTEE

\section{Health Working Papers}

HEALTH CARE QUALITY INDICATORS PROJECT, PATIENT SAFETY INDICATORS REPORT 2009

\section{ANNEX}

\section{Saskia Drösler}

Technical Manual for Facilitaing Cross-National Comparisions for Patient Safety Indicators - This document represents a revised and updated version of OECD Technical Paper No. 19 for the set of patient safety indicators calculated for the 2008-2009 data collection of the OECD Health Care Quality Indicators project. 


\title{
DIRECTORATE FOR EMPLOYMENT, LABOUR AND SOCIAL AFFAIRS
}

\author{
www.oecd.org/els
}

\section{OECD HEALTH WORKING PAPERS}

\section{http://www.oecd.org/els/health/workingpapers}

This series is designed to make available to a wider readership health studies prepared for use within the OECD. Authorship is usually collective, but principal writers are named. The papers are generally available only in their original language - English or French - with a summary in the other.

Comment on the series is welcome, and should be sent to the Directorate for Employment, Labour and Social Affairs, 2, rue André-Pascal, 75775 PARIS CEDEX 16, France.

The opinions expressed and arguments employed here are the responsibility of the author(s) and do not necessarily reflect those of the OECD.

\section{Applications for permission to reproduce or translate all or part of this material should be made to:}

\author{
Head of Publications Service \\ OECD \\ 2, rue André-Pascal \\ 75775 Paris, CEDEX 16 \\ France
}

Copyright OECD 2009 


\section{TABLE OF CONTENTS}

\begin{tabular}{|c|}
\hline THODOLOGICAL ISSUES . \\
\hline 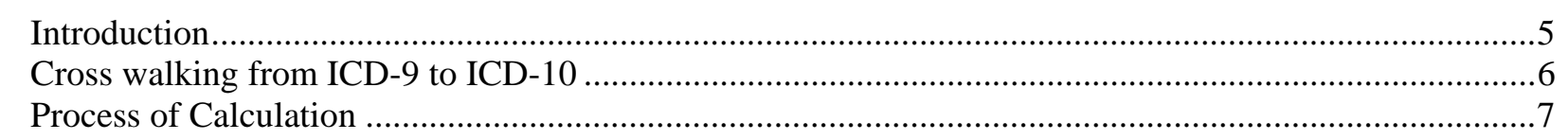 \\
\hline QUICK STEP OVERVIEW OF ESSENTIAL TASKS FOR DATA PREPARATION ..............................11 \\
\hline 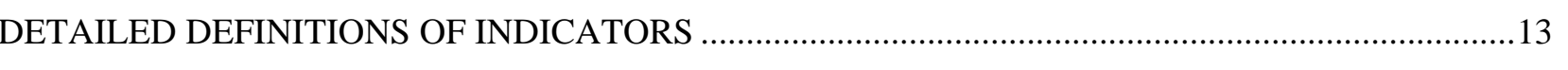 \\
\hline $\begin{array}{l}\text { Catheter-related bloodstream infection, secondary diagnosis field per } 100 \text { discharges (PSI 7) } \\
\text { Postoperative pulmonary embolism (PE) or deep vein thrombosis (DVT), secondary diagnosis field per } \\
100 \text { discharges (PSI 12) } \ldots \ldots \ldots \ldots \ldots \ldots \ldots \ldots \ldots \ldots \ldots \ldots \ldots \ldots \\
\text { Postoperative sepsis, secondary diagnosis field per } 100 \text { discharges (PSI 13) } \\
\text { Accidental puncture or laceration, secondary diagnosis field per } 100 \text { discharges (PSI 15) } \\
\text { Foreign body left in during procedure, secondary diagnosis field per } 100 \text { discharges (PSI 5) } \\
\text { Obstetric trauma }- \text { vaginal delivery with instrument, any diagnosis or procedure field per } 100 . .23 \\
\text { deliveries (PSI 18) }\end{array}$ \\
\hline
\end{tabular}

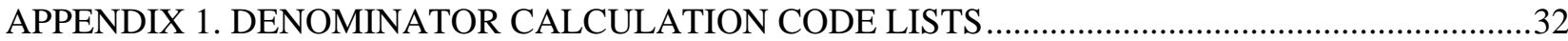

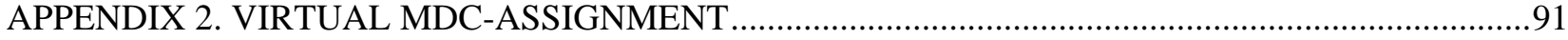

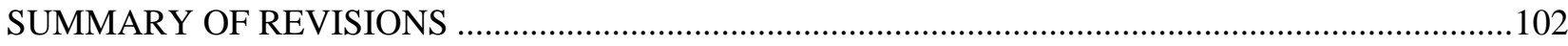

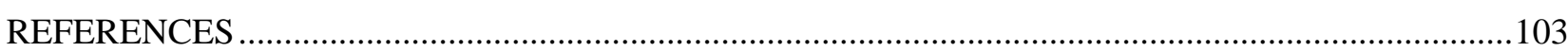




\section{INTRODUCTION}

1. This technical manual was prepared to assist countries in calculating the Patient Safety Indicators included in the OECD Health Care Quality Indicator data collection for 2008-2009.

2. It provides detailed practical advice on calculating each indicator in a selected set of Patient Safety Indicators (PSI) utilising national hospital administrative databases.

3. The selected indicators are set out in Table 1.

Table 1. Selected patient safety indicators for 2008-2009 HCQI data collection

\begin{tabular}{|l|l|}
\hline Area & Indicator name \\
\hline Hospital-acquired infections & Catheter-related bloodstream infection (PSI 7) \\
\hline \multirow{3}{*}{$\begin{array}{l}\text { Operative and post-operative } \\
\text { complications }\end{array}$} & Postoperative pulmonary embolism (PE) or deep vein thrombosis (DVT) (PSI 12) \\
\cline { 2 - 2 } & Postoperative sepsis (PSI 13) \\
\cline { 2 - 2 } Sentinel events & Accidential puncture or laceration (PSI 15) \\
\hline \multirow{2}{*}{ Obstetrics } & Foreign body left in during procedure (PSI 5) \\
\hline & Obstetric trauma - vaginal delivery with instrument (PSI 18) \\
\cline { 2 - 2 } & Obstetric trauma - vaginal delivery without instrument (PSI 19) \\
\hline
\end{tabular}

4. These indicators are derived from the Quality Indicators developed by the US Agency for Healthcare Research and Quality. AHRQ's Patient Safety Indicators (PSIs) are a set of indicators providing information on potential in hospital complications and adverse events following surgeries, procedures, and childbirth. The PSIs were developed after a comprehensive literature review, analysis of ICD-9-CM codes, clinician panel review, implementation of risk adjustment, and empirical analyses (AHRQ, 2006).

5. $\quad$ For each of these indicators, the manual provides:

- Generic coding and calculation instructions related to national hospital administrative databases,

- Cross walk from ICD 9 to ICD 10 codes for each indicator,

- $\quad$ Detailed definitions for calculation of indicators, and

- $\quad$ Flow charts for visualising the calculation process. 


\section{METHODOLOGICAL ISSUES}

\section{Introduction}

6. The methodology for facilitating internationally comparable Patient Safety Indicators set out in this manual contains two key elements:

- Cross-walk between the key disease classifications

- $\quad$ Detailed process of calculation

7. The Patient Safety Indicators dealt with in this manual are specified according to certain diagnosis and, in some instances, procedure codes. There are currently different medical classifications in use for coding diagnosis; the ICD-9 (International Classification of Diseases) classification which is no longer updated by the World Health Organisation (WHO) is the precursor of the present ICD-10 classification. OECD member countries use ICD-9 (e.g. Spain, USA) as well as ICD-10 (e.g. Australia, Canada, Germany). For that reason this manual contains both versions of the coding system.

8. Usually countries do not use the original version of a classification published by the WHO but modify it according to their needs. Country modifications are still consistent with the WHO version, keeping the structure of the classification tree. In some chapters of the ICD classification the country versions are more extensive than the WHO version while in others they are not. This manual does not cover all the different country versions of the ICD.

9. The technical specifications of diagnosis in this manual are based on the ICD-10-WHO, 2006 and on the ICD-9-CM1. Therefore countries seeking to utilise this manual must ensure that before applying the definitions the defined codes for inclusion or exclusion criteria are currently in use. Otherwise the definitions at hand must be extended to include the subgroups added in the country modifications.

10. For example, Table 2 shows that one three-digit WHO code for decubitus ulcer corresponds to 8 four-digit codes in Canada, 5 four-digit codes in Australia and 50 five-digit German codes. To calculate the numerator for the indicator decubitus ulcer, all country specific subgroups of the listed WHO code L89 must be taken into account.

1 Definitions in ICD-9-CM are adopted from AHRQ (2003). 
Table 2. Examples of country versions

\begin{tabular}{|c|c|c|c|c|}
\hline $\begin{array}{l}\text { ICD-10 } \\
\text { WHO } \\
\text { (2006) }\end{array}$ & & $\begin{array}{l}\text { ICD-10-CA } \\
\text { (Canada, 2006) }\end{array}$ & $\begin{array}{l}\text { ICD-10-AM } \\
\text { (Australia, 2006) }\end{array}$ & $\begin{array}{l}\text { ICD-10-GM } \\
\text { (Germany, 2006), a } 5 \text { th digit } \\
\text { has to be used to specify } \\
\text { the location (10 subgroups) }\end{array}$ \\
\hline \multirow{8}{*}{$\begin{array}{l}\text { L89 } \\
\text { Decubitus } \\
\text { ulcer }\end{array}$} & L89.0 & $\begin{array}{l}\text { Decubitus ulcer limited to erythema } \\
\text { only [redness] without skin } \\
\text { breakdown (Stage 1) }\end{array}$ & $\begin{array}{l}\text { Decubitus [pressure] } \\
\text { ulcer, stage I }\end{array}$ & \\
\hline & L89.1 & $\begin{array}{l}\text { Decubitus ulcer limited to breakdown } \\
\text { of skin (Stage 2) }\end{array}$ & $\begin{array}{l}\text { Decubitus [pressure] } \\
\text { ulcer, stage II }\end{array}$ & Decubitus ulcer Stage 1 \\
\hline & L89.2 & $\begin{array}{l}\text { Decubitus ulcer with fat layer } \\
\text { exposed (Stage 3) }\end{array}$ & $\begin{array}{l}\text { Decubitus [pressure] } \\
\text { ulcer, stage III }\end{array}$ & Decubitus ulcer Stage 2 \\
\hline & L89.3 & $\begin{array}{l}\text { Decubitus ulcer with depth involving } \\
\text { muscle (Stage 4) }\end{array}$ & $\begin{array}{l}\text { Decubitus [pressure] } \\
\text { ulcer, stage IV }\end{array}$ & Decubitus ulcer Stage 3 \\
\hline & L89.4 & $\begin{array}{l}\text { Decubitus ulcer with depth involving } \\
\text { bone (Stage 5) }\end{array}$ & & Decubitus ulcer Stage 4 \\
\hline & L89.5 & $\begin{array}{l}\text { Decubitus ulcer with joint space } \\
\text { involvement (Stage 5) }\end{array}$ & & \\
\hline & L89.8 & $\begin{array}{l}\text { Decubitus ulcer with necrosis } \\
\text { involving muscle or bone (Stage } X)\end{array}$ & & \\
\hline & L89.9 & $\begin{array}{l}\text { Decubitus ulcer without mention of } \\
\text { severity }\end{array}$ & $\begin{array}{l}\text { Decubitus [pressure] } \\
\text { ulcer, unspecified }\end{array}$ & Decubitus ulcer, unspecified \\
\hline
\end{tabular}

11. There are several criteria which are not consistent between countries that may influence the calculated rates of the indicators. These are:

- Coding rules

- Definition of principal diagnosis

- Definition of secondary diagnosis

- Use of diagnosis type indicators (e.g. marking of secondary diagnosis as "present at admission”)

- Use of DRG for hospital reimbursement

- Certain administrative case information

- Admission type (elective, from long-term care, transferred from acute care)

- Admission weight of neonates

\section{Cross walking from ICD-9 to ICD-10}

12. The quantitative relationship between ICD-9 and ICD-10 is not one to one. The ICD-10 is much more extensive than the ICD-9 and structures in the classification trees vary between the two. In a preliminary German project (Drösler et al., 2007), mapping of diagnoses and procedures was performed for each definition of the patient safety indicators (AHRQ 2004). Diagnosis mapping was performed using cross walking tables (DIMDI, 2007) between ICD-9-WHO V6.0 and ICD-10-German Modification 2004 in two steps. Updates of the PSI definitions published by the AHRQ have been appended to the translated version.

13. ICD-10 codes were manually revised after a preliminary crosswalk. Mapped ICD-10 codes with an unclear relationship to the original ICD-9-WHO code were compared to the ICD-9-CM, which is the origin of the AHRQ definitions. ICD-10 codes with correspondence in ICD-9-CM were rejected when the matching ICD-9-CM code had not been selected by the AHRQ. Transferred ICD-10 codes were accepted when the medical concept matched the intention of the AHRQ definition. For example, the ICD-10 code 
T80.2 "Infections following infusion, transfusion and therapeutic injection" was included to the numerator specification of indicator "Catheter-related bloodstream infection " because it was a mapped result to the corresponding ICD-9-CM-code 999.3 "Complications of medical care, not elsewhere classified: other infection”.

14. Due to the different country versions of the diagnosis classification, for an international project such as the OECD Health Care Quality Indicators project it is necessary to find a common "classification language". Thus the country specific ICD-10 translations of the indicator definitions have been transformed to the ICD-10-WHO 2006 (WHO, 2006) to serve as the basis for the crosswalk. The ICD-10 codes listed in this manual underwent an international harmonisation process initiated by the International Methodology Consortium for Coded Health Information (IMECCHI) research collaboration (Quan et al., 2008).

\section{Process of Calculation}

15. The numerators pertain to subsets of the denominators. Calculate the denominator quantity first. Then apply the numerator definition to the selected denominator data.

\section{Exclusions of Principal Diagnosis}

16. Verify the documentation rules for the principal diagnosis (main diagnosis, discharge diagnosis) in use for each country is required to decide how the exclusions of the principal diagnosis should be performed.

\section{Definitions of Principal Diagnosis (PDx) ${ }^{2}$}

A. The condition established after evaluation to be chiefly responsible for causing the hospitalisation.

B. The diagnosis that is finally established to be the main reason for the hospital stay; that is demanding the most resources/medical effort over the course of the patients stay.

17. The original AHRQ patient safety manual is based on definition A (Department of Health and Human Services, 2005). For that reason most indicator definitions contain an exclusion rule if the principal diagnosis of the case is equal to a numerator defining ICD code. For these cases it is unlikely that the indicator-defining condition had been acquired during the hospital stay but was pre-existing.

18. In this manual it is assumed that countries using definition B for assignment of principal diagnosis are able to identify the case-related admission diagnosis (ADx) in their data sets. In this case patients with admission diagnosis corresponding to the numerator definition of the indicator should be excluded (see left sided flow chart Figure 1. Primary diagnosis algorithm). Furthermore it shall be avoided that countries using definition B for assignment of principal diagnosis miss numerator cases by assigning specific complications as principal diagnosis. If a diagnosis type indicator is in use, data can be properly rearranged (see right sided flow chart Figure 1. Primary diagnosis algorithm).

\section{Secondary diagnosis}

19. Patent safety indicators are largely constructed from secondary diagnoses. The calculation of the numerator builds on secondary diagnosis for most of the indicators. The indicator definitions refer to

$2 \quad$ Adapted from CIHI (2004). 
conditions aroused post admission. To make sure that all participating countries use the same definition of secondary diagnosis it is presented here:

\section{Definition of Secondary Diagnosis (SDx) ${ }^{8}$}

Comorbid conditions are those conditions for which the patient received treatment and consumed hospital resources in addition to those conditions considered to be the principal, main or discharge diagnosis.

20. Pre-admission conditions without any necessary treatment during the hospital stay do not meet the definition. Pre-admission comorbidities with in-hospital treatment meet the definition of the secondary diagnosis. Countries using diagnosis type indicators have the possibility to distinguish between pre- and post-admission comorbidities. If they perform additional exclusions of numerator cases their calculated rates might be lower than in countries where additional criteria for secondary diagnosis documentation are not in use.

\section{Use of codes for external causes of morbidity and mortality ("E-codes")}

21. Several indicators (e.g. Foreign body left in during procedure) build on diagnoses codes from chapter XX of the ICD-10 or the corresponding supplement of the ICD-9 respectively. The WHO designates those codes for additional documentation of external causes of morbidity. The availability of these codes in country modifications of the ICD may vary. Furthermore their use is optional in some countries. Depending on the extent of available e-codes in country modifications indicator rates may vary between countries.

\section{Exclusions of MDC}

22. In countries using DRG for hospital reimbursement each case is assigned to a MDC (Major Diagnostic Category) by the grouper software. The MDC assignment relies exclusively on the principal diagnosis of the case (definition A above).The calculation of several indicators (Table 3) requires the exclusion of certain MDCs to ensure that whole populations with high risk for a condition are not counted. For example, MDC 14 (pregnancy, childbirth and puerperium) is excluded from the calculation of indicator Postoperative sepsis. Lists of ICD-10-WHO codes referring to certain MDCs are provided in the Appendix 2 - Code List $\mathrm{M}^{3}$ for countries using ICD-10 without DRG reimbursement or if the MDC assignment of data is impossible.

Table 3. Indicators with MDC exclusion

\begin{tabular}{|l|l|l|}
\hline MDC & Condition & Indicators \\
\hline \multirow{3}{*}{ MDC 14 } & \multirow{3}{*}{ Pregnancy, childbirth and puerperium } & Postoperative PE or DVT (PSI 12) \\
\cline { 3 - 3 } & & Postoperative sepsis (PSI 13) \\
\cline { 3 - 3 } & & Accidential puncture or laceration (PSI 15) \\
\hline
\end{tabular}

\section{Procedure Codes}

23. The calculations of three indicators require procedure codes. Those indicators are "Postoperative pulmonary embolism (PE) or deep vein thrombosis (DVT)" and "Obstetric trauma - vaginal delivery with / without instrument". There is no common international medical procedure classification and each country participating in the calculation of the indicators uses a different catalogue for procedure coding. In the

3 Code lists are adapted from (InEK, 2006 and Commonwealth of Australia, 1998). 
project at hand it was not possible to provide a procedure code list for each participating country. The procedure codes from the US ICD-9-CM are listed in this manual because they are part of the original indicator definitions provided by AHRQ. Furthermore, the procedure list provided in this manual shall support countries in adopting corresponding procedures from their classifications in order to perform a precise PSI calculation.

24. Two indicators refer to denominator cases with operative treatment only. Those are:

- Postoperative pulmonary embolism (PE) or deep vein thrombosis (DVT)

- Postoperative sepsis

25. For selection of these cases a comparison between the coded procedures and a list of all operating room procedures available in a country's procedure classification is necessary. For the reasons explained above it is not possible to generate lists of operating room procedures for each country. The following interventional procedures are regarded as operative procedures: Pacemaker Implants, PTCA ${ }^{4}$ or endovascular vessel repair. $\mathrm{D} \& \mathrm{C}^{5}$ is regarded as an operating room procedure where as a perineal laceration repair during a regular vaginal delivery is not.

\section{Flow Charts}

26. For each indicator a flow chart is provided to facilitate the understanding of the indicator definition and the calculation process. For the construction of the flowcharts, definition A of the principal diagnosis ("condition to be chiefly responsible") had been assumed. Countries using definition B ("condition demanding the most resources") for assignment of principal diagnosis are advised to rearrange their data in order to gain comparable results. A proposal for rearrangement is given in the flowchart at Figure 1. Primary diagnosis algorithm.

\section{General Note}

27. Data quality is always a concern in health indicator analysis that can also substantially affect patient safety indicators. In addition to the proposed definitions, a comprehensive review of coding practices, distribution of key data elements and country specific coding standards is strongly recommended for data analysis of these PSIs. Given the nature of the PSIs, small sample size may lead to less precise estimates and requires special attention when reporting these indicators. All of these factors can affect comparability of the PSIs, and need to be addressed when making such comparisons.

\footnotetext{
$4 \quad$ Percutaneous Transluminal Coronary Angioplasty, an intervention in cardiology.
}

$5 \quad$ Dilation and Curettage, a gynaecological or obstetric treatment. 
Figure 1. Primary Diagnosis Algorithm

Algorithms for countries using principal diagnosis definition 2 ("condition demanding the most resources"). Repeat algorithm for each case.

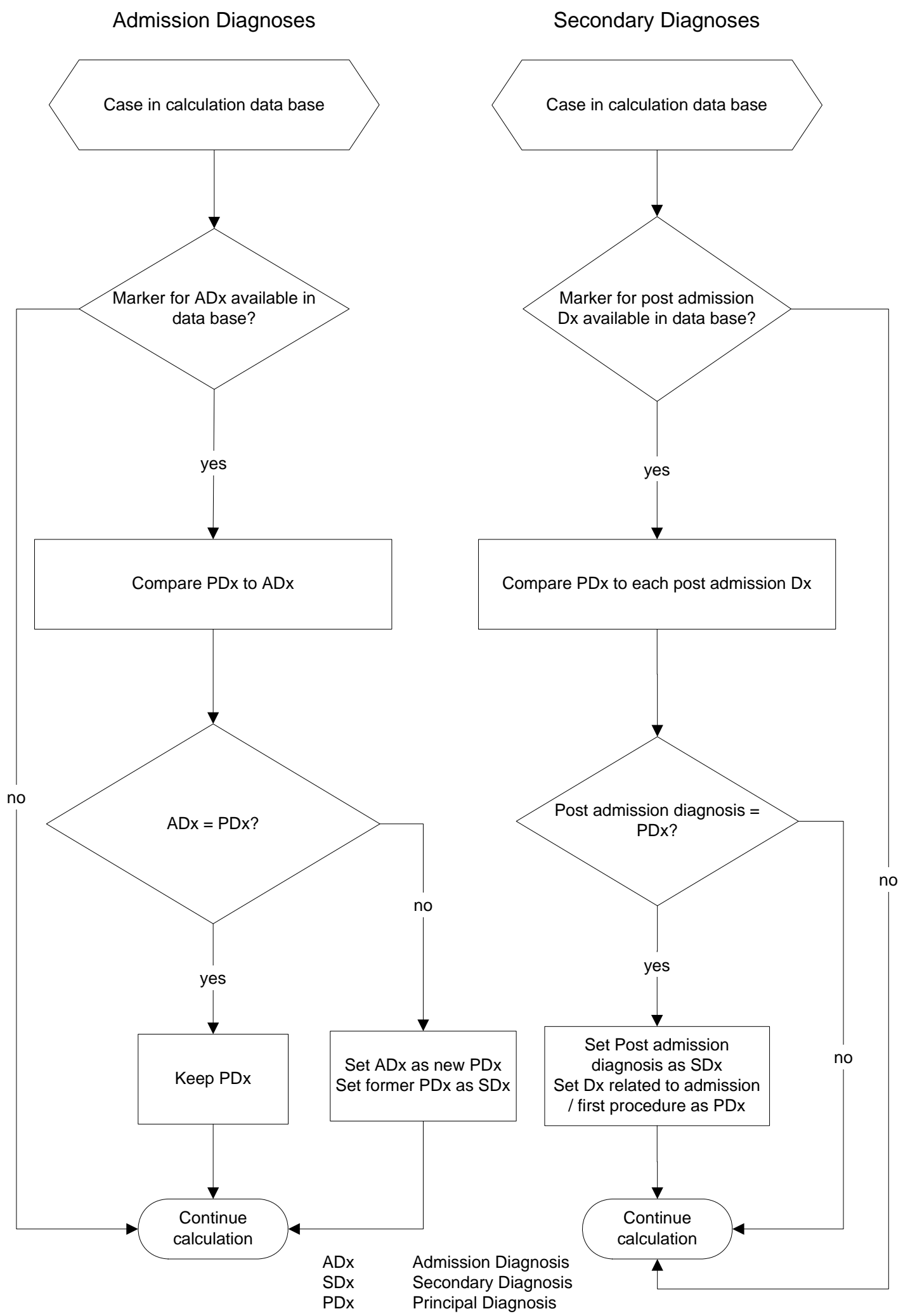




\section{QUICK STEP OVERVIEW OF ESSENTIAL TASKS FOR DATA PREPARATION}

1) The following outlines the key steps in preparing data for the calculation of the Patient Safety Indicators.

2) Convert listed ICD codes to your country's version of ICD.

3) Look up in your ICD classification if there are codes available for SIRS (Systemic Inflammatory Response syndrome). If these codes are available add them to the numerator inclusion list of the indicator Postoperative Sepsis.

4) Look up the procedure codes in use in your country procedure classification for the following procedures:

a. "Interruption of Vena Cava”

i. Add a) to the denominator calculation of indicator Postoperative pulmonary embolism (PE) or deep vein thrombosis (DVT).

b. "Obstetric Trauma"

i. Add b) to the numerator calculation of all Obstetric trauma indicators.

c. "Instrument-Assisted Delivery procedure codes"

i. Use c) to select the denominator population of indicator Obstetric trauma vaginal delivery with instrument.

5) Check the definition of principal diagnosis (PDx) applied in your country.

6) If the PDx definition is "the condition to be chiefly responsible" proceed to step 6. If the PDx definition is "the condition demanding the most resources", rearrange the data as shown in the flowchart at Figure 1. Primary diagnosis algorithm.

7) Flag cases with OR (operating room) procedures designated as "surgical”. A comprehensive list of OR procedures must be provided by your country. An exemplarily list of OR procedures in ICD-9 CM is provided in Appendix 1 of this manual.

8) Check if your database contains cases treated in psychiatric institutions. Such cases are to be excluded from the calculation, however particular psychiatric cases treated in acute care institutions can be retained.

9) Check to which length of stay (either 0 days or 1 day) same day cases are assigned in your database. Make sure that those cases with a length of stay $<24$ hours (or 0 days, if a time stamp is not available in the data) are excluded from the calculation of PSIs 5 and 15. Definitions of PSIs 7 and 13 already contain explicit rules for length of stay exclusions.

10) Apply calculation algorithm to each case as shown in the indicator-related flowcharts. 
DELSA/HEA/WD/HWP(2009)5/ANN

Table 4. List of minimal case-related data-fields used for indicator calculation

\begin{tabular}{|c|c|c|}
\hline Data fields - Case & $\begin{array}{c}\text { Mandatory } \\
\text { Information }\end{array}$ & Possible Variables - Used for QI Calculation \\
\hline patient ID & $\mathrm{x}$ & \\
\hline patient age & $\mathrm{x}$ & years \\
\hline length of stay & $x$ & days \\
\hline admission status & $\mathrm{x}$ & elective - emergency - birth \\
\hline admission source & & home - from acute care - from long-term care \\
\hline principal diagnosis & $x$ & \\
\hline $\begin{array}{l}\text { secondary } \\
\text { diagnosis }\end{array}$ & & $\begin{array}{l}\text { data field should be repeated - number of repetitions depends on the country's } \\
\text { definition of the dataset }\end{array}$ \\
\hline procedure & & $\begin{array}{l}\text { data field may repeat - number of repetitions depends on the country's } \\
\text { definition of the dataset }\end{array}$ \\
\hline date of procedure & & dependant on data field procedure \\
\hline
\end{tabular}




\section{DETAILED DEFINITIONS OF INDICATORS}

\section{Catheter-related bloodstream infection, secondary diagnosis field per 100 discharges (PSI 7)}

\section{Numerator:}

Discharges with selected ICD-codes in any secondary diagnosis field among cases meeting the inclusion and exclusion rules for the denominator.

\section{ICD-9-CM}

Discharges with ICD-9-CM code of 999.3 or 996.62 in any secondary diagnosis field.

\begin{tabular}{|l|l|}
\hline 999.3 & Complications of medical care, not elsewhere classified: Other infection \\
\hline 996.62 & $\begin{array}{l}\text { Infection and inflammatory reaction due to internal prosthetic device, implant, } \\
\text { and graft: Due to vascular device, implant and graft }\end{array}$ \\
\hline
\end{tabular}

\section{ICD-10-WHO}

Discharges with ICD-10-WHO code of T80.2 or T82.7 or T88.0 in any secondary diagnosis field.

\begin{tabular}{|l|l|}
\hline T80.2 & Infections following infusion, transfusion and therapeutic injection \\
\hline T82.7 & $\begin{array}{l}\text { Infection and inflammatory reaction due to other cardiac and vascular devices, } \\
\text { implants and grafts }\end{array}$ \\
\hline T88.0 & Infection following immunization \\
\hline
\end{tabular}

\section{Denominator:}

All surgical and medical discharges, 18 years and older or MDC 14 (pregnancy, childbirth, and puerperium). Assign a principal diagnosis from Appendix 2 - Code List M-3 if criteria "MDC 14" is not available.

\section{Exclude cases:}

- with ICD-9-CM code of 999.3 or 996.62 in the principal diagnosis field or secondary diagnosis present on admission, if known

- with ICD-10-WHO code of T80.2 or T82.7 or T88.0 in the principal diagnosis field

- with length of stay less than 2 days

- with any code for immunocompromised state or cancer (principal diagnosis or secondary diagnosis)

See Appendix 1 - Code List C-1 for ICD-9-CM immunocompromised state codes See Appendix 1 - Code List W-1 for ICD-10-WHO immunocompromised state codes See Appendix 1 - Code List C-2 for ICD-9-CM cancer codes See Appendix 1 - Code List W-2 for ICD-10-WHO cancer codes 


\section{Catheter-Related Bloodstream Infection}

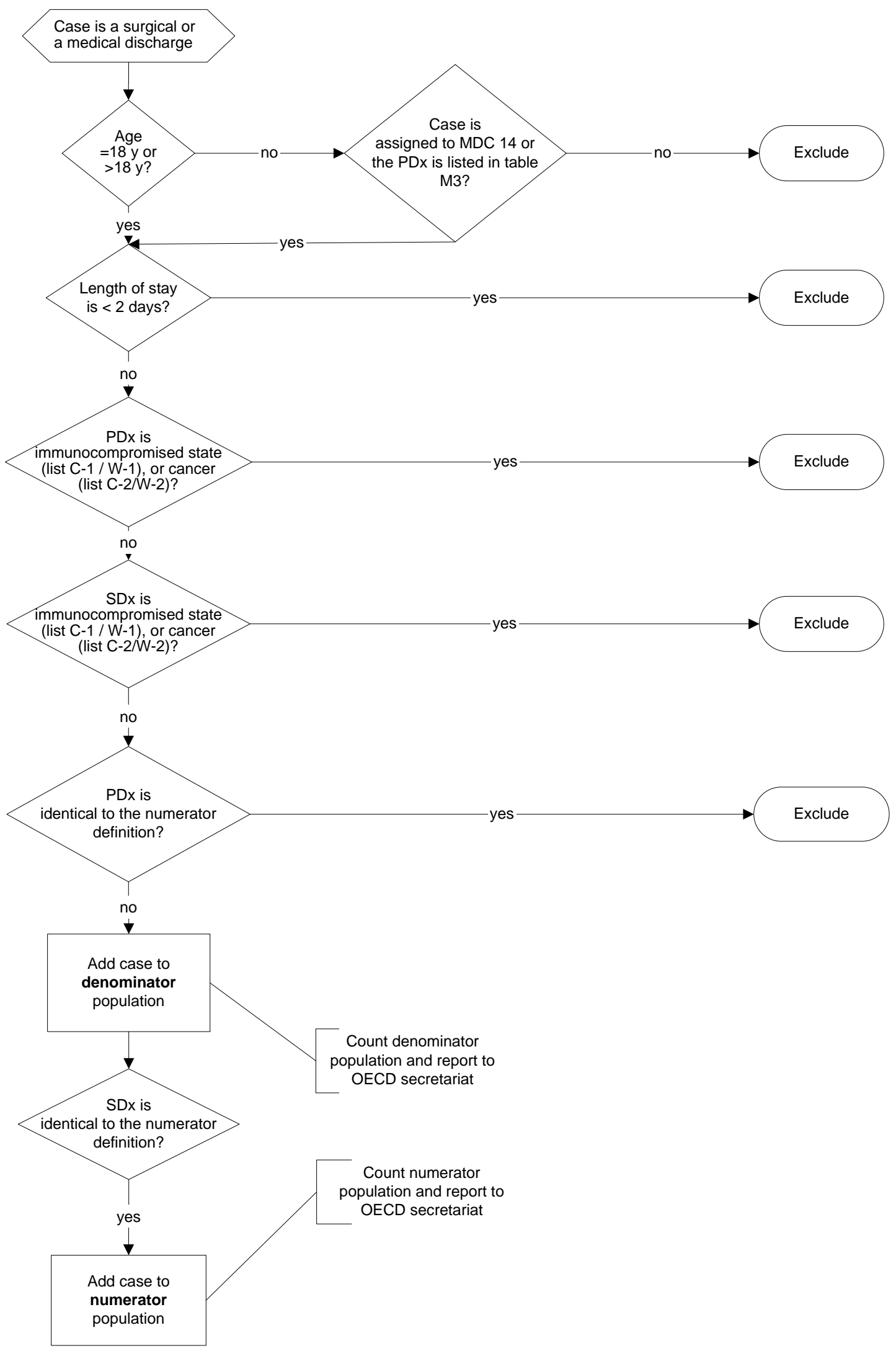


Postoperative pulmonary embolism (PE) or deep vein thrombosis (DVT), secondary diagnosis field per 100 discharges (PSI 12)

\section{Numerator:}

Discharges among cases meeting the inclusion and exclusion rules for the denominator with ICD codes for deep vein thrombosis or pulmonary embolism in any secondary diagnosis field.

ICD-9-CM Pulmonary Embolism and Deep Vein Thrombosis diagnosis codes:

ICD-9-CM Pulmonary Embolism diagnosis codes:

\begin{tabular}{|l|l|}
\hline 41511 & Iatrogenic pulmonary embolism and infarction \\
\hline 41519 & Pulmonary embolism and infarction, other \\
\hline
\end{tabular}

ICD-9-CM Deep Vein Thrombosis diagnosis codes:

\begin{tabular}{|l|l|}
\hline 45111 & Phlebitis and thrombosis of femoral vein (deep) (superficial) \\
\hline 45119 & Phlebitis and thrombophlebitis of deep vessel of lower extremities - other \\
\hline 4512 & Phlebitis and thrombophlebitis of lower extremities \\
\hline 45181 & Phlebitis and thrombophlebitis of iliac vein \\
\hline 4519 & Phlebitis and thrombophlebitis of other sites - of unspecified site \\
\hline 45340 & DVT-emblsm lower ext nos (Oct 04) \\
\hline 45341 & DVT-emb prox lower ext \\
\hline 45342 & DVT-emb distal lower ext \\
\hline 4538 & Other venous embolism and thrombosis of other specified veins \\
\hline 4539 & Other venous embolism and thrombosis of unspecified site \\
\hline
\end{tabular}

ICD-10-WHO Pulmonary Embolism and Deep Vein Thrombosis diagnosis codes:

\begin{tabular}{|l|l|}
\hline I26.0 & Pulmonary embolism with mention of acute cor pulmonale \\
\hline I26.9 & Pulmonary embolism without mention of acute cor pulmonale \\
\hline I80.1 & Phlebitis and thrombophlebitis of femoral vein \\
\hline I80.2 & Phlebitis and thrombophlebitis of other deep vessels of lower extremities \\
\hline I80.3 & Phlebitis and thrombophlebitis of lower extremities, unspecified \\
\hline I80.8 & Phlebitis and thrombophlebitis of other sites \\
\hline I80.9 & Phlebitis and thrombophlebitis of unspecified site \\
\hline I82.8 & Embolism and thrombosis of other specified veins \\
\hline I82.9 & Embolism and thrombosis of unspecified vein \\
\hline
\end{tabular}

Denominator:

All surgical discharges age 18 and older with a code for an operating room procedure

Exclude cases:

- with pre-existing (principal diagnosis or secondary diagnosis present on admission, if known) deep vein thrombosis or pulmonary embolism

- where a procedure for interruption of vena cava is the only operating room procedure

- where a procedure for interruption of vena cava occurs before or on the same day as the first / main operating room procedure. (Note that if day of procedure is not available in the input data file, the rate may be slightly lower than if the information was available)

- MDC 14 (pregnancy, childbirth, and puerperium) or principal diagnosis in Appendix M-3

- with length of stay less than 2 days

ICD-9-CM Interruption of Vena Cava procedure code:

\begin{tabular}{|l|l}
\hline 387 & Interruption of vena cava
\end{tabular}


Postoperative Pulmonary Embolism (PE) or Deep Vein Thrombosis (DVT)

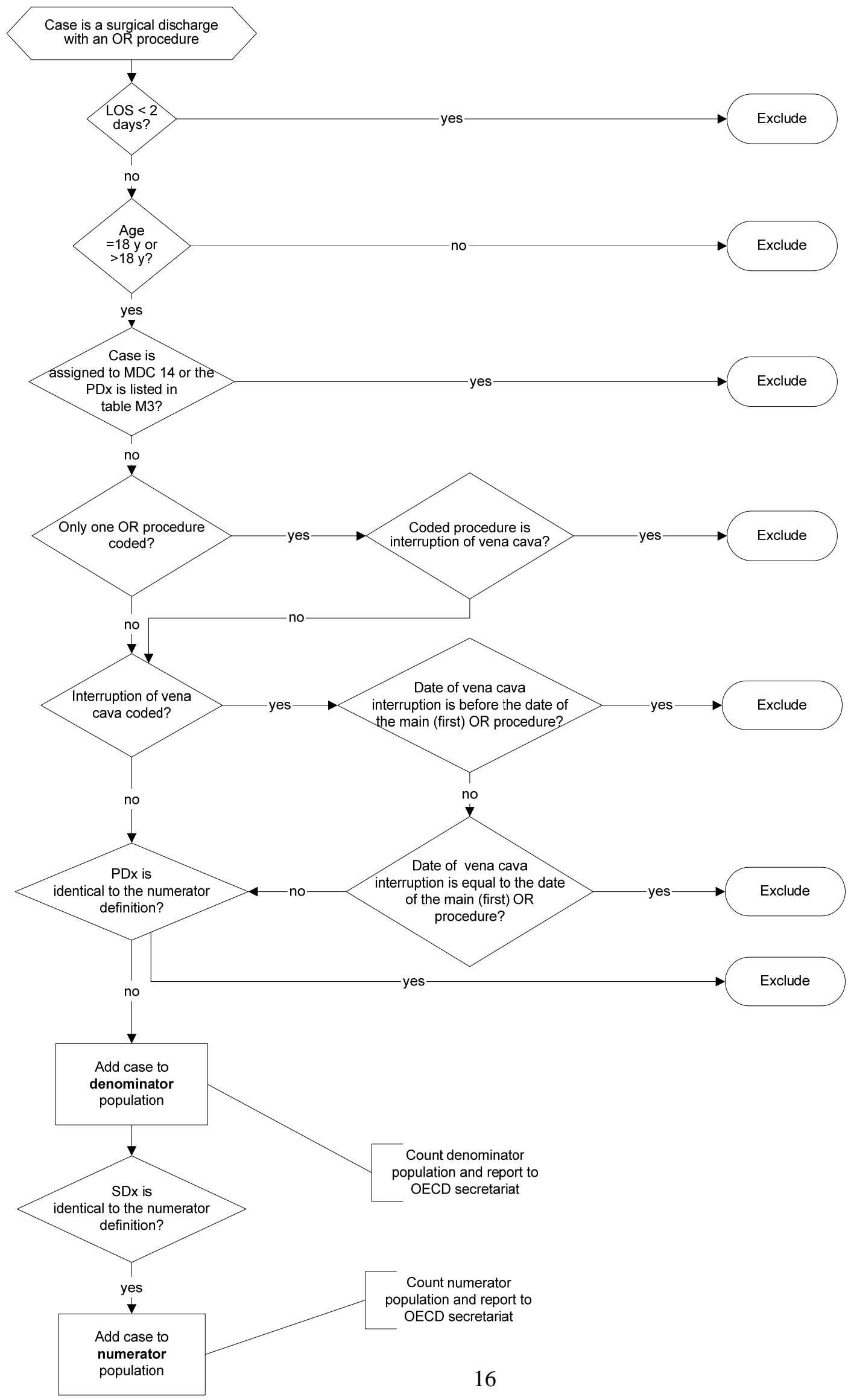




\section{Postoperative sepsis, secondary diagnosis field per 100 discharges (PSI 13)}

\section{Numerator:}

Discharges among cases meeting the inclusion and exclusion rules for the denominator with ICD code for sepsis in any secondary diagnosis field.

\section{ICD-9-CM Sepsis diagnosis codes:}

\begin{tabular}{|l|l|}
\hline 0380 & Streptococcal septicaemia \\
\hline 03810 & Staphylococcal ependence, unspecified \\
\hline 03811 & Staphylococcus aureus septicaemia \\
\hline 03819 & Other staphylococcal septicaemia \\
\hline 0382 & Pneumococcal ependence (streptococcus pneumoniale ependence ) \\
\hline 0383 & Septicaemia due to anaerobes \\
\hline 78552 & Septic shock \\
\hline 78559 & Other shock w/o mention of trauma \\
\hline 9980 & Postoperative shock \\
\hline
\end{tabular}

Septicaemia due to:

\begin{tabular}{|l|l|}
\hline 03840 & Gram-negative organism, unspecified \\
\hline 03841 & Hemophilus influenzae \\
\hline 03842 & Escherichia coli \\
\hline 03843 & Pseudomonas \\
\hline 03844 & Serratia \\
\hline 03849 & Septicaemia due to other gram-negative organisms \\
\hline 0388 & Other specified septicaemias \\
\hline 0389 & Unspecified septicaemia \\
\hline 99591 & $\begin{array}{l}\text { Systemic inflammatory response syndrome due to infectious process w/o organ } \\
\text { dysfunction }\end{array}$ \\
\hline 99592 & $\begin{array}{l}\text { Systematic inflammatory response syndrome due to infectious process w/organ } \\
\text { dysfunction }\end{array}$ \\
\hline
\end{tabular}

\section{ICD-10-WHO Sepsis diagnosis codes:}

\begin{tabular}{|l|l|}
\hline A40.0 & Septicaemia due to streptococcus, group a \\
\hline A40.1 & Septicaemia due to streptococcus, group b \\
\hline A40.2 & Septicaemia due to streptococcus, group d \\
\hline A40.3 & Septicaemia due to streptococcus pneumoniae \\
\hline A40.8 & Other streptococcal septicaemia \\
\hline A40.9 & Streptococcal septicaemia, unspecified \\
\hline A41.0 & Septicaemia due to staphylococcus aureus \\
\hline A41.1 & Septicaemia due to other specified staphylococcus \\
\hline A41.2 & Septicaemia due to unspecified staphylococcus \\
\hline A41.3 & Septicaemia due to haemophilus influenzae \\
\hline A41.4 & Septicaemia due to anaerobes \\
\hline A41.5 & Septicaemia due to other gram-negative organisms \\
\hline A41.8 & Other specified septicaemia \\
\hline A41.9 & Septicaemia, unspecified \\
\hline R57.8 & Other shock \\
\hline T81.1 & Shock during or resulting from a procedure, not elsewhere classified \\
\hline
\end{tabular}


Note: If country version of ICD contains a certain ICD-code for SIRS (Systemic Inflammatory Response syndrome, ICD-10: R65.-) add to numerator inclusion list.

\section{Denominator:}

All elective (defined by the admission type) surgical discharges age 18 and older with a code for an operating room procedure.

\section{Exclude cases:}

- $\quad$ with pre-existing (principal diagnosis or secondary diagnosis present on admission, if known) sepsis or infection

- with a principal diagnosis of infection, or any code for immunocompromised state, or cancer

- MDC 14 (pregnancy, childbirth, and puerperium) or principal diagnosis in Appendix 2 - Code List M-3

- with length of stay of less than 4 days

See Appendix 1 - Code List C-1 for ICD-9-CM immunocompromised state codes

See Appendix 1 - Code List W-1 for ICD-10-WHO immunocompromised state codes

See Appendix 1 - Code List C-2 for ICD-9-CM cancer codes

See Appendix 1 - Code List W-2 for ICD-10-WHO cancer codes

See Appendix 1 - Code List C-10 for ICD-9-CM infection codes

See Appendix 1 - Code List W-10 for ICD-10-WHO infection codes 


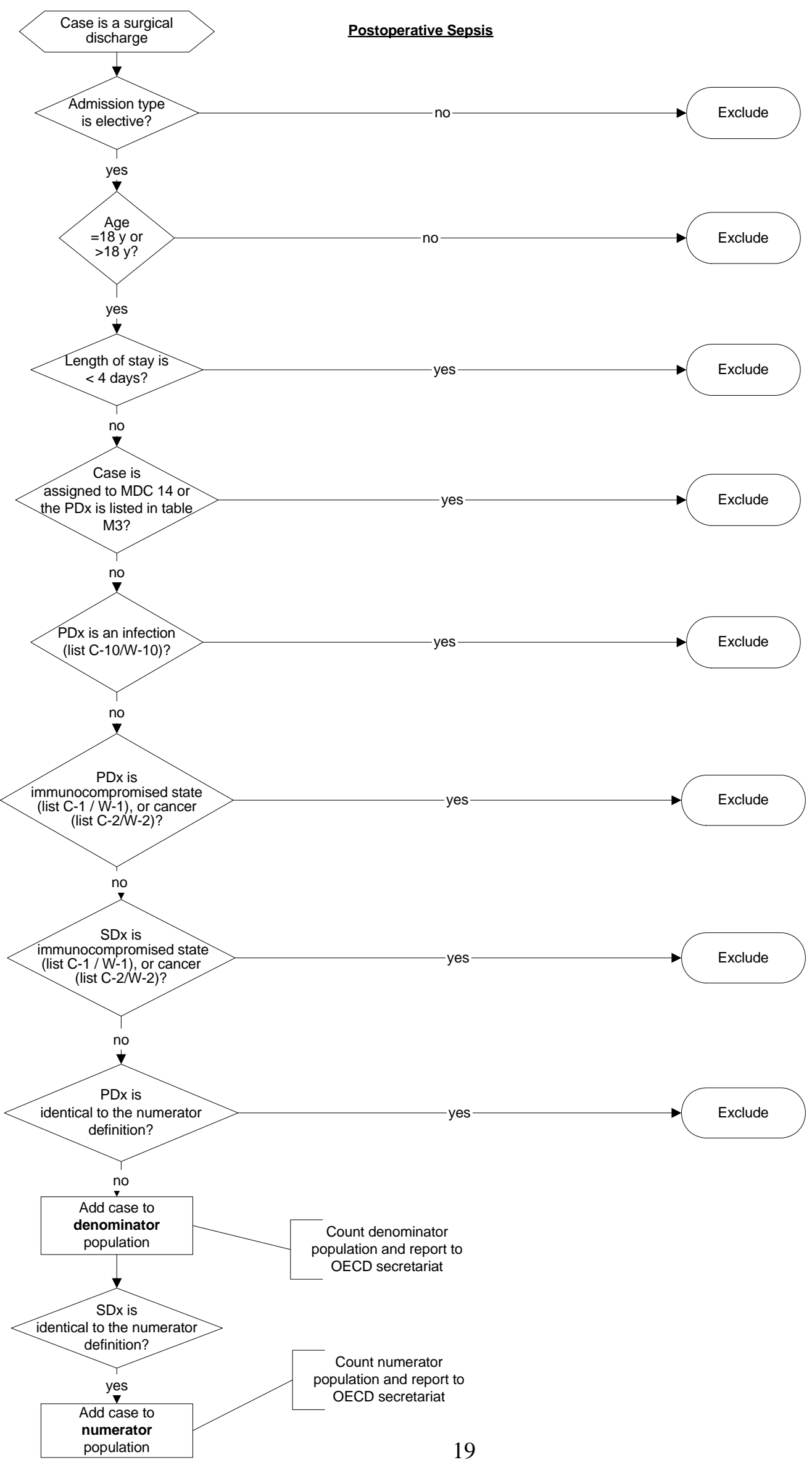




\section{Accidental puncture or laceration, secondary diagnosis field per 100 discharges (PSI 15)}

\section{Numerator:}

Discharges among cases meeting the inclusion and exclusion rules for the denominator with ICD code denoting accidental cut, puncture, perforation or laceration during a procedure in any secondary diagnosis field.

ICD-9-CM Accidental Puncture or Laceration diagnosis codes:

Accidental cut, puncture, perforation, or haemorrhage during medical care.

\begin{tabular}{|l|l|}
\hline E8700 & Surgical operation \\
\hline E8701 & Infusion or transfusion \\
\hline E8702 & Kidney dialysis or other perfusion \\
\hline E8703 & Injection or vaccination \\
\hline E8704 & Endoscopic examination \\
\hline E8705 & Aspiration of fluid or tissue, puncture, and catheterization \\
\hline E8706 & Heart catheterization \\
\hline E8707 & Administration of enema \\
\hline E8708 & Other specified medical care \\
\hline E8709 & Unspecified medical care \\
\hline 9982 & Accidental puncture or laceration during a procedure \\
\hline
\end{tabular}

ICD-10-WHO Accidental Puncture or Laceration diagnosis codes:

\begin{tabular}{|c|l|}
\hline T81.2 & Accidental puncture and laceration during a procedure, not elsewhere classified \\
\hline Y60.0 & $\begin{array}{l}\text { Unintentional cut, puncture, perforation or haemorrhage during surgical and medical } \\
\text { care: during surgical operation }\end{array}$ \\
\hline Y60.1 & $\begin{array}{l}\text { Unintentional cut, puncture, perforation or haemorrhage during surgical and medical } \\
\text { care: during infusion or transfusion }\end{array}$ \\
\hline Y60.2 & $\begin{array}{l}\text { Unintentional cut, puncture, perforation or haemorrhage during surgical and medical } \\
\text { care: during kidney dialysis or other perfusion }\end{array}$ \\
\hline Y60.3 & $\begin{array}{l}\text { Unintentional cut, puncture, perforation or haemorrhage during surgical and medical } \\
\text { care: during injection or immunization }\end{array}$ \\
\hline Y60.4 & $\begin{array}{l}\text { Unintentional cut, puncture, perforation or haemorrhage during surgical and medical } \\
\text { care: during endoscopic examination }\end{array}$ \\
\hline Y60.5 & $\begin{array}{l}\text { Unintentional cut, puncture, perforation or haemorrhage during surgical and medical } \\
\text { care: during heart catheterization }\end{array}$ \\
\hline Y60.6 & $\begin{array}{l}\text { Unintentional cut, puncture, perforation or haemorrhage during surgical and medical } \\
\text { care: during aspiration, puncture and other catheterization }\end{array}$ \\
\hline Y60.7 & $\begin{array}{l}\text { Unintentional cut, puncture, perforation or haemorrhage during surgical and medical } \\
\text { care: during administration of enema }\end{array}$ \\
\hline Y60.8 & $\begin{array}{l}\text { Unintentional cut, puncture, perforation or haemorrhage during surgical and medical } \\
\text { care: during other surgical and medical care }\end{array}$ \\
\hline Y60.9 & $\begin{array}{l}\text { Unintentional cut, puncture, perforation or haemorrhage during surgical and medical } \\
\text { care: during unspecified surgical and medical care }\end{array}$ \\
\hline
\end{tabular}

\section{Denominator:}

All surgical and medical discharges age 18 years and older. 


\section{Exclude cases:}

- with ICD-9-CM code denoting technical difficulty (e.g., accidental cut, puncture, perforation, or laceration) in the principal diagnosis field or secondary diagnosis present on admission, if known

- MDC 14 (pregnancy, childbirth, and puerperium) or principal diagnosis in Appendix 2 Code List M-3

- with a length of stay less than 24 hours (in those countries where a timestamp of admission or discharge is not available cases with a length of stay of 0 days shall be excluded) 


\section{Accidential puncture or laceration}

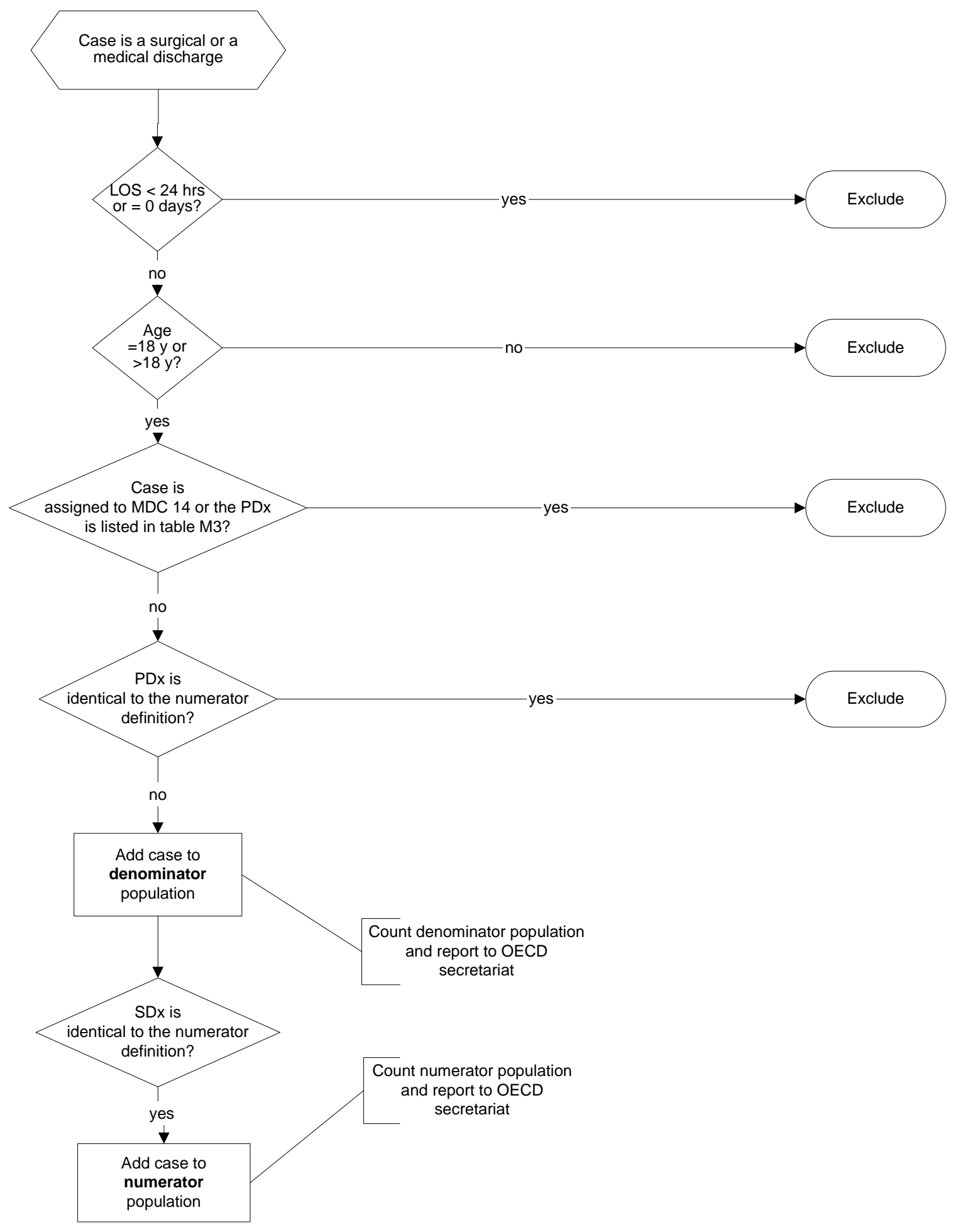


Foreign body left in during procedure, secondary diagnosis field per 100 discharges (PSI 5)

\section{Numerator:}

Discharges with ICD codes for foreign body left in during procedure in any secondary diagnosis field among cases meeting the inclusion and exclusion rules for the denominator.

\section{ICD-9-CM Foreign Body Left in During Procedure diagnosis codes:}

\begin{tabular}{|l|l|}
\hline 9984 & Foreign body accidentally left during a procedure \\
\hline 9987 & Acute reactions to foreign substance accidentally left during a procedure \\
\hline
\end{tabular}

Foreign body left in during:

\begin{tabular}{|l|l|}
\hline E8710 & Surgical operation \\
\hline E8711 & Infusion or transfusion \\
\hline E8712 & Kidney dialysis or other perfusion \\
\hline E8713 & Injection or vaccination \\
\hline E8714 & Endoscopic examination \\
\hline E8715 & Aspiration of fluid or tissue, puncture, and catheterization \\
\hline E8716 & Heart catheterization \\
\hline E8717 & Removal of catheter or packing \\
\hline E8718 & Other specified procedures \\
\hline E8719 & Unspecified procedure \\
\hline
\end{tabular}

\section{ICD-10-WHO Foreign Body Left in During Procedure diagnosis codes:}

\begin{tabular}{|c|l|}
\hline T81.5 & $\begin{array}{l}\text { Foreign body accidentally left in body cavity or operation wound following a } \\
\text { procedure }\end{array}$ \\
\hline T81.6 & Acute reaction to foreign substance accidentally left during a procedure \\
Y61.0 & $\begin{array}{l}\text { Foreign object accidentally left in body during surgical and medical care: During } \\
\text { surgical operation }\end{array}$ \\
\hline Y61.1 & $\begin{array}{l}\text { Foreign object accidentally left in body during surgical and medical care: During } \\
\text { infusion or transfusion }\end{array}$ \\
\hline Y61.2 & $\begin{array}{l}\text { Foreign object accidentally left in body during surgical and medical care: During } \\
\text { kidney dialysis or other perfusion }\end{array}$ \\
\hline Y61.3 & $\begin{array}{l}\text { Foreign object accidentally left in body during surgical and medical care: During } \\
\text { injection or immunization }\end{array}$ \\
\hline Y61.4 & $\begin{array}{l}\text { Foreign object accidentally left in body during surgical and medical care: During } \\
\text { endoscopic examination }\end{array}$ \\
\hline Y61.5 & $\begin{array}{l}\text { Foreign object accidentally left in body during surgical and medical care: During } \\
\text { heart catheterization }\end{array}$ \\
\hline Y61.6 & $\begin{array}{l}\text { Foreign object accidentally left in body during surgical and medical care: During } \\
\text { aspiration, puncture and other catheterization }\end{array}$ \\
\hline Y61.7 & $\begin{array}{l}\text { Foreign object accidentally left in body during surgical and medical care: During } \\
\text { removal of catheter or packing }\end{array}$ \\
\hline Y61.8 & $\begin{array}{l}\text { Foreign object accidentally left in body during surgical and medical care: During } \\
\text { other surgical and medical care }\end{array}$ \\
\hline Y61.9 & $\begin{array}{l}\text { Foreign object accidentally left in body during surgical and medical care: During } \\
\text { unspecified surgical and medical care }\end{array}$ \\
\hline
\end{tabular}




\section{Denominator:}

All surgical and medical discharges, 18 years and older or MDC 14 (pregnancy, childbirth, and puerperium). Assign a principal diagnosis from Appendix 2 - Code List M-3 if criteria "MDC 14" is not available.

\section{Exclude cases}

- $\quad$ with ICD-9-CM codes for foreign body left in during procedure in the principal diagnosis field or secondary diagnosis present on admission, if known.

- $\quad$ with a length of stay less than 24 hours (in those countries where a timestamp of admission or discharge is not available cases with a length of stay of 0 days shall be excluded) 


\section{Foreign body left in during procedure}

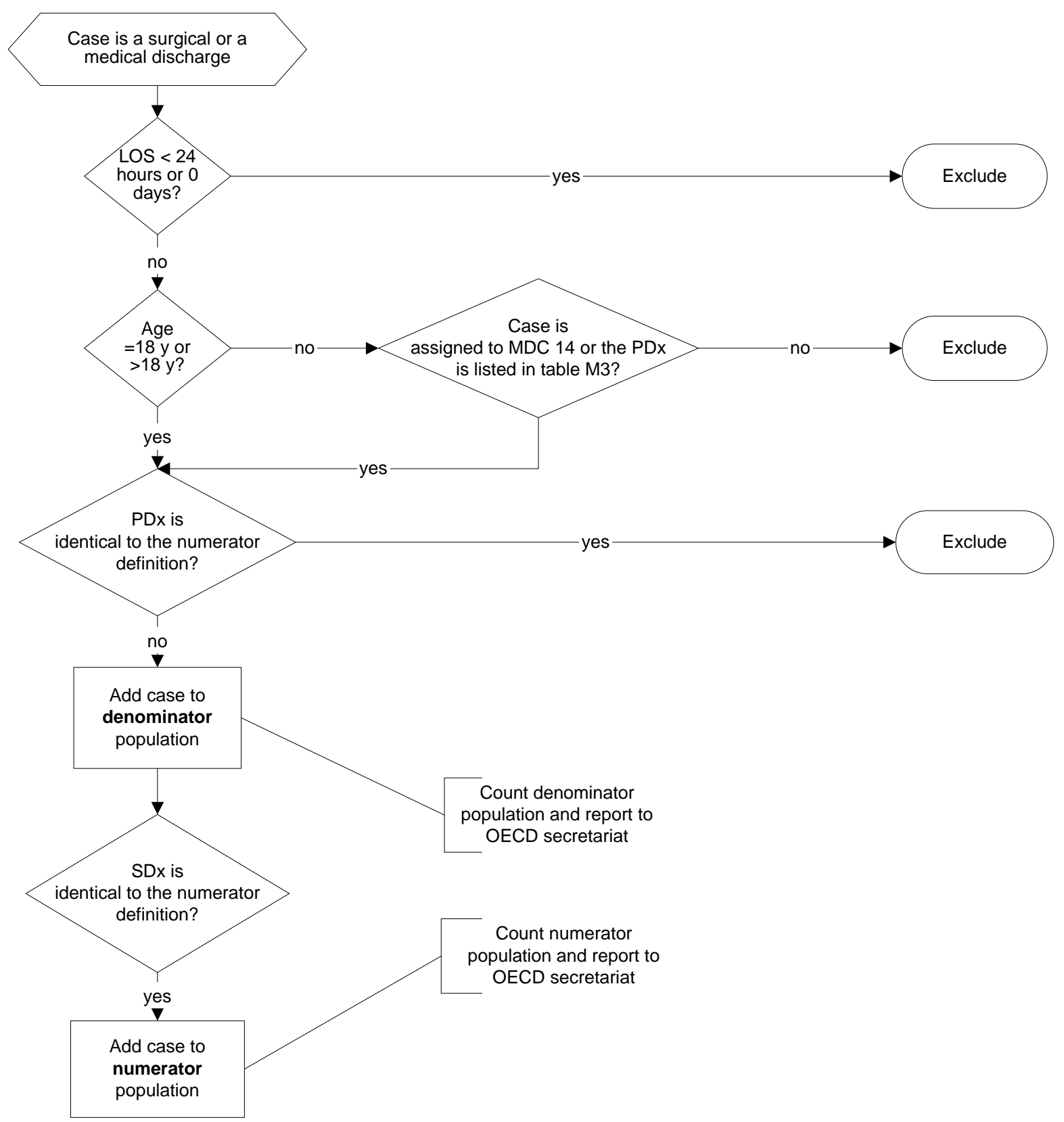


Obstetric trauma - vaginal delivery with instrument, any diagnosis or procedure field per 100 vaginal deliveries (PSI 18)

Numerator ${ }^{6}$ :

Discharges among cases meeting the inclusion and exclusion rules for the denominator with ICD-

9-CM codes for $3^{\text {rd }}$ and $4^{\text {th }}$ degree obstetric trauma in any diagnosis or procedure field.

ICD-9-CM Obstetric Trauma diagnosis codes:

\begin{tabular}{|l|l|}
\hline $66420.1,4$ & $\begin{array}{l}\text { Trauma to perineum and vulva during delivery, third degree perineal } \\
\text { laceration }\end{array}$ \\
\hline $66430.1,4$ & $\begin{array}{l}\text { Trauma to perineum and vulva during delivery, fourth degree perineal } \\
\text { laceration }\end{array}$ \\
\hline
\end{tabular}

ICD-9-CM Obstetric Trauma procedure codes:

\begin{tabular}{|l|l|}
\hline 7550 & Repair of current obstetric lacerations of uterus \\
\hline 7551 & Repair of current obstetric lacerations of cervix \\
\hline 7552 & Repair of current obstetric lacerations of corpus uteri \\
\hline 7561 & Repair of current obstetric lacerations of bladder and urethra \\
\hline 7562 & Repair of current obstetric lacerations of rectum and sphincter \\
\hline
\end{tabular}

ICD-10-WHO Obstetric Trauma diagnosis codes:

\begin{tabular}{|l|l|l|l}
\hline O70.2 & Third degree perineal laceration during delivery \\
\hline O70.3 & Fourth degree perineal laceration durng deivery \\
\hline
\end{tabular}

\begin{tabular}{l|l} 
O70.3 & Fourth degree perineal laceration during delivery
\end{tabular}

\section{Denominator:}

All vaginal delivery discharges with any procedure code for instrument-assisted delivery.

ICD-9-CM Instrument-Assisted Delivery procedure codes:

\begin{tabular}{|l|l|}
\hline 720 & Low forceps operation \\
\hline 721 & Low forceps operation w/ episiotomy \\
\hline 7221 & Mid forceps operation w/ episiotomy \\
\hline 7229 & Other mid forceps operation \\
\hline 7231 & High forceps operation w/ episiotomy \\
\hline 7239 & Other high forceps operation \\
\hline 724 & Forceps rotation of fetal head \\
\hline 7251 & Partial breech extraction w/ forceps to aftercoming head \\
\hline 7253 & Total breech extraction w/ forceps to aftercoming head \\
\hline 726 & Forceps application to aftercoming head \\
\hline 7271 & Vacuum extraction w/ episiotomy \\
\hline 7279 & Vacuum extraction delivery nec \\
\hline 728 & Other specified instrumental delivery \\
\hline 729 & Unspecified instrumental delivery \\
\hline
\end{tabular}

6 In contrast to OECD Health Technical Paper No.18 (OECD, 2004) the definition of this numerator had been harmonised to the AHRQ definition. 


\section{ICD-9-CM Outcome of delivery codes:}

Note: This category is intended for the coding of the outcome of delivery on the mother's record. (Department of Health and Human Services, 2007)

\begin{tabular}{|l|l|}
\hline V27.0 & Single liveborn \\
\hline V27.1 & Single stillborn \\
\hline V27.2 & Twins, both liveborn \\
\hline V27.3 & Twins, one liveborn and one stillborn \\
\hline V27.4 & Twins, both stillborn \\
\hline V27.5 & Other multiple birth, all liveborn \\
\hline V27.6 & Other multiple birth, some liveborn \\
\hline V27.7 & Other multiple birth, all stillborm \\
\hline V27.9 & Unspecified outcome of delivery \\
\hline
\end{tabular}

\section{ICD-10-WHO Outcome of delivery codes:}

Note: This category is intended for use as an additional code to identify the outcome of delivery on the mother's record. (WHO, 2006)

\begin{tabular}{|l|l|}
\hline Z37.0 & Single live birth \\
\hline Z37.1 & Single stillbirth \\
\hline Z37.2 & Twins, both liveborn \\
\hline Z37.3 & Twins, one liveborn and one stillborn \\
\hline Z37.4 & Twins, both stillborn \\
\hline Z37.5 & Other multiple births, all liveborn \\
\hline Z37.6 & Other multiple births, some liveborn \\
\hline Z37.7 & Other multiple births, all stillborn \\
\hline Z37.9 & Outcome of delivery, unspecified \\
\hline
\end{tabular}




\section{Obstetric trauma - Vaginal Delivery with Instrument}

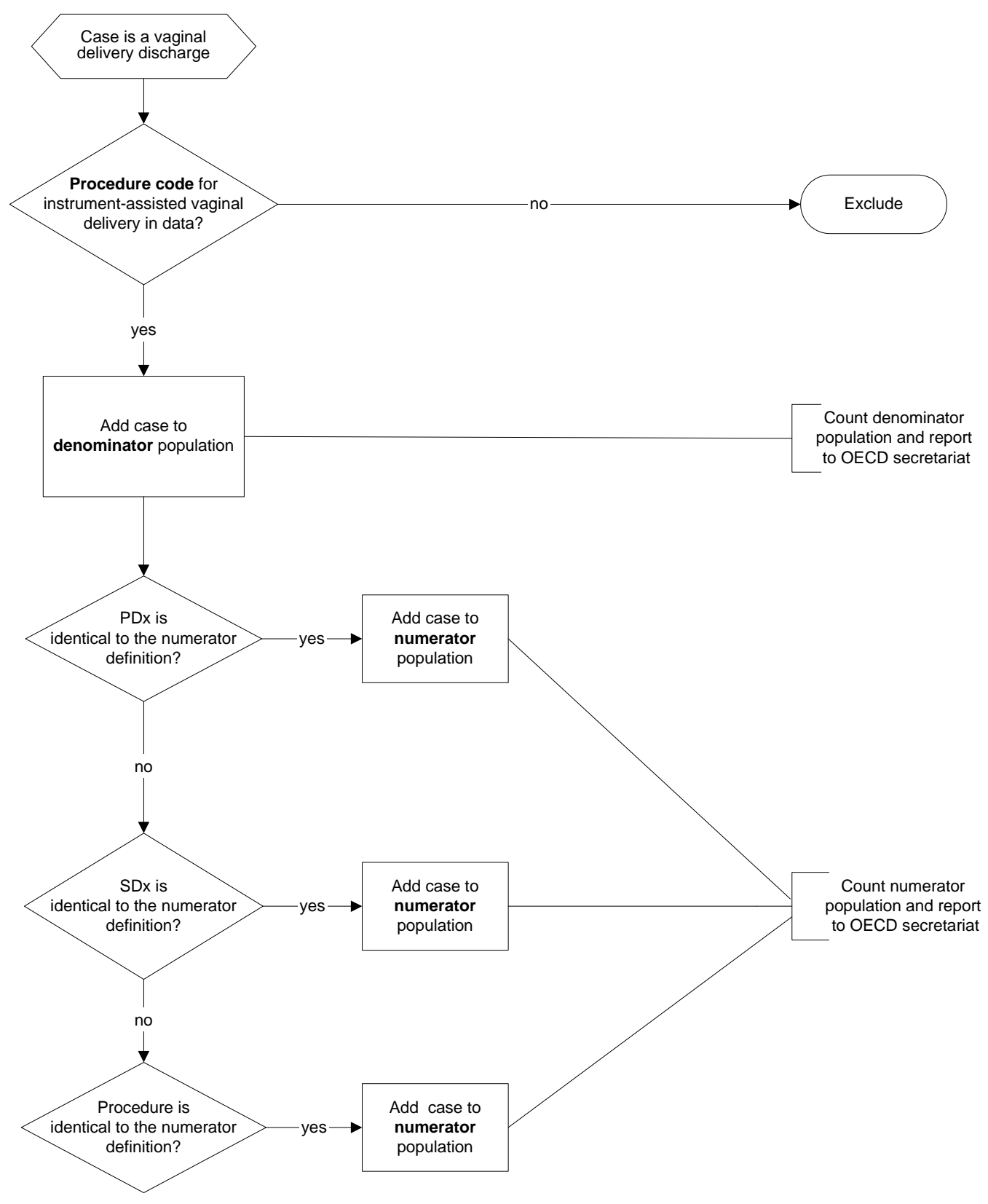




\section{Obstetric trauma—vaginal delivery without instrument (PSI 19)}

\section{Numerator:}

Discharges among cases meeting the inclusion and exclusion rules for the denominator with ICD9-CM codes for $3^{\text {rd }}$ and $4^{\text {th }}$ degree obstetric trauma in any diagnosis or procedure field.

\section{ICD-9-CM Obstetric Trauma diagnosis codes:}

\begin{tabular}{|l|l|l|}
\hline $66420.1,4$ & $\begin{array}{l}\text { Trauma to perineum and vulva during delivery, third degree perineal } \\
\text { laceration }\end{array}$ \\
\hline $66430.1,4$ & $\begin{array}{l}\text { Trauma to perineum and vulva during delivery, fourth degree perineal } \\
\text { laceration }\end{array}$ \\
\hline
\end{tabular}

\section{ICD-9-CM Obstetric Trauma procedure codes:}

\begin{tabular}{|l|l|}
\hline 7550 & Repair of current obstetric lacerations of uterus \\
\hline 7551 & Repair of current obstetric lacerations of cervix \\
\hline 7552 & Repair of current obstetric lacerations of corpus uteri \\
\hline 7561 & Repair of current obstetric lacerations of bladder and urethra \\
\hline 7562 & Repair of current obstetric lacerations of rectum and sphincter \\
\hline
\end{tabular}

\section{ICD-10-WHO Obstetric Trauma diagnosis codes:}

\begin{tabular}{|l|l|}
\hline O70.2 & Third degree perineal laceration during delivery \\
\hline O70.3 & Fourh degree perineal laceraion duing delivery \\
\hline
\end{tabular}

\begin{tabular}{l|l} 
O70.3 & Fourth degree perineal laceration during delivery \\
\hline
\end{tabular}

\section{Denominator:}

All vaginal delivery discharge patients.

\section{ICD-9-CM Outcome of delivery codes:}

Note: This category is intended for the coding of the outcome of delivery on the mother's record. (Department of Health and Human Services, 2007)

\begin{tabular}{|l|l|}
\hline V27.0 & Single liveborn \\
\hline V27.1 & Single stillborn \\
\hline V27.2 & Twins, both liveborn \\
\hline V27.3 & Twins, one liveborn and one stillborn \\
\hline V27.4 & Twins, both stillborn \\
\hline V27.5 & Other multiple birth, all liveborn \\
\hline V27.6 & Other multiple birth, some liveborn \\
\hline V27.7 & Other multiple birth, all stillborm \\
\hline V27.9 & Unspecified outcome of delivery \\
\hline
\end{tabular}




\section{ICD-10-WHO Outcome of delivery codes:}

Note: This category is intended for use as an additional code to identify the outcome of delivery on the mother's record. (WHO, 2006)

\begin{tabular}{|l|l|}
\hline Z37.0 & Single live birth \\
\hline Z37.1 & Single stillbirth \\
\hline Z37.2 & Twins, both liveborn \\
\hline Z37.3 & Twins, one liveborn and one stillborn \\
\hline Z37.4 & Twins, both stillborn \\
\hline Z37.5 & Other multiple births, all liveborn \\
\hline Z37.6 & Other multiple births, some liveborn \\
\hline Z37.7 & Other multiple births, all stillborn \\
\hline Z37.9 & Outcome of delivery, unspecified \\
\hline
\end{tabular}

\section{Exclude cases:}

- With instrument-assisted delivery.

\section{ICD-9-CM Instrument-Assisted Delivery procedure codes}

\begin{tabular}{|l|l|}
\hline 720 & Low forceps operation \\
\hline 721 & Low forceps operation w/ episiotomy \\
\hline 7221 & Mid forceps operation w/ episiotomy \\
\hline 7229 & Other mid forceps operation \\
\hline 7231 & High forceps operation w/ episiotomy \\
\hline 7239 & Other high forceps operation \\
\hline 724 & Forceps rotation of fetal head \\
\hline 7251 & Partial breech extraction w/ forceps to aftercoming head \\
\hline 7253 & Total breech extraction w/ forceps to aftercoming head \\
\hline 726 & Forceps application to aftercoming head \\
\hline 7271 & Vacuum extraction w/ episiotomy \\
\hline 7279 & Vacuum extraction delivery nec \\
\hline 728 & Other specified instrumental delivery \\
\hline 729 & Unspecified instrumental delivery \\
\hline
\end{tabular}




\section{Obstetric trauma - Vaginal Delivery without Instrument}

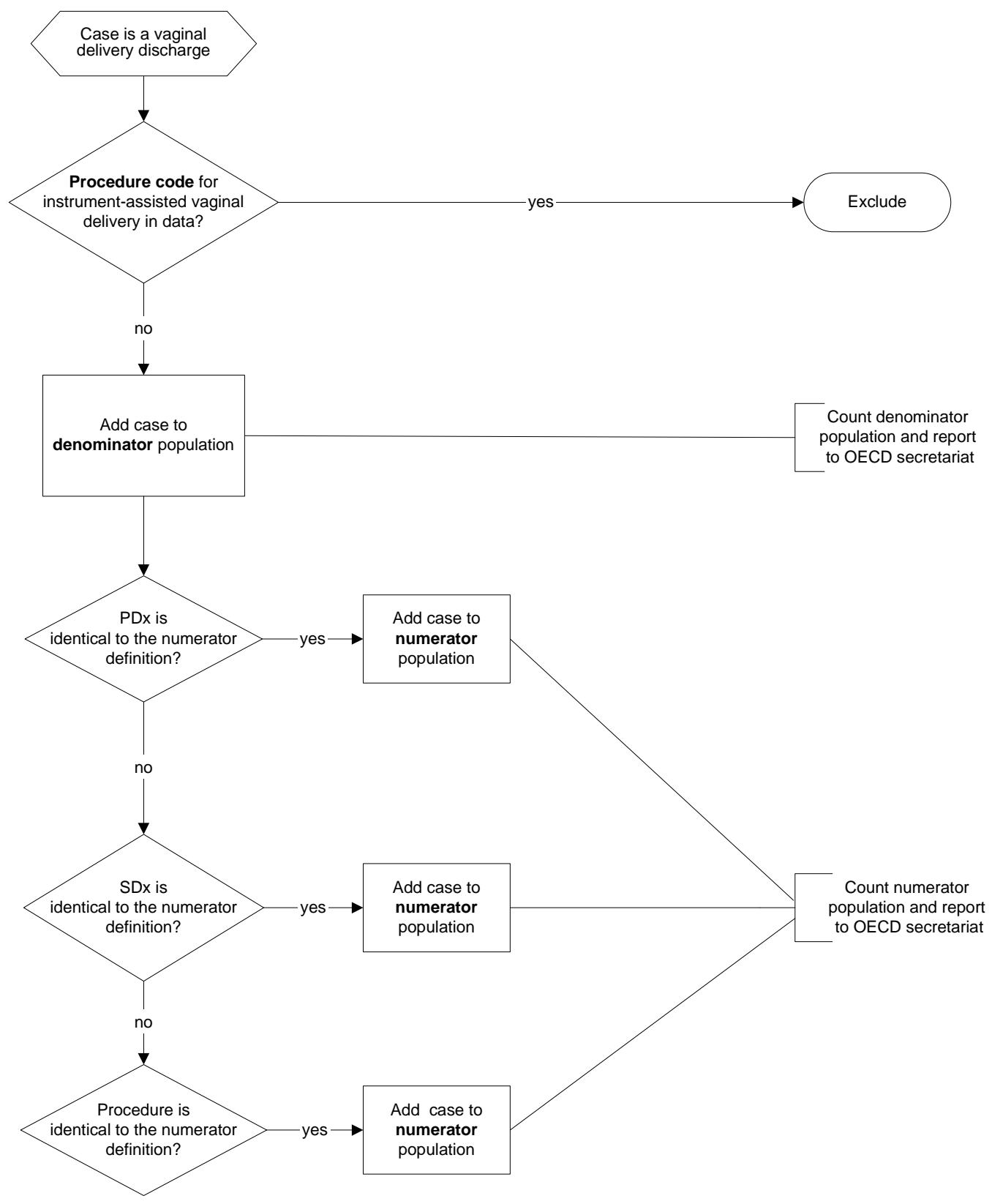




\section{APPENDIX 1. DENOMINATOR CALCULATION CODE LISTS}

Code List C: ICD-9-CM codes for denominator calculation (refer to codes below)

\begin{tabular}{|c|l|l|l|}
\hline $\begin{array}{c}\text { App } \\
\text { No. }\end{array}$ & \multicolumn{1}{|c|}{ Code List } & \multicolumn{1}{|c|}{ Indicator } & \multicolumn{1}{c|}{ Function } \\
\hline C-1 & $\begin{array}{l}\text { ICD-9-CM } \\
\text { immunocompromised } \\
\text { state codes }\end{array}$ & $\begin{array}{l}\text { Catheter-Related } \\
\text { Bloodstream Infection } \\
\text { Postoperative sepsis }\end{array}$ & $\begin{array}{l}\text { Denominator exclusion, if principal } \\
\text { diagnosis or secondary diagnosis }\end{array}$ \\
\hline C-2 & $\begin{array}{l}\text { Catheter-Related } \\
\text { ICD-9-CM cancer codes } \\
\text { Ploodstream Infection, }\end{array}$ & $\begin{array}{l}\text { Denominator exclusion, if principal } \\
\text { diagnosis or secondary diagnosis }\end{array}$ \\
\hline C-10 & $\begin{array}{l}\text { ICD-9-CM codes for } \\
\text { infections }\end{array}$ & Postoperative sepsis & $\begin{array}{l}\text { Denominator exclusion, if principal } \\
\text { diagnosis }\end{array}$ \\
\hline
\end{tabular}

\section{C-1: ICD-9-CM Immunocompromised States diagnosis codes:}

\begin{tabular}{|l|l|}
\hline 042 & HUMAN IMMUNODEFICIENCY VIRUS DISEASE \\
\hline 363 & PNEUMOCYSTOSIS \\
\hline 260 & KWASHIORKOR OCT05- \\
\hline 261 & NUTRITIONAL MARASMUS OCT05- \\
\hline 262 & OTH SEVERE MALNUTRITION OCT05- \\
\hline 23873 & HI GRDE MYELODYS SYN LES OCT06- \\
\hline 23876 & MYELOFI W MYELO METAPLAS OCT06 \\
\hline 27900 & HYPOGAMMAGLOBULINEM NOS \\
\hline 27901 & SELECTIVE IGA IMMUNODEF \\
\hline 27902 & SELECTIVE IGM IMMUNODEF \\
\hline 27903 & SELECTIVE IG DEFIC NEC \\
\hline 27904 & CONG HYPOGAMMAGLOBULINEM \\
\hline 27905 & IMMUNODEFIC W HYPER-IGM \\
\hline 27906 & COMMON VARIABL IMMUNODEF \\
\hline 27909 & HUMORAL IMMUNITY DEF NEC \\
\hline 27910 & IMMUNDEF T-CELL DEF NOS \\
\hline 27911 & DIGEORGES SYNDROME \\
\hline 27912 & WISKOTT-ALDRICH SYNDROME \\
\hline 27913 & NEZELOFS SYNDROME \\
\hline 27919 & DEFIC CELL IMMUNITY NOS \\
\hline 2792 & COMBINED IMMUNITY DEFICIENCY \\
\hline 2793 & UNSPECIFIED IMMUNITY DEFICIENCY \\
\hline 2794 & AUTOIMMUNE DISEASE, NOT ELSEWHERE CLASSIFIED \\
\hline 2798 & OTHER SPECIFIED DISORDERS INVOLVING THE IMMUNE MECHANISM \\
\hline 2799 & UNSPECIFIED DISORDER OF IMMUNE MECHANISM \\
\hline 28409 & CONST APLASTC ANEMIA NEC OCT06- \\
\hline 2841 & PANCYTOPENIA OCT06- \\
\hline 2880 & AGRANULOCYTOSIS OCT05- \\
\hline 28800 & NEUTROPENIA NOS OCT06- \\
\hline
\end{tabular}




\begin{tabular}{|c|c|}
\hline 28801 & CONGENITAL NEUTROPENIA OCT06- \\
\hline 28802 & CYCLIC NEUTROPENIA OCT06- \\
\hline 28803 & DRUG INDUCED NEUTROPENIA OCT06- \\
\hline 28809 & NEUTROPENIA NEC OCT06- \\
\hline 2881 & FUNCTION DIS NEUTROPHILS OCT05- \\
\hline 2882 & GENETIC ANOMALY LEUKOCYT OCT05- \\
\hline 2884 & HEMOPHAGOCYTIC SYNDROMES OCT06- \\
\hline 28850 & LEUKOCYTOPENIA NOS OCT06- \\
\hline 28851 & LYMPHOCYTOPENIA OCT06- \\
\hline 28859 & DECREASED WBC COUNT NEC OCT06- \\
\hline 28953 & NEUTROPENIC SPLENOMEGALY OCT06- \\
\hline 28983 & MYELOFIBROSIS OCT06- \\
\hline 40301 & MAL HYP KIDNEY W CHR KID OCT05- \\
\hline 40311 & BEN HYP KIDNEY W CHR KID OCT05- \\
\hline 40391 & HYP KIDNEY NOS W CHR KID OCT05- \\
\hline 40402 & MAL HY HRT/KID W CHR KID OCT05- \\
\hline 40403 & MAL HYP HRT/KID W HF/KID OCT05- \\
\hline 40412 & BEN HYP HT/KID W CHR KID OCT05- \\
\hline 40413 & BEN HYP HT/KID W HF/KID OCT05- \\
\hline 40492 & HYP HT/KID NOS W CHR KID OCT05- \\
\hline 40493 & HYP HRT/KID NOS W HF/KID OCT05- \\
\hline 5793 & INTEST POSTOP NONABSORB OCT05- \\
\hline 585 & CHRONIC KIDNEY DISEASE OCT05- \\
\hline 5855 & CHRON KIDNEY DIS STAGE V OCT05- \\
\hline 5856 & END STAGE RENAL DISEASE OCT05- \\
\hline 9968 & COMPLICATIONS OF TRANSPLANTED ORGAN \\
\hline 99680 & COMP ORGAN TRANSPLNT NOS \\
\hline 99681 & COMPL KIDNEY TRANSPLANT \\
\hline 99682 & COMPL LIVER TRANSPLANT \\
\hline 99683 & COMPL HEART TRANSPLANT \\
\hline 99684 & COMPL LUNG TRANSPLANT \\
\hline 99685 & COMPL MARROW TRANSPLANT \\
\hline 99686 & COMPL PANCREAS TRANSPLNT \\
\hline 99687 & COMP INTESTINE TRANSPLNT \\
\hline 99689 & COMP OTH ORGAN TRANSPLNT \\
\hline V420 & KIDNEY REPLACED BY TRANSPLANT \\
\hline V421 & HEART REPLACED BY TRANSPLANT \\
\hline V426 & LUNG REPLACED BY TRANSPLANT \\
\hline V427 & LIVER REPLACED BY TRANSPLANT \\
\hline V428 & OTHER SPECIFIED ORGAN OR TISSUE \\
\hline V4281 & BONE MARROW SPECIFIED BY TRANSPLANT \\
\hline V4282 & PERIPHERAL STEM CELLS REPLACED BY TRANSPLANT \\
\hline V4283 & PANCREAS REPLACED BY TRANSPLANT \\
\hline V4284 & INTESTINES REPLACE BY TRANSPLANT \\
\hline V4289 & OTHER REPLACED BY TRANSPLANT \\
\hline V451 & RENAL DIALYSIS STATUS OCT05- \\
\hline V560 & RENAL DIALYSIS ENCOUNTER OCT05- \\
\hline V561 & FT/ADJ XTRCORP DIAL CATH OCT05- \\
\hline V562 & FIT/ADJ PERIT DIAL CATH OCT05- \\
\hline
\end{tabular}


C-2: ICD-9-CM cancer codes (includes 4th and 5th digits)

\begin{tabular}{|c|c|c|c|}
\hline 140 & Malignant neoplasm of lip & 179 & Malignant neoplasm of uterus, part unspecified \\
\hline 141 & Malignant neoplasm of tongue & 180 & Malignant neoplasm of cervix uteri \\
\hline 142 & $\begin{array}{l}\text { Malignant neoplasm of major salivary } \\
\text { glands }\end{array}$ & 181 & Malignant neoplasm of placenta \\
\hline 143 & Malignant neoplasm of gum & 182 & Malignant neoplasm of body of uterus \\
\hline 144 & Malignant neoplasm of floor of mouth & 183 & $\begin{array}{l}\text { Malignant neoplasm of ovary and other uterine } \\
\text { adnexa }\end{array}$ \\
\hline 145 & $\begin{array}{l}\text { Malignant neoplasm of other and } \\
\text { unspecified parts of mouth }\end{array}$ & 184 & $\begin{array}{l}\text { Malignant neoplasm of other and unspecified female } \\
\text { genital organs }\end{array}$ \\
\hline 146 & Malignant neoplasm of oropharynx & 185 & Malignant neoplasm of prostate \\
\hline 147 & Malignant neoplasm of nasopharynx & 186 & Malignant neoplasm of testes \\
\hline 148 & Malignant neoplasm of hypopharynx & 187 & $\begin{array}{l}\text { Malignant neoplasm of penis and other male genital } \\
\text { organs }\end{array}$ \\
\hline 149 & $\begin{array}{l}\text { Malignant neoplasm of other and ill- } \\
\text { defined sites within the lip, oral cavity, } \\
\text { and pharynx }\end{array}$ & -188 & Malignant neoplasm of bladder \\
\hline 150 & Malignant neoplasm of esophagus & 189 & $\begin{array}{l}\text { Malignant neoplasm of kidney and other and } \\
\text { unspecified urinary organs }\end{array}$ \\
\hline 151 & Malignant neoplasm of stomach & 190 & Malignant neoplasm of eye \\
\hline 152 & $\begin{array}{l}\text { Malignant neoplasm of small intestine, } \\
\text { including duodenum }\end{array}$ & 191 & plasm of brain \\
\hline 153 & plasm of colon & 192 & $\begin{array}{l}\text { Malignant neoplasm of other and unspecified parts of } \\
\text { nervous system }\end{array}$ \\
\hline 154 & $\begin{array}{l}\text { Malignant neoplasm of rectum, } \\
\text { rectosigmoid junction, and anus }\end{array}$ & 193 & oplasm of thyroid gland \\
\hline 155 & $\begin{array}{|llll|}\begin{array}{l}\text { Malignant neoplasm of liver and } \\
\text { intrahepatic bile ducts }\end{array} & & & \\
\end{array}$ & 194 & ed structures \\
\hline 156 & $\begin{array}{l}\text { Malignant neoplasm of gallbladder and } \\
\text { extrahepatic bile ducts }\end{array}$ & 195 & of other, and ill-defined sites \\
\hline 157 & Malignant neoplasm of pancreas & 196 & $\begin{array}{l}\text { Secondary and unspecified malignant neoplasm of } \\
\text { lymph nodes }\end{array}$ \\
\hline 158 & $\begin{array}{l}\text { Malignant neoplasm of retroperitoneum } \\
\text { and peritoneum }\end{array}$ & 197 & $\begin{array}{l}\text { Secondary malignant neoplasm of respiratory and } \\
\text { digestive systems }\end{array}$ \\
\hline 159 & $\begin{array}{l}\text { Malignant neoplasm of other and ill- } \\
\text { defined sites within the digestive organs } \\
\text { and peritoneum }\end{array}$ & 198 & Secondary malignant neoplasm of other specified sites \\
\hline 160 & $\begin{array}{l}\text { Malignant neoplasm of nasal cavities, } \\
\text { middle ear, andaccessory sinuses }\end{array}$ & 199 & pecification of site \\
\hline 161 & t neoplasm of larynx & 200 & Lymphos \\
\hline 162 & $\begin{array}{l}\begin{array}{l}\text { Malignant neoplasm of } \\
\text { bronchus, and lung }\end{array} \\
\end{array}$ & 201 & Hodgkin’s Disease \\
\hline 163 & Malignant neoplasm of pleura & 202 & $\begin{array}{l}\begin{array}{l}\text { Other malignant neoplasms of lymphoid and } \\
\text { histiocytic tissues }\end{array} \\
\end{array}$ \\
\hline 164 & $\begin{array}{l}\text { Malignant neoplasm of thymus, heart, } \\
\text { and mediastinum }\end{array}$ & 203 & $\begin{array}{l}\begin{array}{l}\text { Multiple myeloma } \\
\text { neoplasms }\end{array}\end{array}$ \\
\hline 165 & $\begin{array}{l}\text { Malignant neoplasm of other and ill- } \\
\text { defined sites within the respiratory } \\
\text { system and intrathoracic organs }\end{array}$ & & Lymphoid leukemia \\
\hline
\end{tabular}




\begin{tabular}{|c|c|c|c|}
\hline 170 & $\begin{array}{l}\begin{array}{l}\text { Malignant neoplasm of bone at } \\
\text { articular cartilage }\end{array} \\
\end{array}$ & 205 & Myeloid leukemia \\
\hline 171 & $\begin{array}{l}\text { Malignant neoplasm of connective at } \\
\text { other soft tissue }\end{array}$ & 206 & Monocytic leukemia \\
\hline 172 & Malignant melanoma of skin & 207 & Other specified leukemia \\
\hline 174 & Malignant neoplasm of female breast & 208 & Leukemia of unspecified cell type \\
\hline 175 & Malignant neoplasm of male breast & 2386 & $\begin{array}{l}\text { Neoplasm of uncertain behavior of other and } \\
\text { unspecified sites and tissues, plasma cells }\end{array}$ \\
\hline 176 & Karposi’s Sarcoma & 2733 & Macroglobulinemia \\
\hline
\end{tabular}

Personal history of malignant neoplasm:

\begin{tabular}{|c|c|c|c|}
\hline V1000 & Gastrointestinal tract, unspecified & V1049 & Other male genital organs \\
\hline V1001 & Tongue & V1050 & Urinary organ, unspecified \\
\hline V1002 & $\begin{array}{l}\text { Other and unspecified oral cavity and } \\
\text { pharynx }\end{array}$ & HV1051 & Bladder \\
\hline V1003 & Esophagus & V1052 & Kidney \\
\hline V1004 & Stomach & V1053 & Renal pelvis \\
\hline V1005 & Large intestine & V1059 & Urinary organs, other \\
\hline V1006 & $\begin{array}{l}\text { Rectum, rectosigmoid junction, and } \\
\text { anus }\end{array}$ & V1060 & Leukemia, unspecified \\
\hline V1007 & Liver & V1061 & Lymphoid leukemia \\
\hline V1009 & Other & V1062 & Myeloid leukemia \\
\hline V1011 & Bronchus and lung & V1063 & Monocytic leukemia \\
\hline V1012 & Trachea & V1069 & Leukemia, other \\
\hline V1020 & Respiratory organ, unspecified & V1071 & Lymphosarcoma and reticulosarcoma \\
\hline V1021 & Larynx & V1072 & Hodgkin’s Disease \\
\hline V1022 & $\begin{array}{l}\text { Nasal cavities, middle ear, and } \\
\text { accessory sinuses }\end{array}$ & V1079 & Other lymphatic and hematopoietic neoplasms, other \\
\hline V1029 & $\begin{array}{l}\text { Other respiratory and intrathoracic } \\
\text { organs, other }\end{array}$ & V1081 & Bone \\
\hline V103 & Breast & V1082 & Malignant melanoma of skin \\
\hline V1040 & Female genital organ, unspecified & V1083 & Other malignant neoplasm of skin \\
\hline V1041 & Cervix uteri & V1084 & Eye \\
\hline V1042 & Other parts of uterus & V1085 & Brain \\
\hline V1043 & Ovary & V1086 & Other parts of nervous system \\
\hline V1044 & Other female genital organs & V1087 & Thyroid \\
\hline V1045 & Male genital organ, unspecified & V1088 & Other endocrine glands and related structures \\
\hline V1046 & Prostate & V1089 & Other \\
\hline V1047 & Testes & V109 & Unspecified personal history of malignant neoplasm \\
\hline V1048 & Epididymis & & \\
\hline
\end{tabular}

\section{C-10: ICD-9-CM codes for infections}

\begin{tabular}{|l|l|l|l|}
\hline 0010 & Cholera d/t vib cholerae (Oct 05) & 56213 & Dvrtcli colon w hmrhg \\
\hline 0011 & Cholera d/t vib el tor (Oct 05) & 566 & Anal \& rectal abscess \\
\hline 0019 & Cholera nos (Oct 05) & 5670 & Peritonitis in infec dis \\
\hline 0020 & Typhoid fever (Oct 05) & 5671 & Pneumococcal peritonitis \\
\hline 0021 & Paratyphoid fever a (Oct 05) & 5672 & Suppurat peritonitis nec \\
\hline 0022 & Paratyphoid fever b (Oct 05) & 56721 & Peritonitis (acute) gen (Oct 05) \\
\hline
\end{tabular}




\begin{tabular}{|c|c|c|c|}
\hline 0023 & Paratyphoid fever c (Oct 05) & 56722 & Peritoneal abscess (Oct 05) \\
\hline 0029 & Paratyphoid fever nos (Oct 05) & 56723 & Spontan bact peritonitis (Oct 05) \\
\hline 0030 & Salmonella enteritis (Oct 05) & 56729 & Suppurat peritonitis nec (Oct 05) \\
\hline 0031 & Salmonella septicemia (Oct 05) & 56731 & Psoas muscle abscess (Oct 05) \\
\hline 00320 & Local salmonella inf nos (Oct 05) & 56738 & Retroperiton abscess nec (Oct 05) \\
\hline 00321 & Salmonella meningitis (Oct 05) & 56739 & Retroperiton infect nec (Oct 05) \\
\hline 00322 & Salmonella pneumonia (Oct 05) & 56781 & Choleperitonitis (Oct 05) \\
\hline 00323 & Salmonella arthritis (Oct 05) & 56782 & Sclerosing mesenteritis (Oct 05) \\
\hline 00324 & Salmonella osteomyelitis (Oct 05) & 56789 & Peritonitis nec (Oct 05) \\
\hline 00329 & Local salmonella inf nec (Oct 05) & 5679 & Peritonitis nos \\
\hline 0038 & Salmonella infection nec (Oct 05) & 5695 & Intestinal abscess \\
\hline 0039 & Salmonella infection nos (Oct 05) & 56961 & Colosty/enterost infectn \\
\hline 0040 & Shigella dysenteriae (Oct 05) & 5720 & Abscess of liver \\
\hline 0041 & Shigella flexneri (Oct 05) & 5721 & Portal pyemia \\
\hline 0042 & Shigella boydii (Oct 05) & 57400 & Cholelith w ac cholecyst \\
\hline 0043 & Shigella sonnei (Oct 05) & 57401 & Cholelith/ac gb inf-obst \\
\hline 0048 & Shigella infection nec (Oct 05) & 57430 & Choledocholith/ac gb inf \\
\hline 0049 & Shigellosis nos (Oct 05) & 57431 & Choledochlith/ac gb-obst \\
\hline 0050 & Staph food poisoning (Oct 05) & 57460 & Gall\&bil cal w/ac w/o ob \\
\hline 0051 & Botulism (Oct 05) & 57461 & Gall\&bil cal w/ac w obs \\
\hline 0052 & Food pois d/t c. Perfrin (Oct 05$)$ & 57480 & Gal\&bil cal w/ac\&chr w/o \\
\hline 0053 & Food pois: clostrid nec (Oct 05) & 57481 & Gal\&bil cal w/ac\&ch w ob \\
\hline 0054 & Food pois: v. Parahaem (Oct 05) & 5750 & Acute cholecystitis \\
\hline 00581 & Food poisn d/t v. Vulnif (Oct 05) & 57510 & Cholecystitis unspec (Oct 05) \\
\hline 00589 & Bact food poisoning nec (Oct 05) & 57512 & Ac\&chron cholecystitis (Oct 05) \\
\hline 0059 & Food poisoning nos (Oct 05 ) & 5754 & Perforation gallbladder \\
\hline 00800 & Intest infec e coli nos (Oct 05) & 5761 & Cholangitis \\
\hline 00801 & Int inf e coli entrpath (Oct 05) & 5763 & Perforation of bile duct \\
\hline 00802 & Int inf e coli entrtoxgn (Oct 05) & 5770 & Acute pancreatitis (Oct 05) \\
\hline 00803 & Int inf e coli entrnvsv (Oct 05) & 59010 & Ac pyelonephritis nos (Oct 05 ) \\
\hline 00804 & Int inf e coli entrhmrg (Oct 05) & 59011 & Ac pyelonephr w med necr (Oct 05) \\
\hline 00809 & Int inf e coli spcf nec (Oct 05) & 5902 & Renal/perirenal abscess (Oct 05) \\
\hline 0081 & Arizona enteritis (Oct 05) & 5903 & Pyeloureteritis cystica (Oct 05) \\
\hline 0082 & Aerobacter enteritis (Oct 05) & 59080 & Pyelonephritis nos (Oct 05) \\
\hline 0083 & Proteus enteritis (Oct 05) & 59081 & Pyelonephrit in oth dis (Oct 05) \\
\hline 00841 & Staphylococc enteritis (Oct 05) & 5909 & Infection of kidney nos (Oct 05) \\
\hline 00842 & Pseudomonas enteritis (Oct 05) & 5950 & Acute cystitis (Oct 05) \\
\hline 00843 & Int infec campylobacter (Oct 05) & 5954 & Cystitis in oth dis (Oct 05) \\
\hline 00844 & Int inf yrsnia entrcltca (Oct 05) & 59581 & Cystitis cystica (Oct 05) \\
\hline 00845 & Int inf clstrdium dfcile (Oct 05) & 59589 & Cystitis nec (Oct 05) \\
\hline 00846 & Intes infec oth anerobes (Oct 05) & 5959 & Cystitis nos (Oct 05) \\
\hline 00847 & Int inf oth grm neg bctr (Oct 05) & 5970 & Urethral abscess (Oct 05) \\
\hline 00849 & Bacterial enteritis nec (Oct 05) & 59800 & Urethr strict:infect nos (Oct 05) \\
\hline 0085 & Bacterial enteritis nos (Oct 05) & 59801 & Ureth strict:oth infect (Oct 05) \\
\hline 0200 & Bubonic plague (Oct 05) & 5990 & Urin tract infection nos (Oct 05) \\
\hline 0201 & Cellulocutaneous plague (Oct 05) & 6010 & Acute prostatitis (Oct 05) \\
\hline 0202 & Septicemic plague (Oct 05) & 6012 & Abscess of prostate (Oct 05) \\
\hline 0203 & Primary pneumonic plague (Oct 05) & 6013 & Prostatocystitis (Oct 05) \\
\hline 0204 & Secondary pneumon plague (Oct 05) & 6014 & Prostatitis in oth dis (Oct 05) \\
\hline
\end{tabular}




\begin{tabular}{|c|c|c|c|}
\hline 0205 & Pneumonic plague nos (Oct 05) & 6018 & Prostatitis (Oct 05) \\
\hline 0208 & Other types of plague (Oct 05) & 6019 & Prostatitis nos (Oct 05) \\
\hline 0209 & Plague nos (Oct 05) & 6031 & Infected hydrocele (Oct 05) \\
\hline 0210 & Ulceroglandul tularemia (Oct 05) & 6040 & Orchitis with abscess (Oct 05) \\
\hline 0211 & Enteric tularemia (Oct 05) & 60490 & Orchitis/epididymit nos (Oct 05) \\
\hline 0212 & Pulmonary tularemia (Oct 05) & 60491 & Orchitis in oth disease (Oct 05) \\
\hline 0213 & Oculoglandular tularemia (Oct 05) & 6071 & Balanoposthitis (Oct 05) \\
\hline 0218 & Tularemia nec (Oct 05) & 6072 & Inflam dis, penis nec (Oct 05) \\
\hline 0219 & Tularemia nos (Oct 05) & 6080 & Seminal vesiculitis (Oct 05) \\
\hline 0220 & Cutaneous anthrax (Oct 05) & 6084 & Male gen inflam dis nec (Oct 05) \\
\hline 0221 & Pulmonary anthrax (Oct 05) & 6110 & Inflam disease of breast (Oct 05) \\
\hline 0222 & Gastrointestinal anthrax (Oct 05) & 6140 & Ac salpingo-oophoritis (Oct 05) \\
\hline 0223 & Anthrax septicemia (Oct 05) & 6141 & Chron salpingitis oophoritis (Oct \\
\hline 0228 & Other anthrax manifest (Oct 05) & 6142 & Salpingo-oophoritis nos (Oct 05) \\
\hline 0229 & Anthrax nos (Oct 05) & 6143 & Acute parametritis (Oct 05) \\
\hline 0230 & Brucella melitensis (Oct 05) & 6144 & Chron or unsp cellulitis (Oct 05) \\
\hline 0231 & Brucella abortus (Oct 05) & 6145 & Ac pelv peritonitis-fem (Oct 05) \\
\hline 0232 & Brucella suis (Oct 05) & 6149 & Pid nos (Oct 05) \\
\hline 0233 & Brucella canis (Oct 05) & 6150 & Ac uterine inflammation (Oct 05) \\
\hline 0238 & Brucellosis nec (Oct 05) & 6159 & Uterine inflam dis nos (Oct 05) \\
\hline 0239 & Brucellosis nos (Oct 05) & 6160 & Cervicitis (Oct 05) \\
\hline 024 & Glanders (Oct 05) & 61610 & Vaginitis nos (Oct 05) \\
\hline 025 & Melioidosis (Oct 05) & 6163 & Bartholin's glnd abscess (Oct 05) \\
\hline 0260 & Spirillary fever (Oct 05) & 6164 & Abscess of vulva nec (Oct 05) \\
\hline 0261 & Streptobacillary fever (Oct 05) & 63400 & Spon abor w pel inf-unsp (Oct 05) \\
\hline 0269 & Rat-bite fever nos (Oct 05) & 63401 & Spon abor w pelv inf-inc (Oct 05) \\
\hline 0270 & Listeriosis (Oct 05) & 63402 & Spon abor w pel inf-comp (Oct 05) \\
\hline 0271 & Erysipelothrix infection (Oct 05) & 63500 & Leg abor w pelv inf-unsp (Oct 05) \\
\hline 0272 & Pasteurellosis (Oct 05) & 63501 & Leg abor w pelv inf-inc (Oct 05) \\
\hline 0278 & Zoonotic bact dis nec (Oct 05 ) & 63502 & Leg abor w pelv inf-comp (Oct 05) \\
\hline 0279 & Zoonotic bact dis nos (Oct 05 ) & 63600 & Illeg ab w pelv inf-unsp (Oct 05) \\
\hline 0320 & Faucial diphtheria (Oct 05) & 63601 & Illeg ab w pelv inf-inc (Oct 05) \\
\hline 0321 & Nasopharynx diphtheria (Oct 05) & 63602 & Illeg ab w pelv inf-comp (Oct 05) \\
\hline 0322 & Ant nasal diphtheria (Oct 05) & 63700 & Abort nos w pel inf-unsp (Oct 05) \\
\hline 0323 & Laryngeal diphtheria (Oct 05) & 63701 & Abort nos w pel inf-inc (Oct 05) \\
\hline 03281 & Conjunctival diphtheria (Oct 05) & 63702 & Abort nos w pel inf-comp (Oct 05) \\
\hline 03282 & Diphtheritic myocarditis (Oct 05) & 6380 & Attem abort w pelvic inf (Oct 05) \\
\hline 03283 & Diphtheritic peritonitis (Oct 05) & 6390 & Postabortion gu infect (Oct 05) \\
\hline 03284 & Diphtheritic cystitis (Oct 05) & 64650 & Bacteriuria preg-unspec (Oct 05) \\
\hline 03285 & Cutaneous diphtheria (Oct 05) & 64651 & Asym bacteriuria-deliver (Oct 05) \\
\hline 03289 & Diphtheria nec (Oct 05) & 64652 & Asy bacteruria-del w p/p (Oct 05) \\
\hline 0329 & Diphtheria nos (Oct 05) & 64653 & Asy bacteriuria-antepart (Oct 05) \\
\hline 0330 & Bordetella pertussis (Oct 05) & 64654 & Asy bacteriuria-postpart (Oct 05) \\
\hline 0331 & Bordetella parapertussis (Oct 05) & 64660 & Gu infect in preg-unspec (Oct 05) \\
\hline 0338 & Whooping cough nec (Oct 05) & 64661 & Gu infection-delivered (Oct 05) \\
\hline 0339 & Whooping cough nos (Oct 05) & 64662 & Gu infection-deliv w p/p (Oct 05) \\
\hline 0340 & Strep sore throat (Oct 05) & 64663 & Gu infection-antepartum (Oct 05) \\
\hline 0341 & Scarlet fever (Oct 05) & 64664 & Gu infection-postpartum (Oct 05) \\
\hline 035 & Erysipelas (Oct 05) & 64710 & Gonorrhea in preg-unspec (Oct 05) \\
\hline
\end{tabular}




\begin{tabular}{|c|c|c|c|}
\hline 0360 & Meningococcal meningitis (Oct 05) & 64711 & Gonorrhea-delivered (Oct 05) \\
\hline 0361 & Meningococc encephalitis (Oct 05) & 64712 & Gonorrhea-deliver w p/p (Oct 05) \\
\hline 0362 & Meningococcemia (Oct 05) & 64713 & Gonorrhea-antepartum (Oct 05) \\
\hline 0363 & Meningococc adrenal synd (Oct 05) & 64714 & Gonorrhea-postpartum (Oct 05) \\
\hline 03640 & Meningococc carditis nos (Oct 05) & 64780 & Inf dis in preg nec-unsp (Oct 05) \\
\hline 03641 & Meningococc pericarditis (Oct 05) & 64781 & Infect dis nec-delivered (Oct 05) \\
\hline 03642 & Meningococc endocarditis (Oct 05) & 64782 & Infect dis nec-del w p/p (Oct 05) \\
\hline 03643 & Meningococc myocarditis (Oct 05) & 64783 & Infect dis nec-antepart (Oct 05) \\
\hline 03681 & Meningococc optic neurit (Oct 05) & 64784 & Infect dis nec-postpart (Oct 05) \\
\hline 03682 & Meningococc arthropathy (Oct 05) & 64790 & Infect in preg nos-unsp (Oct 05) \\
\hline 03689 & Meningococcal infect nec (Oct 05) & 64791 & Infect nos-delivered (Oct 05) \\
\hline 0369 & Meningococcal infect nos (Oct 05) & 64792 & Infect nos-deliver w p/p (Oct 05) \\
\hline 037 & Tetanus (Oct 05) & 64793 & Infect nos-antepartum (Oct 05) \\
\hline 0380 & Streptococcal septicemia (Oct 05) & 64794 & Infect nos-postpartum (Oct 05) \\
\hline 03810 & Staphylcocc septicem nos (Oct 05) & 65840 & Amniotic infection-unsp (Oct 05) \\
\hline 03811 & Staph aureus septicemia (Oct 05) & 65841 & Amniotic infection-deliv (Oct 05) \\
\hline 03819 & Staphylcocc septicem nec (Oct 05) & 65843 & Amniotic infect-antepart (Oct 05) \\
\hline 0382 & Pneumococcal septicemia (Oct 05) & 67000 & Major puerp infect-unsp (Oct 05) \\
\hline 0383 & Anaerobic septicemia (Oct 05) & 67002 & Major puerp inf-del p/p (Oct 05) \\
\hline 03840 & Gram-neg septicemia nos (Oct 05) & 67004 & Major puerp inf-postpart (Oct 05) \\
\hline 03841 & H. Influenae septicemia (Oct 05) & 67500 & Infect nipple preg-unsp (Oct 05) \\
\hline 03842 & E coli septicemia (Oct 05) & 67501 & Infect nipple-delivered (Oct 05) \\
\hline 03843 & Pseudomonas septicemia (Oct 05) & 67502 & Infect nipple-del w p/p (Oct 05) \\
\hline 03844 & Serratia septicemia (Oct 05) & 67503 & Infect nipple-antepartum (Oct 05) \\
\hline 03849 & Gram-neg septicemia nec (Oct 05) & 67504 & Infect nipple-postpartum (Oct 05) \\
\hline 0388 & Septicemia nec (Oct 05) & 67510 & Breast abscess preg-unsp (Oct 05) \\
\hline 0389 & Septicemia nos (Oct 05) & 67511 & Breast abscess-delivered (Oct 05) \\
\hline 0390 & Cutaneous actinomycosis (Oct 05) & 67512 & Breast abscess-del w p/p (Oct 05) \\
\hline 0391 & Pulmonary actinomycosis (Oct 05) & 67513 & Breast abscess-antepart (Oct 05) \\
\hline 0392 & Abdominal actinomycosis (Oct 05) & 67514 & Breast abscess-postpart (Oct 05) \\
\hline 0393 & Cervicofac actinomycosis (Oct 05) & 67580 & Breast inf preg nec-unsp (Oct 05) \\
\hline 0394 & Madura foot (Oct 05) & 67581 & Breast infect nec-deliv (Oct 05) \\
\hline 0398 & Actinomycosis nec (Oct 05) & 67582 & Breast inf nec-del w p/p (Oct 05) \\
\hline 0399 & Actinomycosis nos (Oct 05) & 67583 & Breast inf nec-antepart (Oct 05) \\
\hline 0400 & Gas gangrene (Oct 05) & 67584 & Breast inf nec-postpart (Oct 05) \\
\hline 0401 & Rhinoscleroma (Oct 05) & 67590 & Breast inf preg nos-unsp (Oct 05) \\
\hline 0402 & Whipple's disease (Oct 05) & 67591 & Breast infect nos-deliv (Oct 05) \\
\hline 0403 & Necrobacillosis (Oct 05) & 67592 & Breast inf nos-del w p/p (Oct 05) \\
\hline 04081 & Tropical pyomyositis (Oct 05) & 67593 & Breast inf nos-antepart (Oct 05) \\
\hline 04082 & Toxic shock syndrome (Oct 05) & 67594 & Breast inf nos-postpart (Oct 05) \\
\hline 04089 & Bacterial diseases nec (Oct 05) & 6800 & Carbuncle of face (Oct 05) \\
\hline 04100 & Streptococcus unspecf (Oct 05) & 6801 & Carbuncle of neck (Oct 05) \\
\hline 04101 & Streptococcus group a (Oct 05) & 6802 & Carbuncle of trunk (Oct 05) \\
\hline 04102 & Streptococcus group b (Oct 05) & 6803 & Carbuncle of arm (Oct 05) \\
\hline 04103 & Streptococcus group c (Oct 05) & 6804 & Carbuncle of hand (Oct 05) \\
\hline 04104 & Enterococcus group d (Oct 05) & 6805 & Carbuncle of buttock (Oct 05) \\
\hline 04105 & Streptococcus group g (Oct 05) & 6806 & Carbuncle of leg (Oct 05) \\
\hline 04109 & Other streptococcus (Oct 05) & 6807 & Carbuncle of foot (Oct 05) \\
\hline 04110 & Staphylococcus unspcfied (Oct 05) & 6808 & Carbuncle, site nec (Oct 05) \\
\hline
\end{tabular}




\begin{tabular}{|c|c|c|c|}
\hline 04111 & Staphylococcus aureus (Oct 05) & 6809 & Carbuncle nos (Oct 05) \\
\hline 04119 & Other staphylococcus (Oct 05) & 68100 & Cellulitis, finger nos (Oct 05) \\
\hline 0412 & Pneumococcus infect nos (Oct 05) & 68101 & Felon (Oct 05) \\
\hline 0413 & Klebsiella infect nos (Oct 05) & 68102 & Onychia of finger (Oct 05) \\
\hline 0414 & E. Coli infect nos (Oct 05) & 68110 & Cellulitis, toe nos (Oct 05) \\
\hline 0415 & H. Influenzae infect nos (Oct 05) & 68111 & Onychia of toe (Oct 05 ) \\
\hline 0416 & Proteus infection nos (Oct 05) & 6819 & Cellulitis of digit nos (Oct 05) \\
\hline 0417 & Pseudomonas infect nos (Oct 05) & 6820 & Cellulitis of face (Oct 05) \\
\hline 04182 & Bacteroides fragilis (Oct 05) & 6821 & Cellulitis of neck (Oct 05) \\
\hline 04183 & Clostridium perfringens (Oct 05) & 6822 & Cellulitis of trunk (Oct 05) \\
\hline 04184 & Other anaerobes (Oct 05) & 6823 & Cellulitis of arm (Oct 05) \\
\hline 04185 & Oth gram negatv bacteria (Oct 05) & 6824 & Cellulitis of hand (Oct 05) \\
\hline 04186 & Helicobacter pylori (Oct 05) & 6825 & Cellulitis of buttock (Oct 05) \\
\hline 04189 & Oth specf bacteria (Oct 05) & 6826 & Cellulitis of leg (Oct 05) \\
\hline 0419 & Bacterial infection nos (Oct 05) & 6827 & Cellulitis of foot (Oct 05) \\
\hline 0980 & Acute gc infect lower gu (Oct 05) & 6828 & Cellulitis, site nec (Oct 05) \\
\hline 09810 & Gc (acute) upper gu nos (Oct 05) & 6829 & Crllulitis, site nos (Oct 05) \\
\hline 09811 & Gc cystitis (acute) (Oct 05) & 683 & Acute lymphadenitis (Oct 05) \\
\hline 09812 & Gc prostatitis (acute) (Oct 05) & 684 & Impetigo (Oct 05) \\
\hline 09813 & Gc orchitis (acute) (Oct 05) & 68600 & Pyoderma nos (Oct 05) \\
\hline 09814 & Gc sem vesiculit (acute) (Oct 05) & 68601 & Pyoderma gangrenosum (Oct 05) \\
\hline 09815 & Gc cervicitis (acute) (Oct 05) & 68609 & Pyoderma other (Oct 05) \\
\hline 09816 & Gc endometritis (acute) (Oct 05) & 6868 & Local skin infection nec (Oct 05) \\
\hline 09817 & Acute gc salpingitis (Oct 05) & 6869 & Local skin infection nos (Oct 05) \\
\hline 09819 & Gc (acute) upper gu nec (Oct 05) & 69581 & Ritter's disease (Oct 05) \\
\hline 0982 & Chr gc infect lower gu (Oct 05) & 70700 & Decubitus ulcer site nos (Oct 05) \\
\hline 09830 & Chr gc upper gu nos (Oct 05) & 70701 & Decubitus ulcer,elbow (Oct 05) \\
\hline 09831 & Gc cystitis, chronic (Oct 05) & 70702 & Decubitus ulcer,up back (Oct 05) \\
\hline 09832 & Gc prostatitis, chronic (Oct 05) & 70703 & Decubitus ulcer,low back (Oct 05) \\
\hline 09833 & Gc orchitis, chronic (Oct 05) & 70704 & Decubitus ulcer,hip (Oct 05) \\
\hline 09834 & Gc sem vesiculitis, chr (Oct 05) & 70705 & Decubitus ulcer,buttock (Oct 05) \\
\hline 09835 & Gc cervicitis, chronic (Oct 05) & 70706 & Decubitus ulcer,ankle (Oct 05) \\
\hline 09836 & Gc endometritis, chronic (Oct 05) & 70707 & Decubitus ulcer,heel (Oct 05) \\
\hline 09837 & Gc salpingitis (chronic) (Oct 05) & 70709 & Decubitus ulcer,site nec (Oct 05) \\
\hline 09839 & Chr gc upper gu nec (Oct 05) & 71100 & Pyogen arthritis-unspec (Oct 05) \\
\hline 09840 & Gonococcal conjunctivit (Oct 05) & 71101 & Pyogen arthritis-shlder (Oct 05) \\
\hline 09841 & Gonococcal iridocyclitis (Oct 05) & 71102 & Pyogen arthritis-up/arm (Oct 05) \\
\hline 09842 & Gonococcal endophthalmia (Oct 05) & 71103 & Pyogen arthritis-forearm (Oct 05) \\
\hline 09843 & Gonococcal keratitis (Oct 05) & 71104 & Pyogen arthritis-hand (Oct 05) \\
\hline 09849 & Gonococcal eye nec (Oct 05) & 71105 & Pyogen arthritis-pelvis (Oct 05) \\
\hline 09850 & Gonococcal arthritis (Oct 05) & 71106 & Pyogen arthritis-1/leg (Oct 05) \\
\hline 09851 & Gonococcal synovitis (Oct 05) & 71107 & Pyogen arthritis-ankle (Oct 05) \\
\hline 09852 & Gonococcal bursitis (Oct 05) & 71108 & Pyogen arthritis nec (Oct 05) \\
\hline 09853 & Gonococcal spondylitis (Oct 05) & 71109 & Pyogen arthritis-mult (Oct 05) \\
\hline 09859 & Gc infect joint nec (Oct 05) & 71190 & Inf arthritis nos-unspec (Oct 05) \\
\hline 0986 & Gonococcal infec pharynx (Oct 05) & 71191 & Inf arthritis nos-shlder (Oct 05) \\
\hline 0987 & Gc infect anus \& rectum (Oct 05) & 71192 & Inf arthritis nos-up/arm (Oct 05) \\
\hline 09881 & Gonococcal keratosis (Oct 05) & 71193 & Inf arthrit nos-forearm (Oct 05) \\
\hline 09882 & Gonococcal meningitis (Oct 05) & 71194 & Inf arthrit nos-hand (Oct 05) \\
\hline
\end{tabular}




\begin{tabular}{|c|c|c|c|}
\hline 09883 & Gonococcal pericarditis (Oct 05) & 71195 & Inf arthrit nos-pelvis (Oct 05) \\
\hline 09884 & Gonococcal endocarditis (Oct 05) & 71196 & Inf arthrit nos-1/leg (Oct 05) \\
\hline 09885 & Gonococcal heart dis nec (Oct 05) & 71197 & Inf arthrit nos-ankle (Oct 05) \\
\hline 09886 & Gonococcal peritonitis (Oct 05) & 71198 & Inf arthrit nos-oth site (Oct 05) \\
\hline 09889 & Gonococcal inf site nec (Oct 05) & 71199 & Inf arthritis nos-mult (Oct 05) \\
\hline 3200 & Hemophilus meningitis (Oct 05) & 7280 & Infective myositis (Oct 05) \\
\hline 3201 & Pneumococcal meningitis (Oct 05) & 72886 & Necrotizing fasciitis (Oct 05) \\
\hline 3202 & Streptococcal meningitis (Oct 05) & 73000 & Ac osteomyelitis-unspec (Oct 05) \\
\hline 3203 & Staphylococc meningitis (Oct 05) & 73001 & Ac osteomyelitis-shlder (Oct 05) \\
\hline 3207 & Mening in oth bact dis (Oct 05) & 73002 & Ac osteomyelitis-up/arm (Oct 05) \\
\hline 32081 & Anaerobic meningitis (Oct 05) & 73003 & Ac osteomyelitis-forearm (Oct 05) \\
\hline 32082 & Mningts gram-neg bct nec (Oct 05) & 73004 & Ac osteomyelitis-hand (Oct 05) \\
\hline 32089 & Meningitis oth spcf bact (Oct 05) & 73005 & Ac osteomyelitis-pelvis (Oct 05) \\
\hline 3209 & Bacterial meningitis nos (Oct 05) & 73006 & Ac osteomyelitis-l/leg (Oct 05) \\
\hline 3229 & Meningitis nos (Oct 05) & 73007 & Ac osteomyelitis-ankle (Oct 05) \\
\hline 3240 & Intracranial abscess (Oct 05) & 73008 & Ac osteomyelitis nec (Oct 05) \\
\hline 3241 & Intraspinal abscess (Oct 05) & 73009 & Ac osteomyelitis-mult (Oct 05) \\
\hline 3249 & Cns abscess nos (Oct 05) & 73010 & Chr osteomyelitis-unsp (Oct 05) \\
\hline 36000 & Purulent endophthalm nos (Oct 05) & 73011 & Chr osteomyelit-shlder (Oct 05) \\
\hline 36001 & Acute endophthalmitis (Oct 05) & 73012 & Chr osteomyelit-up/arm (Oct 05) \\
\hline 36002 & Panophthalmitis (Oct 05) & 73013 & Chr osteomyelit-forearm (Oct 05) \\
\hline 36004 & Vitreous abscess (Oct 05) & 73014 & Chr osteomyelit-hand (Oct 05) \\
\hline 37055 & Corneal abscess (Oct 05) & 73015 & Chr osteomyelit-pelvis (Oct 05) \\
\hline 37200 & Acute conjunctivitis nos (Oct 05) & 73016 & Chr osteomyelit-l/leg (Oct 05) \\
\hline 37203 & Mucopur conjunctivit nec (Oct 05) & 73017 & Chr osteomyelit-ankle (Oct 05) \\
\hline 37204 & Pseudomemb conjunctivit (Oct 05) & 73018 & Chr osteomyelit nec (Oct 05) \\
\hline 37220 & Blepharoconjunctivit nos (Oct 05) & 73019 & Chr osteomyelit-mult (Oct 05) \\
\hline 37221 & Angular blepharoconjunct (Oct 05) & 73020 & Osteomyelitis nos-unspec (Oct 05) \\
\hline 37230 & Conjunctivitis nos (Oct 05) & 73021 & Osteomyelitis nos-shlder (Oct 05) \\
\hline 37300 & Blepharitis nos (Oct 05) & 73022 & Osteomyelitis nos-up/arm (Oct 05) \\
\hline 37301 & Ulcerative blepharitis (Oct 05) & 73023 & Osteomyelit nos-forearm (Oct 05) \\
\hline 37311 & Hordeolum externum (Oct 05) & 73024 & Osteomyelitis nos-hand (Oct 05) \\
\hline 37312 & Hordeolum internum (Oct 05) & 73025 & Osteomyelitis nos-pelvis (Oct 05) \\
\hline 37313 & Abscess of eyelid (Oct 05) & 73026 & Osteomyelitis nos-1/leg (Oct 05) \\
\hline 37500 & Dacryoadenitis nos (Oct 05) & 73027 & Osteomyelitis nos-ankle (Oct 05) \\
\hline 37501 & Acute dacryoadenitis (Oct 05) & 73028 & Osteomyelit nos-oth site (Oct 05) \\
\hline 37530 & Dacryocystitis nos (Oct 05) & 73029 & Osteomyelitis nos-mult (Oct 05) \\
\hline 37531 & Acute canaliculitis (Oct 05) & 73030 & Periostitis-unspec (Oct 05) \\
\hline 37532 & Acute dacryocystitis (Oct 05) & 73031 & Periostitis-shlder (Oct 05) \\
\hline 37600 & Acute inflam nos, orbit (Oct 05) & 73032 & Periostitis-up/arm (Oct 05) \\
\hline 37601 & Orbital cellulitis (Oct 05) & 73033 & Periostitis-forearm (Oct 05) \\
\hline 37602 & Orbital periostitis (Oct 05) & 73034 & Periostitis-hand (Oct 05) \\
\hline 37603 & Orbital osteomyelitis (Oct 05) & 73035 & Periostitis-pelvis (Oct 05) \\
\hline 37604 & Tenonitis (Oct 05) & 73036 & Periostitis-l/leg (Oct 05) \\
\hline 38010 & Infec otitis externa nos (Oct 05) & 73037 & Periostitis-ankle (Oct 05) \\
\hline 38011 & Acute infection of pinna (Oct 05) & 73038 & Periostitis nec (Oct 05) \\
\hline 38012 & Acute swimmers' ear (Oct 05) & 73039 & Periostitis-mult (Oct 05) \\
\hline 38013 & Ac infect extern ear nec (Oct 05) & 73080 & Bone infect nec-unspec (Oct 05) \\
\hline 38014 & Malignant otitis externa (Oct 05) & 73081 & Bone infect nec-shlder (Oct 05) \\
\hline
\end{tabular}




\begin{tabular}{|c|c|c|c|}
\hline 38150 & Eustachian salping nos (Oct 05) & 73082 & Bone infect nec-up/arm (Oct 05) \\
\hline 38151 & Ac eustachian salping (Oct 05) & 73083 & Bone infect nec-forearm (Oct 05) \\
\hline 38200 & Ac supp otitis media nos (Oct 05) & 73084 & Bone infect nec-hand (Oct 05) \\
\hline 38201 & Ac supp om w drum rupt (Oct 05) & 73085 & Bone infect nec-pelvis (Oct 05) \\
\hline 38202 & Ac supp om in oth dis (Oct 05) & 73086 & Bone infect nec-l/leg (Oct 05) \\
\hline 3821 & Chr tubotymp supp otitis media (Oct 05 ) & 73087 & Bone infect nec-ankle (Oct 05) \\
\hline 3822 & Chr atticoantral supp otitis media(Oct 05 ) & 73088 & Bone infect nec-oth site (Oct 05) \\
\hline 3823 & Chr supp otitis media nos (Oct 05) & 73089 & Bone infect nec-mult (Oct 05) \\
\hline 3824 & Suppur otitis media nos (Oct 05) & 73090 & Bone infec nos-unsp site (Oct 05) \\
\hline 3829 & Otitis media nos (Oct 05) & 73091 & Bone infect nos-shlder (Oct 05) \\
\hline 38300 & Ac mastoiditis w/o compl (Oct 05) & 73092 & Bone infect nos-up/arm (Oct 05) \\
\hline 38301 & Subperi mastoid abscess (Oct 05) & 73093 & Bone infect nos-forearm (Oct 05) \\
\hline 38302 & Ac mastoiditis-compl nec (Oct 05) & 73094 & Bone infect nos-hand (Oct 05) \\
\hline 38320 & Petrositis nos (Oct 05) & 73095 & Bone infect nos-pelvis (Oct 05) \\
\hline 38321 & Acute petrositis (Oct 05) & 73096 & Bone infect nos-1/leg (Oct 05) \\
\hline 38400 & Acute myringitis nos (Oct 05) & 73097 & Bone infect nos-ankle (Oct 05) \\
\hline 38630 & Labyrinthitis nos (Oct 05) & 73098 & Bone infect nos-oth site (Oct 05) \\
\hline 38631 & Serous labyrinthitis (Oct 05) & 73099 & Bone infect nos-mult (Oct 05) \\
\hline 38632 & Circumscri labyrinthitis (Oct 05) & 7713 & Tetanus neonatorum (Oct 05) \\
\hline 38633 & Suppurativ labyrinthitis (Oct 05) & 7714 & Omphalitis of newborn (Oct 05) \\
\hline 4200 & Ac pericardit in oth dis (Oct 05$)$ & 7715 & Neonatal infec mastitis (Oct 05) \\
\hline 42090 & Acute pericarditis nos (Oct 05 ) & 77181 & Nb septicemia sepsis (Oct 05) \\
\hline 42099 & Acute pericarditis nec (Oct 05 ) & 77182 & $\mathrm{Nb}$ urinary tract infectn (Oct 05$)$ \\
\hline 4210 & Ac/subac bact endocard (Oct 05 ) & 77183 & Bacteremia of newborn (Oct 05) \\
\hline 4211 & Ac/subac infect endocard (Oct 05) & 77189 & Perinatal infection nec (Oct 05) \\
\hline 4219 & Ac/subac endocardit nos (Oct 05) & 7775 & Necrot enterocolitis nb (Oct 05) \\
\hline 42292 & Septic myocarditis (Oct 05) & 7854 & Gangrene (Oct 05) \\
\hline 4610 & Ac maxillary sinusitis (Oct 05 ) & 78552 & Septic shock (Oct 05) \\
\hline 4611 & Ac frontal sinusitis (Oct 05 ) & 7907 & Bacteremia (Oct 05) \\
\hline 4612 & Ac ethmoidal sinusitis (Oct 05) & 9101 & Abrasion head-infected (Oct 05) \\
\hline 4613 & Ac sphenoidal sinusitis (Oct 05) & 9103 & Blister head-infected (Oct 05) \\
\hline 4618 & Other acute sinusitis (Oct 05) & 9105 & Insect bite head-infect (Oct 05) \\
\hline 4619 & Acute sinusitis nos (Oct 05) & 9107 & Foreign body head-infect (Oct 05) \\
\hline 462 & Acute pharyngitis (Oct 05) & 9109 & Superf inj head nec-inf (Oct 05) \\
\hline 463 & Acute tonsillitis (Oct 05) & 9111 & Abrasion trunk-infected (Oct 05) \\
\hline 46430 & Ac epiglottitis no obstr (Oct 05) & 9113 & Blister trunk-infected (Oct 05) \\
\hline 46431 & Ac epiglottitis w obstr (Oct 05) & 9115 & Insect bite trunk-infec (Oct 05) \\
\hline 4660 & Acute bronchitis (Oct 05) & 9117 & Foreign body trunk-infec (Oct 05) \\
\hline 475 & Peritonsillar abscess (Oct 05) & 9119 & Superf inj trnk nec-inf (Oct 05) \\
\hline 47822 & Parapharyngeal abscess (Oct 05) & 9121 & Abrasion shldr/arm-infec (Oct 05) \\
\hline 47824 & Retropharyngeal abscess (Oct 05) & 9123 & Blister shoulder/arm-inf (Oct 05) \\
\hline 481 & Pneumococcal pneumonia (Oct 05) & 9125 & Insect bite shld/arm-inf (Oct 05) \\
\hline 4820 & K. Pneumoniae pneumonia (Oct 05) & 9127 & Fb shoulder/arm-infect (Oct 05) \\
\hline 4821 & Pseudomonal pneumonia (Oct 05) & 9129 & Superf inj shldr nec-inf (Oct 05) \\
\hline 4822 & H.influenzae pneumonia (Oct 05) & 9131 & Abrasion forearm-infect (Oct 05) \\
\hline 48230 & Streptococcal pneumn nos (Oct 05) & 9133 & Blister forearm-infected (Oct 05) \\
\hline 48231 & Pneumonia strptococcus a (Oct 05) & 9135 & Insect bite forearm-inf (Oct 05) \\
\hline 48232 & Pneumonia strptococcus b (Oct 05) & 9137 & Foreign body forearm-inf (Oct 05) \\
\hline 48239 & Pneumonia oth strep (Oct 05) & 9139 & Suprf inj forarm nec-inf (Oct 05) \\
\hline
\end{tabular}




\begin{tabular}{|c|c|c|c|}
\hline 48240 & Staphylococcal pneu nos (Oct 05) & 9141 & Abrasion hand-infected (Oct 05) \\
\hline 48241 & Staph aureus pneumonia (Oct 05) & 9143 & Blister hand-infected (Oct 05) \\
\hline 48249 & Staph pneumonia nec (Oct 05) & 9145 & Insect bite hand-infect (Oct 05) \\
\hline 48281 & Pneumonia anaerobes (Oct 05) & 9147 & Foreign body hand-infect (Oct 05) \\
\hline 48282 & Pneumonia e coli (Oct 05) & 9149 & Superf inj hand nec-inf (Oct 05) \\
\hline 48283 & Pneumo oth grm-neg bact (Oct 05) & 9151 & Abrasion finger-infected (Oct 05) \\
\hline 48284 & Legionnaires' disease (Oct 05) & 9153 & Blister finger-infected (Oct 05) \\
\hline 48289 & Pneumonia oth spcf bact (Oct 05) & 9155 & Insect bite finger-infec (Oct 05) \\
\hline 4829 & Bacterial pneumonia nos (Oct 05) & 9157 & Foreign body finger-inf (Oct 05) \\
\hline 4843 & Pneumonia in whooping cough (Oct & 9159 & Suprf inj finger nec-inf (Oct 05) \\
\hline 4845 & Pneumonia in anthrax (Oct 05) & 9161 & Abrasion hip/leg-infect (Oct 05) \\
\hline 4848 & Pneumonia in other inf dis (Oct 05) & 9163 & Blister hip \& leg-infect (Oct 05) \\
\hline 485 & Bronchopneumonia org nos (Oct & 9165 & Insect bite hip/leg-inf (Oct 05) \\
\hline 486 & Pneumonia, organism nos (Oct 05) & 9167 & Foreign bdy hip/leg-inf (Oct 05) \\
\hline 490 & Bronchitis nos (Oct 05) & 9169 & Superf inj leg nec-infec (Oct 05) \\
\hline 49122 & Obs chr bronc w ac bronc (Oct 05 ) & 9171 & Abrasion foot/toe-infec (Oct 05) \\
\hline 4941 & Bronchiectasis w ac exac (Oct 05) & 9173 & Blister foot \& toe-infec (Oct 05) \\
\hline 5100 & Empyema with fistula (Oct 05) & 9175 & Insect bite foot/toe-inf (Oct 05) \\
\hline 5109 & Empyema w/o fistula (Oct 05) & 9177 & Foreign bdy foot/toe-inf (Oct 05) \\
\hline 5111 & Bact pleur/effus not tb (Oct 05) & 9179 & Superf inj foot nec-inf (Oct 05) \\
\hline 5130 & Abscess of lung (Oct 05) & 9191 & Abrasion nec-infected (Oct 05) \\
\hline 5131 & Abscess of mediastinum (Oct 05) & 9193 & Blister nec-infected (Oct 05) \\
\hline 51901 & Tracheostomy infection (Oct 05) & 9195 & Insect bite nec-infected (Oct 05) \\
\hline 5192 & Mediastinitis (Oct 05) & 9197 & Superficial fb nec-infec (Oct 05) \\
\hline 5220 & Pulpitis (Oct 05) & 9199 & Superfic inj nec-infect (Oct 05) \\
\hline 5225 & Periapical abscess (Oct 05) & 99590 & Sirs, nos (Oct 05) \\
\hline 5227 & Periapical absc w sinus (Oct 05) & 99591 & Sirs-infect w/o org dysf (Oct 05) \\
\hline 5230 & Acute gingivitis (Oct 05) & 99592 & Sirs-infect w organ dysf (Oct 05) \\
\hline 5233 & Acute periodontitis (Oct 05) & 99660 & $\begin{array}{l}\text { Infect inflamm device implant graft nos (Oct } \\
\text { 05) }\end{array}$ \\
\hline 5264 & Inflammation of jaw (Oct 05) & 99661 & $\begin{array}{l}\text { Infect inflamm cardiac device implant graft } \\
\text { (Oct 05) }\end{array}$ \\
\hline 5273 & Salivary gland abscess (Oct 05) & 99662 & $\begin{array}{l}\text { Infect inflamm vascular device implant graft } \\
\text { (Oct 05) }\end{array}$ \\
\hline 5283 & Cellulitis/abscess mouth (Oct 05) & 99663 & $\begin{array}{l}\text { Infect inflamm nerv device implant graft } \\
\text { (Oct 05) }\end{array}$ \\
\hline 53641 & Gastrostomy infection (Oct 05) & 99664 & Infect inflamm urinary cath (Oct 05) \\
\hline 5400 & Ac append $\mathrm{w}$ peritonitis & 99665 & $\begin{array}{l}\text { Infect inflamm gu device implant graft (Oct } \\
\text { 05) }\end{array}$ \\
\hline 5401 & Abscess of appendix & 99666 & Infect inflamm joint prosth (Oct 05) \\
\hline 5409 & Acute appendicitis nos & 99667 & $\begin{array}{l}\text { Infect inflamm oth orthop device implant } \\
\text { graft nos (Oct 05) }\end{array}$ \\
\hline 541 & Appendicitis nos & 99669 & $\begin{array}{l}\text { Infect inflamm oth device implant graft (Oct } \\
\text { 05) }\end{array}$ \\
\hline 542 & Other appendicitis & 99762 & Infection amputat stump (Oct 05) \\
\hline 56201 & Dvrtcli sml int w/o hmrg & 99851 & Infected postop seroma (Oct 05) \\
\hline 56203 & Dvrtcli sml int w hmrhg & 99859 & Other postop infection (Oct 05) \\
\hline 56211 & Dvrtcli colon w/o hmrhg & 9993 & Infec compl med care nec (Oct 05) \\
\hline
\end{tabular}


Code List W: ICD-10-WHO codes for denominator calculation (refer to codes below)

\begin{tabular}{|c|l|l|l|}
\hline $\begin{array}{c}\text { App } \\
\text { No. }\end{array}$ & \multicolumn{1}{|c|}{ Code List } & \multicolumn{1}{c|}{ Indicator } & \multicolumn{1}{c|}{ Function } \\
\hline W-1 & $\begin{array}{l}\text { ICD-10-WHO } \\
\text { immunocompromised } \\
\text { state codes }\end{array}$ & $\begin{array}{l}\text { Catheter-Related } \\
\text { Bloodstream Infection, } \\
\text { Postoperative sepsis }\end{array}$ & $\begin{array}{l}\text { Denominator exclusion, if principal diagnosis } \\
\text { or secondary diagnosis }\end{array}$ \\
\hline W-2 & $\begin{array}{l}\text { ICD-10-WHO cancer } \\
\text { codes }\end{array}$ & $\begin{array}{l}\text { Catheter-Related } \\
\text { Bloodstream Infection, } \\
\text { Postoperative sepsis }\end{array}$ & $\begin{array}{l}\text { Denominator exclusion, if principal diagnosis } \\
\text { or secondary diagnosis }\end{array}$ \\
\hline W-10 codes & $\begin{array}{l}\text { ICD-10-WHO } \\
\text { for infections }\end{array}$ & Postoperative sepsis & Denominator exclusion, if principal diagnosis \\
\hline
\end{tabular}

\section{W-1 ICD-10-WHO immunocompromised state codes}

\begin{tabular}{|l|l|}
\hline B20.0 & HIV disease resulting in mycobacterial infection \\
\hline B20.1 & HIV disease resulting in other bacterial infections \\
\hline B20.2 & HIV disease resulting in cytomegaloviral disease \\
\hline B20.3 & HIV disease resulting in other viral infections \\
\hline B20.4 & HIV disease resulting in candidiasis \\
\hline B20.5 & HIV disease resulting in other mycoses \\
\hline B20.6 & HIV disease resulting in Pneumocystis carinii pneumonia \\
\hline B20.7 & HIV disease resulting in multiple infections \\
\hline B20.8 & HIV disease resulting in other infectious and parasitic diseases \\
\hline B20.9 & HIV disease resulting in unspecified infectious or parasitic disease \\
\hline B21.0 & HIV disease resulting in Kaposi's sarcoma \\
\hline B21.1 & HIV disease resulting in Burkitt's lymphoma \\
\hline B21.2 & HIV disease resulting in other types of non-Hodgkin's lymphoma \\
\hline B21.3 & $\begin{array}{l}\text { HIV disease resulting in other malignant neoplasms of lymphoid, haematopoietic and related } \\
\text { tissue }\end{array}$ \\
\hline B21.7 & HIV disease resulting in multiple malignant neoplasms \\
\hline B21.8 & HIV disease resulting in other malignant neoplasms \\
\hline B21.9 & HIV disease resulting in unspecified malignant neoplasm \\
\hline B22.0 & HIV disease resulting in encephalopathy \\
\hline B22.1 & HIV disease resulting in lymphoid interstitial pneumonitis \\
\hline B22.2 & HIV disease resulting in wasting syndrome \\
\hline B22.7 & HIV disease resulting in multiple diseases classified elsewhere \\
\hline B23.1 & HIV disease resulting in (persistent) generalized lymphadenopathy \\
\hline B23.2 & $\begin{array}{l}\text { HIV disease resulting in haematological and immunological abnormalities, not elsewhere } \\
\text { classified }\end{array}$ \\
\hline B23.8 & HIV disease resulting in other specified conditions \\
\hline B24 & Unspecified human immunodeficiency virus [HIV] disease \\
\hline B59 & Pneumocystosis \\
\hline D47.1 & Chronic myeloproliferative disease \\
\hline D70 & Agranulocytosis \\
\hline D71 & Functional disorders of polymorphonuclear neutrophils \\
\hline D72.0 & Genetic anomalies of leukocytes \\
\hline D80.0 & Hereditary hypogammaglobulinaemia \\
\hline D80.1 & Nonfamilial hypogammaglobulinaemia \\
\hline & \\
\hline
\end{tabular}




\begin{tabular}{|c|c|}
\hline $\mathrm{D} 80.2$ & Selective deficiency of immunoglobulin A [IgA] \\
\hline D80.3 & Selective deficiency of immunoglobulin G [IgG] subclasses \\
\hline D80.4 & Selective deficiency of immunoglobulin M [IgM] \\
\hline D80.5 & Immunodeficiency with increased immunoglobulin M [IgM] \\
\hline D80.6 & $\begin{array}{llllll}\begin{array}{l}\text { Antibody } \\
\text { hyperimmunoglobulinaemia }\end{array} & \text { with } & \text { near-normal } & \text { immunoglobulins } & \text { or } & \text { with } \\
\end{array}$ \\
\hline D80.7 & Transient hypogammaglobulinaemia of infancy \\
\hline D80.8 & Other immunodeficiencies with predominantly antibody defects \\
\hline D80.9 & Immunodeficiency with predominantly antibody defects, unspecified \\
\hline D81.0 & Severe combined immunodeficiency [SCID] with reticular dysgenesis \\
\hline D81.1 & Severe combined immunodeficiency [SCID] with low T- and B-cell numbers \\
\hline D81.2 & Severe combined immunodeficiency [SCID] with low or normal B-cell numbers \\
\hline D81.3 & Adenosine deaminase [ADA] deficiency \\
\hline D81.4 & Nezelof's syndrome \\
\hline D81.5 & Purine nucleoside phosphorylase [PNP] deficiency \\
\hline D81.6 & Major histocompatibility complex class I deficiency \\
\hline D81.7 & Major histocompatibility complex class II deficiency \\
\hline D81.8 & Other combined immunodeficiencies \\
\hline D81.9 & Combined immunodeficiency, unspecified \\
\hline D82.0 & Wiskott-Aldrich syndrome \\
\hline D82.1 & Di George's syndrome \\
\hline D82.2 & Immunodeficiency with short-limbed stature \\
\hline D82.3 & Immunodeficiency following hereditary defective response to Epstein-Barr virus \\
\hline D82.4 & Hyperimmunoglobulin E [IgE] syndrome \\
\hline D82.8 & Immunodeficiency associated with other specified major defects \\
\hline D82.9 & Immunodeficiency associated with major defect, unspecified \\
\hline D83.0 & $\begin{array}{l}\text { Common variable immunodeficiency with predominant abnormalities of B-cell numbers and } \\
\text { function }\end{array}$ \\
\hline D83.1 & Common variable immunodeficiency with predominant immunoregulatory T-cell disorders \\
\hline D83.2 & Common variable immunodeficiency with autoantibodies to B- or T-cells \\
\hline D83.8 & Other common variable immunodeficiencies \\
\hline D83.9 & Common variable immunodeficiency, unspecified \\
\hline D84.0 & Lymphocyte function antigen-1 [LFA-1] defect \\
\hline D84.1 & Defects in the complement system \\
\hline D84.8 & Other specified immunodeficiencies \\
\hline D84.9 & Immunodeficiency, unspecified \\
\hline D89.8 & Other specified disorders involving the immune mechanism, not elsewhere classified \\
\hline D89.9 & Disorder involving the immune mechanism, unspecified \\
\hline E40 & Kwashiorkor \\
\hline E41 & Nutritional marasmus \\
\hline E42 & Marasmic kwashiorkor \\
\hline E43 & Unspecified severe protein-energy malnutrition \\
\hline $\mathrm{I} 12.0$ & Hypertensive renal disease with renal failure \\
\hline I13.1 & Hypertensive heart and renal disease with renal failure \\
\hline $\mathrm{I} 13.2$ & Hypertensive heart and renal disease with both (congestive) heart failure and renal failure \\
\hline K91.2 & Postsurgical malabsorption, not elsewhere classified \\
\hline N18.0 & End-stage renal disease \\
\hline N18.8 & Other chronic renal failure \\
\hline
\end{tabular}




\begin{tabular}{|l|l|}
\hline T86.0 & Bone-marrow transplant rejection \\
\hline T86.1 & Kidney transplant failure and rejection \\
\hline T86.2 & Heart transplant failure and rejection \\
\hline T86.3 & Heart-lung transplant failure and rejection \\
\hline T86.4 & Liver transplant failure and rejection \\
\hline T86.8 & Failure and rejection of other transplanted organs and tissues \\
\hline T86.9 & Failure and rejection of unspecified transplanted organ and tissue \\
\hline Y83.0 & Surgical Operation with transplant of whole organ or tissue \\
\hline Z49.0 & Preparatory care for dialysis \\
\hline Z49.1 & Extracorporeal dialysis \\
\hline Z49.2 & Other dialysis \\
\hline Z94.0 & Kidney transplant status \\
\hline Z94.1 & Heart transplant status \\
\hline Z94.2 & Lung transplant status \\
\hline Z94.3 & Heart and lungs transplant status \\
\hline Z94.4 & Liver transplant status \\
\hline Z94.8 & Other transplanted organ and tissue status \\
\hline Z94.9 & Transplanted organ and tissue status, unspecified \\
\hline
\end{tabular}

\section{W-2 ICD-10-WHO cancer codes}

\begin{tabular}{|l|l|}
\hline C00.0 & Malignant neoplasm: External upper lip \\
\hline C00.1 & Malignant neoplasm: External lower lip \\
\hline C00.2 & Malignant neoplasm: External lip, unspecified \\
\hline C00.3 & Malignant neoplasm: Upper lip, inner aspect \\
\hline C00.4 & Malignant neoplasm: Lower lip, inner aspect \\
\hline C00.5 & Malignant neoplasm: Lip, unspecified, inner aspect \\
\hline C00.6 & Malignant neoplasm: Commissure of lip \\
\hline C00.8 & Malignant neoplasm: Overlapping lesion of lip \\
\hline C00.9 & Malignant neoplasm: Lip, unspecified \\
\hline C01 & Malignant neoplasm of base of tongue \\
\hline C02.0 & Malignant neoplasm: Dorsal surface of tongue \\
\hline C02.1 & Malignant neoplasm: Border of tongue \\
\hline C02.2 & Malignant neoplasm: Ventral surface of tongue \\
\hline C02.3 & Malignant neoplasm: Anterior two-thirds of tongue, part unspecified \\
\hline C02.4 & Malignant neoplasm: Lingual tonsil \\
\hline C02.8 & Malignant neoplasm: Overlapping lesion of tongue \\
\hline C02.9 & Malignant neoplasm: Tongue, unspecified \\
\hline C03.0 & Malignant neoplasm: Upper gum \\
\hline C03.1 & Malignant neoplasm: Lower gum \\
\hline C03.9 & Malignant neoplasm: Gum, unspecified \\
\hline C04.0 & Malignant neoplasm: Anterior floor of mouth \\
\hline C04.1 & Malignant neoplasm: Lateral floor of mouth \\
\hline C04.8 & Malignant neoplasm: Overlapping lesion of floor of mouth \\
\hline C04.9 & Malignant neoplasm: Floor of mouth, unspecified \\
\hline C05.0 & Malignant neoplasm: Hard palate \\
\hline C05.1 & Malignant neoplasm: Soft palate \\
\hline C05.2 & Malignant neoplasm: Uvula \\
\hline C05.8 & Malignant neoplasm: Overlapping lesion of palate \\
\hline
\end{tabular}




\begin{tabular}{|c|c|}
\hline C05.9 & Malignant neoplasm: Palate, unspecified \\
\hline C06.0 & Malignant neoplasm: Cheek mucosa \\
\hline C06.1 & Malignant neoplasm: Vestibule of mouth \\
\hline C06.2 & Malignant neoplasm: Retromolar area \\
\hline C06.8 & Malignant neoplasm: Overlapping lesion of other and unspecified parts of mouth \\
\hline C06.9 & Malignant neoplasm: Mouth, unspecified \\
\hline $\mathrm{C} 07$ & Malignant neoplasm of parotid gland \\
\hline $\mathrm{C} 08.0$ & Malignant neoplasm: Submandibular gland \\
\hline C08.1 & Malignant neoplasm: Sublingual gland \\
\hline C08.8 & Malignant neoplasm: Overlapping lesion of major salivary glands \\
\hline C08.9 & Malignant neoplasm: Major salivary gland, unspecified \\
\hline C09.0 & Malignant neoplasm: Tonsillar fossa \\
\hline C09.1 & Malignant neoplasm: Tonsillar pillar (anterior)(posterior) \\
\hline $\mathrm{C} 09.8$ & Malignant neoplasm: Overlapping lesion of tonsil \\
\hline C09.9 & Malignant neoplasm: Tonsil, unspecified \\
\hline C10.0 & Malignant neoplasm: Vallecula \\
\hline C10.1 & Malignant neoplasm: Anterior surface of epiglottis \\
\hline C10.2 & Malignant neoplasm: Lateral wall of oropharynx \\
\hline C10.3 & Malignant neoplasm: Posterior wall of oropharynx \\
\hline C10.4 & Malignant neoplasm: Branchial cleft \\
\hline C10.8 & Malignant neoplasm: Overlapping lesion of oropharynx \\
\hline C10.9 & Malignant neoplasm: Oropharynx, unspecified \\
\hline C11.0 & Malignant neoplasm: Superior wall of nasopharynx \\
\hline C11.1 & Malignant neoplasm: Posterior wall of nasopharynx \\
\hline C11.2 & Malignant neoplasm: Lateral wall of nasopharynx \\
\hline C11.3 & Malignant neoplasm: Anterior wall of nasopharynx \\
\hline C11.8 & Malignant neoplasm: Overlapping lesion of nasopharynx \\
\hline C11.9 & Malignant neoplasm: Nasopharynx, unspecified \\
\hline $\mathrm{C} 12$ & Malignant neoplasm of piriform sinus \\
\hline C13.0 & Malignant neoplasm: Postcricoid region \\
\hline C13.1 & Malignant neoplasm: Aryepiglottic fold, hypopharyngeal aspect \\
\hline C13.2 & Malignant neoplasm: Posterior wall of hypopharynx \\
\hline C13.8 & Malignant neoplasm: Overlapping lesion of hypopharynx \\
\hline C13.9 & Malignant neoplasm: Hypopharynx, unspecified \\
\hline C14.0 & Malignant neoplasm: Pharynx, unspecified \\
\hline C14.2 & Malignant neoplasm: Waldeyer's ring \\
\hline C14.8 & Malignant neoplasm: Overlapping lesion of lip, oral cavity and pharynx \\
\hline $\mathrm{C} 15.0$ & Malignant neoplasm: Cervical part of oesophagus \\
\hline C15.1 & Malignant neoplasm: Thoracic part of oesophagus \\
\hline C15.2 & Malignant neoplasm: Abdominal part of oesophagus \\
\hline C15.3 & Malignant neoplasm: Upper third of oesophagus \\
\hline C15.4 & Malignant neoplasm: Middle third of oesophagus \\
\hline C15.5 & Malignant neoplasm: Lower third of oesophagus \\
\hline C15.8 & Malignant neoplasm: Overlapping lesion of oesophagus \\
\hline C15.9 & Malignant neoplasm: Oesophagus, unspecified \\
\hline $\mathrm{C} 16.0$ & Malignant neoplasm: Cardia \\
\hline C16.1 & Malignant neoplasm: Fundus of stomach \\
\hline C16.2 & Malignant neoplasm: Body of stomach \\
\hline
\end{tabular}




\begin{tabular}{|c|c|}
\hline C16.3 & Malignant neoplasm: Pyloric antrum \\
\hline C16.4 & Malignant neoplasm: Pylorus \\
\hline C16.5 & Malignant neoplasm: Lesser curvature of stomach, unspecified \\
\hline C16.6 & Malignant neoplasm: Greater curvature of stomach, unspecified \\
\hline C16.8 & Malignant neoplasm: Overlapping lesion of stomach \\
\hline C16.9 & Malignant neoplasm: Stomach, unspecified \\
\hline $\mathrm{C} 17.0$ & Malignant neoplasm: Duodenum \\
\hline C17.1 & Malignant neoplasm: Jejunum \\
\hline C17.2 & Malignant neoplasm: Ileum \\
\hline C17.3 & Malignant neoplasm: Meckel's diverticulum \\
\hline C17.8 & Malignant neoplasm: Overlapping lesion of small intestine \\
\hline C17.9 & Malignant neoplasm: Small intestine, unspecified \\
\hline C18.0 & Malignant neoplasm: Caecum \\
\hline C18.1 & Malignant neoplasm: Appendix \\
\hline C18.2 & Malignant neoplasm: Ascending colon \\
\hline C18.3 & Malignant neoplasm: Hepatic flexure \\
\hline C18.4 & Malignant neoplasm: Transverse colon \\
\hline C18.5 & Malignant neoplasm: Splenic flexure \\
\hline C18.6 & Malignant neoplasm: Descending colon \\
\hline C18.7 & Malignant neoplasm: Sigmoid colon \\
\hline C18.8 & Malignant neoplasm: Overlapping lesion of colon \\
\hline C18.9 & Malignant neoplasm: Colon, unspecified \\
\hline C19 & Malignant neoplasm of rectosigmoid junction \\
\hline $\mathrm{C} 20$ & Malignant neoplasm of rectum \\
\hline $\mathrm{C} 21.0$ & Malignant neoplasm: Anus, unspecified \\
\hline $\mathrm{C} 21.1$ & Malignant neoplasm: Anal canal \\
\hline $\mathrm{C} 21.2$ & Malignant neoplasm: Cloacogenic zone \\
\hline C21.8 & Malignant neoplasm: Overlapping lesion of rectum, anus and anal canal \\
\hline $\mathrm{C} 22.0$ & Malignant neoplasm: Liver cell carcinoma \\
\hline C22.1 & Malignant neoplasm: Intrahepatic bile duct carcinoma \\
\hline $\mathrm{C} 22.2$ & Malignant neoplasm: Hepatoblastoma \\
\hline $\mathrm{C} 22.3$ & Malignant neoplasm: Angiosarcoma of liver \\
\hline $\mathrm{C} 22.4$ & Malignant neoplasm: Other sarcomas of liver \\
\hline $\mathrm{C} 22.7$ & Malignant neoplasm: Other specified carcinomas of liver \\
\hline $\mathrm{C} 22.9$ & Malignant neoplasm: Liver, unspecified \\
\hline $\mathrm{C} 23$ & Malignant neoplasm of gallbladder \\
\hline $\mathrm{C} 24.0$ & Malignant neoplasm: Extrahepatic bile duct \\
\hline $\mathrm{C} 24.1$ & Malignant neoplasm: Ampulla of Vater \\
\hline $\mathrm{C} 24.8$ & Malignant neoplasm: Overlapping lesion of biliary tract \\
\hline $\mathrm{C} 24.9$ & Malignant neoplasm: Biliary tract, unspecified \\
\hline $\mathrm{C} 25.0$ & Malignant neoplasm: Head of pancreas \\
\hline $\mathrm{C} 25.1$ & Malignant neoplasm: Body of pancreas \\
\hline $\mathrm{C} 25.2$ & Malignant neoplasm: Tail of pancreas \\
\hline $\mathrm{C} 25.3$ & Malignant neoplasm: Pancreatic duct \\
\hline $\mathrm{C} 25.4$ & Malignant neoplasm: Endocrine pancreas \\
\hline $\mathrm{C} 25.7$ & Malignant neoplasm: Other parts of pancreas \\
\hline C25.8 & Malignant neoplasm: Overlapping lesion of pancreas \\
\hline $\mathrm{C} 25.9$ & Malignant neoplasm: Pancreas, unspecified \\
\hline
\end{tabular}




\begin{tabular}{|c|c|}
\hline $\mathrm{C} 26.0$ & Malignant neoplasm: Intestinal tract, part unspecified \\
\hline C26.1 & Malignant neoplasm: Spleen \\
\hline C26.8 & Malignant neoplasm: Overlapping lesion of digestive system \\
\hline C26.9 & Malignant neoplasm: Ill-defined sites within the digestive system \\
\hline C30.0 & Malignant neoplasm: Nasal cavity \\
\hline C30.1 & Malignant neoplasm: Middle ear \\
\hline C31.0 & Malignant neoplasm: Maxillary sinus \\
\hline C31.1 & Malignant neoplasm: Ethmoidal sinus \\
\hline C31.2 & Malignant neoplasm: Frontal sinus \\
\hline C31.3 & Malignant neoplasm: Sphenoidal sinus \\
\hline C31.8 & Malignant neoplasm: Overlapping lesion of accessory sinuses \\
\hline C31.9 & Malignant neoplasm: Accessory sinus, unspecified \\
\hline C32.0 & Malignant neoplasm: Glottis \\
\hline C32.1 & Malignant neoplasm: Supraglottis \\
\hline C32.2 & Malignant neoplasm: Subglottis \\
\hline C32.3 & Malignant neoplasm: Laryngeal cartilage \\
\hline C32.8 & Malignant neoplasm: Overlapping lesion of larynx \\
\hline C32.9 & Malignant neoplasm: Larynx, unspecified \\
\hline C33 & Malignant neoplasm of trachea \\
\hline C34.0 & Malignant neoplasm: Main bronchus \\
\hline C34.1 & Malignant neoplasm: Upper lobe, bronchus or lung \\
\hline C34.2 & Malignant neoplasm: Middle lobe, bronchus or lung \\
\hline C34.3 & Malignant neoplasm: Lower lobe, bronchus or lung \\
\hline C34.8 & Malignant neoplasm: Overlapping lesion of bronchus and lung \\
\hline C34.9 & Malignant neoplasm: Bronchus or lung, unspecified \\
\hline C37 & Malignant neoplasm of thymus \\
\hline C38.0 & Malignant neoplasm: Heart \\
\hline C38.1 & Malignant neoplasm: Anterior mediastinum \\
\hline C38.2 & Malignant neoplasm: Posterior mediastinum \\
\hline C38.3 & Malignant neoplasm: Mediastinum, part unspecified \\
\hline C38.4 & Malignant neoplasm: Pleura \\
\hline C38.8 & Malignant neoplasm: Overlapping lesion of heart, mediastinum and pleura \\
\hline C39.0 & Malignant neoplasm: Upper respiratory tract, part unspecified \\
\hline C39.8 & Malignant neoplasm: Overlapping lesion of respiratory and intrathoracic organs \\
\hline C39.9 & Malignant neoplasm: Ill-defined sites within the respiratory system \\
\hline C40.0 & Malignant neoplasm: Scapula and long bones of upper limb \\
\hline C40.1 & Malignant neoplasm: Short bones of upper limb \\
\hline C40.2 & Malignant neoplasm: Long bones of lower limb \\
\hline C40.3 & Malignant neoplasm: Short bones of lower limb \\
\hline C40.8 & Malignant neoplasm: Overlapping lesion of bone and articular cartilage of limbs \\
\hline C40.9 & Malignant neoplasm: Bone and articular cartilage of limb, unspecified \\
\hline C41.0 & Malignant neoplasm: Bones of skull and face \\
\hline C41.1 & Malignant neoplasm: Mandible \\
\hline C41.2 & Malignant neoplasm: Vertebral column \\
\hline C41.3 & Malignant neoplasm: Ribs, sternum and clavicle \\
\hline C41.4 & Malignant neoplasm: Pelvic bones, sacrum and coccyx \\
\hline C41.8 & Malignant neoplasm: Overlapping lesion of bone and articular cartilage \\
\hline C41.9 & Malignant neoplasm: Bone and articular cartilage, unspecified \\
\hline
\end{tabular}




\begin{tabular}{|c|c|}
\hline C43.0 & Malignant neoplasm: Malignant melanoma of lip \\
\hline C43.1 & Malignant neoplasm: Malignant melanoma of eyelid, including canthus \\
\hline C43.2 & Malignant neoplasm: Malignant melanoma of ear and external auricular canal \\
\hline C43.3 & Malignant neoplasm: Malignant melanoma of other and unspecified parts of face \\
\hline C43.4 & Malignant neoplasm: Malignant melanoma of scalp and neck \\
\hline C43.5 & Malignant neoplasm: Malignant melanoma of trunk \\
\hline C43.6 & Malignant neoplasm: Malignant melanoma of upper limb, including shoulder \\
\hline C43.7 & Malignant neoplasm: Malignant melanoma of lower limb, including hip \\
\hline C43.8 & Malignant neoplasm: Overlapping malignant melanoma of skin \\
\hline C43.9 & Malignant neoplasm: Malignant melanoma of skin, unspecified \\
\hline C45.0 & Mesothelioma of pleura \\
\hline C45.1 & Mesothelioma of peritoneum \\
\hline C45.2 & Mesothelioma of pericardium \\
\hline C45.7 & Mesothelioma of other sites \\
\hline C45.9 & Mesothelioma, unspecified \\
\hline C46.0 & Kaposi's sarcoma of skin \\
\hline C46.1 & Kaposi's sarcoma of soft tissue \\
\hline C46.2 & Kaposi's sarcoma of palate \\
\hline C46.3 & Kaposi's sarcoma of lymph nodes \\
\hline C46.7 & Kaposi's sarcoma of other sites \\
\hline C46.8 & Kaposi's sarcoma of multiple organs \\
\hline C46.9 & Kaposi's sarcoma, unspecified \\
\hline C47.0 & Malignant neoplasm: Peripheral nerves of head, face and neck \\
\hline C47.1 & Malignant neoplasm: Peripheral nerves of upper limb, including shoulder \\
\hline C47.2 & Malignant neoplasm: Peripheral nerves of lower limb, including hip \\
\hline C47.3 & Malignant neoplasm: Peripheral nerves of thorax \\
\hline C47.4 & Malignant neoplasm: Peripheral nerves of abdomen \\
\hline C47.5 & Malignant neoplasm: Peripheral nerves of pelvis \\
\hline C47.6 & Malignant neoplasm: Peripheral nerves of trunk, unspecified \\
\hline C47.8 & $\begin{array}{l}\text { Malignant neoplasm: Overlapping lesion of peripheral nerves and autonomic nervous } \\
\text { system }\end{array}$ \\
\hline C47.9 & Malignant neoplasm: Peripheral nerves and autonomic nervous system, unspecified \\
\hline C48.0 & Malignant neoplasm: Retroperitoneum \\
\hline C48.1 & Malignant neoplasm: Specified parts of peritoneum \\
\hline C48.2 & Malignant neoplasm: Peritoneum, unspecified \\
\hline C48.8 & Malignant neoplasm: Overlapping lesion of retroperitoneum and peritoneum \\
\hline C49.0 & Malignant neoplasm: Connective and soft tissue of head, face and neck \\
\hline C49.1 & Malignant neoplasm: Connective and soft tissue of upper limb, including shoulder \\
\hline C49.2 & Malignant neoplasm: Connective and soft tissue of lower limb, including hip \\
\hline C49.3 & Malignant neoplasm: Connective and soft tissue of thorax \\
\hline C49.4 & Malignant neoplasm: Connective and soft tissue of abdomen \\
\hline C49.5 & Malignant neoplasm: Connective and soft tissue of pelvis \\
\hline C49.6 & Malignant neoplasm: Connective and soft tissue of trunk, unspecified \\
\hline C49.8 & Malignant neoplasm: Overlapping lesion of connective and soft tissue \\
\hline C49.9 & Malignant neoplasm: Connective and soft tissue, unspecified \\
\hline $\mathrm{C} 50.0$ & Malignant neoplasm: Nipple and areola \\
\hline C50.1 & Malignant neoplasm: Central portion of breast \\
\hline C50.2 & Malignant neoplasm: Upper-inner quadrant of breast \\
\hline
\end{tabular}




\begin{tabular}{|c|c|}
\hline C50.3 & Malignant neoplasm: Lower-inner quadrant of breast \\
\hline C50.4 & Malignant neoplasm: Upper-outer quadrant of breast \\
\hline C50.5 & Malignant neoplasm: Lower-outer quadrant of breast \\
\hline C50.6 & Malignant neoplasm: Axillary tail of breast \\
\hline C50.8 & Malignant neoplasm: Overlapping lesion of breast \\
\hline C50.9 & Malignant neoplasm: Breast, unspecified \\
\hline C51.0 & Malignant neoplasm: Labium majus \\
\hline C51.1 & Malignant neoplasm: Labium minus \\
\hline C51.2 & Malignant neoplasm: Clitoris \\
\hline C51.8 & Malignant neoplasm: Overlapping lesion of vulva \\
\hline C51.9 & Malignant neoplasm: Vulva, unspecified \\
\hline $\mathrm{C} 52$ & Malignant neoplasm of vagina \\
\hline C53.0 & Malignant neoplasm: Endocervix \\
\hline C53.1 & Malignant neoplasm: Exocervix \\
\hline C53.8 & Malignant neoplasm: Overlapping lesion of cervix uteri \\
\hline C53.9 & Malignant neoplasm: Cervix uteri, unspecified \\
\hline C54.0 & Malignant neoplasm: Isthmus uteri \\
\hline C54.1 & Malignant neoplasm: Endometrium \\
\hline C54.2 & Malignant neoplasm: Myometrium \\
\hline C54.3 & Malignant neoplasm: Fundus uteri \\
\hline C54.8 & Malignant neoplasm: Overlapping lesion of corpus uteri \\
\hline C54.9 & Malignant neoplasm: Corpus uteri, unspecified \\
\hline $\mathrm{C} 55$ & Malignant neoplasm of uterus, part unspecified \\
\hline C56 & Malignant neoplasm of ovary \\
\hline C57.0 & Malignant neoplasm: Fallopian tube \\
\hline C57.1 & Malignant neoplasm: Broad ligament \\
\hline C57.2 & Malignant neoplasm: Round ligament \\
\hline C57.3 & Malignant neoplasm: Parametrium \\
\hline C57.4 & Malignant neoplasm: Uterine adnexa, unspecified \\
\hline C57.7 & Malignant neoplasm: Other specified female genital organs \\
\hline C57.8 & Malignant neoplasm: Overlapping lesion of female genital organs \\
\hline C57.9 & Malignant neoplasm: Female genital organ, unspecified \\
\hline $\mathrm{C} 58$ & Malignant neoplasm of placenta \\
\hline C60.0 & Malignant neoplasm: Prepuce \\
\hline C60.1 & Malignant neoplasm: Glans penis \\
\hline C60.2 & Malignant neoplasm: Body of penis \\
\hline C60.8 & Malignant neoplasm: Overlapping lesion of penis \\
\hline C60.9 & Malignant neoplasm: Penis, unspecified \\
\hline $\mathrm{C} 61$ & Malignant neoplasm of prostate \\
\hline C62.0 & Malignant neoplasm: Undescended testis \\
\hline C62.1 & Malignant neoplasm: Descended testis \\
\hline C62.9 & Malignant neoplasm: Testis, unspecified \\
\hline C63.0 & Malignant neoplasm: Epididymis \\
\hline C63.1 & Malignant neoplasm: Spermatic cord \\
\hline C63.2 & Malignant neoplasm: Scrotum \\
\hline C63.7 & Malignant neoplasm: Other specified male genital organs \\
\hline C63.8 & Malignant neoplasm: Overlapping lesion of male genital organs \\
\hline C63.9 & Malignant neoplasm: Male genital organ, unspecified \\
\hline
\end{tabular}




\begin{tabular}{|c|c|}
\hline C64 & Malignant neoplasm of kidney, except renal pelvis \\
\hline $\mathrm{C65}$ & Malignant neoplasm of renal pelvis \\
\hline C66 & Malignant neoplasm of ureter \\
\hline C67.0 & Malignant neoplasm: Trigone of bladder \\
\hline C67.1 & Malignant neoplasm: Dome of bladder \\
\hline C67.2 & Malignant neoplasm: Lateral wall of bladder \\
\hline C67.3 & Malignant neoplasm: Anterior wall of bladder \\
\hline C67.4 & Malignant neoplasm: Posterior wall of bladder \\
\hline C67.5 & Malignant neoplasm: Bladder neck \\
\hline C67.6 & Malignant neoplasm: Ureteric orifice \\
\hline C67.7 & Malignant neoplasm: Urachus \\
\hline C67.8 & Malignant neoplasm: Overlapping lesion of bladder \\
\hline C67.9 & Malignant neoplasm: Bladder, unspecified \\
\hline C68.0 & Malignant neoplasm: Urethra \\
\hline C68.1 & Malignant neoplasm: Paraurethral gland \\
\hline C68.8 & Malignant neoplasm: Overlapping lesion of urinary organs \\
\hline C68.9 & Malignant neoplasm: Urinary organ, unspecified \\
\hline C69.0 & Malignant neoplasm: Conjunctiva \\
\hline C69.1 & Malignant neoplasm: Cornea \\
\hline C69.2 & Malignant neoplasm: Retina \\
\hline C69.3 & Malignant neoplasm: Choroid \\
\hline C69.4 & Malignant neoplasm: Ciliary body \\
\hline C69.5 & Malignant neoplasm: Lacrimal gland and duct \\
\hline C69.6 & Malignant neoplasm: Orbit \\
\hline C69.8 & Malignant neoplasm: Overlapping lesion of eye and adnexa \\
\hline C69.9 & Malignant neoplasm: Eye, unspecified \\
\hline $\mathrm{C} 70.0$ & Malignant neoplasm: Cerebral meninges \\
\hline C70.1 & Malignant neoplasm: Spinal meninges \\
\hline C70.9 & Malignant neoplasm: Meninges, unspecified \\
\hline C71.0 & Malignant neoplasm: Cerebrum, except lobes and ventricles \\
\hline C71.1 & Malignant neoplasm: Frontal lobe \\
\hline $\mathrm{C} 71.2$ & Malignant neoplasm: Temporal lobe \\
\hline C71.3 & Malignant neoplasm: Parietal lobe \\
\hline C71.4 & Malignant neoplasm: Occipital lobe \\
\hline C71.5 & Malignant neoplasm: Cerebral ventricle \\
\hline C71.6 & Malignant neoplasm: Cerebellum \\
\hline C71.7 & Malignant neoplasm: Brain stem \\
\hline C71.8 & Malignant neoplasm: Overlapping lesion of brain \\
\hline C71.9 & Malignant neoplasm: Brain, unspecified \\
\hline C72.0 & Malignant neoplasm: Spinal cord \\
\hline C72.1 & Malignant neoplasm: Cauda equina \\
\hline C72.2 & Malignant neoplasm: Olfactory nerve \\
\hline C72.3 & Malignant neoplasm: Optic nerve \\
\hline C72.4 & Malignant neoplasm: Acoustic nerve \\
\hline C72.5 & Malignant neoplasm: Other and unspecified cranial nerves \\
\hline C72.8 & $\begin{array}{l}\text { Malignant neoplasm: Overlapping lesion of brain and other parts of central nervous } \\
\text { system }\end{array}$ \\
\hline C72.9 & Malignant neoplasm: Central nervous system, unspecified \\
\hline
\end{tabular}




\begin{tabular}{|c|c|}
\hline $\mathrm{C73}$ & Malignant neoplasm of thyroid gland \\
\hline C74.0 & Malignant neoplasm: Cortex of adrenal gland \\
\hline C74.1 & Malignant neoplasm: Medulla of adrenal gland \\
\hline C74.9 & Malignant neoplasm: Adrenal gland, unspecified \\
\hline C75.0 & Malignant neoplasm: Parathyroid gland \\
\hline C75.1 & Malignant neoplasm: Pituitary gland \\
\hline C75.2 & Malignant neoplasm: Craniopharyngeal duct \\
\hline C75.3 & Malignant neoplasm: Pineal gland \\
\hline C75.4 & Malignant neoplasm: Carotid body \\
\hline C75.5 & Malignant neoplasm: Aortic body and other paraganglia \\
\hline C75.8 & Malignant neoplasm: Pluriglandular involvement, unspecified \\
\hline C75.9 & Malignant neoplasm: Endocrine gland, unspecified \\
\hline C76.0 & Malignant neoplasm of other and ill-defined sites: Head, face and neck \\
\hline C76.1 & Malignant neoplasm of other and ill-defined sites: Thorax \\
\hline C76.2 & Malignant neoplasm of other and ill-defined sites: Abdomen \\
\hline C76.3 & Malignant neoplasm of other and ill-defined sites: Pelvis \\
\hline C76.4 & Malignant neoplasm of other and ill-defined sites: Upper limb \\
\hline C76.5 & Malignant neoplasm of other and ill-defined sites: Lower limb \\
\hline C76.7 & Malignant neoplasm of other and ill-defined sites: Other ill-defined sites \\
\hline C76.8 & $\begin{array}{l}\text { Malignant neoplasm of other and ill-defined sites: Overlapping lesion of other and ill- } \\
\text { defined sites }\end{array}$ \\
\hline C77.0 & Secondary and unspecified malignant neoplasm: Lymph nodes of head, face and neck \\
\hline C77.1 & Secondary and unspecified malignant neoplasm: Intrathoracic lymph nodes \\
\hline C77.2 & Secondary and unspecified malignant neoplasm: Intra-abdominal lymph nodes \\
\hline C77.3 & $\begin{array}{l}\text { Secondary and unspecified malignant neoplasm: Axillary and upper limb lymph } \\
\text { nodes }\end{array}$ \\
\hline C77.4 & $\begin{array}{l}\text { Secondary and unspecified malignant neoplasm: Inguinal and lower limb lymph } \\
\text { nodes }\end{array}$ \\
\hline C77.5 & Secondary and unspecified malignant neoplasm: Intrapelvic lymph nodes \\
\hline C77.8 & Secondary and unspecified malignant neoplasm: Lymph nodes of multiple regions \\
\hline C77.9 & Secondary and unspecified malignant neoplasm: Lymph node, unspecified \\
\hline C78.0 & Secondary malignant neoplasm of lung \\
\hline C78.1 & Secondary malignant neoplasm of mediastinum \\
\hline C78.2 & Secondary malignant neoplasm of pleura \\
\hline C78.3 & Secondary malignant neoplasm of other and unspecified respiratory organs \\
\hline C78.4 & Secondary malignant neoplasm of small intestine \\
\hline C78.5 & Secondary malignant neoplasm of large intestine and rectum \\
\hline C78.6 & Secondary malignant neoplasm of retroperitoneum and peritoneum \\
\hline C78.7 & Secondary malignant neoplasm of liver \\
\hline C78.8 & Secondary malignant neoplasm of other and unspecified digestive organs \\
\hline C79.0 & Secondary malignant neoplasm of kidney and renal pelvis \\
\hline C79.1 & Secondary malignant neoplasm of bladder and other and unspecified urinary organs \\
\hline C79.2 & Secondary malignant neoplasm of skin \\
\hline C79.3 & Secondary malignant neoplasm of brain and cerebral meninges \\
\hline C79.4 & Secondary malignant neoplasm of other and unspecified parts of nervous system \\
\hline C79.5 & Secondary malignant neoplasm of bone and bone marrow \\
\hline C79.6 & Secondary malignant neoplasm of ovary \\
\hline C79.7 & Secondary malignant neoplasm of adrenal gland \\
\hline
\end{tabular}




\begin{tabular}{|c|c|}
\hline C79.8 & Secondary malignant neoplasm of other specified sites \\
\hline $\mathrm{C} 80$ & Malignant neoplasm without specification of site \\
\hline C81.0 & Hodgkin's disease: Lymphocytic predominance \\
\hline C81.1 & Hodgkin's disease: Nodular sclerosis \\
\hline C81.2 & Hodgkin's disease: Mixed cellularity \\
\hline C81.3 & Hodgkin's disease: Lymphocytic depletion \\
\hline C81.7 & Hodgkin's disease: Other Hodgkin's disease \\
\hline C81.9 & Hodgkin's disease: Hodgkin's disease, unspecified \\
\hline C82.0 & Non-Hodgkin's lymphoma: Small cleaved cell, follicular \\
\hline C82.1 & Non-Hodgkin's lymphoma: Mixed small cleaved and large cell, follicular \\
\hline C82.2 & Non-Hodgkin's lymphoma: Large cell, follicular \\
\hline C82.7 & Other types of follicular non-Hodgkin's lymphoma \\
\hline C82.9 & Follicular non-Hodgkin's lymphoma, unspecified \\
\hline C83.0 & Non-Hodgkin's lymphoma: Small cell (diffuse) \\
\hline C83.1 & Non-Hodgkin's lymphoma: Small cleaved cell (diffuse) \\
\hline C83.2 & Non-Hodgkin's lymphoma: Mixed small and large cell (diffuse) \\
\hline C83.3 & Non-Hodgkin's lymphoma: Large cell (diffuse) \\
\hline C83.4 & Non-Hodgkin's lymphoma: Immunoblastic (diffuse) \\
\hline C83.5 & Non-Hodgkin's lymphoma: Lymphoblastic (diffuse) \\
\hline C83.6 & Non-Hodgkin's lymphoma: Undifferentiated (diffuse) \\
\hline C83.7 & Burkitt's tumour \\
\hline C83.8 & Other types of diffuse non-Hodgkin's lymphoma \\
\hline C83.9 & Diffuse non-Hodgkin's lymphoma, unspecified \\
\hline C84.0 & Mycosis fungoides \\
\hline C84.1 & Sezary's disease \\
\hline C84.2 & T-zone lymphoma \\
\hline C84.3 & Lymphoepithelioid lymphoma \\
\hline C84.4 & Peripheral T-cell lymphoma \\
\hline C84.5 & Other and unspecified T-cell lymphomas \\
\hline C85.0 & Lymphosarcoma \\
\hline C85.1 & B-cell lymphoma, unspecified \\
\hline C85.7 & Other specified types of non-Hodgkin's lymphoma \\
\hline C85.9 & Non-Hodgkin's lymphoma, unspecified type \\
\hline C88.0 & Waldenstr,m's macroglobulinaemia \\
\hline C90.0 & Multiple myeloma \\
\hline C90.1 & Plasma cell leukaemia \\
\hline C90.2 & Plasmacytoma, extramedullary \\
\hline C91.0 & Acute lymphoblastic leukaemia \\
\hline C91.1 & Chronic lymphocytic leukaemia \\
\hline C91.2 & Subacute lymphocytic leukaemia \\
\hline C91.3 & Prolymphocytic leukaemia \\
\hline C91.4 & Hairy-cell leukaemia \\
\hline C91.5 & Adult T-cell leukaemia \\
\hline C91.7 & Other lymphoid leukaemia \\
\hline C91.9 & Lymphoid leukaemia, unspecified \\
\hline C92.0 & Acute myeloid leukaemia \\
\hline C92.1 & Chronic myeloid leukaemia \\
\hline C92.2 & Subacute myeloid leukaemia \\
\hline
\end{tabular}




\begin{tabular}{|c|c|}
\hline C92.3 & Myeloid sarcoma \\
\hline C92.4 & Acute promyelocytic leukaemia \\
\hline C92.5 & Acute myelomonocytic leukaemia \\
\hline C92.7 & Other myeloid leukaemia \\
\hline C92.9 & Myeloid leukaemia, unspecified \\
\hline C93.0 & Acute monocytic leukaemia \\
\hline C93.1 & Chronic monocytic leukaemia \\
\hline C93.2 & Subacute monocytic leukaemia \\
\hline C93.7 & Other monocytic leukaemia \\
\hline C93.9 & Monocytic leukaemia, unspecified \\
\hline C94.0 & Acute erythraemia and erythroleukaemia \\
\hline C94.1 & Chronic erythraemia \\
\hline C94.2 & Acute megakaryoblastic leukaemia \\
\hline C94.3 & Mast cell leukaemia \\
\hline C94.4 & Acute panmyelosis \\
\hline C94.5 & Acute myelofibrosis \\
\hline C94.7 & Other specified leukaemias \\
\hline C95.0 & Acute leukaemia of unspecified cell type \\
\hline C95.1 & Chronic leukaemia of unspecified cell type \\
\hline C95.2 & Subacute leukaemia of unspecified cell type \\
\hline C95.7 & Other leukaemia of unspecified cell type \\
\hline C95.9 & Leukaemia, unspecified \\
\hline C96.0 & Letterer-Siwe disease \\
\hline C96.1 & Malignant histiocytosis \\
\hline C96.2 & Malignant mast cell tumour \\
\hline C96.3 & True histiocytic lymphoma \\
\hline C96.7 & Other specified malignant neoplasms of lymphoid, haematopoietic and related tissue \\
\hline C96.9 & Malignant neoplasm of lymphoid, haematopoietic and related tissue, unspecified \\
\hline C97 & Malignant neoplasms of independent (primary) multiple sites \\
\hline Z85.0 & Personal history of malignant neoplasm of digestive organs \\
\hline Z85.1 & Personal history of malignant neoplasm of trachea, bronchus and lung \\
\hline Z85.2 & Personal history of malignant neoplasm of other respiratory and intrathoracic organs \\
\hline Z85.3 & Personal history of malignant neoplasm of breast \\
\hline Z85.4 & Personal history of malignant neoplasm of genital organs \\
\hline Z85.5 & Personal history of malignant neoplasm of urinary tract \\
\hline Z85.6 & Personal history of leukaemia \\
\hline Z85.7 & $\begin{array}{l}\text { Personal history of other malignant neoplasms of lymphoid, haematopoietic and } \\
\text { related tissues }\end{array}$ \\
\hline Z85.8 & Personal history of malignant neoplasms of other organs and systems \\
\hline Z85.9 & Personal history of malignant neoplasm, unspecified \\
\hline
\end{tabular}

\section{W-10 ICD-10-WHO codes for infections}

\begin{tabular}{|c|l|}
\hline A00.0 & Cholera due to Vibrio cholerae 01, biovar cholerae \\
\hline A00.1 & Cholera due to Vibrio cholerae 01, biovar eltor \\
\hline A00.9 & Cholera, unspecified \\
\hline A01.0 & Typhoid fever \\
\hline A01.1 & Paratyphoid fever A \\
\hline A01.2 & Paratyphoid fever B \\
\hline A01.3 & Paratyphoid fever C \\
\hline
\end{tabular}




\begin{tabular}{|c|c|}
\hline A01.4 & Paratyphoid fever, unspecified \\
\hline A02.0 & Salmonella enteritis \\
\hline A02.1 & Salmonella septicaemia \\
\hline A02.2 & Localized salmonella infections \\
\hline A02.8 & Other specified salmonella infections \\
\hline A02.9 & Salmonella infection, unspecified \\
\hline A03.0 & Shigellosis due to Shigella dysenteriae \\
\hline A03.1 & Shigellosis due to Shigella flexneri \\
\hline A03.2 & Shigellosis due to Shigella boydii \\
\hline A03.3 & Shigellosis due to Shigella sonnei \\
\hline A03.8 & Other shigellosis \\
\hline A03.9 & Shigellosis, unspecified \\
\hline A04.0 & Enteropathogenic Escherichia coli infection \\
\hline A04.1 & Enterotoxigenic Escherichia coli infection \\
\hline A04.2 & Enteroinvasive Escherichia coli infection \\
\hline A04.3 & Enterohaemorrhagic Escherichia coli infection \\
\hline $\mathrm{A} 04.4$ & Other intestinal Escherichia coli infections \\
\hline A04.5 & Campylobacter enteritis \\
\hline A04.6 & Enteritis due to Yersinia enterocolitica \\
\hline A04.7 & Enterocolitis due to Clostridium difficile \\
\hline A04.8 & Other specified bacterial intestinal infections \\
\hline A04.9 & Bacterial intestinal infection, unspecified \\
\hline A05.0 & Foodborne staphylococcal intoxication \\
\hline A05.1 & Botulism \\
\hline A05.2 & Foodborne Clostridium perfringens [Clostridium welchii] intoxication \\
\hline A05.3 & Foodborne Vibrio parahaemolyticus intoxication \\
\hline A05.4 & Foodborne Bacillus cereus intoxication \\
\hline A05.8 & Other specified bacterial foodborne intoxications \\
\hline A05.9 & Bacterial foodborne intoxication, unspecified \\
\hline A20.0 & Bubonic plague \\
\hline A20.1 & Cellulocutaneous plague \\
\hline A20.2 & Pneumonic plague \\
\hline A20.3 & Plague meningitis \\
\hline A20.7 & Septicaemic plague \\
\hline A20.8 & Other forms of plague \\
\hline A20.9 & Plague, unspecified \\
\hline A21.0 & Ulceroglandular tularaemia \\
\hline A21.1 & Oculoglandular tularaemia \\
\hline A21.2 & Pulmonary tularaemia \\
\hline A21.3 & Gastrointestinal tularaemia \\
\hline A21.7 & Generalized tularaemia \\
\hline A21.8 & Other forms of tularaemia \\
\hline A21.9 & Tularaemia, unspecified \\
\hline A22.0 & Cutaneous anthrax \\
\hline A22.1 & Pulmonary anthrax \\
\hline A22.2 & Gastrointestinal anthrax \\
\hline A22.7 & Anthrax septicaemia \\
\hline A22.8 & Other forms of anthrax \\
\hline A22.9 & Anthrax, unspecified \\
\hline
\end{tabular}




\begin{tabular}{|c|c|}
\hline A23.0 & Brucellosis due to Brucella melitensis \\
\hline A23.1 & Brucellosis due to Brucella abortus \\
\hline A23.2 & Brucellosis due to Brucella suis \\
\hline A23.3 & Brucellosis due to Brucella canis \\
\hline A23.8 & Other brucellosis \\
\hline A23.9 & Brucellosis, unspecified \\
\hline A24.0 & Glanders \\
\hline A24.1 & Acute and fulminating melioidosis \\
\hline A24.2 & Subacute and chronic melioidosis \\
\hline A24.3 & Other melioidosis \\
\hline A24.4 & Melioidosis, unspecified \\
\hline A25.0 & Spirillosis \\
\hline A25.1 & Streptobacillosis \\
\hline A25.9 & Rat-bite fever, unspecified \\
\hline A26.0 & Cutaneous erysipeloid \\
\hline A26.7 & Erysipelothrix septicaemia \\
\hline A26.8 & Other forms of erysipeloid \\
\hline A26.9 & Erysipeloid, unspecified \\
\hline A28.0 & Pasteurellosis \\
\hline A28.1 & Cat-scratch disease \\
\hline A28.2 & Extraintestinal yersiniosis \\
\hline A28.8 & Other specified zoonotic bacterial diseases, not elsewhere classified \\
\hline A28.9 & Zoonotic bacterial disease, unspecified \\
\hline A32.0 & Cutaneous listeriosis \\
\hline A32.1 & Listerial meningitis and meningoencephalitis \\
\hline A32.7 & Listerial septicaemia \\
\hline A32.8 & Other forms of listeriosis \\
\hline A32.9 & Listeriosis, unspecified \\
\hline A33 & Tetanus neonatorum \\
\hline A34 & Obstetrical tetanus \\
\hline A35 & Other tetanus \\
\hline A36.0 & Pharyngeal diphtheria \\
\hline A36.1 & Nasopharyngeal diphtheria \\
\hline A36.2 & Laryngeal diphtheria \\
\hline A36.3 & Cutaneous diphtheria \\
\hline A36.8 & Other diphtheria \\
\hline A36.9 & Diphtheria, unspecified \\
\hline A37.0 & Whooping cough due to Bordetella pertussis \\
\hline A37.1 & Whooping cough due to Bordetella parapertussis \\
\hline A37.8 & Whooping cough due to other Bordetella species \\
\hline A37.9 & Whooping cough, unspecified \\
\hline A38 & Scarlet fever \\
\hline A39.0 & Meningococcal meningitis \\
\hline A39.1 & Waterhouse-Friderichsen syndrome \\
\hline A39.2 & Acute meningococcaemia \\
\hline A39.3 & Chronic meningococcaemia \\
\hline A39.4 & Meningococcaemia, unspecified \\
\hline A39.5 & Meningococcal heart disease \\
\hline A39.8 & Other meningococcal infections \\
\hline
\end{tabular}




\begin{tabular}{|c|c|}
\hline A39.9 & Meningococcal infection, unspecified \\
\hline A40.0 & Septicaemia due to streptococcus, group A \\
\hline A40.1 & Septicaemia due to streptococcus, group B \\
\hline A40.2 & Septicaemia due to streptococcus, group D \\
\hline A40.3 & Septicaemia due to Streptococcus pneumoniae \\
\hline A40.8 & Other streptococcal septicaemia \\
\hline A40.9 & Streptococcal septicaemia, unspecified \\
\hline A41.0 & Septicaemia due to Staphylococcus aureus \\
\hline A41.1 & Septicaemia due to other specified staphylococcus \\
\hline A41.2 & Septicaemia due to unspecified staphylococcus \\
\hline A41.3 & Septicaemia due to Haemophilus influenzae \\
\hline A41.4 & Septicaemia due to anaerobes \\
\hline A41.5 & Septicaemia due to other Gram-negative organisms \\
\hline A41.8 & Other specified septicaemia \\
\hline A41.9 & Septicaemia, unspecified \\
\hline A42.0 & Pulmonary actinomycosis \\
\hline A42.1 & Abdominal actinomycosis \\
\hline A42.2 & Cervicofacial actinomycosis \\
\hline A42.7 & Actinomycotic septicaemia \\
\hline A42.8 & Other forms of actinomycosis \\
\hline A42.9 & Actinomycosis, unspecified \\
\hline A43.0 & Pulmonary nocardiosis \\
\hline A43.1 & Cutaneous nocardiosis \\
\hline A43.8 & Other forms of nocardiosis \\
\hline A43.9 & Nocardiosis, unspecified \\
\hline A46 & Erysipelas \\
\hline A48.0 & Gas gangrene \\
\hline A48.1 & Legionnaires' disease \\
\hline A48.2 & Nonpneumonic Legionnaires' disease [Pontiac fever] \\
\hline A48.3 & Toxic shock syndrome \\
\hline A48.4 & Brazilian purpuric fever \\
\hline A48.8 & Other specified bacterial diseases \\
\hline A49.0 & Staphylococcal infection, unspecified \\
\hline A49.1 & Streptococcal infection, unspecified \\
\hline A49.2 & Haemophilus influenzae infection, unspecified \\
\hline A49.3 & Mycoplasma infection, unspecified \\
\hline A49.8 & Other bacterial infections of unspecified site \\
\hline A49.9 & Bacterial infection, unspecified \\
\hline A54.0 & $\begin{array}{l}\text { Gonococcal infection of lower genitourinary tract without periurethral or accessory gland } \\
\text { abscess }\end{array}$ \\
\hline A54.1 & $\begin{array}{l}\text { Gonococcal infection of lower genitourinary tract with periurethral and accessory gland } \\
\text { abscess }\end{array}$ \\
\hline A54.2 & Gonococcal pelviperitonitis and other gonococcal genitourinary infections \\
\hline A54.3 & Gonococcal infection of eye \\
\hline A54.4 & Gonococcal infection of musculoskeletal system \\
\hline A54.5 & Gonococcal pharyngitis \\
\hline A54.6 & Gonococcal infection of anus and rectum \\
\hline A54.8 & Other gonococcal infections \\
\hline A54.9 & Gonococcal infection, unspecified \\
\hline
\end{tabular}




\begin{tabular}{|c|c|}
\hline B95.0 & Streptococcus, group A, as the cause of diseases classified to other chapters \\
\hline B95.1 & Streptococcus, group B, as the cause of diseases classified to other chapters \\
\hline B95.2 & Streptococcus, group D, as the cause of diseases classified to other chapters \\
\hline B95.3 & Streptococcus pneumoniae as the cause of diseases classified to other chapters \\
\hline B95.4 & Other streptococcus as the cause of diseases classified to other chapters \\
\hline B95.5 & Unspecified streptococcus as the cause of diseases classified to other chapters \\
\hline B95.6 & Staphylococcus aureus as the cause of diseases classified to other chapters \\
\hline B95.7 & Other staphylococcus as the cause of diseases classified to other chapters \\
\hline B95.8 & Unspecified staphylococcus as the cause of diseases classified to other chapters \\
\hline B96.0 & $\begin{array}{l}\text { Mycoplasma pneumoniae [M. pneumoniae] as the cause of diseases classified to other } \\
\text { chapters }\end{array}$ \\
\hline B96.1 & Klebsiella pneumoniae [K. pneumoniae] as the cause of diseases classified to other chapters \\
\hline B96.2 & Escherichia coli [E. coli] as the cause of diseases classified to other chapters \\
\hline B96.3 & Haemophilus influenzae [H. influenzae] as the cause of diseases classified to other chapters \\
\hline B96.4 & Proteus (mirabilis)(morganii) as the cause of diseases classified to other chapters \\
\hline B96.5 & $\begin{array}{l}\text { Pseudomonas (aeruginosa)(mallei)(pseudomallei) as the cause of diseases classified to } \\
\text { other chapters }\end{array}$ \\
\hline B96.6 & Bacillus fragilis [B. fragilis] as the cause of diseases classified to other chapters \\
\hline B96.7 & Clostridium perfringens [C. perfringens] as the cause of diseases classified to other chapters \\
\hline B96.8 & Other specified bacterial agents as the cause of diseases classified to other chapters \\
\hline D73.3 & Abscess of spleen \\
\hline E32.1 & Abscess of thymus \\
\hline G00.0 & Haemophilus meningitis \\
\hline G00.1 & Pneumococcal meningitis \\
\hline G00.2 & Streptococcal meningitis \\
\hline G00.3 & Staphylococcal meningitis \\
\hline G00.8 & Other bacterial meningitis \\
\hline G00.9 & Bacterial meningitis, unspecified \\
\hline G03.8 & Meningitis due to other specified causes \\
\hline G03.9 & Meningitis, unspecified \\
\hline G04.2 & Bacterial meningoencephalitis and meningomyelitis, not elsewhere classified \\
\hline G06.0 & Intracranial abscess and granuloma \\
\hline G06.1 & Intraspinal abscess and granuloma \\
\hline G06.2 & Extradural and subdural abscess, unspecified \\
\hline G07 & Intracranial and intraspinal abscess and granuloma in diseases classified elsewhere \\
\hline H00.0 & Hordeolum and other deep inflammation of eyelid \\
\hline H01.0 & Blepharitis \\
\hline H01.8 & Other specified inflammation of eyelid \\
\hline H04.0 & Dacryoadenitis \\
\hline H04.3 & Acute and unspecified inflammation of lacrimal passages \\
\hline H04.4 & Chronic inflammation of lacrimal passages \\
\hline H05.0 & Acute inflammation of orbit \\
\hline H10.0 & Mucopurulent conjunctivitis \\
\hline H10.2 & Other acute conjunctivitis \\
\hline H10.3 & Acute conjunctivitis, unspecified \\
\hline H10.5 & Blepharoconjunctivitis \\
\hline H10.8 & Other conjunctivitis \\
\hline H10.9 & Conjunctivitis, unspecified \\
\hline H13.1 & Conjunctivitis in infectious and parasitic diseases classified elsewhere \\
\hline
\end{tabular}




\begin{tabular}{|c|c|}
\hline H44.0 & Purulent endophthalmitis \\
\hline H60.0 & Abscess of external ear \\
\hline H60.1 & Cellulitis of external ear \\
\hline H60.2 & Malignant otitis externa \\
\hline H60.3 & Other infective otitis externa \\
\hline H60.9 & Otitis externa, unspecified \\
\hline H66.0 & Acute suppurative otitis media \\
\hline H66.1 & Chronic tubotympanic suppurative otitis media \\
\hline H66.2 & Chronic atticoantral suppurative otitis media \\
\hline H66.3 & Other chronic suppurative otitis media \\
\hline H66.4 & Suppurative otitis media, unspecified \\
\hline H66.9 & Otitis media, unspecified \\
\hline H68.0 & Eustachian salpingitis \\
\hline H70.0 & Acute mastoiditis \\
\hline H70.2 & Petrositis \\
\hline H73.0 & Acute myringitis \\
\hline H83.0 & Labyrinthitis \\
\hline I30.1 & Infective pericarditis \\
\hline I30.8 & Other forms of acute pericarditis \\
\hline I30.9 & Acute pericarditis, unspecified \\
\hline I32.0 & Pericarditis in bacterial diseases classified elsewhere \\
\hline I33.0 & Acute and subacute infective endocarditis \\
\hline I33.9 & Acute endocarditis, unspecified \\
\hline $\mathrm{I} 40.0$ & Infective myocarditis \\
\hline J01.0 & Acute maxillary sinusitis \\
\hline J01.1 & Acute frontal sinusitis \\
\hline $\mathrm{J} 01.2$ & Acute ethmoidal sinusitis \\
\hline J01.3 & Acute sphenoidal sinusitis \\
\hline $\mathrm{J} 01.4$ & Acute pansinusitis \\
\hline J01.8 & Other acute sinusitis \\
\hline J01.9 & Acute sinusitis, unspecified \\
\hline J02.0 & Streptococcal pharyngitis \\
\hline J02.8 & Acute pharyngitis due to other specified organisms \\
\hline J02.9 & Acute pharyngitis, unspecified \\
\hline J03.0 & Streptococcal tonsillitis \\
\hline J03.8 & Acute tonsillitis due to other specified organisms \\
\hline J03.9 & Acute tonsillitis, unspecified \\
\hline J05.1 & Acute epiglottitis \\
\hline J13 & Pneumonia due to Streptococcus pneumoniae \\
\hline J14 & Pneumonia due to Haemophilus influenzae \\
\hline $\mathrm{J} 15.0$ & Pneumonia due to Klebsiella pneumoniae \\
\hline $\mathrm{J} 15.1$ & Pneumonia due to Pseudomonas \\
\hline $\mathrm{J} 15.2$ & Pneumonia due to staphylococcus \\
\hline J15.3 & Pneumonia due to streptococcus, group B \\
\hline $\mathrm{J} 15.4$ & Pneumonia due to other streptococci \\
\hline $\mathrm{J} 15.5$ & Pneumonia due to Escherichia coli \\
\hline J15.6 & Pneumonia due to other aerobic Gram-negative bacteria \\
\hline $\mathrm{J} 15.7$ & Pneumonia due to Mycoplasma pneumoniae \\
\hline $\mathrm{J} 15.8$ & Other bacterial pneumonia \\
\hline
\end{tabular}




\begin{tabular}{|c|c|}
\hline J15.9 & Bacterial pneumonia, unspecified \\
\hline J17.0 & Pneumonia in bacterial diseases classified elsewhere \\
\hline J18.0 & Bronchopneumonia, unspecified \\
\hline J18.1 & Lobar pneumonia, unspecified \\
\hline J18.8 & Other pneumonia, organism unspecified \\
\hline $\mathrm{J} 20.0$ & Acute bronchitis due to Mycoplasma pneumoniae \\
\hline J20.1 & Acute bronchitis due to Haemophilus influenzae \\
\hline $\mathrm{J} 20.2$ & Acute bronchitis due to streptococcus \\
\hline J34.0 & Abscess, furuncle and carbuncle of nose \\
\hline J36 & Peritonsillar abscess \\
\hline J39.0 & Retropharyngeal and parapharyngeal abscess \\
\hline J39.1 & Other abscess of pharynx \\
\hline $\mathrm{J} 40$ & Bronchitis, not specified as acute or chronic \\
\hline J44.0 & Chronic obstructive pulmonary disease with acute lower respiratory infection \\
\hline J85.0 & Gangrene and necrosis of lung \\
\hline J85.1 & Abscess of lung with pneumonia \\
\hline J85.2 & Abscess of lung without pneumonia \\
\hline J85.3 & Abscess of mediastinum \\
\hline J86.0 & Pyothorax with fistula \\
\hline J86.9 & Pyothorax without fistula \\
\hline J90 & Pleural effusion, not elsewhere classified \\
\hline J98.5 & Diseases of mediastinum, not elsewhere classified \\
\hline K04.0 & Pulpitis \\
\hline K04.6 & Periapical abscess with sinus \\
\hline K04.7 & Periapical abscess without sinus \\
\hline K05.0 & Acute gingivitis \\
\hline K05.2 & Acute periodontitis \\
\hline K10.2 & Inflammatory conditions of jaws \\
\hline K11.3 & Abscess of salivary gland \\
\hline K12.2 & Cellulitis and abscess of mouth \\
\hline K35.0 & Acute appendicitis with generalized peritonitis \\
\hline K35.1 & Acute appendicitis with peritoneal abscess \\
\hline K35.9 & Acute appendicitis, unspecified \\
\hline K36 & Other appendicitis \\
\hline K37 & Unspecified appendicitis \\
\hline K57.0 & Diverticular disease of small intestine with perforation and abscess \\
\hline K57.1 & Diverticular disease of small intestine without perforation or abscess \\
\hline K57.2 & Diverticular disease of large intestine with perforation and abscess \\
\hline K57.3 & Diverticular disease of large intestine without perforation or abscess \\
\hline K57.4 & Diverticular disease of both small and large intestine with perforation and abscess \\
\hline K57.5 & Diverticular disease of both small and large intestine without perforation or abscess \\
\hline K57.8 & Diverticular disease of intestine, part unspecified, with perforation and abscess \\
\hline K57.9 & Diverticular disease of intestine, part unspecified, without perforation or abscess \\
\hline K61.0 & Anal abscess \\
\hline K61.1 & Rectal abscess \\
\hline K61.2 & Anorectal abscess \\
\hline K61.3 & Ischiorectal abscess \\
\hline K61.4 & Intrasphincteric abscess \\
\hline K63.0 & Abscess of intestine \\
\hline
\end{tabular}




\begin{tabular}{|c|c|}
\hline K65.0 & Acute peritonitis \\
\hline K65.8 & Other peritonitis \\
\hline K65.9 & Peritonitis, unspecified \\
\hline K67.1 & Gonococcal peritonitis \\
\hline K75.0 & Abscess of liver \\
\hline K75.1 & Phlebitis of portal vein \\
\hline K80.0 & Calculus of gallbladder with acute cholecystitis \\
\hline K80.3 & Calculus of bile duct with cholangitis \\
\hline K80.4 & Calculus of bile duct with cholecystitis \\
\hline K81.0 & Acute cholecystitis \\
\hline K81.8 & Other cholecystitis \\
\hline K81.9 & Cholecystitis, unspecified \\
\hline K82.2 & Perforation of gallbladder \\
\hline K83.0 & Cholangitis \\
\hline K83.2 & Perforation of bile duct \\
\hline K85.0 & Idiopathic acute pancreatitis \\
\hline K85.1 & Biliary acute pancreatitis \\
\hline K85.2 & Alcohol-induced acute pancreatitis \\
\hline K85.3 & Drug-induced acute pancreatitis \\
\hline K85.8 & Other acute pancreatitis \\
\hline K85.9 & Acute pancreatitis, unspecified \\
\hline L00 & Staphylococcal scalded skin syndrome \\
\hline L01.0 & Impetigo [any organism] [any site] \\
\hline L01.1 & Impetiginization of other dermatoses \\
\hline L02.0 & Cutaneous abscess, furuncle and carbuncle of face \\
\hline L02.1 & Cutaneous abscess, furuncle and carbuncle of neck \\
\hline L02.2 & Cutaneous abscess, furuncle and carbuncle of trunk \\
\hline L02.3 & Cutaneous abscess, furuncle and carbuncle of buttock \\
\hline L02.4 & Cutaneous abscess, furuncle and carbuncle of limb \\
\hline L02.8 & Cutaneous abscess, furuncle and carbuncle of other sites \\
\hline L02.9 & Cutaneous abscess, furuncle and carbuncle, unspecified \\
\hline L03.0 & Cellulitis of finger and toe \\
\hline L03.1 & Cellulitis of other parts of limb \\
\hline L03.2 & Cellulitis of face \\
\hline L03.3 & Cellulitis of trunk \\
\hline L03.8 & Cellulitis of other sites \\
\hline L03.9 & Cellulitis, unspecified \\
\hline L04.0 & Acute lymphadenitis of face, head and neck \\
\hline L04.1 & Acute lymphadenitis of trunk \\
\hline L04.2 & Acute lymphadenitis of upper limb \\
\hline L04.3 & Acute lymphadenitis of lower limb \\
\hline L04.8 & Acute lymphadenitis of other sites \\
\hline L04.9 & Acute lymphadenitis, unspecified \\
\hline L05.0 & Pilonidal cyst with abscess \\
\hline L08.0 & Pyoderma \\
\hline L08.8 & Other specified local infections of skin and subcutaneous tissue \\
\hline L08.9 & Local infection of skin and subcutaneous tissue, unspecified \\
\hline L30.3 & Infective dermatitis \\
\hline M00.0 & Staphylococcal arthritis and polyarthritis \\
\hline
\end{tabular}




\begin{tabular}{|c|c|}
\hline M00.1 & Pneumococcal arthritis and polyarthritis \\
\hline M00.2 & Other streptococcal arthritis and polyarthritis \\
\hline M00.8 & Arthritis and polyarthritis due to other specified bacterial agents \\
\hline M00.9 & Pyogenic arthritis, unspecified \\
\hline M03.0 & Postmeningococcal arthritis \\
\hline M03.1 & Postinfective arthropathy in syphilis \\
\hline M03.2 & Other postinfectious arthropathies in diseases classified elsewhere \\
\hline M03.6 & Reactive arthropathy in other diseases classified elsewhere \\
\hline M46.2 & Osteomyelitis of vertebra \\
\hline M60.0 & Infective myositis \\
\hline M63.0 & Myositis in bacterial diseases classified elsewhere \\
\hline M72..6 & Necrotizing fasciitis \\
\hline M73.0 & Gonococcal bursitis \\
\hline M86.0 & Acute haematogenous osteomyelitis \\
\hline M86.1 & Other acute osteomyelitis \\
\hline M86.2 & Subacute osteomyelitis \\
\hline M86.3 & Chronic multifocal osteomyelitis \\
\hline M86.4 & Chronic osteomyelitis with draining sinus \\
\hline M86.5 & Other chronic haematogenous osteomyelitis \\
\hline M86.6 & Other chronic osteomyelitis \\
\hline M86.8 & Other osteomyelitis \\
\hline M86.9 & Osteomyelitis, unspecified \\
\hline M90.1 & Periostitis in other infectious diseases classified elsewhere \\
\hline N10 & Acute tubulo-interstitial nephritis \\
\hline N12 & Tubulo-interstitial nephritis, not specified as acute or chronic \\
\hline N13.6 & Pyonephrosis \\
\hline N15.1 & Renal and perinephric abscess \\
\hline N30.0 & Acute cystitis \\
\hline N30.8 & Other cystitis \\
\hline N30.9 & Cystitis, unspecified \\
\hline N34.0 & Urethral abscess \\
\hline N39.0 & Urinary tract infection, site not specified \\
\hline N41.0 & Acute prostatitis \\
\hline N41.2 & Abscess of prostate \\
\hline N41.3 & Prostatocystitis \\
\hline N41.8 & Other inflammatory diseases of prostate \\
\hline N41.9 & Inflammatory disease of prostate, unspecified \\
\hline N43.1 & Infected hydrocele \\
\hline N45.0 & Orchitis, epididymitis and epididymo-orchitis with abscess \\
\hline N45.9 & Orchitis, epididymitis and epididymo-orchitis without abscess \\
\hline N48.1 & Balanoposthitis \\
\hline $\mathrm{N} 48.2$ & Other inflammatory disorders of penis \\
\hline N49.0 & Inflammatory disorders of seminal vesicle \\
\hline N49.1 & Inflammatory disorders of spermatic cord, tunica vaginalis and vas deferens \\
\hline N49.2 & Inflammatory disorders of scrotum \\
\hline N49.8 & Inflammatory disorders of other specified male genital organs \\
\hline N49.9 & Inflammatory disorder of unspecified male genital organ \\
\hline N51.0 & Disorders of prostate in diseases classified elsewhere \\
\hline N51.1 & Disorders of testis and epididymis in diseases classified elsewhere \\
\hline
\end{tabular}




\begin{tabular}{|c|c|}
\hline N61 & Inflammatory disorders of breast \\
\hline N70.0 & Acute salpingitis and oophoritis \\
\hline N70.1 & Chronic salpingitis and oophoritis \\
\hline N70.9 & Salpingitis and oophoritis, unspecified \\
\hline N71.0 & Acute inflammatory disease of uterus \\
\hline N71.9 & Inflammatory disease of uterus, unspecified \\
\hline N72 & Inflammatory disease of cervix uteri \\
\hline N73.0 & Acute parametritis and pelvic cellulitis \\
\hline N73.1 & Chronic parametritis and pelvic cellulitis \\
\hline N73.2 & Unspecified parametritis and pelvic cellulitis \\
\hline N73.3 & Female acute pelvic peritonitis \\
\hline N73.5 & Female pelvic peritonitis, unspecified \\
\hline N73.9 & Female pelvic inflammatory disease, unspecified \\
\hline N75.1 & Abscess of Bartholin's gland \\
\hline N76.0 & Acute vaginitis \\
\hline N76.1 & Subacute and chronic vaginitis \\
\hline N76.2 & Acute vulvitis \\
\hline N76.3 & Subacute and chronic vulvitis \\
\hline N76.4 & Abscess of vulva \\
\hline N76.8 & Other specified inflammation of vagina and vulva \\
\hline O03.0 & Spontaneous abortion, incomplete, complicated by genital tract and pelvic infection \\
\hline O03.5 & $\begin{array}{l}\text { Spontaneous abortion, complete or unspecified, complicated by genital tract and pelvic } \\
\text { infection }\end{array}$ \\
\hline O04.0 & Medical abortion, incomplete, complicated by genital tract and pelvic infection \\
\hline O04.5 & Medical abortion, complete or unspecified, complicated by genital tract and pelvic infection \\
\hline O05.0 & Other abortion, incomplete, complicated by genital tract and pelvic infection \\
\hline O05.5 & Other abortion, complete or unspecified, complicated by genital tract and pelvic infection \\
\hline O06.0 & Unspecified abortion, incomplete, complicated by genital tract and pelvic infection \\
\hline O06.5 & $\begin{array}{l}\text { Unspecified abortion, complete or unspecified, complicated by genital tract and pelvic } \\
\text { infection }\end{array}$ \\
\hline O07.0 & Failed medical abortion, complicated by genital tract and pelvic infection \\
\hline O07.5 & $\begin{array}{l}\text { Other and unspecified failed attempted abortion, complicated by genital tract and pelvic } \\
\text { infection }\end{array}$ \\
\hline O08.0 & Genital tract and pelvic infection following abortion and ectopic and molar pregnancy \\
\hline O23.0 & Infections of kidney in pregnancy \\
\hline O23.1 & Infections of bladder in pregnancy \\
\hline O23.2 & Infections of urethra in pregnancy \\
\hline O23.3 & Infections of other parts of urinary tract in pregnancy \\
\hline O23.4 & Unspecified infection of urinary tract in pregnancy \\
\hline O23.5 & Infections of the genital tract in pregnancy \\
\hline O23.9 & Other and unspecified genitourinary tract infection in pregnancy \\
\hline O41.1 & Infection of amniotic sac and membranes \\
\hline O86.1 & Other infection of genital tract following delivery \\
\hline O86.2 & Urinary tract infection following delivery \\
\hline O86.3 & Other genitourinary tract infections following delivery \\
\hline O86.4 & Pyrexia of unknown origin following delivery \\
\hline O91.0 & Infection of nipple associated with childbirth \\
\hline O91.1 & Abscess of breast associated with childbirth \\
\hline O91.2 & Nonpurulent mastitis associated with childbirth \\
\hline
\end{tabular}




\begin{tabular}{|c|c|}
\hline O98.2 & Gonorrhoea complicating pregnancy, childbirth and the puerperium \\
\hline O98.8 & $\begin{array}{l}\text { Other maternal infectious and parasitic diseases complicating pregnancy, childbirth and the } \\
\text { puerperium }\end{array}$ \\
\hline O98.9 & $\begin{array}{l}\text { Unspecified maternal infectious or parasitic disease complicating pregnancy, childbirth and } \\
\text { the puerperium }\end{array}$ \\
\hline P36.0 & Sepsis of newborn due to streptococcus, group B \\
\hline P36.1 & Sepsis of newborn due to other and unspecified streptococci \\
\hline P36.2 & Sepsis of newborn due to Staphylococcus aureus \\
\hline P36.3 & Sepsis of newborn due to other and unspecified staphylococci \\
\hline P36.4 & Sepsis of newborn due to Escherichia coli \\
\hline P36.5 & Sepsis of newborn due to anaerobes \\
\hline P36.8 & Other bacterial sepsis of newborn \\
\hline P36.9 & Bacterial sepsis of newborn, unspecified \\
\hline P38 & Omphalitis of newborn with or without mild haemorrhage \\
\hline P39.0 & Neonatal infective mastitis \\
\hline P39.2 & Intra-amniotic infection of fetus, not elsewhere classified \\
\hline P39.3 & Neonatal urinary tract infection \\
\hline P39.4 & Neonatal skin infection \\
\hline P39.8 & Other specified infections specific to the perinatal period \\
\hline P39.9 & Infection specific to the perinatal period, unspecified \\
\hline P77 & Necrotizing enterocolitis of fetus and newborn \\
\hline R02 & Gangrene, not elsewhere classified \\
\hline R57.8 & Other shock \\
\hline T80.2 & Infections following infusion, transfusion and therapeutic injection \\
\hline T81.4 & Infection following a procedure, not elsewhere classified \\
\hline T82.6 & Infection and inflammatory reaction due to cardiac valve prosthesis \\
\hline T82.7 & $\begin{array}{l}\text { Infection and inflammatory reaction due to other cardiac and vascular devices, implants and } \\
\text { grafts }\end{array}$ \\
\hline T83.5 & $\begin{array}{l}\text { Infection and inflammatory reaction due to prosthetic device, implant and graft in urinary } \\
\text { system }\end{array}$ \\
\hline T83.6 & $\begin{array}{l}\text { Infection and inflammatory reaction due to prosthetic device, implant and graft in genital } \\
\text { tract }\end{array}$ \\
\hline T84.5 & Infection and inflammatory reaction due to internal joint prosthesis \\
\hline T84.6 & Infection and inflammatory reaction due to internal fixation device [any site] \\
\hline T84.7 & $\begin{array}{l}\text { Infection and inflammatory reaction due to other internal orthopaedic prosthetic devices, } \\
\text { implants and grafts }\end{array}$ \\
\hline T84.9 & Unspecified complication of internal orthopaedic prosthetic device, implant and graft \\
\hline T85.7 & $\begin{array}{l}\text { Infection and inflammatory reaction due to other internal prosthetic devices, implants and } \\
\text { grafts }\end{array}$ \\
\hline T87.4 & Infection of amputation stump \\
\hline T88.0 & Infection following immunization \\
\hline
\end{tabular}


Code List P: ICD-9-CM Procedure codes for assignment of operative discharges (denominators in PSIs 12 and 13) ${ }^{7}$

Procedure code list adopetd from Agency for Healthcare Research and Quality, PSI Technical Specifications, Version 3.2, March 2008 Patient Safety Indicators Download. AHRQ Quality Indicators. March 2007. Agency for Healthcare Research and Quality, Rockville, MD. http://www.qualityindicators.ahrq.gov/psi_download.htm 


\begin{tabular}{|c|c|}
\hline 0044 & $\begin{array}{l}\text { PROC-VESSEL } \\
\text { OCT06- }\end{array}$ \\
\hline 050 & MPL CRT PACE \\
\hline 51 & LLAT SYS \\
\hline 052 & MP/REP LEAD LF VEN SYS \\
\hline 0053 & IMP/REP CRT PACEMAKR GEN \\
\hline 0054 & IMP/REP CRT DEFIB GENAT \\
\hline 0056 & $\begin{array}{llll}\text { INS/REP } & \text { IMPL } & \text { SENSOR } & \text { LEAD } \\
\text { OCT06- } & & & \\
\end{array}$ \\
\hline 0057 & $\begin{array}{llll}\text { IMP/REP } & \text { SUBCUE } & \text { CARD } & \text { DEV } \\
\text { OCT06- } & & & \\
\end{array}$ \\
\hline 0061 & $\begin{array}{l}\text { PERC ANGIO PRECEREB VES (OCT } \\
\text { 04) }\end{array}$ \\
\hline 0062 & $\begin{array}{l}\text { PERC ANGIO INTRACRAN } \\
\text { (OCT 04) }\end{array}$ \\
\hline 0066 & $\begin{array}{l}\text { PTCA OR CORONARY ATHER } \\
\text { OCT05- }\end{array}$ \\
\hline 0070 & $\begin{array}{l}\text { REV HIP REPL-ACETAB/FEM } \\
\text { OCT05- }\end{array}$ \\
\hline 0071 & $\begin{array}{l}\text { REV HIP REPL-ACETAB } \\
\text { OCT05- }\end{array}$ \\
\hline 0072 & REV HIP REPL-FEM COMP OCT05- \\
\hline 0073 & REV HIP REPL-LINER/HEAD OCT05- \\
\hline 0074 & $\begin{array}{l}\text { HIP REPL } \\
\text { OCT05- }\end{array}$ \\
\hline 0075 & $\begin{array}{l}\text { HIP REP } \\
\text { OCT05- }\end{array}$ \\
\hline 0076 & SURF-CERMC/CERMC \\
\hline 0077 & $\begin{array}{l}\text { HIP REPL } \\
\text { OCT06- }\end{array}$ \\
\hline 0080 & $\begin{array}{l}\text { REV KNEE REI } \\
\text { OCT05- }\end{array}$ \\
\hline 0081 & $\begin{array}{lll}\text { REV KNEE } & \text { REPL-TIBIA } & \text { COMP } \\
\text { OCT05- } & & \\
\end{array}$ \\
\hline 0082 & $\begin{array}{l}\text { REV KNEE REPL-FEMUR } \\
\text { OCT05- }\end{array}$ \\
\hline 0083 & $\begin{array}{l}\text { REV KNEE REPLACE-PATELLA } \\
\text { OCT05- }\end{array}$ \\
\hline 0084 & REV KNEE REPL-TIBIA LIN OCT05- \\
\hline 0085 & $\begin{array}{l}\text { RESRF } \\
\text { OCT06- }\end{array}$ \\
\hline 0086 & $\begin{array}{l}\text { RESRF } \\
\text { OCT06- }\end{array}$ \\
\hline 0087 & HIPPART-ACETABLUM \\
\hline 0112 & OPE \\
\hline 0114 & $\mathrm{C}$ \\
\hline 0115 & SKU \\
\hline 0118 & $\mathrm{OTH}$ \\
\hline 0119 & ROCEDURE \\
\hline 0121 & CRANIAL SI \\
\hline
\end{tabular}

\begin{tabular}{|c|c|}
\hline 0122 & REMOV INTRACRAN STIMULAT \\
\hline 0123 & REOPEN CRANIOTOMY SITE \\
\hline 0124 & OTHER CRANIOTOMY \\
\hline 0125 & OTHER CRANIECTOMY \\
\hline 0126 & $\begin{array}{ll}\text { INS CATH-CRANIAL } & \text { CAVITY } \\
\text { OCT05- } & \\
\end{array}$ \\
\hline 0127 & $\begin{array}{lll}\text { REM } & \text { CATH-CRANIAL } & \text { CAVITY } \\
\text { OCT05- } & & \\
\end{array}$ \\
\hline 0128 & $\begin{array}{lll}\text { INTRACEREB } & \text { CTH-BURR } & \text { HOLE } \\
\text { OCT06- } & & \\
\end{array}$ \\
\hline 0131 & INCISE CEREBRAL MENINGES \\
\hline 0132 & LOBOTOMY \& TRACTOTOMY \\
\hline 0139 & OTHER BRAIN INCISION \\
\hline 0141 & THALAMUS OPERATIONS \\
\hline 0142 & GLOBUS PALLIDUS OPS \\
\hline 0151 & EX CEREB MENINGEAL LES \\
\hline 0152 & HEMISPHERECTOMY \\
\hline 0153 & BRAIN LOBECTOMY \\
\hline 0159 & OTHER BRAIN EXCISION \\
\hline 016 & EXCISE SKULL LESION \\
\hline 0201 & LINEAR CRANIEC \\
\hline 0202 & ELEVATE SKULL FX FRAGMNT \\
\hline 0203 & SKULL FLAP FORMATION \\
\hline 0204 & BONE GRAFT TO SKULL \\
\hline 0205 & SKULL PLATE INSERTION \\
\hline 0206 & CRANIAL OSTEOPLASTY NEC \\
\hline 0207 & SKULL PLATE REMOVAL \\
\hline 0211 & SIMPLE SUTURE OF DURA \\
\hline 0212 & BRAIN MENINGE REPAIR NEC \\
\hline 0213 & MENINGE VESSEL LIGATION \\
\hline 0214 & CHOROID PLEXECTOMY \\
\hline 022 & VENTRICULOSTOMY \\
\hline 0231 & VENTRICL SHUNT-HEAD/NECK \\
\hline 0232 & VENTRI SHUNT-CIRCULA SYS \\
\hline 0233 & VENTRICL SHUNT-THORAX \\
\hline 0234 & VENTRICL SHUNT-ABDOMEN \\
\hline 0235 & VENTRI SHUNT-UNINARY SYS \\
\hline 0239 & OTHER VENTRICULAR SHUNT \\
\hline 0242 & REPLACE VENTRICLE SHUNT \\
\hline 0243 & REMOVE VENTRICLE SHUNT \\
\hline 0291 & LYSIS CORTICAL ADHESION \\
\hline 0292 & BRAIN REPAIR \\
\hline 0293 & IMPLANT BRAIN STIMULATOR \\
\hline 0294 & INSERT/REPLAC SKULL TONG \\
\hline 0299 & SKULL \& BRAIN OP NEC \\
\hline 0301 & REMOVAL FB SPINAL CANAL \\
\hline 0302 & REOPEN LAMINECTOMY SITE \\
\hline 0309 & SPINAL CANAL EXPLOR NEC \\
\hline 031 & INTRASPIN NERVE ROOT DIV \\
\hline 0321 & PERCUTANEOUS CHORDOTOMY \\
\hline 0329 & DOTOMY \\
\hline
\end{tabular}




\begin{tabular}{|l|l|}
\hline 0332 & SPINAL CORD/MENINGES BX \\
\hline 0339 & OTHER SPINAL DX PROC \\
\hline 034 & EXCIS SPINAL CORD LESION \\
\hline 0351 & SPINE MENINGOCELE REPAIR \\
\hline 0352 & MYELOMENINGOCEL REPAIR \\
\hline 0353 & VERTEBRAL FX REPAIR \\
\hline 0359 & SPINAL STRUCT REPAIR NEC \\
\hline 036 & SPINAL CORD ADHESIOLYSIS \\
\hline 0371 & SUBARACH-PERITON SHUNT \\
\hline 0372 & SUBARACH-URETERAL SHUNT \\
\hline 0379 & OTH SPINAL THECAL SHUNT \\
\hline 0393 & INSERT SPINAL STIMULATOR \\
\hline 0394 & REMOVE SPINAL STIMULATOR \\
\hline 0397 & REVISE SPINE THECA SHUNT \\
\hline 0398 & REMOVE SPINE THECA SHUNT \\
\hline 0399 & SPINE CANAL STRUC OP NEC \\
\hline 0401 & EXCISION ACOUSTC NEUROMA \\
\hline 0402 & TRIGEMINAL NERV DIVISION \\
\hline 0403 & PERIPH NERVE DIV NEC \\
\hline 0404 & PERIPH NERVE INCIS NEC \\
\hline 0405 & GASSERIAN GANGLIONECTOMY \\
\hline 0406 & PERIPH GANGLIONECT NEC \\
\hline 0407 & PERIPH NERV EXCISION NEC \\
\hline 0412 & OPEN PERIPH NERVE BIOPSY \\
\hline 0419 & PERIPH NERVE DX PROC NEC \\
\hline 043 & PERIPHERAL NERVE SUTURE \\
\hline 0441 & DECOMPRESS TRIGEM ROOT \\
\hline 0442 & CRAN NERV ROOT DECOM NEC \\
\hline 0443 & CARPAL TUNNEL RELEASE \\
\hline 0444 & TARSAL TUNNEL RELEASE \\
\hline 0449 & PER NERVE ADHESIOLYS NEC \\
\hline 045 & PERIPHERAL NERVE GRAFT \\
\hline 046 & PERIPH NERVE TRANSPOSIT \\
\hline 0471 & HYPOGLOSS-FACIAL ANASTOM \\
\hline 0472 & ACCESSORY-FACIAL ANASTOM \\
\hline 0473 & ACCESS-HYPOGLOSS ANASTOM \\
\hline 0474 & PERIPH NERV ANASTOM NEC \\
\hline 0475 & POSTOP REVIS PER NERV OP \\
\hline 0476 & LATE REPAIR PER NERV INJ \\
\hline 0479 & OTHER NEUROPLASTY \\
\hline 0491 & NEURECTASIS \\
\hline 0492 & IMPLANT PERIPH STIMULAT \\
\hline 0493 & REMOVE PERIPH STIMULATOR \\
\hline 0499 & PERIPHERAL NERVE OPS NEC \\
\hline 050 & SYMPATH NERVE DIVISION \\
\hline 0511 & SYMPATHETIC NERVE BIOPSY \\
\hline 0519 & SYMPATH NRV DX PROC NEC \\
\hline 0521 & SPHENOPALATIN GANGLIONEC \\
\hline 0522 & CERVICAL SYMPATHECTOMY \\
\hline 0524 & PUMBAR SYMPATHECTOMY \\
\hline &
\end{tabular}

\begin{tabular}{|c|c|}
\hline 0525 & PERIART SYMPATHECTOMY \\
\hline 0529 & OTHER SYMPATHECTOMY \\
\hline 0581 & SYMPATHETIC NERVE REPAIR \\
\hline 0589 & SYMPATHETIC NERVE OP NEC \\
\hline 059 & OTHER NERVOUS SYSTEM OPS \\
\hline 0602 & REOPEN THYROID FIELD WND \\
\hline 0609 & INCIS THYROID FIELD NEC \\
\hline 0612 & OPEN THYROID GLAND BX \\
\hline 0613 & PARATHYROID BIOPSY \\
\hline 0619 & THYR/PARATHY DX PROC NEC \\
\hline 062 & UNILAT THYROID LOBECTOMY \\
\hline 0631 & EXCISION THYROID LESION \\
\hline 0639 & PART THYROIDECTOMY NEC \\
\hline 064 & COMPLETE THYROIDECTOMY \\
\hline 0650 & SUBSTERN THYROIDECT NOS \\
\hline 0651 & $\begin{array}{l}\text { PART SUBSTERN THYROIDECT } \\
\end{array}$ \\
\hline 0652 & TOT SUBSTERN THYROIDECT \\
\hline 066 & LINGUAL THYROID EXCISION \\
\hline 067 & THYROGLOSS DUCT EXCISION \\
\hline 0681 & TOTAL PARATHYROIDECTOMY \\
\hline 0689 & OTHER PARATHYROIDECTOMY \\
\hline 0691 & THYROID ISTHMUS DIVISION \\
\hline 0692 & THYROID VESSEL LIGATION \\
\hline 0693 & THYROID SUTURE \\
\hline 0694 & THYROID REIMPLANTATION \\
\hline 0695 & PARATHYROID REIMPLANT \\
\hline 0698 & OTHER THYROID OPERATIONS \\
\hline 0699 & OTHER PARATHYROID OPS \\
\hline 0700 & ADRENAL EXPLORATION NOS \\
\hline 0701 & UNILAT ADRENAL EXPLORAT \\
\hline 0702 & BILAT ADRENAL EXPLORAT \\
\hline 0712 & OPEN ADRENAL GLAND BX \\
\hline 0713 & TRANSFRONT PITUITARY BX \\
\hline 0714 & TRANSPHEN PITUITARY BX \\
\hline 0715 & PITUITARY BIOPSY NOS \\
\hline 0716 & THYMUS BIOPSY \\
\hline 0717 & PINEAL BIOPSY \\
\hline 0719 & ENDOCRINE DX PROC NEC \\
\hline 0721 & ADRENAL LESION EXCISION \\
\hline 0722 & UNILATERAL ADRENALECTOMY \\
\hline 0729 & PART ADRENALECTOMY NEC \\
\hline 073 & BILATERAL ADRENALECTOMY \\
\hline 0741 & ADRENAL INCISION \\
\hline 0742 & ADRENAL NERVE DIVISION \\
\hline 0743 & ADRENAL VESSEL LIGATION \\
\hline 0744 & ADRENAL REPAIR \\
\hline 0745 & ADRENAL REIMPLANTATION \\
\hline 0749 & ADRENAL OPERATION NEC \\
\hline 0751 & PINEAL FIELD EXPLORATION \\
\hline 0752 & PINEAL GLAND INCISION \\
\hline 0753 & PARTIAL PINEALECTOMY \\
\hline
\end{tabular}




\begin{tabular}{|c|c|}
\hline 0754 & TOTAL PINEALECTOMY \\
\hline 0759 & PINEAL OPERATION NEC \\
\hline 0761 & EXC PITUIT LES-TRANSFRON \\
\hline 0762 & EXC PITUIT LES-TRANSPHEN \\
\hline 0763 & PART EXCIS PITUITARY NOS \\
\hline 0764 & TOT EXC PITUIT-TRANSFRON \\
\hline 0765 & TOT EXC PITUIT-TRANSPHEN \\
\hline 0768 & TOTAL EXC PITUITARY NEC \\
\hline 0769 & TOTAL EXC PITUITARY NOS \\
\hline 0771 & PITUITARY FOSSA EXPLORAT \\
\hline 0772 & PITUITARY GLAND INCISION \\
\hline 0779 & PITUITARY OPERATION NEC \\
\hline 0780 & THYMECTOMY NOS \\
\hline 0781 & PART EXCISION OF THYMUS \\
\hline 0782 & TOTAL EXCISION OF THYMUS \\
\hline 0791 & THYMUS FIELD EXPLORATION \\
\hline 0792 & INCISION OF THYMUS \\
\hline 0793 & REPAIR OF THYMUS \\
\hline 0794 & THYMUS TRANSPLANTATION \\
\hline 0799 & THYMUS OPERATION NEC \\
\hline 0811 & EYELID BIOPSY \\
\hline 0820 & REMOVE EYELID LESION NOS \\
\hline 0821 & CHALAZION EXCISION \\
\hline 0822 & EXCISE MINOR LES LID NEC \\
\hline 0823 & EXC MAJ LES LID PRT-THIC \\
\hline 0824 & EXC MAJ LES LID FUL-THIC \\
\hline 0825 & DESTRUCTION LID LESION \\
\hline 0831 & PTOSIS REP-FRONT MUS SUT \\
\hline 0832 & PTOSIS REP-FRON MUS SLNG \\
\hline 0833 & PTOSIS REP-LEVAT MUS ADV \\
\hline 0834 & PTOSIS REP-LEVAT MUS NEC \\
\hline 0835 & PTOS REP-TARSAL TECHNIQ \\
\hline 0836 & BLEPHAROPTOS REPAIR NEC \\
\hline 0837 & REDUC OVERCORRECT PTOSIS \\
\hline 0838 & CORRECT LID RETRACTION \\
\hline 0841 & THERMOCAUT/ENTROPION REP \\
\hline 0842 & SUTURE ENTROPION REPAIR \\
\hline 0843 & WEDG RESEC ENTROPION REP \\
\hline 0844 & LID RECONS ENTROPION REP \\
\hline 0849 & ENTROPION/ECTROP REP NEC \\
\hline 0851 & CANTHOTOMY \\
\hline 0852 & BLEPHARORRHAPHY \\
\hline 0859 & ADJUST LID POSITION NEC \\
\hline 0861 & LID RECONST W SKIN GRAFT \\
\hline 0862 & LID RECONST W MUC GRAFT \\
\hline 0863 & LID RECONST W HAIR GRAFT \\
\hline 0864 & LID RECON-TARSOCONJ FLAP \\
\hline 0869 & LID RECONSTR W GRAFT NEC \\
\hline 0870 & LID RECONSTRUCTION NOS \\
\hline 0871 & LID MARG RECON-PART THIC \\
\hline 0872 & LID RECONS-PART THIC NEC \\
\hline
\end{tabular}

\begin{tabular}{|l|l|}
\hline 0873 & LID MARG RECONS FUL THIC \\
\hline 0874 & LID RECONST-FUL THIC NEC \\
\hline 0891 & ELECTROSURG LID EPILAT \\
\hline 0892 & CRYOSURG LID EPILATION \\
\hline 0893 & EYELID EPILATION NEC \\
\hline 0899 & EYELID OPERATION NEC \\
\hline 090 & LACRIMAL GLAND INCISION \\
\hline 0911 & LACRIMAL GLAND BIOPSY \\
\hline 0912 & LACRIMAL SAC BIOPSY \\
\hline 0919 & LACRIMAL SYS DX PROC NEC \\
\hline 0920 & EXC LACRIMAL GLAND NOS \\
\hline 0921 & EXCIS LES LACRIMAL GLAND \\
\hline 0922 & PART DACRYOADENECT NEC \\
\hline 0923 & TOTAL DACRYOADENECTOMY \\
\hline 093 & OTHER LACRIMAL GLAND OPS \\
\hline 0941 & LACRIMAL PUNCTUM PROBE \\
\hline 0942 & LAC CANALICULI PROBE \\
\hline 0943 & NASOLACRIMAL DUCT PROBE \\
\hline 0944 & NASOLAC DUCT INTUBAT \\
\hline 0949 & LAC PASSAGE MANIP NEC \\
\hline 0951 & LAC PUNCTUM INCISION \\
\hline 0952 & LAC CANALICULI INCISION \\
\hline 0953 & LACRIMAL SAC INCISION \\
\hline 0959 & LACRIM PASSAGE INCIS NEC \\
\hline 096 & LACRIM SAC/PASSAGE EXCIS \\
\hline 0971 & CORRECT EVERTED PUNCTUM \\
\hline 0972 & PUNCTUM REPAIR NEC \\
\hline 0973 & CANALICULUS REPAIR \\
\hline 0981 & DACRYOCYSTORHINOSTOMY \\
\hline 0982 & CONJUNCTIVOCYSTORHINOST \\
\hline 0983 & CONJUNCTIVORHINOS W TUBE \\
\hline 0991 & LAC PUNCTUM OBLITERATION \\
\hline 0999 & LACRIMAL SYSTEM OP NEC \\
\hline 100 & INCISE/REMOV CONJUNCT FB \\
\hline 101 & CONJUNCTIVA INCISION NEC \\
\hline 1021 & CONJUNCTIVAL BIOPSY \\
\hline 1029 & CONJUNCTIVA DX PROC NEC \\
\hline 1031 & EXCISE CONJUNCTIV LESION \\
\hline 1032 & DESTRUCT CONJUNC LES NEC \\
\hline 1033 & OTH CONJUNC DESTRUC PROC \\
\hline 1041 & SYMBLEPH REP W FREE GRFT \\
\hline 1042 & GRAFT CONJUNC CUL-DE-SAC \\
\hline 1043 & CONJUN CUL-DE-SAC RX NEC \\
\hline 1044 & CONJUNC FREE GRAFT NEC \\
\hline 1049 & CONJUNCTIVOPLASTY NEC \\
\hline 105 & CONJUNC/LID ADHESIOLYSIS \\
\hline 106 & REPAIR CONJUNCT LACERAT \\
\hline 1099 & CONJUNCTIVAL OP NEC \\
\hline 111 & CORNEAL INCISION \\
\hline
\end{tabular}


DELSA/HEA/WD/HWP(2009)5/ANN

\begin{tabular}{|c|c|}
\hline 1121 & CORNEAL SCRAPE FOR SMEAR \\
\hline 1122 & CORNEAL BIOPSY \\
\hline 1129 & CORNEAL DX PROC NEC \\
\hline 1131 & PTERYGIUM TRANSPOSITION \\
\hline 1132 & PTERYG EXC W CORNEA GRFT \\
\hline 1139 & PTERYGIUM EXCISION NEC \\
\hline 1141 & MECH REMOV CORNEA EPITH \\
\hline 1142 & THERMOCAUT CORNEA LESION \\
\hline 1143 & CRYOTHERAP CORNEA LESION \\
\hline 1149 & DESTRUCT CORNEA LES NEC \\
\hline 1151 & SUTURE CORNEA LACERATION \\
\hline 1152 & REP CORNEA POSTOP DEHISC \\
\hline 1153 & RX CORNEA LAC W CONJ FLP \\
\hline 1159 & CORNEAL REPAIR NEC \\
\hline 1160 & CORNEAL TRANSPLANT NOS \\
\hline 1161 & LAM KERATPLAST W AUTGRFT \\
\hline 1162 & LAMELLAR KERATOPLAST NEC \\
\hline 1163 & PERF KERATOPL W AUTOGRFT \\
\hline 1164 & PERFORAT KERATOPLAST NEC \\
\hline 1169 & CORNEAL TRANSPLANT NEC \\
\hline 1171 & KERATOMILEUSIS \\
\hline 1172 & KERATOPHAKIA \\
\hline 1173 & KERATOPROSTHESIS \\
\hline 1174 & THERMOKERATOPLASTY \\
\hline 1175 & RADIAL KERATOTOMY \\
\hline 1176 & EPIKERATOPHAKIA \\
\hline 1179 & CORNEA RECONSTRUCT NEC \\
\hline 1191 & CORNEAL TATTOOING \\
\hline 1192 & REMOVE CORNEAL IMPLANT \\
\hline 1199 & CORNEAL OPERATION NEC \\
\hline 1200 & REMOV ANT SEGMNT FB NOS \\
\hline 1201 & MAGNET REMOV ANT SEG FB \\
\hline 1202 & NONMAG REMOV ANT SEG FB \\
\hline 1211 & IRIDOTOMY W TRANSFIXION \\
\hline 1212 & IRIDOTOMY NEC \\
\hline 1213 & PROLAPSED IRIS EXCISION \\
\hline 1214 & IRIDECTOMY NEC \\
\hline 1221 & DX ASPIRAT-ANT CHAMBER \\
\hline 1222 & IRIS BIOPSY \\
\hline 1229 & ANT SEGMENT DX PROC NEC \\
\hline 1231 & GONIOSYNECHIAE LYSIS \\
\hline 1232 & ANT SYNECHIA LYSIS NEC \\
\hline 1233 & POST SYNECHIAE LYSIS \\
\hline 1234 & CORNEOVITREAL ADHESIOLYS \\
\hline 1235 & COREOPLASTY \\
\hline 1239 & IRIDOPLASTY NEC \\
\hline 1240 & REMOV ANT SEGMNT LES NOS \\
\hline 1241 & NONEXC DESTRUC IRIS LES \\
\hline 1242 & EXCISION OF IRIS LESION \\
\hline 1243 & NONEXC DESTR CIL BOD LES \\
\hline 1244 & EXCISE CILIARY BODY LES \\
\hline
\end{tabular}

\begin{tabular}{|c|c|}
\hline 1251 & GONIOPUNCTURE \\
\hline 1252 & GONIOTOMY \\
\hline 1253 & GONIOTOMY W GONIOPUNCTUR \\
\hline 1254 & TRABECULOTOMY AB EXTERNO \\
\hline 1255 & CYCLODIALYSIS \\
\hline 1259 & FACILIT INTRAOC CIRC NEC \\
\hline 1261 & TREPHIN SCLERA W IRIDECT \\
\hline 1262 & THERMCAUT SCLER W IRIDEC \\
\hline 1263 & IRIDENCLEISIS/IRIDOTASIS \\
\hline 1264 & TRABECULECTOM AB EXTERNO \\
\hline 1265 & SCLER FISTULIZ W IRIDECT \\
\hline 1266 & POSTOP REVIS SCL FISTUL \\
\hline 1269 & SCLER FISTULIZING OP NEC \\
\hline 1271 & CYCLODIATHERMY \\
\hline 1272 & CYCLOCRYOTHERAPY \\
\hline 1273 & CYCLOPHOTOCOAGULATION \\
\hline 1274 & CIL BODY DIMINUTION NOS \\
\hline 1279 & GLAUCOMA PROCEDURE NEC \\
\hline 1281 & SUTURE SCLERAL LACER \\
\hline 1282 & SCLERAL FISTULA REPAIR \\
\hline 1283 & REVIS ANT SEG OP WND NEC \\
\hline 1284 & DESTRUCT SCLERAL LESION \\
\hline 1285 & REPAIR STAPHYLOM W GRAFT \\
\hline 1286 & REP SCLER STAPHYLOMA NEC \\
\hline 1287 & GRAFT REINFORCE SCLERA \\
\hline 1288 & SCLERA REINFORCEMENT NEC \\
\hline 1289 & SCLERAL OPERATION NEC \\
\hline 1291 & THERAPEUT EVAC ANT CHAMB \\
\hline 1292 & ANTERIOR CHAMBER INJECT \\
\hline 1293 & REMOV EPITHEL DOWNGROWTH \\
\hline 1297 & IRIS OPERATION NEC \\
\hline 1298 & CILIARY BODY OP NEC \\
\hline 1299 & ANTERIOR CHAMBER OP NEC \\
\hline 1300 & REMOVE FB LENS NOS \\
\hline 1301 & MAGNET REMOVE FB LENS \\
\hline 1302 & NONMAGNET REMOVE FB LENS \\
\hline 1311 & TEMP-INF INTRCAP LENS EX \\
\hline 1319 & INTRACAPSUL LENS EXT NEC \\
\hline 132 & LINEAR EXTRACAP LENS EXT \\
\hline 133 & SIMPL ASPIR LENS EXTRACT \\
\hline 1341 & CATARAC PHACOEMULS/ASPIR \\
\hline 1342 & POST CATARAC FRAG/ASPIR \\
\hline 1343 & CATARACT FRAG/ASPIR NEC \\
\hline 1351 & TEMP-INF XTRACAP LENS EX \\
\hline 1359 & EXTRACAP LENS EXTRAC NEC \\
\hline 1361 & EXTRACAP LENS EXTRAC NEC \\
\hline 1362 & EXTRACAP LENS EXTRAC NEC \\
\hline 1363 & EXTRACAP LENS EXTRAC NEC \\
\hline 1364 & AFTER-CATAR DISCISSION \\
\hline 1365 & AFTER-CATARACT EXCISION \\
\hline 1366 & AFTER CATAR FRAGMNTATION \\
\hline
\end{tabular}




\begin{tabular}{|l|l|}
\hline 1369 & CATARACT EXTRACTION NEC \\
\hline 1370 & INSERT PSEUDOPHAKOS NOS \\
\hline 1371 & INSERT LENS AT CATAR EXT \\
\hline 1372 & SECONDARY INSERT LENS \\
\hline 138 & IMPLANTED LENS REMOVAL \\
\hline 139 & OTHER OPERATIONS ON LENS \\
\hline 1390 & OPERATION ON LENS NEC OCT06- \\
\hline 1391 & IMPL INTRAOC TELESC PROS \\
\hline 1400 & REMO6- \\
\hline 1401 & MAGNET REMOV POST SEG FB \\
\hline 1402 & NONMAG REMOV POST SEG FB \\
\hline 1411 & DIAGNOST VITREOUS ASPIR \\
\hline 1419 & DX PROC POST SEG NEC \\
\hline 1421 & CHORIORET LES DIATHERMY \\
\hline 1422 & CHORIORETIN LES CRYOTHER \\
\hline 1426 & CHORIORET LES RADIOTHER \\
\hline 1427 & CHORIORET LES RAD IMPLAN \\
\hline 1429 & CHORIORET LES DESTR NEC \\
\hline 1431 & RETINAL TEAR DIATHERMY \\
\hline 1432 & RETINAL TEAR CRYOTHERAPY \\
\hline 1439 & RETINAL TEAR REPAIR NEC \\
\hline 1441 & SCLERAL BUCKLE W IMPLANT \\
\hline 1449 & SCLERAL BUCKLING NEC \\
\hline 1451 & DETACH RETINA-DIATHERMY \\
\hline 1452 & DETACH RETINA-CRYOTHERAP \\
\hline 1453 & DETACH RETINA XENON COAG \\
\hline 1454 & DETACH RETINA LASER COAG \\
\hline 1455 & DETACH RET PHOTOCOAG NOS \\
\hline 1459 & REPAIR RETINA DETACH NEC \\
\hline 146 & REMOV PROS MAT POST SEG \\
\hline 1471 & ANTERIOR REMOV VITREOUS \\
\hline 1472 & VITREOUS REMOVAL NEC \\
\hline 1473 & ANTERIOR MECHAN VITRECT \\
\hline 1474 & MECH VITRECTOMY NEC \\
\hline 1475 & VITREOUS SUBSTITUT INJEC \\
\hline 1479 & VITREOUS OPERATION NEC \\
\hline 149 & OTHER POST SEGMENT OPS \\
\hline 1501 & EXTRAOC MUSC-TEND BIOPSY \\
\hline 1509 & EXTRAOC MUSC DX PROC NEC \\
\hline 1511 & ONE EXTRAOC MUS RECESS \\
\hline 1512 & 1 EXTRAOC MUSCL ADVANCE \\
\hline 1513 & 1 EXTRAOC MUSCL RESECT \\
\hline 1519 & XTRAOC MUS OP/DETACH NEC \\
\hline 1521 & LENGTHEN 1 EXTRAOC MUSC \\
\hline 1522 & SHORTEN 1 EXTRAOC MUSC \\
\hline 1529 & OP ON 1 EXTRAOC MUSC NEC \\
\hline 154 & OTE DPTACH $>1$ XTROC MUS $~$ \\
\hline & EXTRATRAOC MUS \\
\hline
\end{tabular}

\begin{tabular}{|l|l|}
\hline 157 & EXTRAOC MUSC INJ REPAIR \\
\hline 159 & OTH EXTRAOC MUS-TEND OP \\
\hline 1601 & ORBITOTOMY W BONE FLAP \\
\hline 1602 & ORBITOTOMY W IMPLANT \\
\hline 1609 & ORBITOTOMY NEC \\
\hline 161 & REMOVE PENETRAT FB EYE \\
\hline 1622 & DIAGNOSTIC ASP OF ORBIT \\
\hline 1623 & EYEBALL \& ORBIT BIOPSY \\
\hline 1629 & EYEBAL/ORBIT DX PROC NEC \\
\hline 1631 & EYE EVISC W SYNCH IMPLAN \\
\hline 1639 & EYEBALL EVISCERATION NEC \\
\hline 1641 & EYE ENUC/IMPLAN/MUSC ATT \\
\hline 1642 & EYE ENUC W IMPLANT NEC \\
\hline 1649 & EYEBALL ENUCLEATION NEC \\
\hline 1651 & RADICAL ORBITOMAXILLECT \\
\hline 1652 & ORBIT EXENT W BONE REMOV \\
\hline 1659 & ORBITAL EXENTERATION NEC \\
\hline 1661 & 2NDRY OCULAR IMP INSERT \\
\hline 1662 & REVIS/REINSERT OCUL IMP \\
\hline 1663 & REVIS ENUC SOCKET W GRFT \\
\hline 1664 & ENUC SOCKET REVIS NEC \\
\hline 1665 & 2NDRY EXENT CAVITY GRAFT \\
\hline 1666 & REVIS EXENTER CAVITY NEC \\
\hline 1669 & 2ND OP POST EYE REM NEC \\
\hline 1671 & REMOVE OCULAR IMPLANT \\
\hline 1672 & REMOVE ORBITAL IMPLANT \\
\hline 1681 & REPAIR OF ORBITAL WOUND \\
\hline 1682 & REPAIR EYEBALL RUPTURE \\
\hline 1689 & EYE/ORBIT INJ REPAIR NEC \\
\hline 1692 & EXCISION ORBITAL LESION \\
\hline 1693 & EXCISION EYE LESION NOS \\
\hline 1698 & OPERATION ON ORBIT NEC \\
\hline 1699 & OPERATION ON EYEBALL NEC \\
\hline 1821 & PREAURICULAR SINUS EXCIS \\
\hline 1831 & RAD EXCIS EXT EAR LES \\
\hline 1839 & EXCIS EXTERNAL EAR NEC \\
\hline 185 & CORRECTION PROMINENT EAR \\
\hline 186 & EXT AUDIT CANAL RECONSTR \\
\hline 1871 & CONSTRUCTION EAR AURICLE \\
\hline 1872 & REATTACH AMPUTATED EAR \\
\hline 1879 & PLASTIC REP EXT EAR NEC \\
\hline 189 & OTHER EXT EAR OPERATIONS \\
\hline 190 & STAPES MOBILIZATION \\
\hline 1911 & STAPEDECT W REPLAC INCUS \\
\hline 1919 & STAPEDECTOMY NEC \\
\hline 1921 & REV STAPDEC W INCUS REPL \\
\hline 1929 & STAPEDECTOMY REVIS NEC \\
\hline 193 & OSSICULAR CHAIN OP NEC \\
\hline 1952 & MYRINGOPLASTY \\
\hline 1953 & TYPE T TYMPANOPLASTY TYMPANOPLASTY \\
\hline & \\
\hline 19
\end{tabular}




\begin{tabular}{|l|l|}
\hline 1954 & TYPE 4 TYMPANOPLASTY \\
\hline 1955 & TYPE 5 TYMPANOPLASTY \\
\hline 196 & TYMPANOPLASTY REVISION \\
\hline 199 & MIDDLE EAR REPAIR NEC \\
\hline 2001 & MYRINGOTOMY W INTUBATION \\
\hline 2021 & MASTOID INCISION \\
\hline 2022 & PETRUS PYRAM AIR CEL INC \\
\hline 2023 & MIDDLE EAR INCISION \\
\hline 2032 & MID \& INNER EAR BIOPSY \\
\hline 2039 & MID/IN EAR DX PROC NEC \\
\hline 2041 & SIMPLE MASTOIDECTOMY \\
\hline 2042 & RADICAL MASTOIDECTOMY \\
\hline 2049 & MASTOIDECTOMY NEC \\
\hline 2051 & EXCISE MIDDLE EAR LESION \\
\hline 2059 & MIDDLE EAR EXCISION NEC \\
\hline 2061 & INNER EAR FENESTRATION \\
\hline 2062 & REVIS INNER EAR FENESTRA \\
\hline 2071 & ENDOLYMPHATIC SHUNT \\
\hline 2072 & INNER EAR INJECTION \\
\hline 2079 & INC/EXC/DESTR IN EAR NEC \\
\hline 2091 & TYMPANOSYMPATHECTOMY \\
\hline 2092 & MASTOIDECTOMY REVISION \\
\hline 2093 & REPAIR OVAL/ROUND WINDOW \\
\hline 2095 & ELECMAG HEAR DEV IMPLANT \\
\hline 2096 & IMPLT COCHLEAR PROST NOS \\
\hline 2097 & IMP/REP SCHAN COCH PROS \\
\hline 2098 & IMP/REP MCHAN COCHL PROS \\
\hline 2099 & MID-INNER EAR OPS NEC \\
\hline 2104 & ETHMOID ART LIGAT-EPIST \\
\hline 2105 & MAX ART LIG FOR EPISTAX \\
\hline 2106 & EXT CAROT ART LIG-EPIST \\
\hline 2107 & NASAL SEPT GRFT-EPISTAX \\
\hline 2109 & EPISTAXIS CONTROL NEC \\
\hline 214 & RESECTION OF NOSE \\
\hline 215 & SUBMUC NASAL SEPT RESECT \\
\hline 2161 & DIATHER/CRYO TURBINECTOM \\
\hline 2162 & TURBINATE FRACTURE \\
\hline 2169 & TURBINECTOMY NEC \\
\hline 2172 & OPEN REDUCTION NASAL FX \\
\hline 2182 & NASAL FISTULA CLOSURE \\
\hline 2183 & TOT NASAL RECONSTRUCTION \\
\hline 2184 & REVISION RHINOPLASTY \\
\hline 2185 & AUGMENTATION RHINOPLASTY \\
\hline 2186 & LIMITED RHINOPLASTY \\
\hline 2187 & RHINOPLASTY NEC \\
\hline 2188 & SEPTOPLASTY NEC \\
\hline 2199 & NASAL REPAIR NEC \\
\hline 2231 & NASAL OPERATION NEC \\
\hline 2239 & EXT MAXILLARY ANTROT NEC \\
\hline
\end{tabular}

\begin{tabular}{|c|c|}
\hline 2241 & FRONTAL SINUSOTOMY \\
\hline 2242 & FRONTAL SINUSECTOMY \\
\hline 2250 & SINUSOTOMY NOS \\
\hline 2251 & ETHMOIDOTOMY \\
\hline 2252 & SPHENOIDOTOMY \\
\hline 2253 & MULTIPLE SINUS INCISION \\
\hline 2260 & SINUSECTOMY NOS \\
\hline 2261 & C-LUC EXC MAX SINUS LES \\
\hline 2262 & EXC MAX SINUS LESION NEC \\
\hline 2263 & ETHMOIDECTOMY \\
\hline 2264 & SPHENOIDECTOMY \\
\hline 2271 & NASAL SINUS FISTULA CLOS \\
\hline 2279 & NASAL SINUS REPAIR NEC \\
\hline 229 & OTHER NASAL SINUS OPS \\
\hline 242 & GINGIVOPLASTY \\
\hline 244 & EXC OF DENTAL LES OF JAW \\
\hline 245 & ALVEOLOPLASTY \\
\hline 2502 & OPEN BIOPSY OF TONGUE \\
\hline 251 & DESTRUCTION TONGUE LES \\
\hline 252 & PARTIAL GLOSSECTOMY \\
\hline 253 & COMPLETE GLOSSECTOMY \\
\hline 254 & RADICAL GLOSSECTOMY \\
\hline 2559 & REPAIR OF TONGUE NEC \\
\hline 2594 & OTHER GLOSSOTOMY \\
\hline 2599 & TONGUE OPERATION NEC \\
\hline 2612 & OPEN BX SALIV GLAND/DUCT \\
\hline 2621 & SALIVARY CYST MARSUPIAL \\
\hline 2629 & SALIV LESION EXCIS NEC \\
\hline 2630 & SIALOADENECTOMY NOS \\
\hline 2631 & PARTIAL SIALOADENECTOMY \\
\hline 2632 & COMPLETE SIALOADENECTOMY \\
\hline 2641 & SUTURE OF SALIV GLND LAC \\
\hline 2642 & SALIVARY FISTULA CLOSURE \\
\hline 2649 & SALIVARY REPAIR NEC \\
\hline 2699 & SALIVARY OPERATION NEC \\
\hline 270 & DRAIN FACE \& MOUTH FLOOR \\
\hline 271 & INCISION OF PALATE \\
\hline 2721 & BONY PALATE BIOPSY \\
\hline 2722 & UVULA AND SOFT PALATE BX \\
\hline 2731 & LOC EXC BONY PALATE LES \\
\hline 2732 & WIDE EXC BONY PALATE LES \\
\hline 2742 & WIDE EXCISION OF LIP LES \\
\hline 2743 & EXCISION OF LIP LES NEC \\
\hline 2749 & EXCISION OF MOUTH NEC \\
\hline 2753 & CLOSURE OF MOUTH FISTULA \\
\hline 2754 & REPAIR OF CLEFT LIP \\
\hline 2755 & FULL-THICK GRFT TO MOUTH \\
\hline 2756 & SKIN GRAFT TO MOUTH NEC \\
\hline 2757 & PEDICLE ATTACH TO MOUTH \\
\hline 2759 & MOUTH REPAIR NEC \\
\hline 2761 & SUTURE OF PALATE LACERAT \\
\hline
\end{tabular}




\begin{tabular}{|c|c|}
\hline 2762 & CLEFT PALATE CORRECTION \\
\hline 2763 & REVIS CLEFT PALAT REPAIR \\
\hline 2769 & OTH PLASTIC REPAIR PALAT \\
\hline 2771 & INCISION OF UVULA \\
\hline 2772 & EXCISION OF UVULA \\
\hline 2773 & REPAIR OF UVULA \\
\hline 2779 & OTHER UVULA OPERATIONS \\
\hline 2792 & MOUTH INCISION NOS \\
\hline 2799 & ORAL CAVITY OPS NEC \\
\hline 280 & PERITONSILLAR I \& D \\
\hline 2811 & TONSIL\&ADENOID BIOPSY \\
\hline 2819 & TONSIL\&ADENOID DX OP NEC \\
\hline 282 & TONSILLECTOMY \\
\hline 283 & TONSILLECTOMY/ADENOIDEC \\
\hline 284 & EXCISION OF TONSIL TAG \\
\hline 285 & EXCISION LINGUAL TONSIL \\
\hline 286 & ADENOIDECTOMY \\
\hline 287 & HEMORR CONTRL POST T \& A \\
\hline 2891 & INCIS TO REMOV TONSIL FB \\
\hline 2892 & EXCIS TONSIL/ADENOID LES \\
\hline 2899 & TONSIL/ADENOID OPS NEC \\
\hline 290 & PHARYNGOTOMY \\
\hline 292 & EXC BRANCHIAL CLEFT CYST \\
\hline 293 & EXC BRANCHIAL CLEFT CYST \\
\hline 2931 & CRICOPHARYNGEAL MYOTOMY \\
\hline 2932 & PHARYNGEAL DIVERTICULEC \\
\hline 2933 & PHARYNGECTOMY \\
\hline 2939 & EXCIS/DESTR LES PHAR NEC \\
\hline 294 & PLASTIC OP ON PHARYNX \\
\hline 2951 & SUTURE OF PHARYNGEAL LAC \\
\hline 2952 & CLOS BRANCH CLEFT FISTUL \\
\hline 2953 & CLOS PHARYNX FISTULA NEC \\
\hline 2954 & LYSIS PHARYNGEAL ADHES \\
\hline 2959 & PHARYNGEAL REPAIR NEC \\
\hline 2992 & DIVIS GLOSSOPHARYNG NERV \\
\hline 2999 & PHARYNGEAL OPERATION NEC \\
\hline 3001 & LARYNX CYST MARSUPIALIZ \\
\hline 3009 & DESTRUCT LARYNX LES NEC \\
\hline 301 & HEMILARYNGECTOMY \\
\hline 3021 & EPIGLOTTIDECTOMY \\
\hline 3022 & VOCAL CORDECTOMY \\
\hline 3029 & OTHER PART LARYNGECTOMY \\
\hline 303 & COMPLETE LARYNGECTOMY \\
\hline 304 & RADICAL LARYNGECTOMY \\
\hline 3121 & MEDIASTINAL TRACHEOSTOMY \\
\hline 3129 & OTHER PERM TRACHEOSTOMY \\
\hline 313 & INCIS LARYNX TRACHEA NEC \\
\hline 3145 & OPN BX LARYNX OR TRACHEA \\
\hline 315 & LOCAL DESTRUC TRACH LES \\
\hline 3161 & SUTURE OF LARYNGEAL LAC \\
\hline 3162 & LARYNGEAL FISTULA CLOS \\
\hline
\end{tabular}

\begin{tabular}{|c|c|}
\hline 3163 & LARYNGOSTOMY REVISION \\
\hline 3164 & LARYNGEAL FX REPAIR \\
\hline 3169 & OTHER LARYNGEAL REPAIR \\
\hline 3171 & SUTURE OF TRACHEAL LACER \\
\hline 3172 & CLOSURE OF TRACHEOSTOMY \\
\hline 3173 & TRACHEA FISTULA CLOS NEC \\
\hline 3174 & REVISION OF TRACHEOSTOMY \\
\hline 3175 & TRACHEAL RECONSTRUCTION \\
\hline 3179 & OTHER TRACHEAL REPAIR \\
\hline 3191 & LARYNGEAL NERV DIVISION \\
\hline 3192 & LYSIS TRACH/LARYNX ADHES \\
\hline 3198 & OTH LARYNGEAL OPERATION \\
\hline 3199 & OTHER TRACHEAL OPERATION \\
\hline 320 & OTHER TRACHEAL OPERATION \\
\hline 3209 & OTHER DESTRUC BRONC LES \\
\hline 321 & OTHER BRONCHIAL EXCISION \\
\hline 3221 & EMPHYSEMA BLEB PLICATION \\
\hline 3222 & $\begin{array}{l}\text { LUNG VOL REDUCTION SURG } \\
\end{array}$ \\
\hline 3223 & $\begin{array}{l}\text { OPEN ABLTN LUNG } \\
\text { OCT06- }\end{array}$ \\
\hline 3224 & $\begin{array}{l}\text { PERC ABLTN LUNG } \\
\text { OCT06- }\end{array}$ \\
\hline 3225 & $\begin{array}{l}\text { THOR ABLTN LUNG } \\
\text { OCT06- }\end{array}$ \\
\hline 3226 & $\begin{array}{llll}\text { ABLTN } & \text { LUNG } & \text { TISS } & \text { NEC/NOS } \\
\text { OCT06- } & & & \\
\end{array}$ \\
\hline 3229 & DESTROY LOC LUNG LES NEC \\
\hline 323 & SEGMENTAL LUNG RESECTION \\
\hline 324 & LOBECTOMY OF LUNG \\
\hline 325 & COMPLETE PNEUMONECTOMY \\
\hline 326 & RAD DISSEC THORAC STRUCT \\
\hline 329 & OTHER EXCISION OF LUNG \\
\hline 330 & INCISION OF BRONCHUS \\
\hline 331 & ON OF LUNG \\
\hline 3325 & OPEN BRONCHIAL BIOPSY \\
\hline 3327 & CLOS ENDOSCOPIC LUNG BX \\
\hline 3328 & OPEN LUNG BIOPSY \\
\hline 3329 & BRONCH/LUNG DX PROC NEC \\
\hline 3334 & THORACOPLASTY \\
\hline 3339 & SURG COLLAPS OF LUNG NEC \\
\hline 3341 & BRONCHIAL LACERAT SUTURE \\
\hline 3342 & BRONCHIAL FISTULA CLOS \\
\hline 3343 & LUNG LACERATION CLOSURE \\
\hline 3348 & BRONCHIAL REPAIR NEC \\
\hline 3349 & LUNG REPAIR NEC \\
\hline 335 & LUNG REPAIR NEC \\
\hline 3350 & LUNG TRANSPLANT NOS \\
\hline 3351 & UNILAT LUNG TRANSPLANT \\
\hline 3352 & BILAT LUNG TRANSPLANT \\
\hline 336 & COMB HEART/LUNG TRANSPLA \\
\hline 3392 & BRONCHIAL LIGATION \\
\hline
\end{tabular}




\begin{tabular}{|l|l|}
\hline 3393 & PUNCTURE OF LUNG \\
\hline 3398 & BRONCHIAL OPERATION NEC \\
\hline 3399 & LUNG OPERATION NEC \\
\hline 3402 & EXPLORATORY THORACOTOMY \\
\hline 3403 & REOPEN THORACOTOMY SITE \\
\hline 341 & INCISION OF MEDIASTINUM \\
\hline 3421 & TRANSPLEURA THORACOSCOPY \\
\hline 3422 & MEDIASTINOSCOPY \\
\hline 3426 & OPEN MEDIASTINAL BIOPSY \\
\hline 3427 & BIOPSY OF DIAPHRAGM \\
\hline 3428 & DX PROCEDURE THORAX NEC \\
\hline 3429 & DX PROC MEDIASTINUM NEC \\
\hline 343 & DESTRUCT MEDIASTIN LES \\
\hline 344 & DESTRUCT CHEST WALL LES \\
\hline 3451 & DECORTICATION OF LUNG \\
\hline 3459 & OTHER PLEURAL EXCISION \\
\hline 346 & SCARIFICATION OF PLEURA \\
\hline 3473 & CLOS THORACIC FISTUL NEC \\
\hline 3474 & PECTUS DEFORMITY REPAIR \\
\hline 3479 & OTHER CHEST WALL REPAIR \\
\hline 3481 & EXCISE DIAPHRAGM LESION \\
\hline 3482 & SUTURE DIAPHRAGM LACERAT \\
\hline 3483 & CLOSE DIAPHRAGM FISTULA \\
\hline 3484 & OTHER DIAPHRAGM REPAIR \\
\hline 3485 & IMPLANT DIAPHRA PACEMAKE \\
\hline 3489 & DIAPHRAGM OPERATION NEC \\
\hline 3493 & REPAIR OF PLEURA \\
\hline 3499 & THORACIC OPERATION NEC \\
\hline 3500 & CLOSED VALVOTOMY NOS \\
\hline 3501 & CLOSED AORTIC VALVOTOMY \\
\hline 3502 & CLOSED MITRAL VALVOTOMY \\
\hline 3503 & CLOSED PULMON VALVOTOMY \\
\hline 3504 & CLOSED TRICUSP VALVOTOMY \\
\hline 3510 & OPEN VALVULOPLASTY NOS \\
\hline 3511 & OPN AORTIC VALVULOPLASTY \\
\hline 3512 & OPN MITRAL VALVULOPLASTY \\
\hline 3513 & OPN PULMON VALVULOPLASTY \\
\hline 3514 & OPN TRICUS VALVULOPLASTY \\
\hline 3520 & REPLACE HEART VALVE NOS \\
\hline 3521 & REPLACE AORT VALV-TISSUE \\
\hline 3522 & REPLACE AORTIC VALVE NEC \\
\hline 3523 & REPLACE MITR VALV-TISSUE \\
\hline 3524 & REPLACE MITRAL VALVE NEC \\
\hline 3525 & REPLACE PULM VALV-TISSUE \\
\hline 3526 & REPLACE PULMON VALVE NEC \\
\hline 3527 & REPLACE TRIC VALV-TISSUE \\
\hline 3528 & REPLACE TRICUSP VALV NEC \\
\hline 3531 & PAPILLARY MUSCLE OPS \\
\hline 3533 & CHORDAE TENDINEAE OPS \\
\hline 3534 & INFUNDIBULECTOMY \\
\hline
\end{tabular}

\begin{tabular}{|c|c|}
\hline 3535 & TRABECUL CARNEAE CORD OP \\
\hline 3539 & TISS ADJ TO VALV OPS NEC \\
\hline 3542 & CREATE SEPTAL DEFECT \\
\hline 3550 & PROSTH REP HRT SEPTA NOS \\
\hline 3551 & PROS REP ATRIAL DEF-OPN \\
\hline 3552 & PROS REPAIR ATRIA DEF-CL \\
\hline 3553 & PROST REPAIR VENTRIC DEF \\
\hline 3554 & PROS REP ENDOCAR CUSHION \\
\hline 3555 & $\begin{array}{l}\text { PROS REP VENTRC } \\
\text { OCT06- }\end{array}$ \\
\hline 3560 & GRFT REPAIR HRT SEPT NOS \\
\hline 3561 & GRAFT REPAIR ATRIAL DEF \\
\hline 3562 & GRAFT REPAIR VENTRIC DEF \\
\hline 3563 & GRFT REP ENDOCAR CUSHION \\
\hline 3570 & HEART SEPTA REPAIR NOS \\
\hline 3571 & ATRIA SEPTA DEF REP NEC \\
\hline 3572 & VENTR SEPTA DEF REP NEC \\
\hline 3573 & ENDOCAR CUSHION REP NEC \\
\hline 3581 & TOT REPAIR TETRAL FALLOT \\
\hline 3582 & TOTAL REPAIR OF TAPVC \\
\hline 3583 & TOT REP TRUNCUS ARTERIOS \\
\hline 3584 & TOT COR TRANSPOS GRT VES \\
\hline 3591 & INTERAT VEN RETRN TRANSP \\
\hline 3592 & CONDUIT RT VENT-PUL ART \\
\hline 3593 & CONDUIT LEFT VENTR-AORTA \\
\hline 3594 & CONDUIT ARTIUM-PULM ART \\
\hline 3595 & HEART REPAIR REVISION \\
\hline 3596 & PERC HEART VALVULOPLASTY \\
\hline 3598 & OTHER HEART SEPTA OPS \\
\hline 3599 & OTHER HEART VALVE OPS \\
\hline 3600 & OTHER HEART VALVE OPS \\
\hline 3601 & PTCA-1 VES/ATH W/O AGENT \\
\hline 3602 & PTCA-1 VES/ATH W AGENT \\
\hline 3603 & OPEN CORONRY ANGIOPLASTY \\
\hline 3605 & PTCA-MULTIPLE VESSEL/ATH \\
\hline 3609 & REM OF COR ART OBSTR NEC \\
\hline 3610 & AORTOCORONARY BYPASS NOS \\
\hline 3611 & AORTOCOR BYPAS-1 COR ART \\
\hline 3612 & AORTOCOR BYPAS-2 COR ART \\
\hline 3613 & AORTOCOR BYPAS-3 COR ART \\
\hline 3614 & AORTCOR BYPAS-4+ COR ART \\
\hline 3615 & 1 INT MAM-COR ART BYPASS \\
\hline 3616 & 2 INT MAM-COR ART BYPASS \\
\hline 3617 & ABD-CORON ARTERY BYPASS \\
\hline 3619 & HRT REVAS BYPS ANAS NEC \\
\hline 362 & ARTERIAL IMPLANT REVASC \\
\hline 363 & ARTERIAL IMPLANT REVASC \\
\hline 3631 & OPEN CHEST TRANS REVASC \\
\hline 3632 & OTH TRANSMYO REVASCULAR \\
\hline 3633 & $\begin{array}{l}\text { ENDO TRANSMYO REVASCULAR } \\
\text { OCT06- }\end{array}$ \\
\hline
\end{tabular}




\begin{tabular}{|c|c|}
\hline 3634 & $\begin{array}{l}\text { PERC TRANSMYO REVASCULAR } \\
\text { OCT06- }\end{array}$ \\
\hline 3639 & OTH HEART REVASCULAR \\
\hline 3691 & CORON VESS ANEURYSM REP \\
\hline 3699 & HEART VESSEL OP NEC \\
\hline 3710 & INCISION OF HEART NOS \\
\hline 3711 & CARDIOTOMY \\
\hline 3712 & PERICARDIOTOMY \\
\hline 3724 & PERICARDIAL BIOPSY \\
\hline 3731 & PERICARDIECTOMY \\
\hline 3732 & HEART ANEURYSM EXCISION \\
\hline 3733 & EXC/DEST HRT LESION OPEN \\
\hline 3734 & EXC/DEST HRT LES OTHER \\
\hline 3735 & PARTIAL VENTRICULECTOMY \\
\hline 374 & HEART \& PERICARD REPAIR \\
\hline 3741 & $\begin{array}{l}\text { IMPL CARDIAC SUPPORT } \\
\text { OCT05- }\end{array}$ \\
\hline 3749 & $\begin{array}{lll}\text { HEART/PERICARD } & \text { REPR } & \text { NEC } \\
\text { OCT05- } & & \\
\end{array}$ \\
\hline 375 & HEART \& PERICARD REPAIR \\
\hline 3751 & TRANSPLANTATION \\
\hline 3752 & T REP HRT SYS \\
\hline 3753 & REPL/REP T \\
\hline 3754 & REPL/REP C \\
\hline 3761 & PULSATION BALLOON IMPLAN \\
\hline 3762 & IMPLANT HRT ASST SYS NEC \\
\hline 3763 & REPLACE HRT ASSIST SYST \\
\hline 3764 & REMOVE HEART ASSIST SYS \\
\hline 3765 & IMP EXT PUL HRT ASST SYS \\
\hline 3766 & IMP IMP PUL HRT ASST SYS \\
\hline 3767 & OSTIMUL SYS \\
\hline 3774 & INT OR REF \\
\hline 3775 & REVISION OF LEAD \\
\hline 3776 & REPL TV ATRI-VENT LEAD \\
\hline 3777 & REMOVAL OF LEAD W/O REPL \\
\hline 3779 & REVIS OR RELOCATE POCKET \\
\hline 3780 & INT OR REPL PERM PACEMKR \\
\hline 3785 & REPL PACEM W 1-CHAM, NON \\
\hline 3786 & REPL PACEM 1-CHAM, RATE \\
\hline 3787 & REPL PACEM W DUAL-CHAM \\
\hline 3789 & REVISE OR REMOVE PACEMAK \\
\hline 3790 & $\begin{array}{l}\text { INS LEFT ATR APPEND DEV (OCT } \\
04 \text { ) }\end{array}$ \\
\hline 3791 & OPN CHEST CARDIAC MASSAG \\
\hline 3794 & IMPLT/REPL CARDDEFIB TOT \\
\hline 3795 & IMPLT CARDIODEFIB LEADS \\
\hline 3796 & IMPLT CARDIODEFIB GENATR \\
\hline 3797 & REPL CARDIODEFIB LEADS \\
\hline 3798 & REPL CARDIODEFIB GENRATR \\
\hline 3799 & OTHER HEART/PERICARD OPS \\
\hline
\end{tabular}

\begin{tabular}{|l|l|}
\hline 3800 & INCISION OF VESSEL NOS \\
\hline 3801 & INTRACRAN VESSEL INCIS \\
\hline 3802 & HEAD/NECK VES INCIS NEC \\
\hline 3803 & UPPER LIMB VESSEL INCIS \\
\hline 3804 & INCISION OF AORTA \\
\hline 3805 & THORACIC VESSEL INC NEC \\
\hline 3806 & ABDOMEN ARTERY INCISION \\
\hline 3807 & ABDOMINAL VEIN INCISION \\
\hline 3808 & LOWER LIMB ARTERY INCIS \\
\hline 3809 & LOWER LIMB VEIN INCISION \\
\hline 3810 & ENDARTERECTOMY NOS \\
\hline 3811 & INTRACRAN ENDARTERECTOMY \\
\hline 3812 & HEAD \& NECK ENDARTER NEC \\
\hline 3813 & UPPER LIMB ENDARTERECTOM \\
\hline 3814 & ENDARTERECTOMY OF AORTA \\
\hline 3815 & THORACIC ENDARTERECTOMY \\
\hline 3816 & ABDOMINAL ENDARTERECTOMY \\
\hline 3818 & LOWER LIMB ENDARTERECT \\
\hline 3821 & BLOOD VESSEL BIOPSY \\
\hline 3829 & BLOOD VESSEL DX PROC NEC \\
\hline 3830 & VESSEL RESECT/ANAST NOS \\
\hline 3831 & INTRACRAN VES RESEC-ANAS \\
\hline 3832 & HEAD/NECK VES RESEC-ANAS \\
\hline 3833 & ARM VESSEL RESECT/ANAST \\
\hline 3834 & AORTA RESECTION \& ANAST \\
\hline 3835 & THOR VESSEL RESECT/ANAST \\
\hline 3836 & ABD VESSEL RESECT/ANAST \\
\hline 3837 & ABD VEIN RESECT \& ANAST \\
\hline 3838 & LEG ARTERY RESECT/ANAST \\
\hline 3839 & LEG VEIN RESECT/ANASTOM \\
\hline 3840 & VESSEL RESECT/REPLAC NOS \\
\hline 3841 & INTRACRAN VES RESEC-REPL \\
\hline 3842 & HEAD/NECK VES RESEC-REPL \\
\hline 3843 & ARM VES RESECT W REPLACE \\
\hline 3844 & RESECT ABDM AORTA W REPL \\
\hline 3845 & RESECT THORAC VES W REPL \\
\hline 3846 & ABD ARTERY RESEC W REPLA \\
\hline 3847 & ABD VEIN RESECT W REPLAC \\
\hline 3848 & LEG ARTERY RESEC W REPLA \\
\hline 3849 & LEG VEIN RESECT W REPLAC \\
\hline 3850 & VARICOSE V LIG-STRIP NOS \\
\hline 3851 & INTCRAN VAR V LIG-STRIP \\
\hline 3852 & HEAD/NECK VAR V LIG-STR \\
\hline 3853 & ARM VARICOSE V LIG-STRIP \\
\hline 3855 & THORAC VAR V LIG-STRIP \\
\hline 3857 & ABD VARICOS V LIGA-STRIP \\
\hline 3859 & LEG VARICOS V LIGA-STRIP \\
\hline 3861 & INTRACRAN VESSEL EXCIS \\
\hline 3863 & ARM VESSEL EXCISION \\
\hline
\end{tabular}




\begin{tabular}{|c|c|}
\hline 3864 & EXCISION OF AORTA \\
\hline 3865 & THORACIC VESSEL EXCISION \\
\hline 3866 & ABDOMINAL ARTERY EXCIS \\
\hline 3867 & ABDOMINAL VEIN EXCISION \\
\hline 3868 & LEG ARTERY EXCISION \\
\hline 3869 & LEG VEIN EXCISION \\
\hline 387 & INTERRUPTION VENA CAVA \\
\hline 3880 & SURG VESSEL OCCLUS NEC \\
\hline 3881 & OCCLUS INTRACRAN VES NEC \\
\hline 3882 & OCCLUS HEAD/NECK VES NEC \\
\hline 3883 & OCCLUDE ARM VESSEL NEC \\
\hline 3884 & OCCLUDE AORTA NEC \\
\hline 3885 & OCCLUDE THORACIC VES NEC \\
\hline 3886 & OCCLUDE ABD ARTERY NEC \\
\hline 3887 & OCCLUDE ABD VEIN NEC \\
\hline 3888 & OCCLUDE LEG ARTERY NEC \\
\hline 3889 & OCCLUDE LEG VEIN NEC \\
\hline 390 & SYSTEMIC-PULM ART SHUNT \\
\hline 391 & INTRA-ABD VENOUS SHUNT \\
\hline 3921 & CAVAL-PULMON ART ANASTOM \\
\hline 3922 & AORTA-SUBCLV-CAROT BYPAS \\
\hline 3923 & INTRATHORACIC SHUNT NEC \\
\hline 3924 & AORTA-RENAL BYPASS \\
\hline 3925 & AORTA-ILIAC-FEMOR BYPASS \\
\hline 3926 & INTRA-ABDOMIN SHUNT NEC \\
\hline 3927 & DIALYSIS ARTERIOVENOSTOM \\
\hline 3928 & EXTRACRAN-INTRACR BYPASS \\
\hline 3929 & VASC SHUNT \& BYPASS NEC \\
\hline 3930 & SUTURE OF VESSEL NOS \\
\hline 3931 & SUTURE OF ARTERY \\
\hline 3932 & SUTURE OF VEIN \\
\hline 3941 & POSTOP VASC OP HEM CONTR \\
\hline 3942 & REVIS REN DIALYSIS SHUNT \\
\hline 3943 & REMOV REN DIALYSIS SHUNT \\
\hline 3949 & VASC PROC REVISION NEC \\
\hline 3950 & ANGIO/ATH NON-CORO VES \\
\hline 3951 & CLIPPING OF ANEURYSM \\
\hline 3952 & ANEURYSM REPAIR NEC \\
\hline 3953 & ARTERIOVEN FISTULA REP \\
\hline 3954 & RE-ENTRY OPERATION \\
\hline 3955 & REIMPLAN ABERR RENAL VES \\
\hline 3956 & REPAIR VESS W TIS PATCH \\
\hline 3957 & REP VESS W SYNTH PATCH \\
\hline 3958 & REPAIR VESS W PATCH NOS \\
\hline 3959 & REPAIR OF VESSEL NEC \\
\hline 397 & PER CARDIOPULMON BYPASS \\
\hline 3971 & ENDO IMPL GRFT ABD AORTA \\
\hline 3972 & ENDOVASC REPAIR HEAD VES \\
\hline 3973 & $\begin{array}{l}\text { ENDO IMP GRFT THOR AORTA } \\
\text { OCT05- }\end{array}$ \\
\hline 3974 & $\begin{array}{lllll}\text { ENDO } & \text { REM } & \text { OBS } & \text { HD/NECK } & \text { VES }\end{array}$ \\
\hline
\end{tabular}

\begin{tabular}{|l|l|}
\hline & OCTO6- \\
\hline 3979 & ENDO REPAIR OTHER VESSEL \\
\hline 398 & VASCULAR BODY OPERATIONS \\
\hline 3991 & FREEING OF VESSEL \\
\hline 3992 & VEIN INJECT-SCLEROS AGNT \\
\hline 3993 & INSERT VES-TO-VES CANNUL \\
\hline 3994 & REPLAC VES-TO-VES CANNUL \\
\hline 3998 & HEMORRHAGE CONTROL NOS \\
\hline 3999 & VESSEL OPERATION NEC \\
\hline 400 & INCIS LYMPHATIC STRUCTUR \\
\hline 4011 & LYMPHATIC STRUCT BIOPSY \\
\hline 4019 & LYMPHATIC DIAG PROC NEC \\
\hline 4021 & EXCIS DEEP CERVICAL NODE \\
\hline 4022 & EXCISE INT MAMMARY NODE \\
\hline 4023 & EXCISE AXILLARY NODE \\
\hline 4024 & EXCISE INGUINAL NODE \\
\hline 4029 & SIMP EXC LYMPH STRUC NEC \\
\hline 403 & REGIONAL LYMPH NODE EXC \\
\hline 4040 & RAD NECK DISSECTION NOS \\
\hline 4041 & UNILAT RAD NECK DISSECT \\
\hline 4042 & BILAT RAD NECK DISSECT \\
\hline 4050 & RAD NODE DISSECTION NOS \\
\hline 4051 & RAD DISSEC AXILLARY NODE \\
\hline 4052 & RAD DISSEC PERIAORT NODE \\
\hline 4053 & RAD DISSECT ILIAC NODES \\
\hline 4054 & RADICAL GROIN DISSECTION \\
\hline 4059 & RAD NODE DISSECTION NEC \\
\hline 4061 & THORAC DUCT CANNULATION \\
\hline 4062 & THORACIC DUCT FISTULIZAT \\
\hline 4063 & CLOSE THORACIC DUCT FIST \\
\hline 4064 & LIGATE THORACIC DUCT \\
\hline 4069 & THORACIC DUCT OP NEC \\
\hline 409 & LYMPH STRUCTURE OP NEC \\
\hline 410 & BONE MARROW TRNSPLNT \\
\hline 4100 & BONE MARROW TRNSPLNT NOS \\
\hline 4101 & AUTO BONE MT W/O PURG \\
\hline 4102 & ALO BONE MARROW TRNSPLNT \\
\hline 4103 & ALLOGRFT BONE MARROW NOS \\
\hline 4104 & AUTO HEM STEM CT W/O PUR \\
\hline 4105 & ALLO HEM STEM CT W/O PUR \\
\hline 4106 & CORD BLD STEM CELL TRANS \\
\hline 4107 & AUTO HEM STEM CT W PURG \\
\hline 4108 & ALLO HEM STEM CT W PURG \\
\hline 4109 & AUTO BONE MT W PURGING \\
\hline 412 & SPLENOTOMY \\
\hline 4133 & OPEN SPLEEN BIOPSY \\
\hline 4141 & SPLENIC CYST MARSUPIAL \\
\hline 4142 & EXC SPLENIC LESION/TISS \\
\hline 4193 & PARTIAL SPLENECTOMY \\
\hline & EXC OF ACCESSORY SPLEEN \\
\hline
\end{tabular}




\begin{tabular}{|l|l|}
\hline 4194 & SPLEEN TRANSPLANTATION \\
\hline 4195 & REPAIR OF SPLEEN \\
\hline 4199 & SPLEEN OPERATION NEC \\
\hline 4201 & ESOPHAGEAL WEB INCISION \\
\hline 4209 & ESOPHAGEAL INCISION NEC \\
\hline 4210 & ESOPHAGOSTOMY NOS \\
\hline 4211 & CERVICAL ESOPHAGOSTOMY \\
\hline 4212 & ESOPH POUCH EXTERIORIZAT \\
\hline 4219 & EXT FISTULIZAT ESOPH NEC \\
\hline 4221 & ESOPHAGOSCOPY BY INCIS \\
\hline 4225 & OPEN BIOPSY OF ESOPHAGUS \\
\hline 4231 & LOC EXCIS ESOPH DIVERTIC \\
\hline 4232 & LOCAL EXCIS ESOPHAG NEC \\
\hline 4239 & DESTRUCT ESOPHAG LES NEC \\
\hline 4240 & ESOPHAGECTOMY NOS \\
\hline 4241 & PARTIAL ESOPHAGECTOMY \\
\hline 4242 & TOTAL ESOPHAGECTOMY \\
\hline 4251 & THORAC ESOPHAGOESOPHAGOS \\
\hline 4252 & THORAC ESOPHAGOGASTROST \\
\hline 4253 & THORAC SM BOWEL INTERPOS \\
\hline 4254 & THORAC ESOPHAGOENTER NEC \\
\hline 4255 & THORAC LG BOWEL INTERPOS \\
\hline 4256 & THORAC ESOPHAGOCOLOS NEC \\
\hline 4258 & THORAC INTERPOSITION NEC \\
\hline 4259 & THORAC ESOPHAG ANAST NEC \\
\hline 4261 & STERN ESOPHAGOESOPHAGOST \\
\hline 4262 & STERN ESOPHAGOGASTROSTOM \\
\hline 4263 & STERN SM BOWEL INTERPOS \\
\hline 4264 & STERN ESOPHAGOENTER NEC \\
\hline 4265 & STERN LG BOWEL INTERPOS \\
\hline 4266 & STERN ESOPHAGOCOLOS NEC \\
\hline 4268 & STERN INTERPOSITION NEC \\
\hline 4269 & STERN ESOPHAG ANAST NEC \\
\hline 427 & ESOPHAGOMYOTOMY \\
\hline 4282 & SUTURE ESOPHAGEAL LACER \\
\hline 4283 & ESOPHAGOSTOMY CLOSURE \\
\hline 4284 & ESOPH FISTULA REPAIR NEC \\
\hline 4285 & ESOPHAG STRICTURE REPAIR \\
\hline 4286 & PROD SUBQ TUNNEL NO ANAS \\
\hline 4287 & ESOPHAGEAL GRAFT NEC \\
\hline 4289 & ESOPHAGEAL REPAIR NEC \\
\hline 4291 & LIGATION ESOPH VARIX \\
\hline 430 & GASTROTOMY \\
\hline 431 & GASTROTOMY \\
\hline 432 & OTHER GASTROSTOMY \\
\hline 4342 & LOCAL GASTR EXCISION NEC \\
\hline 437 & POCAL GASTR DESTRUCT NEC \\
\hline
\end{tabular}

\begin{tabular}{|c|c|}
\hline 4381 & PART GAST W JEJ TRANSPOS \\
\hline 4389 & PARTIAL GASTRECTOMY NEC \\
\hline 4391 & TOT GAST W INTES INTERPO \\
\hline 4399 & TOTAL GASTRECTOMY NEC \\
\hline 4400 & VAGOTOMY NOS \\
\hline 4401 & TRUNCAL VAGOTOMY \\
\hline 4402 & HIGHLY SELECT VAGOTOMY \\
\hline 4403 & SELECTIVE VAGOTOMY NEC \\
\hline 4411 & TRANSABDOMIN GASTROSCOPY \\
\hline 4415 & OPEN GASTRIC BIOPSY \\
\hline 442 & GASTRIC DIAGNOS PROC NEC \\
\hline 4421 & DILATE PYLORUS, INCISION \\
\hline 4429 & OTHER PYLOROPLASTY \\
\hline 4431 & HIGH GASTRIC BYPASS \\
\hline 4432 & PERCU GASTROJEJUNOSTOMY \\
\hline 4438 & $\begin{array}{l}\text { LAP GASTROENTEROSTOMY (OCT } \\
\text { 04) }\end{array}$ \\
\hline 4439 & GASTROENTEROSTOMY NEC \\
\hline 4440 & SUTURE PEPTIC ULCER NOS \\
\hline 4441 & SUT GASTRIC ULCER SITE \\
\hline 4442 & SUTURE DUODEN ULCER SITE \\
\hline 445 & REVISION GASTRIC ANASTOM \\
\hline 4461 & SUTURE GASTRIC LACERAT \\
\hline 4463 & CLOSE GASTRIC FISTUL NEC \\
\hline 4464 & GASTROPEXY \\
\hline 4465 & ESOPHAGOGASTROPLASTY \\
\hline 4466 & CREAT ESOPHAGASTR SPHINC \\
\hline 4467 & $\begin{array}{l}\text { LAP CREAT ESOPH SPHINCT (OCT } \\
\text { 04) }\end{array}$ \\
\hline 4468 & $\begin{array}{l}\text { LAPAROSCOP GASTROPLSTY (OCT } \\
04 \text { ) }\end{array}$ \\
\hline 4469 & GASTRIC REPAIR NEC \\
\hline 4491 & LIGATE GASTRIC VARICES \\
\hline 4492 & INTRAOP GASTRIC MANIPUL \\
\hline 4495 & $\begin{array}{l}\text { LAP GASTRIC RESTRIC PROC (OCT } \\
04 \text { ) }\end{array}$ \\
\hline 4496 & $\begin{array}{l}\text { LAP REV GAST RESTRI PROC (OCT } \\
\text { 04) }\end{array}$ \\
\hline 4497 & $\begin{array}{l}\text { LAP REM GAST RESTRIC DEV (OCT } \\
\text { 04) }\end{array}$ \\
\hline 4498 & $\begin{array}{l}\text { ADJUST GAST RESTRICT DEV (OCT } \\
\text { 04) }\end{array}$ \\
\hline 4499 & GASTRIC OPERATION NEC \\
\hline 4500 & INTESTINAL INCISION NOS \\
\hline 4501 & DUODENAL INCISION \\
\hline 4502 & SMALL BOWEL INCISION NEC \\
\hline 4503 & LARGE BOWEL INCISION \\
\hline 4511 & TRANSAB SM BOWEL ENDOSC \\
\hline 4515 & OPEN SMALL BOWEL BIOPSY \\
\hline 4521 & TRANSAB LG BOWEL ENDOSC \\
\hline 4526 & OPEN LARGE BOWEL BIOPSY \\
\hline
\end{tabular}




\begin{tabular}{|l|l|}
\hline 4531 & OTH EXCISE DUODENUM LES \\
\hline 4532 & DESTRUCT DUODEN LES NEC \\
\hline 4533 & LOCAL EXCIS SM BOWEL NEC \\
\hline 4534 & DESTR SM BOWEL LES NEC \\
\hline 4541 & EXCISE LG INTESTINE LES \\
\hline 4549 & DESTRUC LG BOWEL LES NEC \\
\hline 4550 & INTEST SEG ISOLAT NOS \\
\hline 4551 & SM BOWEL SEGMENT ISOLAT \\
\hline 4552 & LG BOWEL SEGMENT ISOLAT \\
\hline 4561 & MULT SEG SM BOWEL EXCIS \\
\hline 4562 & PART SM BOWEL RESECT NEC \\
\hline 4563 & TOTAL REMOVAL SM BOWEL \\
\hline 4571 & MULT SEG LG BOWEL EXCIS \\
\hline 4572 & CECECTOMY \\
\hline 4573 & RIGHT HEMICOLECTOMY \\
\hline 4574 & TRANSVERSE COLON RESECT \\
\hline 4575 & LEFT HEMICOLECTOMY \\
\hline 4576 & SIGMOIDECTOMY \\
\hline 4579 & PART LG BOWEL EXCIS NEC \\
\hline 458 & TOT INTRA-ABD COLECTOMY \\
\hline 4590 & INTESTINAL ANASTOM NOS \\
\hline 4591 & SM-TO-SM BOWEL ANASTOM \\
\hline 4592 & SM BOWEL-RECT STUMP ANAS \\
\hline 4593 & SMALL-TO-LARGE BOWEL NEC \\
\hline 4594 & LG-TO-LG BOWEL ANASTOM \\
\hline 4595 & ANAL ANASTOMOSIS \\
\hline 4601 & SM BOWEL EXTERIORIZATION \\
\hline 4602 & RESECT EXT SEG SM BOWEL \\
\hline 4603 & LG BOWEL EXTERIORIZATION \\
\hline 4604 & RESECT EXT SEG LG BOWEL \\
\hline 4610 & COLOSTOMY NOS \\
\hline 4611 & TEMPORARY COLOSTOMY \\
\hline 4612 & TEMPORARY COLOSTOMY \\
\hline 4613 & PERMANENT COLOSTOMY \\
\hline 4620 & ILEOSTOMY NOS \\
\hline 4621 & TEMPORARY ILEOSTOMY \\
\hline 4622 & CONTINENT ILEOSTOMY \\
\hline 4623 & PERMANENT ILEOSTOMY NEC \\
\hline 4640 & INTEST STOMA REVIS NOS \\
\hline 4641 & SM BOWEL STOMA REVISION \\
\hline 4642 & PERICOLOST HERNIA REPAIR \\
\hline 4643 & LG BOWEL STOMA REVIS NEC \\
\hline 4650 & INTEST STOMA CLOSURE NOS \\
\hline 4651 & SM BOWEL STOMA CLOSURE \\
\hline 4652 & LG BOWEL STOMA CLOSURE \\
\hline 4660 & INTESTINAL FIXATION NOS \\
\hline 4661 & SM BOWEL-ABD WALL FIXAT \\
\hline 4663 & SMALL BOWEL FIXATION NEC \\
\hline 4671 & LAROWEL-ABD WALL FIXAT \\
\hline
\end{tabular}

\begin{tabular}{|c|c|}
\hline 4672 & DUODENAL FISTULA CLOSURE \\
\hline 4673 & SMALL BOWEL SUTURE NEC \\
\hline 4674 & CLOSE SM BOWEL FIST NEC \\
\hline 4675 & $\begin{array}{l}\text { SUTURE LG BOWEL LACERAT } \\
\end{array}$ \\
\hline 4676 & CLOSE LG BOWEL FISTULA \\
\hline 4679 & REPAIR OF INTESTINE NEC \\
\hline 4680 & INTRA-AB BOWEL MANIP NOS \\
\hline 4681 & INTRA-ABD SM BOWEL MANIP \\
\hline 4682 & INTRA-ABD LG BOWEL MANIP \\
\hline 4691 & MYOTOMY OF SIGMOID COLON \\
\hline 4692 & MYOTOMY OF COLON NEC \\
\hline 4693 & REVISE SM BOWEL ANASTOM \\
\hline 4694 & REVISE LG BOWEL ANASTOM \\
\hline 4697 & TRANSPLANT OF INTESTINE \\
\hline 4699 & INTESTINAL OP NEC \\
\hline 470 & INTESTINAL OP NEC \\
\hline 4701 & LAP APPENDECTOMY \\
\hline 4709 & OTHER APPENDECTOMY \\
\hline 471 & OTHER APPENDECTOMY \\
\hline 4711 & LAP INCID APPENDECTOMY \\
\hline 4719 & OTHER INCID APPENDECTOMY \\
\hline 472 & DRAIN APPENDICEAL ABSC \\
\hline 4791 & APPENDICOSTOMY \\
\hline 4792 & CLOSE APPENDICEAL FISTUL \\
\hline 4799 & APPENDICEAL OPS NEC \\
\hline 480 & PROCTOTOMY \\
\hline 481 & PROCTOSTOMY \\
\hline 4821 & TRANSAB PROCTOSIGMOIDOSC \\
\hline 4825 & OPEN RECTAL BIOPSY \\
\hline 4835 & LOCAL EXCIS RECTAL LES \\
\hline 4841 & SOAVE SUBMUC RECT RESECT \\
\hline 4849 & PULL-THRU RECT RESEC NEC \\
\hline 485 & ABD-PERINEAL RECT RESECT \\
\hline 4861 & TRANSSAC RECTOSIGMOIDECT \\
\hline 4862 & ANT RECT RESECT W COLOST \\
\hline 4863 & ANTERIOR RECT RESECT NEC \\
\hline 4864 & POSTERIOR RECT RESECTION \\
\hline 4865 & DUHAMEL RECTAL RESECTION \\
\hline 4866 & DUHAMEL RECTAL RESECTION \\
\hline 4869 & RECTAL RESECTION NEC \\
\hline 4871 & SUTURE OF RECTAL LACER \\
\hline 4872 & CLOSURE OF PROCTOSTOMY \\
\hline 4873 & CLOSE RECTAL FIST NEC \\
\hline 4874 & RECTORECTOSTOMY \\
\hline 4875 & ABDOMINAL PROCTOPEXY \\
\hline 4876 & PROCTOPEXY NEC \\
\hline 4879 & REPAIR OF RECTUM NEC \\
\hline 4881 & PERIRECTAL INCISION \\
\hline 4882 & PERIRECTAL EXCISION \\
\hline 4891 & INCIS RECTAL STRICTURE \\
\hline 4892 & ANORECTAL MYOMECTOMY \\
\hline
\end{tabular}




\begin{tabular}{|c|c|}
\hline 4893 & REPAIR PERIRECT FISTULA \\
\hline 4899 & RECTAL PERIRECT OP NEC \\
\hline 4901 & INCIS PERIANAL ABSCESS \\
\hline 4902 & PERIANAL INCISION NEC \\
\hline 4904 & PERIANAL EXCISION NEC \\
\hline 4911 & ANAL FISTULOTOMY \\
\hline 4912 & ANAL FISTULECTOMY \\
\hline 493 & ANAL/PERIAN DX PROC NEC \\
\hline 4939 & OTHER DESTRUC ANUS LES \\
\hline 4944 & HEMORRHOID CRYOTHERAPY \\
\hline 4945 & HEMORRHOID LIGATION \\
\hline 4946 & HEMORRHOIDECTOMY \\
\hline 4949 & HEMORRHOID PROCEDURE NEC \\
\hline 4951 & LEFT LAT SPHINCTEROTOMY \\
\hline 4952 & POST SPHINCTEROTOMY \\
\hline 4959 & ANAL SPHINCTEROTOMY NEC \\
\hline 496 & EXCISION OF ANUS \\
\hline 4971 & SUTURE ANAL LACERATION \\
\hline 4972 & ANAL CERCLAGE \\
\hline 4973 & CLOSURE OF ANAL FISTULA \\
\hline 4974 & GRACILIS MUSC TRANSPLAN \\
\hline 4975 & IMPL OR REV ART ANAL SPH \\
\hline 4976 & REMOV ART ANAL SPHINCTER \\
\hline 4979 & ANAL SPHINCT REPAIR NEC \\
\hline 4991 & INCISION OF ANAL SEPTUM \\
\hline 4992 & INSERT SUBQ ANAL STIMUL \\
\hline 4993 & ANAL INCISION NEC \\
\hline 4994 & REDUCTION ANAL PROLAPSE \\
\hline 4995 & CONTROL ANAL HEMORRHAGE \\
\hline 4999 & ANAL OPERATION NEC \\
\hline 500 & HEPATOTOMY \\
\hline 5012 & OPEN LIVER BIOPSY \\
\hline 5019 & HEPATIC DX PROC NEC \\
\hline 5021 & MARSUPIALIZAT LIVER LES \\
\hline 5022 & PARTIAL HEPATECTOMY \\
\hline 5023 & $\begin{array}{l}\text { OPN ABLTN LIVER } \\
\text { OCT06- }\end{array}$ \\
\hline 5024 & PERC ABLTN LIVER LES/TIS OCT06- \\
\hline 5025 & LAP ABLTN LIVER LES/TISS OCT06- \\
\hline 5026 & $\begin{array}{llll}\text { ABLTN } & \text { LIVER } & \text { LES/TISS } & \text { NEC } \\
\text { OCT06- }\end{array}$ \\
\hline 5029 & DESTRUC HEPATIC LES NEC \\
\hline 503 & HEPATIC LOBECTOMY \\
\hline 504 & TOTAL HEPATECTOMY \\
\hline 5051 & AUXILIARY LIVER TRANSPL \\
\hline 5059 & LIVER TRANSPLANT NEC \\
\hline 5061 & CLOSURE LIVER LACERAT \\
\hline 5069 & LIVER REPAIR NEC \\
\hline 5102 & TROCAR CHOLECYSTOSTOMY \\
\hline 5103 & CHOLECYSTOSTOMY NEC \\
\hline 5104 & CHOLECYSTOTOMY NEC \\
\hline
\end{tabular}

\begin{tabular}{|c|c|}
\hline 5113 & OPEN BILIARY TRACT BX \\
\hline 5119 & BILIARY TR DX PROC NEC \\
\hline 5121 & OTH PART CHOLECYSTECTOMY \\
\hline 5122 & CHOLECYSTECTOMY \\
\hline 5123 & LAPAROSCOPIC CHOLECYSTEC \\
\hline 5124 & LAP PART CHOLECYSTECTOMY \\
\hline 5131 & GB-TO-HEPAT DUCT ANAST \\
\hline 5132 & GB-TO-INTESTINE ANASTOM \\
\hline 5133 & GB-TO-PANCREAS ANASTOM \\
\hline 5134 & GB-TO-STOMACH ANASTOMOS \\
\hline 5135 & GALLBLADDER ANASTOM NEC \\
\hline 5136 & CHOLEDOCHOENTEROSTOMY \\
\hline 5137 & HEPATIC DUCT-GI ANASTOM \\
\hline 5139 & BILE DUCT ANASTOMOS NEC \\
\hline 5141 & CDE FOR CALCULUS REMOV \\
\hline 5142 & CDE FOR OBSTRUCTION NEC \\
\hline 5143 & CHOLEDOCHOHEPAT INTUBAT \\
\hline 5149 & INCIS OBSTR BILE DUC NEC \\
\hline 5151 & COMMON DUCT EXPLORATION \\
\hline 5159 & BILE DUCT INCISION NEC \\
\hline 5161 & EXCIS CYST DUCT REMNANT \\
\hline 5162 & EXCIS AMPULLA OF VATER \\
\hline 5163 & COMMON DUCT EXCIS NEC \\
\hline 5169 & BILE DUCT EXCISION NEC \\
\hline 5171 & SIMPLE SUT-COMMON DUCT \\
\hline 5172 & CHOLEDOCHOPLASTY \\
\hline 5179 & BILE DUCT REPAIR NEC \\
\hline 5181 & SPHINCTER OF ODDI DILAT \\
\hline 5182 & PANCREAT SPHINCTEROTOM \\
\hline 5183 & PANCREAT SPHINCTEROPLAS \\
\hline 5189 & SPHINCT OF ODDI OP NEC \\
\hline 5191 & REPAIR GB LACERATION \\
\hline 5192 & CLOSURE CHOLECYSTOSTOMY \\
\hline 5193 & CLOS BILIARY FISTUL NEC \\
\hline 5194 & REVIS BILE TRACT ANASTOM \\
\hline 5195 & REMOVE BILE DUCT PROSTH \\
\hline 5199 & BILIARY TRACT OP NEC \\
\hline 5201 & CATH DRAIN-PANCREAT CYST \\
\hline 5209 & PANCREATOTOMY NEC \\
\hline 5212 & OPEN PANCREATIC BIOPSY \\
\hline 5219 & PANCREATIC DX PROC NEC \\
\hline 522 & PANCREATIC DX PROC NEC \\
\hline 5222 & OTHER DESTRU PANCREA LES \\
\hline 523 & PANCREAT CYST MARSUPIALI \\
\hline 524 & INT DRAIN PANCREAT CYST \\
\hline 5251 & PROXIMAL PANCREATECTOMY \\
\hline 5252 & DISTAL PANCREATECTOMY \\
\hline 5253 & RAD SUBTOT PANCREATECTOM \\
\hline 5259 & PARTIAL PANCREATECT NEC \\
\hline 526 & TOTAL PANCREATECTOMY \\
\hline 527 & RAD PANCREATICODUODENECT \\
\hline
\end{tabular}




\begin{tabular}{|c|c|}
\hline 5280 & PANCREAT TRANSPLANT NOS \\
\hline 5281 & REIMPLANT PANCREATIC TIS \\
\hline 5282 & PANCREATIC HOMOTRANSPLAN \\
\hline 5283 & PANCREATIC HETEROTRANSPL \\
\hline 5291 & TRNSPLNT ISLETS LANG NOS \\
\hline 5292 & CANNULATION PANCREA DUC \\
\hline 5295 & PANCREATIC REPAIR NEC \\
\hline 5296 & PANCREATIC ANASTOMOSIS \\
\hline 5299 & PANCREATIC OPERATION NEC \\
\hline 5300 & UNILAT ING HERN REP NOS \\
\hline 5301 & REPAIR DIRECT ING HERNIA \\
\hline 5302 & REPAIR INDIR ING HERNIA \\
\hline 5303 & DIR ING HERNIA REP-GRAFT \\
\hline 5304 & IND ING HERNIA REP-GRAFT \\
\hline 5305 & ING HERNIA REP-GRAFT NOS \\
\hline 5310 & BILAT ING HERNIA REP NOS \\
\hline 5311 & BILAT DIR ING HERN REP \\
\hline 5312 & BILAT IND ING HERN REP \\
\hline 5313 & BIL DIR/IND ING HRN REP \\
\hline 5314 & BIL DIR ING HRN REP-GRFT \\
\hline 5315 & BIL IND ING HRN REP-GRFT \\
\hline 5316 & BIL DIR/IND ING HERN-PRO \\
\hline 5317 & BIL ING HRN REP-GRFT NOS \\
\hline 5321 & UNIL FEMOR HRN REP-GRFT \\
\hline 5329 & UNIL FEMOR HERN REP NEC \\
\hline 5331 & BIL FEM HERN REPAIR-GRFT \\
\hline 5339 & BIL FEM HERN REPAIR NEC \\
\hline 5341 & UMBIL HERNIA REPAIR-GRFT \\
\hline 5349 & UMBIL HERNIA REPAIR NEC \\
\hline 5351 & INCISIONAL HERNIA REPAIR \\
\hline 5359 & ABD WALL HERN REPAIR NEC \\
\hline 5361 & INCIS HERNIA REPAIR-GRFT \\
\hline 5369 & ABD HERN REPAIR-GRFT NEC \\
\hline 537 & ABD REPAIR-DIAPHR HERNIA \\
\hline 5380 & THOR REP-DIAPH HERN NOS \\
\hline 5381 & DIAPHRAGMATIC PLICATION \\
\hline 5382 & PARASTERN HERNIA REPAIR \\
\hline 539 & OTHER HERNIA REPAIR \\
\hline 540 & ABDOMINAL WALL INCISION \\
\hline 5411 & EXPLORATORY LAPAROTOMY \\
\hline 5412 & REOPEN RECENT LAP SITE \\
\hline 5419 & LAPAROTOMY NEC \\
\hline 5421 & LAPAROSCOPY \\
\hline 5422 & ABDOMINAL WALL BIOPSY \\
\hline 5423 & PERITONEAL BIOPSY \\
\hline 5429 & ABD REGION DX PROC NEC \\
\hline 543 & DESTRUCT ABD WALL LESION \\
\hline 544 & DESTRUCT PERITONEAL TISS \\
\hline 545 & DESTRUCT PERITONEAL TISS \\
\hline 5451 & LAP PERITON ADHESIOLYSIS \\
\hline 5459 & OTH PERITON ADHESIOLYSIS \\
\hline
\end{tabular}

\begin{tabular}{|c|c|}
\hline 5461 & RECLOSE POST OP DISRUPT \\
\hline 5462 & DELAYED CLOS ABD WOUND \\
\hline 5463 & ABD WALL SUTURE NEC \\
\hline 5464 & PERITONEAL SUTURE \\
\hline 5471 & REPAIR OF GASTROSCHISIS \\
\hline 5472 & ABDOMEN WALL REPAIR NEC \\
\hline 5473 & PERITONEAL REPAIR NEC \\
\hline 5474 & OMENTAL REPAIR NEC \\
\hline 5475 & MESENTERIC REPAIR NEC \\
\hline 5492 & REMOVE FB FROM PERITON \\
\hline 5493 & CREATE CUTANPERITON FIST \\
\hline 5494 & CREAT PERITONEOVAS SHUNT \\
\hline 5495 & PERITONEAL INCISION \\
\hline 5501 & NEPHROTOMY \\
\hline 5502 & NEPHROSTOMY \\
\hline 5503 & PERCU NEPHROSTM W/O FRAG \\
\hline 5504 & PERCU NEPHROSTMY W FRAG \\
\hline 5511 & PYELOTOMY \\
\hline 5512 & PYELOSTOMY \\
\hline 5524 & OPEN RENAL BIOPSY \\
\hline 5529 & RENAL DIAGNOST PROC NEC \\
\hline 5531 & RENAL LES MARSUPIALIZAT \\
\hline 5532 & $\begin{array}{l}\text { OPN ABLTN RENAL } \\
\text { OCT06- }\end{array}$ \\
\hline 5533 & $\begin{array}{l}\text { PERC ABLTN RENL } \\
\text { OCT06- }\end{array}$ \\
\hline 5534 & $\begin{array}{l}\text { LAP ABLTN RENAL } \\
\text { OCT06- }\end{array}$ \\
\hline 5535 & $\begin{array}{llll}\text { ABLTN } & \text { RENAL } & \text { LES/TISS } & \text { NEC } \\
\text { OCT06- } & & & \\
\end{array}$ \\
\hline 5539 & LOC DESTR RENAL LES NEC \\
\hline 554 & PARTIAL NEPHRECTOMY \\
\hline 5551 & NEPHROURETERECTOMY \\
\hline 5552 & SOLITARY KIDNEY NEPHRECT \\
\hline 5553 & REJECTED KIDNEY NEPHRECT \\
\hline 5554 & BILATERAL NEPHRECTOMY \\
\hline 5561 & RENAL AUTOTRANSPLANT \\
\hline 5569 & KIDNEY TRANSPLANT NEC \\
\hline 557 & NEPHROPEXY \\
\hline 5581 & SUTURE KIDNEY LACERATION \\
\hline 5582 & CLOSE NEPHROST \& PYELOST \\
\hline 5583 & CLOSE RENAL FISTULA NEC \\
\hline 5584 & REDUCE RENAL PEDICL TORS \\
\hline 5585 & SYMPHYSIOTOMY \\
\hline 5586 & RENAL ANASTOMOSIS \\
\hline 5587 & CORRECT URETEROPELV JUNC \\
\hline 5589 & RENAL REPAIR NEC \\
\hline 5591 & RENAL DECAPSULATION \\
\hline 5597 & IMPLANT MECHANIC KIDNEY \\
\hline 5598 & REMOV MECHANICAL KIDNEY \\
\hline 5599 & RENAL OPERATION NEC \\
\hline
\end{tabular}




\begin{tabular}{|l|l|}
\hline 560 & TU REMOV URETER OBSTRUCT \\
\hline 561 & URETERAL MEATOTOMY \\
\hline 562 & URETEROTOMY \\
\hline 5634 & OPEN URETERAL BIOPSY \\
\hline 5639 & URETERAL DX PROCEDUR NEC \\
\hline 5640 & URETERECTOMY NOS \\
\hline 5641 & PARTIAL URETERECTOMY \\
\hline 5642 & TOTAL URETERECTOMY \\
\hline 5651 & FORM CUTAN ILEOURETEROST \\
\hline 5652 & REVIS CUTAN ILEOURETEROS \\
\hline 5661 & FORM CUTAN URETEROSTOMY \\
\hline 5662 & REVIS CUTAN URETEROS NEC \\
\hline 5671 & URIN DIVERSION TO BOWEL \\
\hline 5672 & REVIS URETEROENTEROSTOMY \\
\hline 5673 & NEPHROCYSTANASTOMOSI NOS \\
\hline 5674 & URETERONEOCYSTOSTOMY \\
\hline 5675 & TRANSURETEROURETEROSTOMY \\
\hline 5679 & URETERAL ANASTOMOSIS NEC \\
\hline 5681 & INTRALUM URETE ADHESIOLY \\
\hline 5682 & SUTURE URETERAL LACERAT \\
\hline 5683 & URETEROSTOMY CLOSURE \\
\hline 5684 & CLOSE URETER FISTULA NEC \\
\hline 5685 & URETEROPEXY \\
\hline 5686 & REMOVE URETERAL LIGATURE \\
\hline 5689 & REPAIR OF URETER NEC \\
\hline 5692 & IMPLANT URETERAL STIMUL \\
\hline 5693 & REPLACE URETERAL STIMUL \\
\hline 5694 & REMOVE URETERAL STIMULAT \\
\hline 5695 & LIGATION OF URETER \\
\hline 5699 & URETERAL OPERATION NEC \\
\hline 5712 & CYSTOTOMY \& ADHESIOLYSIS \\
\hline 5718 & OTHER SUPRAPU CYSTOSTOMY \\
\hline 5719 & CYSTOTOMY NEC \\
\hline 5721 & VESICOSTOMY \\
\hline 5722 & REVISE CLO VESICOSTOMY \\
\hline 5733 & CLOS TRANSURETH BLADD BX \\
\hline 5734 & OPEN BLADDER BIOPSY \\
\hline 5739 & BLADDER DIAGNOS PROC NEC \\
\hline 5741 & TU ADHESIOLYSIS BLADDER \\
\hline 5749 & TU DESTRUC BLADD LES NEC \\
\hline 5751 & EXCISION OF URACHUS \\
\hline 5759 & BLADDER LES DESTRUCT NEC \\
\hline 576 & PARTIAL CYSTECTOMY \\
\hline 5771 & RADICAL CYSTECTOMY \\
\hline 5779 & TOTAL CYSTECTOMY NEC \\
\hline 5781 & SUTURE BLADDER LACERAT \\
\hline 5782 & CYSTOSTOMY CLOSURE \\
\hline 5784 & VESIC FISTULA REPAIR NEC \\
\hline 5786 & BLADDER EXSTROPHY REPAIR \\
\hline
\end{tabular}

\begin{tabular}{|l|l|}
\hline 5787 & BLADDER RECONSTRUCTION \\
\hline 5788 & BLADDER ANASTOMOSIS NEC \\
\hline 5789 & BLADDER REPAIR NEC \\
\hline 5791 & BLADDER SPHINCTEROTOMY \\
\hline 5793 & CONTROL BLADD HEMORRHAGE \\
\hline 5796 & IMPLANT BLADDER STIMULAT \\
\hline 5797 & REPLACE BLADDER STIMULAT \\
\hline 5798 & REMOVE BLADDER STIMULAT \\
\hline 5799 & BLADDER OPERATION NEC \\
\hline 580 & URETHROTOMY \\
\hline 581 & URETHRAL MEATOTOMY \\
\hline 5841 & SUTURE URETHRAL LACERAT \\
\hline 5842 & URETHROSTOMY CLOSURE \\
\hline 5843 & CLOSE URETH FISTULA NEC \\
\hline 5844 & URETHRAL REANASTOMOSIS \\
\hline 5845 & HYPO-EPISPADIUS REPAIR \\
\hline 5846 & URETH RECONSTRUCTION NEC \\
\hline 5847 & URETHRAL MEATOPLASTY \\
\hline 5849 & URETHRAL REPAIR NEC \\
\hline 585 & URETH STRICTURE RELEASE \\
\hline 5891 & PERIURETHRAL INCISION \\
\hline 5892 & PERIURETHRAL EXCISION \\
\hline 5893 & IMPLT ARTF URIN SPHINCT \\
\hline 5899 & URETH/PERIURETH OP NEC \\
\hline 5900 & RETROPERIT DISSECT NOS \\
\hline 5901 & RETROPERIT DISSECT NOS \\
\hline 5902 & PERIREN ADHESIOLYS NEC \\
\hline 5903 & LAP LYS PERIREN/URET ADH \\
\hline 5909 & PERIREN/URETER INCIS NEC \\
\hline 5911 & OTH LYS PERIVES ADHESIO \\
\hline 5912 & LAP LYS PERIVESURETH ADH \\
\hline 5919 & PERIVESICAL INCISION NEC \\
\hline 5921 & PERIREN/URETERAL BIOPSY \\
\hline 5929 & PERIREN/URET DX PROC NEC \\
\hline 593 & URETHROVES JUNCT PLICAT \\
\hline 594 & SUPRAPUBIC SLING OP \\
\hline 595 & RETROPUBIC URETH SUSPENS \\
\hline 596 & PARAURETHRAL SUSPENSION \\
\hline 5971 & LEVATOR MUSC SUSPENSION \\
\hline 5979 & URIN INCONTIN REPAIR NEC \\
\hline 5991 & PERIREN/VESICLE EXCISION \\
\hline 5992 & PERIREN/VESICLE OP NEC \\
\hline 600 & INCISION OF PROSTATE \\
\hline 6012 & OPEN PROSTATIC BIOPSY \\
\hline 6014 & OPEN SEMINAL VESICLES BX \\
\hline 6015 & PERIPROSTATIC BIOPSY \\
\hline 6018 & PROSTATIC DX PROCED NEC \\
\hline 6019 & SEMIN VES DX PROCED NEC \\
\hline 6021 & TEMIN VES DX PROCED NEC \\
\hline 6029 & OTH TRANSURETH PROSTATEC \\
\hline
\end{tabular}




\begin{tabular}{|l|l|}
\hline 603 & SUPRAPUBIC PROSTATECTOMY \\
\hline 604 & RETROPUBIC PROSTATECTOMY \\
\hline 605 & RADICAL PROSTATECTOMY \\
\hline 6061 & LOS EXCIS PROSTATIC LES \\
\hline 6062 & PERINEAL PROSTATECTOMY \\
\hline 6069 & PROSTATECTOMY NEC \\
\hline 6072 & SEMINAL VESICLE INCISION \\
\hline 6073 & SEMINAL VESICLE EXCISION \\
\hline 6079 & SEMINAL VESICLE OP NEC \\
\hline 6081 & PERIPROSTATIC INCISION \\
\hline 6082 & PERIPROSTATIC EXCISION \\
\hline 6093 & REPAIR OF PROSTATE \\
\hline 6094 & CONTROL PROSTATE HEMORR \\
\hline 6095 & TRANS BAL DIL PROS URETH \\
\hline 6096 & TU DESTR PROSTATE BY MT \\
\hline 6097 & OTH TU DESTR PROS - RT \\
\hline 6099 & PROSTATIC OPERATION NEC \\
\hline 612 & EXCISION OF HYDROCELE \\
\hline 6142 & SCROTAL FISTULA REPAIR \\
\hline 6149 & SCROTUM/TUNIC REPAIR NEC \\
\hline 6192 & EXCISION TUNICA LES NEC \\
\hline 6199 & SCROTUM \& TUNICA OP NEC \\
\hline 620 & INCISION OF TESTES \\
\hline 6212 & OPEN TESTICULAR BIOPSY \\
\hline 6219 & TESTES DX PROCEDURE NEC \\
\hline 622 & TESTICULAR LES DESTRUCT \\
\hline 623 & UNILATERAL ORCHIECTOMY \\
\hline 6241 & REMOVE BOTH TESTES \\
\hline 6242 & REMOVE SOLITARY TESTIS \\
\hline 625 & ORCHIOPEXY \\
\hline 6261 & SUTURE TESTICULAR LACER \\
\hline 6269 & TESTICULAR REPAIR NEC \\
\hline 627 & INSERT TESTICULAR PROSTH \\
\hline 6299 & TESTICULAR OPERATION NEC \\
\hline 6309 & SPERMAT CORD/VAS DX NEC \\
\hline 631 & EXC SPERMATIC VARICOCELE \\
\hline 632 & EXCISE EPIDIDYMIS CYST \\
\hline 633 & EXCISE CORD/EPID LES NEC \\
\hline 634 & EPIDIDYMECTOMY \\
\hline 6351 & SUTURE CORD \& EPID LACER \\
\hline 6353 & TRANSPLANT SPERMAT CORD \\
\hline 6359 & CORD \& EPIDID REPAIR NEC \\
\hline 6381 & SUTURE VAS \& EPIDID LAC \\
\hline 6382 & POSTOP VAS RECONSTRUCT \\
\hline 6383 & EPIDIDYMOVASOSTOMY \\
\hline 6385 & REMOV VAS DEFERENS VALVE \\
\hline 6389 & VAS \& EPIDIDY REPAIR NEC \\
\hline 6393 & SPERMATIC CORD INCISION \\
\hline 6395 & INSERT VALVE IN VAS DEF \\
\hline & \\
\hline $6 E R M ~$ \\
\hline
\end{tabular}

\begin{tabular}{|c|c|}
\hline 6399 & CORD/EPID/VAS OPS NEC \\
\hline 640 & CIRCUMCISION \\
\hline 6411 & PENILE BIOPSY \\
\hline 642 & LOCAL EXCIS PENILE LES \\
\hline 643 & AMPUTATION OF PENIS \\
\hline 6441 & SUTURE PENILE LACERATION \\
\hline 6442 & RELEASE OF CHORDEE \\
\hline 6443 & CONSTRUCTION OF PENIS \\
\hline 6444 & RECONSTRUCTION OF PENIS \\
\hline 6445 & REPLANTATION OF PENIS \\
\hline 6449 & PENILE REPAIR NEC \\
\hline 645 & SEX TRANSFORMAT OP NEC \\
\hline 6492 & INCISION OF PENIS \\
\hline 6493 & DIVISION OF PENILE ADHES \\
\hline 6495 & INS NONINFL PENIS PROSTH \\
\hline 6496 & REMOVE INT PENILE PROSTH \\
\hline 6497 & INS INFLATE PENIS PROSTH \\
\hline 6498 & PENILE OPERATION NEC \\
\hline 6499 & MALE GENITAL OP NEC \\
\hline 650 & MALE GENITAL OP NEC \\
\hline 6501 & LAPAROSCOPIC OOPHOROTOMY \\
\hline 6509 & OTHER OOPHOROTOMY \\
\hline 6511 & OVARIAN ASPIRAT BIOPSY \\
\hline 6512 & OVARIAN BIOPSY NEC \\
\hline 6513 & LAP BIOPSY OF OVARY \\
\hline 6514 & OTH LAP DX PROC OVARIES \\
\hline 6519 & OVARIAN DX PROCEDURE NEC \\
\hline 6521 & OVARIAN CYST MARSUPIALIZ \\
\hline 6522 & OVARIAN WEDGE RESECTION \\
\hline 6523 & LAP MARSUP OVARIAN CYST \\
\hline 6524 & LAP WEDGE RESECT OVARY \\
\hline 6525 & OTH LAP LOC EXC DEST OVA \\
\hline 6529 & LOCAL DESTR OVA LES NEC \\
\hline 653 & LOCAL DESTR OVA LES NEC \\
\hline 6531 & LAP UNILAT OOPHORECTOMY \\
\hline 6539 & OTH UNILAT OOPHORECTOMY \\
\hline 654 & OTH UNILAT OOPHORECTOMY \\
\hline 6541 & LAP UNI SALPINGO-OOPHOR \\
\hline 6549 & OTH UNI SALPINGO-OOPHOR \\
\hline 6551 & OTH REMOVE BOTH OVARIES \\
\hline 6552 & OTH REMOVE REMAIN OVARY \\
\hline 6553 & LAP REMOVE BOTH OVARIES \\
\hline 6554 & LAP REMOVE REMAIN OVARY \\
\hline 6561 & OTH REMOVE OVARIES/TUBES \\
\hline 6562 & OTH REMOVE REM OVA/TUBE \\
\hline 6563 & LAP REMOVE OVARIES/TUBES \\
\hline 6564 & LAP REMOVE REM OVA/TUBE \\
\hline 6571 & OTH SIMPLE SUTURE OVARY \\
\hline 6572 & OTH REIMPLANT OF OVARY \\
\hline 6573 & OTH SALPINGO-OOPHOROPLAS \\
\hline 6574 & LAP SIMPLE SUTURE OVARY \\
\hline
\end{tabular}




\begin{tabular}{|c|c|}
\hline 6575 & LAP REIMPLANT OF OVARY \\
\hline 6576 & LAP SALPINGO-OOPHOROPLAS \\
\hline 6579 & REPAIR OF OVARY NEC \\
\hline 658 & REPAIR OF OVARY NEC \\
\hline 6581 & LAP ADHESIOLYS OVA/TUBE \\
\hline 6589 & ADHESIOLYSIS OVARY/TUBE \\
\hline 6591 & ASPIRATION OF OVARY \\
\hline 6592 & TRANSPLANTATION OF OVARY \\
\hline 6593 & MANUAL RUPT OVARIAN CYST \\
\hline 6594 & OVARIAN DENERVATION \\
\hline 6595 & OVARIAN TORSION RELEASE \\
\hline 6599 & OVARIAN OPERATION NEC \\
\hline 660 & OVARIAN OPERATION NEC \\
\hline 6601 & SALPINGOTOMY \\
\hline 6602 & SALPINGOSTOMY \\
\hline 6611 & FALLOPIAN TUBE BIOPSY \\
\hline 6619 & FALLOP TUBE DX PROC NEC \\
\hline 6621 & BILAT ENDOSC CRUSH TUBE \\
\hline 6622 & BILAT ENDOSC DIVIS TUBE \\
\hline 6629 & BILAT ENDOS OCC TUBE NEC \\
\hline 6631 & BILAT TUBAL CRUSHING NEC \\
\hline 6632 & BILAT TUBAL DIVISION NEC \\
\hline 6639 & BILAT TUBAL DESTRUCT NEC \\
\hline 664 & TOTAL UNILAT SALPINGECT \\
\hline 6651 & REMOVE BOTH FALLOP TUBES \\
\hline 6652 & REMOVE SOLITARY FAL TUBE \\
\hline 6661 & DESTROY FALLOP TUBE LES \\
\hline 6662 & REMOV TUBE \& ECTOP PREG \\
\hline 6663 & BILAT PART SALPINGEC NOS \\
\hline 6669 & PARTIAL SALPINGECTOM NEC \\
\hline 6671 & SIMPL SUTURE FALLOP TUBE \\
\hline 6672 & SALPINGO-OOPHOROSTOMY \\
\hline 6673 & SALPINGO-SALPINGOSTOMY \\
\hline 6674 & SALPINGO-UTEROSTOMY \\
\hline 6679 & FALLOP TUBE REPAIR NEC \\
\hline 6692 & $\begin{array}{l}\text { UNILAT FALLOP TUBE DESTR } \\
\end{array}$ \\
\hline 6693 & IMPL FALLOP TUBE PROSTH \\
\hline 6694 & REMOV FALLOP TUBE PROSTH \\
\hline 6695 & BLOW THERAPEUT INTO TUBE \\
\hline 6696 & FALLOPIAN TUBE DILATION \\
\hline 6697 & BURY FIMBRIAE IN UTERUS \\
\hline 6699 & FALLOPIAN TUBE OP NEC \\
\hline 6711 & ENDOCERVICAL BIOPSY \\
\hline 6712 & CERVICAL BIOPSY NEC \\
\hline 6719 & CERVICAL DX PROCEDUR NEC \\
\hline 672 & CONIZATION OF CERVIX \\
\hline 6731 & CERVICAL CYST MARSUPIAL \\
\hline 6732 & CERVICAL LES CAUTERIZAT \\
\hline 6733 & CERVICAL LES CRYOTHERAPY \\
\hline 6739 & CERVICAL LES DESTRUC NEC \\
\hline 674 & AMPUTATION OF CERVIX \\
\hline
\end{tabular}

\begin{tabular}{|c|c|}
\hline 675 & AMPUTATION OF CERVIX \\
\hline 6751 & TRANSAB CERCLAGE CERVIX \\
\hline 6759 & OTH REP INT CERVICAL OS \\
\hline 6761 & SUTURE CERVICAL LACERAT \\
\hline 6762 & CERVICAL FISTULA REPAIR \\
\hline 6769 & CERVICAL REPAIR NEC \\
\hline 680 & HYSTEROTOMY \\
\hline 6813 & OPEN UTERINE BIOPSY \\
\hline 6814 & OPEN UTERINE LIGAMENT BX \\
\hline 6815 & CLOS UTERINE LIGAMENT BX \\
\hline 6816 & CLOSED UTERINE BIOPSY \\
\hline 6819 & UTERUS/ADNEX DX PROC NEC \\
\hline 6821 & ENDOMET SYNECHIAE DIVIS \\
\hline 6822 & INCISION UTERINE SEPTUM \\
\hline 6823 & ENDOMETRIAL ABLATION \\
\hline 6829 & UTERINE LES DESTRUCT NEC \\
\hline 683 & UTERINE LES DESTRUCT NEC \\
\hline 6831 & LAP SCERVIC HYSTERECTOMY \\
\hline 6839 & $\begin{array}{l}\text { OTH SUBTOT ABD HYSTERECT } \\
\text { OCT03- }\end{array}$ \\
\hline 684 & TOTAL ABD HYSTERECTOMY \\
\hline 6841 & $\begin{array}{l}\text { LAP TOTAL ABDOMINAL HYST } \\
\text { OCT06- }\end{array}$ \\
\hline 6849 & TOTAL ABD HYST NEC/NOS OCT06- \\
\hline 685 & VAGINAL HYSTERECTOMY \\
\hline 6851 & LAP AST VAG HYSTERECTOMY \\
\hline 6859 & CTOMY NEC/NOS \\
\hline 686 & RADICAL ABD HYSTERECTOMY \\
\hline 6861 & $\begin{array}{l}\text { LAP RADICAL ABDOMNL HYST } \\
\text { OCT06- }\end{array}$ \\
\hline 6869 & $\begin{array}{l}\text { RADICAL ABD } \\
\text { OCT06- }\end{array}$ \\
\hline 687 & RADICAL VAG HYSTERECTOMY \\
\hline 6871 & $\begin{array}{l}\text { LAP RADICAL VAGINAL HYST } \\
\text { OCT06- }\end{array}$ \\
\hline 6879 & $\begin{array}{l}\text { RADICAL VAG HYST NEC/NOS } \\
\text { OCT06- }\end{array}$ \\
\hline 688 & PELVIC EVISCERATION \\
\hline 689 & HYSTERECTOMY NEC/NOS \\
\hline 6901 & D \& C FOR PREG TERMINAT \\
\hline 6902 & D \& C POST DELIVERY \\
\hline 6909 & D \& C NEC \\
\hline 6911 & D \& C NEC \\
\hline 6919 & DESTRUC UTER SUPPORT NEC \\
\hline 6921 & INTERPOSIT OP UTERIN LIG \\
\hline 6922 & UTERINE SUSPENSION NEC \\
\hline 6923 & VAG REPAIR INVERS UTERUS \\
\hline 6929 & UTERUS/ADNEXA REPAIR NEC \\
\hline 693 & PARACERV UTERINE DENERV \\
\hline 6941 & SUTURE UTERINE LACERAT \\
\hline 694 & CLOSURE UTERINE FISTUL \\
\hline
\end{tabular}




\begin{tabular}{|l|l|}
\hline 6949 & UTERINE REPAIR NEC \\
\hline 6951 & ASPIRAT CURET-PREG TERMI \\
\hline 6952 & ASPIRAT CURET-POST DELIV \\
\hline 6995 & INCISION OF CERVIX \\
\hline 6997 & REMOVE PENETRAT CERV FB \\
\hline 6998 & UTERINE SUPPORT OP NEC \\
\hline 6999 & UTERINE OPERATION NEC \\
\hline 7012 & CULDOTOMY \\
\hline 7013 & INTRALUM VAG ADHESIOLYS \\
\hline 7014 & VAGINOTOMY NEC \\
\hline 7023 & CUL-DE-SAC BIOPSY \\
\hline 7024 & VAGINAL BIOPSY \\
\hline 7029 & VAGIN/CUL-DE-SAC DX NEC \\
\hline 7031 & HYMENECTOMY \\
\hline 7032 & EXCIS CUL-DE-SAC LESION \\
\hline 7033 & EXCISION VAGINAL LESION \\
\hline 704 & VAGINAL OBLITERATION \\
\hline 7050 & CYSTOCEL/RECTOCEL REPAIR \\
\hline 7051 & CYSTOCELE REPAIR \\
\hline 7052 & RECTOCELE REPAIR \\
\hline 7061 & VAGINAL CONSTRUCTION \\
\hline 7062 & VAGINAL RECONSTRUCTION \\
\hline 7071 & SUTURE VAGINA LACERATION \\
\hline 7072 & REPAIR COLOVAGIN FISTULA \\
\hline 7073 & REPAIR RECTOVAG FISTULA \\
\hline 7074 & REP VAGINOENT FISTUL NEC \\
\hline 7075 & REPAIR VAG FISTULA NEC \\
\hline 7076 & HYMENORRHAPHY \\
\hline 7077 & VAGINAL SUSPENS \& FIXAT \\
\hline 7079 & VAGINAL REPAIR NEC \\
\hline 708 & VAGINAL VAULT OBLITERAT \\
\hline 7091 & VAGINAL OPERATION NEC \\
\hline 7092 & CUL-DE-SAC OPERATION NEC \\
\hline 7101 & VULVAR ADHESIOLYSIS \\
\hline 7109 & INCIS VULVA/PERINEUM NEC \\
\hline 7111 & VULVAR BIOPSY \\
\hline 7119 & VULVAR DIAGNOS PROC NEC \\
\hline 7122 & INCISE BARTHOLIN"S GLAND \\
\hline 7123 & BARTHOLIN GLAND MARSUP \\
\hline 7124 & DESTRUC BARTHOLIN GLAND \\
\hline 7129 & BARTHOLIN"S GLAND OP NEC \\
\hline 713 & LOCAL VULVAR EXCIS NEC \\
\hline 714 & OPERATIONS ON CLITORIS \\
\hline 715 & RADICAL VULVECTOMY \\
\hline 7161 & UNILATERAL VULVECTOMY \\
\hline 7162 & BILATERAL VULVECTOMY \\
\hline 7172 & RUTURE VULVAR LACERATION \\
\hline 719 & OULV VULVAR FISTULA \\
\hline
\end{tabular}

\begin{tabular}{|c|c|}
\hline 7394 & PUBIOTOMY TO ASSIST DEL \\
\hline 7399 & OPS ASSISTING DELIV NEC \\
\hline 740 & CLASSICAL C-SECTION \\
\hline 741 & LOW CERVICAL C-SECTION \\
\hline 742 & EXTRAPERITONEAL C-SECT \\
\hline 743 & REM EXTRATUB ECTOP PREG \\
\hline 744 & CESAREAN SECTION NEC \\
\hline 7491 & $\begin{array}{l}\text { HYSTEROTOMY TO TERMIN PG } \\
\end{array}$ \\
\hline 7499 & CESAREAN SECTION NOS \\
\hline 7536 & CORRECTION FETAL DEFECT \\
\hline 7550 & REPAIR OB LAC UTERUS NOS \\
\hline 7551 & REPAIR OB LACERAT CERVIX \\
\hline 7552 & REPAIR OB LAC CORP UTERI \\
\hline 7561 & REPAIR OB LAC BLAD/URETH \\
\hline 7593 & SURG CORR INVERT UTERUS \\
\hline 7599 & OBSTETRIC OPERATION NEC \\
\hline 7601 & FACIAL BONE SEQUESTRECT \\
\hline 7609 & FACIAL BONE INCISION NEC \\
\hline 7611 & FACIAL BONE BIOPSY \\
\hline 7619 & FACIAL BONE DX PROC NEC \\
\hline 762 & DESTRUCT FACIAL BONE LES \\
\hline 7631 & PARTIAL MANDIBULECTOMY \\
\hline 7639 & PART FACIAL OSTECTOM NEC \\
\hline 7641 & TOT MANDIBULEC W RECONST \\
\hline 7642 & TOTAL MANDIBULECTOMY NEC \\
\hline 7643 & MANDIBULAR RECONST NEC \\
\hline 7644 & TOT FACE OSTECT W RECONS \\
\hline 7645 & TOT FACE BONE OSTECT NEC \\
\hline 7646 & FACIAL BONE RECONSTR NEC \\
\hline 765 & TEMPOROMAND ARTHROPLASTY \\
\hline 7661 & CL OSTEOPLASTY MAND RAMI \\
\hline 7662 & OPEN OSTEOPLAS MAND RAMI \\
\hline 7663 & OSTEOPLASTY MANDIBLE BDY \\
\hline 7664 & MAND ORTHOGNATHIC OP NEC \\
\hline 7665 & SEG OSTEOPLASTY MAXILLA \\
\hline 7666 & TOT OSTEOPLASTY MAXILLA \\
\hline 7667 & REDUCTION GENIOPLASTY \\
\hline 7668 & AUGMENTATION GENIOPLASTY \\
\hline 7669 & FACIAL BONE REPAIR NEC \\
\hline 7670 & REDUCTION FACIAL FX NOS \\
\hline 7672 & OPN REDUCT MALAR/ZYGO FX \\
\hline 7674 & OPEN REDUCT MAXILLARY FX \\
\hline 7676 & OPEN REDUCT MANDIBLE FX \\
\hline 7677 & OPEN REDUCT ALVEOLAR FX \\
\hline 7679 & OPEN REDUCT FACE FX NEC \\
\hline 7691 & BONE GRAFT TO FACE BONE \\
\hline 7692 & SYN IMPLANT TO FACE BONE \\
\hline 7694 & OPEN REDUCT TM DISLOCAT \\
\hline 7697 & REMOVE INT FIX FACE BONE \\
\hline 7699 & FACIAL BONE/JNT OP NEC \\
\hline 7700 & SEQUESTRECTOMY NOS \\
\hline
\end{tabular}




\begin{tabular}{|c|c|}
\hline 7701 & CHEST CAGE SEQUESTREC \\
\hline 7702 & HUMERUS SEQUESTRECTOMY \\
\hline 7703 & RADIUS \& ULNA SEQUESTREC \\
\hline 7704 & METACARP/CARP SEQUESTREC \\
\hline 7705 & FEMORAL SEQUESTRECTOMY \\
\hline 7706 & PATELLAR SEQUESTRECTOMY \\
\hline 7707 & TIBIA/FIBULA SEQUESTREC \\
\hline 7708 & METATAR/TAR SEQUESTREC \\
\hline 7709 & SEQUESTRECTOMY NEC \\
\hline 7710 & OTHER BONE INCISION NOS \\
\hline 7711 & OTHER CHEST CAGE INCIS \\
\hline 7712 & OTHER HUMERUS INCISION \\
\hline 7713 & OTHER RADIUS/ULNA INCIS \\
\hline 7714 & OTH METACARP/CARP INCIS \\
\hline 7715 & OTHER FEMORAL INCISION \\
\hline 7716 & OTHER PATELLAR INCISION \\
\hline 7717 & OTHER TIBIA/FIBULA INCIS \\
\hline 7718 & OTH METATARS/TARS INCIS \\
\hline 7719 & BONE INCIS W/O DIV NEC \\
\hline 7720 & WEDGE OSTEOTOMY NOS \\
\hline 7721 & CHEST CAGE WEDG OSTEOTOM \\
\hline 7722 & HUMERUS WEDGE OSTEOTOMY \\
\hline 7723 & RADIUS/ULNA WEDG OSTEOTO \\
\hline 7724 & METACAR/CAR WEDG OSTEOTO \\
\hline 7725 & FEMORAL WEDGE OSTEOTOMY \\
\hline 7726 & $\begin{array}{l}\text { PATELLAR WEDGE OSTEOTOMY } \\
\end{array}$ \\
\hline 7727 & TIBIA/FIBUL WEDG OSTEOT \\
\hline 7728 & METATAR/TAR WEDG OSTEOT \\
\hline 7729 & WEDGE OSTEOTOMY NEC \\
\hline 7730 & OTHER BONE DIVISION NOS \\
\hline 7731 & CHEST CAGE BONE DIV NEC \\
\hline 7732 & HUMERUS DIVISION NEC \\
\hline 7733 & RADIUS/ULNA DIVISION NEC \\
\hline 7734 & METACAR/CAR DIVISION NEC \\
\hline 7735 & FEMORAL DIVISION NEC \\
\hline 7736 & PATELLAR DIVISION NEC \\
\hline 7737 & TIBIA/FIBULA DIV NEC \\
\hline 7738 & METATAR/TAR DIVISION NEC \\
\hline 7739 & BONE DIVISION NEC \\
\hline 7740 & BONE BIOPSY NOS \\
\hline 7741 & CHEST CAGE BONE BIOPSY \\
\hline 7742 & HUMERUS BIOPSY \\
\hline 7743 & RADIUS \& ULNA BIOPSY \\
\hline 7744 & METACARPAL/CARPAL BIOPSY \\
\hline 7745 & FEMORAL BIOPSY \\
\hline 7746 & PATELLAR BIOPSY \\
\hline 7747 & TIBIA \& FIBULA BIOPSY \\
\hline 7748 & METATARSAL/TARSAL BIOPSY \\
\hline 7749 & BONE BIOPSY NEC \\
\hline 7751 & BUNIONECT/SFT/OSTEOTOMY \\
\hline 7752 & BUNIONECT/SFT/ARTHRODES \\
\hline
\end{tabular}

\begin{tabular}{|c|c|}
\hline 7753 & OTH BUNIONECT W SFT CORR \\
\hline 7754 & EXC CORRECT BUNIONETTE \\
\hline 7756 & REPAIR OF HAMMER TOE \\
\hline 7757 & REPAIR OF CLAW TOE \\
\hline 7758 & OTH EXC, FUS, REPAIR TOE \\
\hline 7759 & BUNIONECTOMY NEC \\
\hline 7760 & LOC EXC BONE LESION NOS \\
\hline 7761 & EXC CHEST CAGE BONE LES \\
\hline 7762 & LOC EXC BONE LES HUMERUS \\
\hline 7763 & LOC EXC LES RADIUS/ULNA \\
\hline 7764 & LOC EXC LES METACAR/CAR \\
\hline 7765 & LOC EXC BONE LES FEMUR \\
\hline 7766 & LOC EXC BONE LES PATELLA \\
\hline 7767 & LOC EXC LES TIBIA/FIBULA \\
\hline 7768 & LOC EXC LES METATAR/TAR \\
\hline 7769 & LOC EXC BONE LESION NEC \\
\hline 7770 & EXCISE BONE FOR GRFT NOS \\
\hline 7771 & EX CHEST CAGE BONE-GFT \\
\hline 7772 & EXCISE HUMERUS FOR GRAFT \\
\hline 7773 & EXCIS RADIUS/ULNA-GRAFT \\
\hline 7774 & EXCIS METACAR/CAR-GRAFT \\
\hline 7775 & EXCISE FEMUR FOR GRAFT \\
\hline 7776 & EXCISE PATELLA FOR GRAFT \\
\hline 7777 & EXCISE TIB/FIB FOR GRAFT \\
\hline 7778 & EXCIS METATAR/TAR-GRAFT \\
\hline 7779 & EXCISE BONE FOR GFT NEC \\
\hline 7780 & OTH PART OSTECTOMY NOS \\
\hline 7781 & OTH CHEST CAGE OSTECTOMY \\
\hline 7782 & PARTIAL HUMERECTOMY NEC \\
\hline 7783 & PART OSTECT-RADIUS/ULNA \\
\hline 7784 & PART OSTECT-METACAR/CAR \\
\hline 7785 & PART OSTECTOMY-FEMUR \\
\hline 7786 & PARTIAL PATELLECTOMY \\
\hline 7787 & PART OSTECT-TIBIA/FIBULA \\
\hline 7788 & PART OSTECT-METATAR/TAR \\
\hline 7789 & PARTIAL OSTECTOMY NEC \\
\hline 7790 & TOTAL OSTECTOMY NOS \\
\hline 7791 & TOT CHEST CAGE OSTECTOMY \\
\hline 7792 & TOTAL OSTECTOMY-HUMERUS \\
\hline 7793 & TOT OSTECT-RADIUS/ULNA \\
\hline 7794 & TOT OSTECT-METACARP/CARP \\
\hline 7795 & TOT OSTECTOMY-FEMUR \\
\hline 7796 & TOTAL PATELLECTOMY \\
\hline 7797 & TOT OSTECT-TIBIA/FIBULA \\
\hline 7798 & TOT OSTECT-METATARS/TARS \\
\hline 7799 & TOTAL OSTECTOMY NEC \\
\hline 7800 & BONE GRAFT NOS \\
\hline 7801 & BONE GRAFT TO CHEST CAGE \\
\hline 7802 & BONE GRAFT TO HUMERUS \\
\hline 7803 & BONE GRAFT-RADIUS/ULNA \\
\hline 7804 & BONE GRFT TO METACAR/CAR \\
\hline
\end{tabular}




\begin{tabular}{|l|l|}
\hline 7805 & BONE GRAFT TO FEMUR \\
\hline 7806 & BONE GRAFT TO PATELLA \\
\hline 7807 & BONE GRAFT-TIBIA/FIBULA \\
\hline 7808 & BONE GRAFT-METATAR/TAR \\
\hline 7809 & BONE GRAFT NEC \\
\hline 7810 & APPLIC EXT FIX DEV NOS \\
\hline 7811 & APPL EXT FIX-CHEST CAGE \\
\hline 7812 & APPLIC EXT FIX-HUMERUS \\
\hline 7813 & APPL EXT FIX-RADIUS/ULNA \\
\hline 7814 & APPL EXT FIX-METACAR/CAR \\
\hline 7815 & APPLIC EXT FIX DEV-FEMUR \\
\hline 7816 & APPL EXT FIX DEV-PATELLA \\
\hline 7817 & APPL EXT FIX-TIB/FIBULA \\
\hline 7818 & APPL EXT FIX-METATAR/TAR \\
\hline 7819 & APPLIC EXT FIX DEV NEC \\
\hline 7820 & LIMB SHORTEN PROC NOS \\
\hline 7822 & LIMB SHORT PROC-HUMERUS \\
\hline 7823 & LIMB SHORTEN-RADIUS/ULNA \\
\hline 7824 & LIMB SHORTEN-METACAR/CAR \\
\hline 7825 & LIMB SHORT PROC-FEMUR \\
\hline 7827 & LIMB SHORTEN-TIB/FIBULA \\
\hline 7828 & LIMB SHORTEN-METATAR/TAR \\
\hline 7829 & LIMB SHORTEN PROC NEC \\
\hline 7830 & LIMB LENGTHEN PROC NOS \\
\hline 7831 & LIMB LENGTHEN PROC NOS \\
\hline 7832 & LIMB LENGTH PROC-HUMERUS \\
\hline 7833 & LIMB LENGTH-RADIUS/ULNA \\
\hline 7834 & LIMB LENGTH-METACAR/CAR \\
\hline 7835 & LIMB LENGTH PROC-FEMUR \\
\hline 7837 & LIMB LENGTHEN-TIB/FIBULA \\
\hline 7838 & LIMB LENGTHN-METATAR/TAR \\
\hline 7839 & LIMB LENGTHEN PROC NEC \\
\hline 7840 & OTH BONE REPAIR/PLAST OP \\
\hline 7841 & OTH CHEST CAGE REP/PLAST \\
\hline 7842 & OTH HUMERUS REPAIR/PLAST \\
\hline 7843 & OTH RAD/ULN REPAIR/PLAST \\
\hline 7844 & OTH METAC/CARP REP/PLAST \\
\hline 7845 & OTH FEMUR REPAIR/PLASTIC \\
\hline 7846 & OTH PATELLA REPAIR/PLAST \\
\hline 7847 & OTH TIB/FIB REPAIR/PLAST \\
\hline 7848 & OTH META/TAR REPA/PLAST \\
\hline 7849 & OTH BONE REPA/PLAST NEC \\
\hline 7850 & INT FIX W/O FX REDUC NOS \\
\hline 7851 & INT FIXATION-CHEST CAGE \\
\hline 7852 & INT FIXATION-HUMERUS \\
\hline 7854 & INT FIXATION-RADIUS/ULNA \\
\hline 7858 & INT FIXATION-METACAR/CAR \\
\hline
\end{tabular}

\begin{tabular}{|c|c|}
\hline 7859 & INT FIX-NO FX REDUCT NEC \\
\hline 7860 & REMOVE IMP DEVICE NOS \\
\hline 7861 & REMOV IMP DEV-CHEST CAGE \\
\hline 7862 & REMOVE IMPL DEV-HUMERUS \\
\hline 7863 & REMOV IMP DEV-RADIUS/ULN \\
\hline 7864 & REMOV IMP DEV-METAC/CARP \\
\hline 7865 & REMOVE IMP DEVICE-FEMUR \\
\hline 7866 & REMOV IMP DEVICE-PATELLA \\
\hline 7867 & REMOV IMP DEV-TIB/FIBULA \\
\hline 7868 & REMOVE IMP DEV-METAT/TAR \\
\hline 7869 & REMOVE IMPL DEVICE NEC \\
\hline 7870 & OSTEOCLASIS NOS \\
\hline 7871 & OSTEOCLASIS-CHEST CAGE \\
\hline 7872 & OSTEOCLASIS-HUMERUS \\
\hline 7873 & OSTEOCLASIS-RADIUS/ULNA \\
\hline 7874 & OSTEOCLASIS-METACAR/CAR \\
\hline 7875 & OSTEOCLASIS-FEMUR \\
\hline 7876 & OSTEOCLASIS-PATELLA \\
\hline 7877 & OSTEOCLASIS-TIBIA/FIBULA \\
\hline 7878 & OSTEOCLASIS-METATAR/TAR \\
\hline 7879 & OSTEOCLASIS NEC \\
\hline 7880 & OTHER BONE DX PROC NOS \\
\hline 7881 & OTH DX PROCED-CHEST CAGE \\
\hline 7882 & OTH DX PROCED-HUMERUS \\
\hline 7883 & OTH DX PROC-RADIUS/ULNA \\
\hline 7884 & OTH DX PROC-METACAR/CAR \\
\hline 7885 & OTH DX PROCED-FEMUR \\
\hline 7886 & OTH DX PROCED-PATELLA \\
\hline 7887 & OTH DX PROC-TIBIA/FIBULA \\
\hline 7888 & OTH DX PROC-METATAR/TAR \\
\hline 7889 & OTHER BONE DX PROC NEC \\
\hline 7890 & INSERT BONE STIMUL NOS \\
\hline 7891 & INSERT BONE STIMUL-CHEST \\
\hline 7892 & INSERT BONE STIM-HUMERUS \\
\hline 7893 & INSER BONE STIM-RAD/ULNA \\
\hline 7894 & INSER BONE STIM-META/CAR \\
\hline 7895 & INSERT BONE STIM-FEMUR \\
\hline 7896 & INSERT BONE STIM-PATELLA \\
\hline 7897 & INSER BONE STIM-TIB/FIB \\
\hline 7898 & INSER BONE STIM-META/TAR \\
\hline 7899 & INSERT BONE STIMUL NEC \\
\hline 7910 & CL FX REDUC-INT FIX NOS \\
\hline 7911 & CLOS RED-INT FIX HUMERUS \\
\hline 7912 & CL RED-INT FIX RAD/ULNA \\
\hline 7913 & CL RED-INT FIX METAC/CAR \\
\hline 7914 & CLOSE RED-INT FIX FINGER \\
\hline 7915 & CLOSED RED-INT FIX FEMUR \\
\hline 7916 & CL RED-INT FIX TIB/FIBU \\
\hline 7917 & CL RED-INT FIX METAT/TAR \\
\hline 7918 & CLOSE RED-INT FIX TOE FX \\
\hline 7919 & CL FX REDUC-INT FIX NEC \\
\hline
\end{tabular}




\begin{tabular}{|c|c|}
\hline 7920 & OPEN FX REDUCTION NOS \\
\hline 7921 & OPEN REDUC-HUMERUS FX \\
\hline 7922 & OPEN REDUC-RADIUS/ULN FX \\
\hline 7923 & OPEN REDUC-METAC/CAR FX \\
\hline 7924 & OPEN REDUCTION-FINGER FX \\
\hline 7925 & OPEN REDUCTION-FEMUR FX \\
\hline 7926 & OPEN REDUC-TIBIA/FIB FX \\
\hline 7927 & OPEN REDUC-METAT/TARS FX \\
\hline 7928 & OPEN REDUCTION-TOE FX \\
\hline 7929 & OPEN FX REDUCTION NEC \\
\hline 7930 & OPN FX RED W INT FIX NOS \\
\hline 7931 & OPEN RED-INT FIX HUMERUS \\
\hline 7932 & OP RED-INT FIX RAD/ULNA \\
\hline 7933 & OP RED-INT FIX METAC/CAR \\
\hline 7934 & OPEN RED-INT FIX FINGER \\
\hline 7935 & OPEN REDUC-INT FIX FEMUR \\
\hline 7936 & OP RED-INT FIX TIB/FIBUL \\
\hline 7937 & OP RED-INT FIX METAT/TAR \\
\hline 7938 & OPEN REDUCT-INT FIX TOE \\
\hline 7939 & OPN FX RED W INT FIX NEC \\
\hline 7940 & CLS REDUC-SEP EPIPHY NOS \\
\hline 7941 & CLOSE RED-HUMERUS EPIPHY \\
\hline 7942 & CLS RED-RADIUS/UL EPIPHY \\
\hline 7945 & CLOSE REDUC-FEMUR EPIPHY \\
\hline 7946 & CLS RED-TIBIA/FIB EPIPHY \\
\hline 7949 & CLS REDUC-SEP EPIPHY NEC \\
\hline 7950 & OPEN RED-SEP EPIPHY NOS \\
\hline 7951 & OPN RED-SEP EPIPHY-HUMER \\
\hline 7952 & OP RED-RADIUS/ULN EPIPHY \\
\hline 7955 & OPN RED-SEP EPIPHY-FEMUR \\
\hline 7956 & OP RED-TIBIA/FIB EPIPHYS \\
\hline 7959 & OPEN RED-SEP EPIPHY NEC \\
\hline 7960 & OPEN FX SITE DEBRIDE NOS \\
\hline 7961 & DEBRID OPEN FX-HUMERUS \\
\hline 7962 & DEBRID OPN FX-RADIUS/ULN \\
\hline 7963 & DEBRID OPN FX-METAC/CAR \\
\hline 7964 & DEBRID OPN FX-FINGER \\
\hline 7965 & DEBRID OPN FX-FEMUR \\
\hline 7966 & DEBRID OPN FX-TIBIA/FIB \\
\hline 7967 & DEBRID OPN FX-METAT/TAR \\
\hline 7968 & DEBRID OPN FX-TOE \\
\hline 7969 & OPEN FX SITE DEBRIDE NEC \\
\hline 7980 & OPEN REDUC-DISLOCAT NOS \\
\hline 7981 & OPN REDUC DISLOC-SHOULDR \\
\hline 7982 & OPEN REDUC-ELBOW DISLOC \\
\hline 7983 & OPEN REDUC-WRIST DISLOC \\
\hline 7984 & OPN REDUC DISLOC-HAND \\
\hline 7985 & OPEN REDUC-HIP DISLOCAT \\
\hline 7986 & OPEN REDUC-KNEE DISLOCAT \\
\hline 7987 & OPEN REDUC-ANKLE DISLOC \\
\hline 7988 & OPN REDUC DISLOC-FT/TOE \\
\hline
\end{tabular}

\begin{tabular}{|c|c|}
\hline 7989 & OPEN REDUC-DISLOCAT NEC \\
\hline 7990 & UNSPEC OP BONE INJ NOS \\
\hline 7991 & HUMERUS INJURY OP NOS \\
\hline 7992 & RADIUS/ULNA INJ OP NOS \\
\hline 7993 & METACARP/CARP INJ OP NOS \\
\hline 7994 & FINGER INJURY OP NOS \\
\hline 7995 & FEMUR INJURY OP NOS \\
\hline 7996 & TIBIA/FIBULA INJ OP NOS \\
\hline 7997 & METATARS/TARS INJ OP NOS \\
\hline 7998 & TOE INJURY OPERATION NOS \\
\hline 7999 & UNSPEC OP-BONE INJ NEC \\
\hline 8000 & ARTHROT \& PROS REMOV NOS \\
\hline 8001 & ARTHROT/PROS REMOV-SHLDR \\
\hline 8002 & ARTHROT/PROS REMOV-ELBOW \\
\hline 8003 & ARTHROT/PROS REMOV-WRIST \\
\hline 8004 & ARTHROT/PROS REMOV-HAND \\
\hline 8005 & ARTHROT/PROS REMOV-HIP \\
\hline 8006 & ARTHROT/PROS REMOV-KNEE \\
\hline 8007 & ARTHROT/PROS REMOV-ANKLE \\
\hline 8008 & ARTHROT/PROS REMOV-FOOT \\
\hline 8009 & ARTHROT \& PROS REMOV NEC \\
\hline 8010 & OTHER ARTHROTOMY NOS \\
\hline 8011 & OTH ARTHROTOMY-SHOULDER \\
\hline 8012 & OTH ARTHROTOMY-ELBOW \\
\hline 8013 & OTH ARTHROTOMY-WRIST \\
\hline 8014 & OTH ARTHROTOMY-HAND/FNGR \\
\hline 8015 & OTH ARTHROTOMY-HIP \\
\hline 8016 & OTH ARTHROTOMY-KNEE \\
\hline 8017 & OTH ARTHROTOMY-ANKLE \\
\hline 8018 & OTH ARTHROTOMY-FOOT/TOE \\
\hline 8019 & OTHER ARTHROTOMY NEC \\
\hline 8020 & ARTHROSCOPY NOS \\
\hline 8021 & SHOULDER ARTHROSCOPY \\
\hline 8022 & ELBOW ARTHROSCOPY \\
\hline 8023 & WRIST ARTHROSCOPY \\
\hline 8024 & HAND \& FINGER ARTHROSCOP \\
\hline 8025 & HIP ARTHROSCOPY \\
\hline 8026 & KNEE ARTHROSCOPY \\
\hline 8027 & ANKLE ARTHROSCOPY \\
\hline 8028 & FOOT \& TOE ARTHROSCOPY \\
\hline 8029 & ARTHROSCOPY NEC \\
\hline 8040 & JT STRUCTUR DIVISION NOS \\
\hline 8041 & SHOULDER STRUCT DIVISION \\
\hline 8042 & ELBOW STRUCTURE DIVISION \\
\hline 8043 & WRIST STRUCTURE DIVISION \\
\hline 8044 & HAND JOINT STRUCT DIVIS \\
\hline 8045 & HIP STRUCTURE DIVISION \\
\hline 8046 & KNEE STRUCTURE DIVISION \\
\hline 8047 & ANKLE STRUCTURE DIVISION \\
\hline 8048 & FOOT JOINT STRUCT DIVIS \\
\hline 8049 & JT STRUCTUR DIVISION NEC \\
\hline
\end{tabular}




\begin{tabular}{|l|l|}
\hline 805 & JT STRUCTUR DIVISION NEC \\
\hline 8050 & EXC/DEST INTVRT DISC NOS \\
\hline 8051 & EXCISION INTERVERT DISC \\
\hline 8059 & OTH EXC/DEST INTVRT DISC \\
\hline 806 & EXCIS KNEE SEMILUN CARTL \\
\hline 8070 & SYNOVECTOMY-SITE NOS \\
\hline 8071 & SHOULDER SYNOVECTOMY \\
\hline 8072 & ELBOW SYNOVECTOMY \\
\hline 8073 & WRIST SYNOVECTOMY \\
\hline 8074 & HAND SYNOVECTOMY \\
\hline 8075 & HIP SYNOVECTOMY \\
\hline 8076 & KNEE SYNOVECTOMY \\
\hline 8077 & ANKLE SYNOVECTOMY \\
\hline 8078 & FOOT SYNOVECTOMY \\
\hline 8079 & SYNOVECTOMY-SITE NEC \\
\hline 8080 & DESTRUCT JOINT LES NOS \\
\hline 8081 & DESTRUC-SHOULDER LES NEC \\
\hline 8082 & DESTRUC-ELBOW LESION NEC \\
\hline 8083 & DESTRUC-WRIST LESION NEC \\
\hline 8084 & DESTRUC-HAND JT LES NEC \\
\hline 8085 & DESTRUCT-HIP LESION NEC \\
\hline 8086 & DESTRUCT-KNEE LESION NEC \\
\hline 8087 & DESTRUC-ANKLE LESION NEC \\
\hline 8088 & DESTRUC-FOOT JT LES NEC \\
\hline 8089 & DESTRUCT JOINT LES NEC \\
\hline 8090 & EXCISION OF JOINT NOS \\
\hline 8091 & EXCISION OF SHOULDER NEC \\
\hline 8092 & EXCISION OF ELBOW NEC \\
\hline 8093 & EXCISION OF WRIST NEC \\
\hline 8094 & EXCISION HAND JOINT NEC \\
\hline 8095 & EXCISION OF HIP NEC \\
\hline 8096 & EXCISION OF KNEE NEC \\
\hline 8097 & EXCISION OF ANKLE NEC \\
\hline 8098 & EXCISION FOOT JOINT NEC \\
\hline 8099 & EXCISION OF JOINT NEC \\
\hline 8100 & SPINAL FUSION NOS \\
\hline 8101 & ATLAS-AXIS FUSION \\
\hline 8102 & OTHER CERVICAL FUS ANT \\
\hline 8103 & OTHER CERVICAL FUS POST \\
\hline 8104 & DORSAL/DORSOLUM FUS ANT \\
\hline 8105 & DORSAL/DORSOLUM FUS POST \\
\hline 8106 & LUMBAR/LUMBOSAC FUS ANT \\
\hline 8107 & LUMBAR/LUMBOSAC FUS LAT \\
\hline 8108 & LUMBAR/LUMBOSAC FUS POST \\
\hline 8109 & LUMBAR/LUMBOSAC FUS POST \\
\hline 8111 & ANKLE FUSION \\
\hline 8113 & SUIPLE ARTHRODESIS \\
\hline 8116 & MIDTARAR FUSION \\
\hline & TARSOMETATARARAL FUSION \\
\hline
\end{tabular}

\begin{tabular}{|c|c|}
\hline 8117 & OTHER FUSION OF FOOT \\
\hline 8118 & OTHER FUSION OF FOOT \\
\hline 8120 & ARTHRODESIS NOS \\
\hline 8121 & ARTHRODESIS OF HIP \\
\hline 8122 & ARTHRODESIS OF KNEE \\
\hline 8123 & ARTHRODESIS OF SHOULDER \\
\hline 8124 & ARTHRODESIS OF ELBOW \\
\hline 8125 & CARPORADIAL FUSION \\
\hline 8126 & METACARPOCARPAL FUSION \\
\hline 8127 & METACARPOPHALANGEAL FUS \\
\hline 8128 & INTERPHALANGEAL FUSION \\
\hline 8129 & ARTHRODESIS NEC \\
\hline 8130 & SPINAL REFUSION NOS \\
\hline 8131 & REFUSION OF ATLAS-AXIS \\
\hline 8132 & REFUSION OF OTH CERV ANT \\
\hline 8133 & REFUS OF OTH CERV POST \\
\hline 8134 & REFUSION OF DORSAL ANT \\
\hline 8135 & REFUSION OF DORSAL POST \\
\hline 8136 & REFUSION OF LUMBAR ANT \\
\hline 8137 & REFUSION OF LUMBAR LAT \\
\hline 8138 & REFUSION OF LUMBAR POST \\
\hline 8139 & REFUSION OF SPINE NEC \\
\hline 8140 & REPAIR OF HIP, NEC \\
\hline 8141 & REPAIR OF HIP, NEC \\
\hline 8142 & FIVE-IN-ONE KNEE REPAIR \\
\hline 8143 & TRIAD KNEE REPAIR \\
\hline 8144 & PATELLAR STABILIZATION \\
\hline 8145 & CRUCIATE LIG REPAIR NEC \\
\hline 8146 & COLLATERL LIG REPAIR NEC \\
\hline 8147 & OTHER REPAIR OF KNEE \\
\hline 8148 & OTHER REPAIR OF KNEE \\
\hline 8149 & OTHER REPAIR OF ANKLE \\
\hline 8151 & TOTAL HIP REPLACEMENT \\
\hline 8152 & PARTIAL HIP REPLACEMENT \\
\hline 8153 & REVISE HIP REPLACEMENT \\
\hline 8154 & TOTAL KNEE REPLACEMENT \\
\hline 8155 & REVISE KNEE REPLACEMENT \\
\hline 8156 & TOTAL ANKLE REPLACEMENT \\
\hline 8157 & REPL JOINT OF FOOT, TOE \\
\hline 8159 & REV JT REPL LOW EXT NEC \\
\hline 8161 & 360 SPINAL FUSION \\
\hline 8162 & FUS/REFUS 2-3 VERTEBRAE \\
\hline 8163 & FUS/REFUS 4-8 VERTEBRAE \\
\hline 8164 & FUS/REFUS 9 VERTEBRAE \\
\hline 8165 & VERTEBROPLASTY (OCT 04) \\
\hline 8166 & KYPHOPLASTY (OCT 04) \\
\hline 8169 & $\begin{array}{l}\text { OTH HIP REPAIR JAN80--SEP89 } \\
\text { OCT05- }\end{array}$ \\
\hline 8171 & $\begin{array}{l}\text { ARTHROPLAS METACARP WIT } \\
\end{array}$ \\
\hline 8172 & ARTHROPLASTY METACAR W/O \\
\hline 8173 & TOTAL WRIST REPLACEMENT \\
\hline
\end{tabular}




\begin{tabular}{|c|c|}
\hline 8174 & ARTHROPLASTY CARPAL WIT \\
\hline 8175 & ARTHROPLASTY CARPAL W/O \\
\hline 8179 & OTH REPAIR HAN/FIN/WRIS \\
\hline 8180 & TOTAL SHOULDER REPLACE \\
\hline 8181 & PARTIAL SHOULDER REPLACE \\
\hline 8182 & REP RECUR SHLDER DISLOC \\
\hline 8183 & SHOULDER ARTHROPLAST NEC \\
\hline 8184 & TOTAL ELBOW REPLACEMENT \\
\hline 8185 & ELBOW ARTHROPLASTY NEC \\
\hline 8186 & ELBOW ARTHROPLASTY NEC \\
\hline 8187 & ELBOW ARTHROPLASTY NEC \\
\hline 8193 & SUTUR CAPSUL/LIGAMEN ARM \\
\hline 8194 & $\begin{array}{l}\text { SUTURE CAPSUL/LIG ANK/FT } \\
\end{array}$ \\
\hline 8195 & SUTUR CAPSUL/LIG LEG NEC \\
\hline 8196 & OTHER REPAIR OF JOINT \\
\hline 8197 & REV JT REPL UPPER EXTREM \\
\hline 8198 & OTHER JOINT DX PROCEDURE \\
\hline 8199 & JOINT STRUCTURE OP NEC \\
\hline 8201 & EXPLOR TEND SHEATH-HAND \\
\hline 8202 & MYOTOMY OF HAND \\
\hline 8203 & BURSOTOMY OF HAND \\
\hline 8209 & INC SOFT TISSUE HAND NEC \\
\hline 8211 & TENOTOMY OF HAND \\
\hline 8212 & FASCIOTOMY OF HAND \\
\hline 8219 & DIV SOFT TISSUE HAND NEC \\
\hline 8221 & EXC LES TEND SHEATH HAND \\
\hline 8222 & EXCISION HAND MUSCLE LES \\
\hline 8229 & EXC LES SFT TISS HND NEC \\
\hline 8231 & BURSECTOMY OF HAND \\
\hline 8232 & EXCIS HAND TEND FOR GRFT \\
\hline 8233 & HAND TENONECTOMY NEC \\
\hline 8234 & EXC HND MUS/FAS FOR GRFT \\
\hline 8235 & HAND FASCIECTOMY NEC \\
\hline 8236 & OTHER MYECTOMY OF HAND \\
\hline 8239 & HAND SOFT TISSUE EXC NEC \\
\hline 8241 & SUTURE TENDN SHEATH HAND \\
\hline 8242 & DELAY SUT FLEX TEND HAND \\
\hline 8243 & DELAY SUT HAND TEND NEC \\
\hline 8244 & SUTUR FLEX TEND HAND NEC \\
\hline 8245 & SUTURE HAND TENDON NEC \\
\hline 8246 & SUTURE HAND MUSCLE/FASC \\
\hline 8251 & HAND TENDON ADVANCEMENT \\
\hline 8252 & HAND TENDON RECESSION \\
\hline 8253 & HAND TENDON REATTACHMENT \\
\hline 8254 & HAND MUSCLE REATTACHMENT \\
\hline 8255 & CHNG HND MUS/TEN LNG NEC \\
\hline 8256 & TRANSPLANT HAND TEND NEC \\
\hline 8257 & TRANSPOSIT HAND TEND NEC \\
\hline 8258 & TRANSPLANT HAND MUSC NEC \\
\hline 8259 & TRANSPOSIT HAND MUSC NEC \\
\hline 8261 & POLLICIZATION OPERATION \\
\hline
\end{tabular}

\begin{tabular}{|c|c|}
\hline 8269 & THUMB RECONSTRUCTION NEC \\
\hline 8271 & HAND TEND PULLEY RECONST \\
\hline 8272 & PLAST OP HND-MUS/FAS GRF \\
\hline 8279 & PLAST OP HAND W GRFT NEC \\
\hline 8281 & TRANSFER OF FINGER \\
\hline 8282 & REPAIR OF CLEFT HAND \\
\hline 8283 & REPAIR OF MACRODACTYLY \\
\hline 8284 & REPAIR OF MALLET FINGER \\
\hline 8285 & OTHER TENODESIS OF HAND \\
\hline 8286 & OTHER TENOPLASTY OF HAND \\
\hline 8289 & HAND PLASTIC OP NEC \\
\hline 8291 & LYSIS OF HAND ADHESIONS \\
\hline 8299 & HAND MUS/TEN/FAS/OPS NEC \\
\hline 8301 & TENDON SHEATH EXPLORAT \\
\hline 8302 & MYOTOMY \\
\hline 8303 & BURSOTOMY \\
\hline 8309 & SOFT TISSUE INCISION NEC \\
\hline 8311 & ACHILLOTENOTOMY \\
\hline 8312 & ADDUCTOR TENOTOMY OF HIP \\
\hline 8313 & OTHER TENOTOMY \\
\hline 8314 & FASCIOTOMY \\
\hline 8319 & SOFT TISSUE DIVISION NEC \\
\hline 8321 & SOFT TISSUE BIOPSY \\
\hline 8329 & SOFT TISSUE DX PROC NEC \\
\hline 8331 & EXCIS LES TENDON SHEATH \\
\hline 8332 & EXCIS LESION OF MUSCLE \\
\hline 8339 & EXC LES SOFT TISSUE NEC \\
\hline 8341 & TENDON EXCISION FOR GRFT \\
\hline 8342 & OTHER TENONECTOMY \\
\hline 8343 & MUSC/FASC EXCIS FOR GRFT \\
\hline 8344 & OTHER FASCIECTOMY \\
\hline 8345 & OTHER MYECTOMY \\
\hline 8349 & OTHER SOFT TISSUE EXCIS \\
\hline 835 & BURSECTOMY \\
\hline 8361 & TENDON SHEATH SUTURE \\
\hline 8362 & DELAYED TENDON SUTURE \\
\hline 8363 & ROTATOR CUFF REPAIR \\
\hline 8364 & OTHER SUTURE OF TENDON \\
\hline 8365 & OTHER MUSCLE/FASC SUTURE \\
\hline 8371 & TENDON ADVANCEMENT \\
\hline 8372 & TENDON RECESSION \\
\hline 8373 & TENDON REATTACHMENT \\
\hline 8374 & MUSCLE REATTACHMENT \\
\hline 8375 & TENDON TRNSFR/TRANSPLANT \\
\hline 8376 & OTHER TENDON TRANSPOSIT \\
\hline 8377 & MUSCLE TRNSFR/TRANSPLANT \\
\hline 8379 & OTHER MUSCLE TRANSPOSIT \\
\hline 8381 & TENDON GRAFT \\
\hline 8382 & MUSCLE OR FASCIA GRAFT \\
\hline 8383 & TENDON PULLEY RECONSTRUC \\
\hline 8384 & CLUBFOOT RELEASE NEC \\
\hline
\end{tabular}


DELSA/HEA/WD/HWP(2009)5/ANN

\begin{tabular}{|c|c|}
\hline 8385 & MUSC/TEND LNG CHANGE NEC \\
\hline 8386 & QUADRICEPSPLASTY \\
\hline 8387 & OTHER PLASTIC OPS MUSCLE \\
\hline 8388 & OTHER PLASTIC OPS TENDON \\
\hline 8389 & OTHER PLASTIC OPS FASCIA \\
\hline 8391 & ADHESIOLYSIS MUS/TEN/FAS \\
\hline 8392 & INSERT SKEL MUSC STIMULA \\
\hline 8393 & REMOV SKEL MUSC STIMULAT \\
\hline 8399 & MUS/TEN/FAS/BUR OP NEC \\
\hline 8400 & UPPER LIMB AMPUTAT NOS \\
\hline 8401 & FINGER AMPUTATION \\
\hline 8402 & THUMB AMPUTATION \\
\hline 8403 & AMPUTATION THROUGH HAND \\
\hline 8404 & DISARTICULATION OF WRIST \\
\hline 8405 & AMPUTATION THRU FOREARM \\
\hline 8406 & DISARTICULATION OF ELBOW \\
\hline 8407 & AMPUTATION THRU HUMERUS \\
\hline 8408 & SHOULDER DISARTICULATION \\
\hline 8409 & FOREQUARTER AMPUTATION \\
\hline 8410 & LOWER LIMB AMPUTAT NOS \\
\hline 8411 & TOE AMPUTATION \\
\hline 8412 & AMPUTATION THROUGH FOOT \\
\hline 8413 & DISARTICULATION OF ANKLE \\
\hline 8414 & AMPUTAT THROUGH MALLEOLI \\
\hline 8415 & BELOW KNEE AMPUTAT NEC \\
\hline 8416 & DISARTICULATION OF KNEE \\
\hline 8417 & ABOVE KNEE AMPUTATION \\
\hline 8418 & DISARTICULATION OF HIP \\
\hline 8419 & HINDQUARTER AMPUTATION \\
\hline 8421 & THUMB REATTACHMENT \\
\hline 8422 & FINGER REATTACHMENT \\
\hline 8423 & FOREARM/WRIST/HAND REATT \\
\hline 8424 & UPPER ARM REATTACHMENT \\
\hline 8425 & TOE REATTACHMENT \\
\hline 8426 & FOOT REATTACHMENT \\
\hline 8427 & LOWER LEG/ANKLE REATTACH \\
\hline 8428 & THIGH REATTACHMENT \\
\hline 8429 & REATTACHMENT NEC \\
\hline 843 & AMPUTATION STUMP REVIS \\
\hline 8440 & IMPLNT/FIT PROS LIMB NOS \\
\hline 8444 & IMPLANT ARM PROSTHESIS \\
\hline 8448 & IMPLANT LEG PROSTHESIS \\
\hline 8458 & 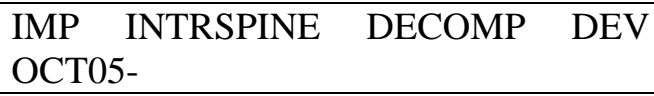 \\
\hline 8459 & INSERT OTH SPIN DEVICE \\
\hline 8460 & 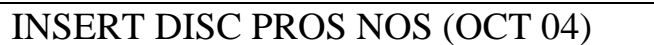 \\
\hline 8461 & $\begin{array}{l}\text { INS PART DISC PROS CERV (OCT } \\
\text { 04) }\end{array}$ \\
\hline 8462 & $\begin{array}{l}\text { INS TOT DISC PROST CERV (OCT } \\
\text { 04) }\end{array}$ \\
\hline 8 & INS SPIN DISC PROS THOR \\
\hline
\end{tabular}

\begin{tabular}{|c|c|}
\hline 8464 & $\begin{array}{l}\text { INS PART DISC PROS LUMB (OCT } \\
04 \text { ) }\end{array}$ \\
\hline 8465 & $\begin{array}{l}\text { INS TOTL DISC PROS LUMB (OCT } \\
\text { 04) }\end{array}$ \\
\hline 8466 & REVISE DISC PROST CERV (OCT 04) \\
\hline 8467 & $\begin{array}{l}\text { REVISE DISC PROST THORA (OCT } \\
\text { 04) }\end{array}$ \\
\hline 8468 & $\begin{array}{l}\text { REVISE DISC PROSTH LUMB (OCT } \\
04 \text { ) }\end{array}$ \\
\hline 8469 & REVISE DISC PROSTH NOS (OCT 04) \\
\hline 8472 & APP EXT FIX DEV-RING SYS OCT05- \\
\hline 8473 & APP HYBRID EXT FIX DEV OCT05- \\
\hline 8491 & AMPUTATION NOS \\
\hline 8492 & SEPARAT EQUAL JOIN TWIN \\
\hline 8493 & SEPARAT UNEQUL JOIN TWIN \\
\hline 8499 & MUSCULOSKELETAL OP NEC \\
\hline 8512 & OPEN BREAST BIOPSY \\
\hline 8520 & BREAST TISSU DESTRUC NOS \\
\hline 8521 & LOCAL EXCIS BREAST LES \\
\hline 8522 & QUADRANT RESECT BREAST \\
\hline 8523 & SUBTOTAL MASTECTOMY \\
\hline 8524 & EXC ECTOPIC BREAST TISSU \\
\hline 8525 & EXCISION OF NIPPLE \\
\hline 8531 & UNILAT REDUCT MAMMOPLAST \\
\hline 8532 & BILAT REDUCT MAMMOPLASTY \\
\hline 8533 & UNIL SUBQ MAMMECT-IMPLNT \\
\hline 8534 & UNILAT SUBQ MAMMECT NEC \\
\hline 8535 & BIL SUBQ MAMMECT-IMPLANT \\
\hline 8536 & BILAT SUBQ MAMMECTOM NEC \\
\hline 8541 & UNILAT SIMPLE MASTECTOMY \\
\hline 8542 & BILAT SIMPLE MASTECTOMY \\
\hline 8543 & UNILAT EXTEN SIMP MASTEC \\
\hline 8544 & BILAT EXTEND SIMP MASTEC \\
\hline 8545 & UNILAT RADICAL MASTECTOM \\
\hline 8546 & BILAT RADICAL MASTECTOMY \\
\hline 8547 & UNIL EXT RAD MASTECTOMY \\
\hline 8548 & BIL EXTEN RAD MASTECTOMY \\
\hline 8550 & AUGMENT MAMMOPLASTY NOS \\
\hline 8553 & UNILAT BREAST IMPLANT \\
\hline 8554 & BILATERAL BREAST IMPLANT \\
\hline 856 & MASTOPEXY \\
\hline 857 & TOTAL BREAST RECONSTRUCT \\
\hline 8582 & BREAST SPLIT-THICK GRAFT \\
\hline 8583 & BREAST FULL-THICK GRAFT \\
\hline 8584 & BREAST PEDICLE GRAFT \\
\hline 8585 & BREAST MUSCLE FLAP GRAFT \\
\hline 8586 & TRANSPOSITION OF NIPPLE \\
\hline 8587 & NIPPLE REPAIR NEC \\
\hline 8589 & MAMMOPLASTY NEC \\
\hline 8593 & BREAST IMPLANT REVISION \\
\hline 8594 & BREAST IMPLANT REMOVAL \\
\hline
\end{tabular}




\begin{tabular}{|l|l|}
\hline 8595 & INSER BREAST TISSU EXPAN \\
\hline 8596 & REMOV BREAST TISSU EXPAN \\
\hline 8599 & BREAST OPERATION NEC \\
\hline 8606 & INSERT INFUSION PUMP \\
\hline 8621 & EXCISION OF PILONID CYST \\
\hline 8622 & EXC WOUND DEBRIDEMENT \\
\hline 8625 & DERMABRASION \\
\hline 864 & RADICAL EXCIS SKIN LES \\
\hline 8660 & FREE SKIN GRAFT NOS \\
\hline 8661 & FULL-THICK HAND SKIN GRF \\
\hline 8662 & HAND SKIN GRAFT NEC \\
\hline 8663 & FULL-THICK SKIN GRFT NEC \\
\hline 8665 & HETEROGRAFT TO SKIN \\
\hline 8666 & HOMOGRAFT TO SKIN \\
\hline 8667 & DERMAL REGENER GRAFT \\
\hline 8669 & FREE SKIN GRAFT NEC \\
\hline 8670 & PEDICLE GRAFT/FLAP NOS \\
\hline 8671 & CUT \& PREP PEDICLE GRAFT \\
\hline 8672 & PEDICLE GRAFT ADVANCEMEN \\
\hline 8673 & ATTACH PEDICLE TO HAND \\
\hline 8674 & ATTACH PEDICLE GRAFT NEC \\
\hline
\end{tabular}

\begin{tabular}{|l|l|}
\hline 8675 & REVISION OF PEDICLE GRFT \\
\hline 8681 & REPAIR FACIAL WEAKNESS \\
\hline 8682 & FACIAL RHYTIDECTOMY \\
\hline 8683 & SIZE REDUCT PLASTIC OP \\
\hline 8684 & RELAXATION OF SCAR \\
\hline 8685 & SYNDACTYLY CORRECTION \\
\hline 8686 & ONYCHOPLASTY \\
\hline 8689 & SKIN REPAIR \& PLASTY NEC \\
\hline 8691 & SKIN EXCISION FOR GRAFT \\
\hline 8693 & INSERT TISSUE EXPANDER \\
\hline 8694 & $\begin{array}{l}\text { INS/REPL SINGLE PUL GEN (OCT } \\
04)\end{array}$ \\
\hline 8695 & $\begin{array}{l}\text { INS/REPL DUAL PULSE GEN (OCT } \\
04)\end{array}$ \\
\hline 8696 & $\begin{array}{l}\text { INSERT/REPL OTH NEUROST (OCT } \\
04)\end{array}$ \\
\hline 8697 & INS/REP 1 PUL GEN OCT05- \\
\hline 8698 & INS/REP 2 PUL GEN OCT05- \\
\hline 8753 & INTRAOPER CHOLANGIOGRAM \\
\hline 9504 & ANESTHETIZED EYE EXAM \\
\hline
\end{tabular}




\section{APPENDIX 2. VIRTUAL MDC-ASSIGNMENT}

Code lists in ICD-10-WHO for simulation of MDC assignment, see separate excel file.

- M-3 Code list for MDC-14 (Postoperative PE or DVT, Postoperative sepsis, Accidental puncture or laceration)

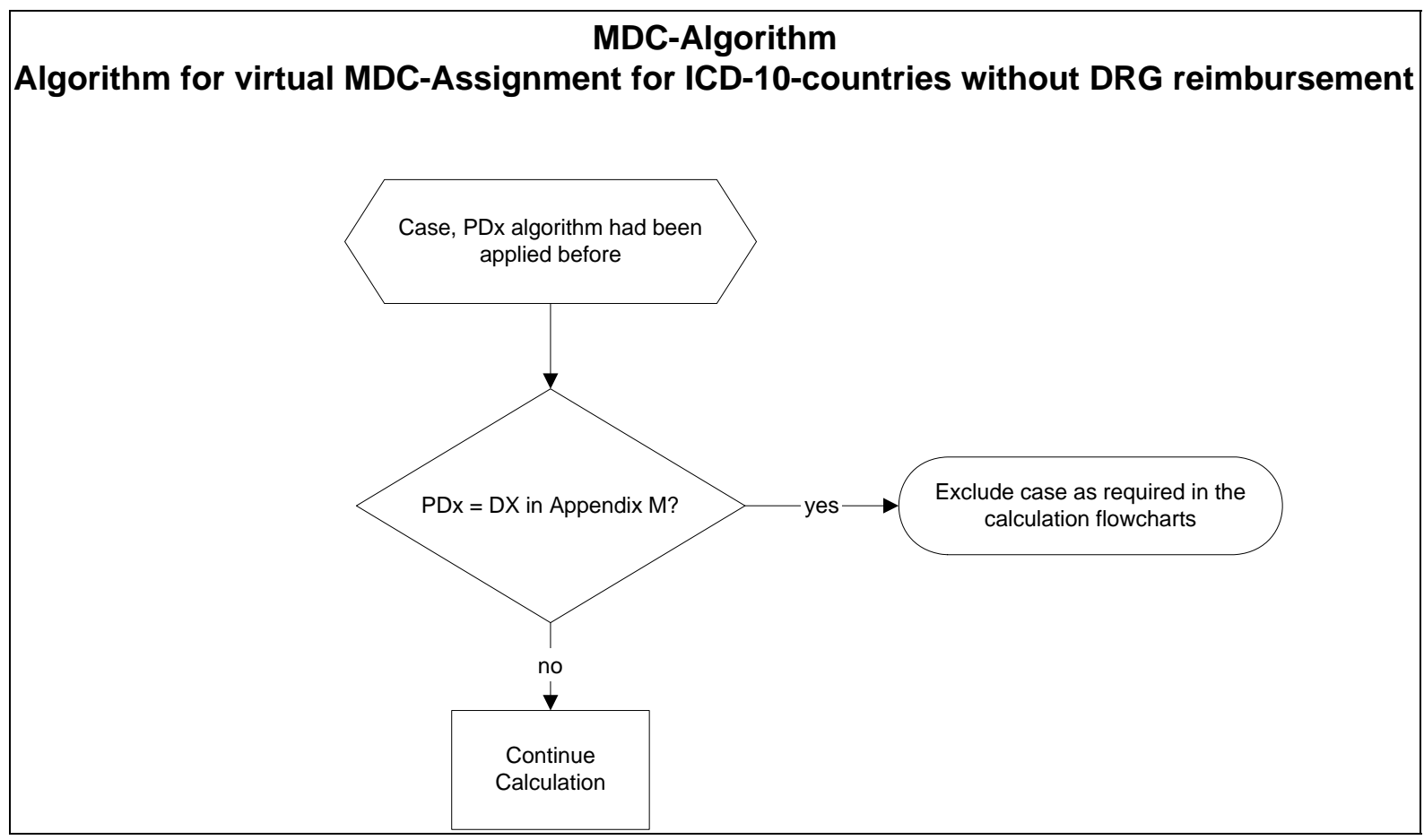

Code lists are adapted from:

- $\quad$ German Diagnosis Related Groups, Version 2006. Definitionshandbuch. Institut für das Entgeltsystem im Krankenhaus gGmbH (InEK), Siegburg, Germany, and

- $\quad$ Australian Refined Diagnosis Related Groups V 4.1. Definitions Manual, Vol. 1-3. Commonwealth of Australia 1998App. 


\section{M-3 Code list for MDC-14 (Postop PE or DVT, Postop sepsis, Accidental puncture or laceration)}

\begin{tabular}{|c|c|c|}
\hline $\begin{array}{l}\text { ICD-10 } \\
\text { WHO }\end{array}$ & Title & MDC \\
\hline A34 & Obstetrical tetanus & 14 \\
\hline F53.0 & $\begin{array}{l}\text { Mild mental and behavioural disorders associated with the puerperium, not elsewhere } \\
\text { classified }\end{array}$ & 14 \\
\hline F53.1 & $\begin{array}{l}\text { Severe mental and behavioural disorders associated with the puerperium, not } \\
\text { elsewhere classified }\end{array}$ & 14 \\
\hline F53.8 & \begin{tabular}{|l}
$\begin{array}{l}\text { Other mental and behavioural disorders associated with the puerperium, not } \\
\text { elsewhere classified }\end{array}$ \\
\end{tabular} & 14 \\
\hline F53.9 & Puerperal mental disorder, unspecified & 14 \\
\hline O00.0 & Abdominal pregnancy & 14 \\
\hline O00.1 & Tubal pregnancy & 14 \\
\hline O00.2 & Ovarian pregnancy & 14 \\
\hline O00.8 & Other ectopic pregnancy & 14 \\
\hline O00.9 & Ectopic pregnancy, unspecified & 14 \\
\hline O01.0 & Classical hydatidiform mole & 14 \\
\hline O01.1 & Incomplete and partial hydatidiform mole & 14 \\
\hline O01.9 & Hydatidiform mole, unspecified & 14 \\
\hline O02.0 & Blighted ovum and nonhydatidiform mole & 14 \\
\hline O02.1 & Missed abortion & 14 \\
\hline O02.8 & Other specified abnormal products of conception & 14 \\
\hline O02.9 & Abnormal product of conception, unspecified & 14 \\
\hline O03.0 & Spontaneous abortion, incomplete, complicated by genital tract and pelvic infection & 14 \\
\hline O03.1 & Spontaneous abortion, incomplete, complicated by delayed or excessive haemorrhage & 14 \\
\hline O03.2 & Spontaneous abortion, incomplete, complicated by embolism & 14 \\
\hline O03.3 & Spontaenous abortion, incomplete, with other and unspecified complications & 14 \\
\hline O03.4 & Spontaneous abortion, incomplete, without complication & 14 \\
\hline O03.5 & $\begin{array}{l}\text { Spontaneous abortion, complete or unspecified, complicated by genital tract and } \\
\text { pelvic infection }\end{array}$ & 14 \\
\hline O03.6 & $\begin{array}{l}\text { Spontaneous abortion, complete or unspecified, complicated by delayed or excessive } \\
\text { haemorrhage }\end{array}$ & 14 \\
\hline O03.7 & Spontaneous abortion, complete or unspecified, complicated by embolism & 14 \\
\hline O03.8 & \begin{tabular}{|l}
$\begin{array}{l}\text { Spontaneous abortion, complete or unspecified, with other and unspecified } \\
\text { complications }\end{array}$ \\
\end{tabular} & 14 \\
\hline O03.9 & Spontaneous abortion, complete or unspecified, without complication & 14 \\
\hline O04.0 & Medical abortion, incomplete, complicated by genital tract and pelvic infection & 14 \\
\hline O04.1 & Medical abortion, incomplete, complicated by delayed or excessive haemorrhage & 14 \\
\hline O04.2 & Medical abortion, incomplete, complicated by embolism & 14 \\
\hline O04.3 & Medical abortion, incomplete, with other and unspecified complications & 14 \\
\hline O04.4 & Medical abortion, incomplete, without complication & 14 \\
\hline O04.5 & $\begin{array}{l}\text { Medical abortion, complete or unspecified, complicated by genital tract and pelvic } \\
\text { infection }\end{array}$ & 14 \\
\hline O04.6 & $\begin{array}{l}\text { Medical abortion, complete or unspecified, complicated by delayed or excessive } \\
\text { haemorrhage }\end{array}$ & 14 \\
\hline O04.7 & Medical abortion, complete or unspecified, complicated by embolism & 14 \\
\hline O04.8 & Medical abortion, complete or unspecified, with other and unspecified complications & 14 \\
\hline O04.9 & Medical abortion, complete or unspecified, without complication & 14 \\
\hline O05.0 & Other abortion, incomplete, complicated by genital tract and pelvic infection & 14 \\
\hline O05.1 & Other abortion, incomplete, complicated by delayed or excessive haemorrhage & 14 \\
\hline
\end{tabular}




\begin{tabular}{|c|c|c|}
\hline O05.2 & Other abortion, incomplete, complicated by embolism & 14 \\
\hline O05.3 & Other abortion, incomplete, with other and unspecified complications & 14 \\
\hline O05.4 & Other abortion, incomplete, without complication & 14 \\
\hline O05.5 & $\begin{array}{l}\text { Other abortion, complete or unspecified, complicated by genital tract and pelvic } \\
\text { infection }\end{array}$ & 14 \\
\hline O05.6 & $\begin{array}{l}\text { Other abortion, complete or unspecified, complicated by delayed or excessive } \\
\text { haemorrhage }\end{array}$ & 14 \\
\hline O05.7 & Other abortion, complete or unspecified, complicated by embolism & 14 \\
\hline O05.8 & Other abortion, complete or unspecified, with other and unspecified complications & 14 \\
\hline O05.9 & Other abortion, complete or unspecified, without complication & 14 \\
\hline O06.0 & Unspecified abortion, incomplete, complicated by genital tract and pelvic infection & 14 \\
\hline O06.1 & Unspecified abortion, incomplete, complicated by delayed or excessive haemorrhage & 14 \\
\hline O06.2 & Unspecified abortion, incomplete, complicated by embolism & 14 \\
\hline O06.3 & Unspecified abortion, incomplete, with other and unspecified complications & 14 \\
\hline O06.4 & Unspecified abortion, incomplete, without complication & 14 \\
\hline O06.5 & $\begin{array}{l}\text { Unspecified abortion, complete or unspecified, complicated by genital tract and } \\
\text { pelvic infection }\end{array}$ & 14 \\
\hline O06.6 & $\begin{array}{l}\text { Unspecified abortion, complete or unspecified, complicated by delayed or excessive } \\
\text { haemorrhage }\end{array}$ & 14 \\
\hline O06.7 & Unspecified abortion, complete or unspecified, complicated by embolism & 14 \\
\hline O06.8 & $\begin{array}{l}\begin{array}{l}\text { Unspecified abortion, complete or unspecified, with other and unspecified } \\
\text { complications }\end{array} \\
\end{array}$ & 14 \\
\hline O06.9 & Unspecified abortion, complete or unspecified, without complication & 14 \\
\hline O07.0 & Failed medical abortion, complicated by genital tract and pelvic infection & 14 \\
\hline O07.1 & Failed medical abortion, complicated by delayed or excessive haemorrhage & 14 \\
\hline O07.2 & Failed medical abortion, complicated by embolism & 14 \\
\hline O07.3 & Failed medical abortion, with other and unspecified complications & 14 \\
\hline O07.4 & Failed medical abortion, without complication & 14 \\
\hline O07.5 & $\begin{array}{l}\text { Other and unspecified failed attempted abortion, complicated by genital tract and } \\
\text { pelvic infection }\end{array}$ & 14 \\
\hline O07.6 & $\begin{array}{l}\text { Other and unspecified failed attempted abortion, complicated by delayed or excessive } \\
\text { haemorrhage }\end{array}$ & 14 \\
\hline O07.7 & Other and unspecified failed attempted abortion, complicated by embolism & 14 \\
\hline O07.8 & $\begin{array}{l}\text { Other and unspecified failed attempted abortion, with other and unspecified } \\
\text { complications }\end{array}$ & 14 \\
\hline O07.9 & Other and unspecified failed attempted abortion, without complication & 14 \\
\hline O08.0 & Genital tract and pelvic infection following abortion and ectopic and molar pregnancy & 14 \\
\hline O08.1 & $\begin{array}{l}\text { Delayed or excessive haemorrhage following abortion and ectopic and molar } \\
\text { pregnancy }\end{array}$ & 14 \\
\hline O08.2 & Embolism following abortion and ectopic and molar pregnancy & 14 \\
\hline O08.3 & Shock following abortion and ectopic and molar pregnancy & 14 \\
\hline O08.4 & Renal failure following abortion and ectopic and molar pregnancy & 14 \\
\hline O08.5 & Metabolic disorders following abortion and ectopic and molar pregnancy & 14 \\
\hline O08.6 & $\begin{array}{l}\text { Damage to pelvic organs and tissues following abortion and ectopic and molar } \\
\text { pregnancy }\end{array}$ & 14 \\
\hline O08.7 & Other venous complications following abortion and ectopic and molar pregnancy & 14 \\
\hline O08.8 & Other complications following abortion and ectopic and molar pregnancy & 14 \\
\hline O08.9 & Complication following abortion and ectopic and molar pregnancy, unspecified & 14 \\
\hline O10.0 & $\begin{array}{l}\text { Pre-existing essential hypertension complicating pregnancy, childbirth and the } \\
\text { puerperium }\end{array}$ & 14 \\
\hline
\end{tabular}




\begin{tabular}{|c|c|c|}
\hline O10.1 & $\begin{array}{l}\text { Pre-existing hypertensive heart disease complicating pregnancy, childbirth and the } \\
\text { puerperium }\end{array}$ & 14 \\
\hline O10.2 & $\begin{array}{l}\text { Pre-existing hypertensive renal disease complicating pregnancy, childbirth and the } \\
\text { puerperium }\end{array}$ & 14 \\
\hline O10.3 & $\begin{array}{l}\text { Pre-existing hypertensive heart and renal disease complicating pregnancy, childbirth } \\
\text { and the puerperium }\end{array}$ & 14 \\
\hline O10.4 & $\begin{array}{l}\text { Pre-existing secondary hypertension complicating pregnancy, childbirth and the } \\
\text { puerperium }\end{array}$ & 14 \\
\hline O10.9 & $\begin{array}{l}\text { Unspecified pre-existing hypertension complicating pregnancy, childbirth and the } \\
\text { puerperium }\end{array}$ & 14 \\
\hline O11 & Pre-existing hypertensive disorder with superimposed proteinuria & 14 \\
\hline O12.0 & Gestational oedema & 14 \\
\hline O12.1 & Gestational proteinuria & 14 \\
\hline O12.2 & Gestational oedema with proteinuria & 14 \\
\hline $\mathrm{O} 13$ & Gestational [pregnancy-induced] hypertension without significant proteinuria & 14 \\
\hline O14.0 & Moderate pre-eclampsia & 14 \\
\hline O14.1 & Severe pre-eclampsia & 14 \\
\hline O14.9 & Pre-eclampsia, unspecified & 14 \\
\hline O15.0 & Eclampsia in pregnancy & 14 \\
\hline O15.1 & Eclampsia in labour & 14 \\
\hline O15.2 & Eclampsia in the puerperium & 14 \\
\hline O15.9 & Eclampsia, unspecified as to time period & 14 \\
\hline O16 & Unspecified maternal hypertension & 14 \\
\hline $\mathrm{O} 20.0$ & Threatened abortion & 14 \\
\hline O20.8 & Other haemorrhage in early pregnancy & 14 \\
\hline O20.9 & Haemorrhage in early pregnancy, unspecified & 14 \\
\hline O21.0 & Mild hyperemesis gravidarum & 14 \\
\hline O21.1 & Hyperemesis gravidarum with metabolic disturbance & 14 \\
\hline O21.2 & Late vomiting of pregnancy & 14 \\
\hline O21.8 & Other vomiting complicating pregnancy & 14 \\
\hline O21.9 & Vomiting of pregnancy, unspecified & 14 \\
\hline O22.0 & Varicose veins of lower extremity in pregnancy & 14 \\
\hline O22.1 & Genital varices in pregnancy & 14 \\
\hline $\mathrm{O} 22.2$ & Superficial thrombophlebitis in pregnancy & 14 \\
\hline O22.3 & Deep phlebothrombosis in pregnancy & 14 \\
\hline O22.4 & Haemorrhoids in pregnancy & 14 \\
\hline $\mathrm{O} 22.5$ & Cerebral venous thrombosis in pregnancy & 14 \\
\hline O22.8 & Other venous complications in pregnancy & 14 \\
\hline O22.9 & Venous complication in pregnancy, unspecified & 14 \\
\hline O23.0 & Infections of kidney in pregnancy & 14 \\
\hline O23.1 & Infections of bladder in pregnancy & 14 \\
\hline O23.2 & Infections of urethra in pregnancy & 14 \\
\hline O23.3 & Infections of other parts of urinary tract in pregnancy & 14 \\
\hline O23.4 & Unspecified infection of urinary tract in pregnancy & 14 \\
\hline O23.5 & Infections of the genital tract in pregnancy & 14 \\
\hline O23.9 & Other and unspecified genitourinary tract infection in pregnancy & 14 \\
\hline O24.0 & Diabetes mellitus in pregnancy: Pre-existing diabetes mellitus, insulin-dependent & 14 \\
\hline O24.1 & Diabetes mellitus in pregnancy: Pre-existing diabetes mellitus, non-insulin-dependent & 14 \\
\hline O24.2 & Diabetes mellitus in pregnancy: Pre-existing malnutrition-related diabetes mellitus & 14 \\
\hline O24.3 & Diabetes mellitus in pregnancy: Pre-existing diabetes mellitus, unspecified & 14 \\
\hline
\end{tabular}




\begin{tabular}{|c|c|c|}
\hline O24.4 & Diabetes mellitus arising in pregnancy & 14 \\
\hline O24.9 & Diabetes mellitus in pregnancy, unspecified & 14 \\
\hline $\mathrm{O} 25$ & Malnutrition in pregnancy & 14 \\
\hline O26.0 & Excessive weight gain in pregnancy & 14 \\
\hline O26.1 & Low weight gain in pregnancy & 14 \\
\hline O26.2 & Pregnancy care of habitual aborter & 14 \\
\hline O26.3 & Retained intrauterine contraceptive device in pregnancy & 14 \\
\hline O26.4 & Herpes gestationis & 14 \\
\hline O26.5 & Maternal hypotension syndrome & 14 \\
\hline O26.6 & Liver disorders in pregnancy, childbirth and the puerperium & 14 \\
\hline O26.7 & Subluxation of symphysis (pubis) in pregnancy, childbirth and the puerperium & 14 \\
\hline O26.8 & Other specified pregnancy-related conditions & 14 \\
\hline O26.9 & Pregnancy-related condition, unspecified & 14 \\
\hline O28.0 & Abnormal haematological finding on antenatal screening of mother & 14 \\
\hline O28.1 & Abnormal biochemical finding on antenatal screening of mother & 14 \\
\hline O28.2 & Abnormal cytological finding on antenatal screening of mother & 14 \\
\hline O28.3 & Abnormal ultrasonic finding on antenatal screening of mother & 14 \\
\hline O28.4 & Abnormal radiological finding on antenatal screening of mother & 14 \\
\hline O28.5 & Abnormal chromosomal and genetic finding on antenatal screening of mother & 14 \\
\hline O28.8 & Other abnormal findings on antenatal screening of mother & 14 \\
\hline O28.9 & Abnormal finding on antenatal screening of mother, unspecified & 14 \\
\hline O29.0 & Pulmonary complications of anaesthesia during pregnancy & 14 \\
\hline O29.1 & Cardiac complications of anaesthesia during pregnancy & 14 \\
\hline O29.2 & Central nervous system complications of anaesthesia during pregnancy & 14 \\
\hline O29.3 & Toxic reaction to local anaesthesia during pregnancy & 14 \\
\hline O29.4 & Spinal and epidural anaesthesia-induced headache during pregnancy & 14 \\
\hline O29.5 & Other complications of spinal and epidural anaesthesia during pregnancy & 14 \\
\hline O29.6 & Failed or difficult intubation during pregnancy & 14 \\
\hline O29.8 & Other complications of anaesthesia during pregnancy & 14 \\
\hline O29.9 & Complication of anaesthesia during pregnancy, unspecified & 14 \\
\hline O30.0 & Twin pregnancy & 14 \\
\hline O30.1 & Triplet pregnancy & 14 \\
\hline O30.2 & Quadruplet pregnancy & 14 \\
\hline O30.8 & Other multiple gestation & 14 \\
\hline O30.9 & Multiple gestation, unspecified & 14 \\
\hline O31.0 & Papyraceous fetus & 14 \\
\hline O31.1 & Continuing pregnancy after abortion of one fetus or more & 14 \\
\hline O31.2 & Continuing pregnancy after intrauterine death of one fetus or more & 14 \\
\hline O31.8 & Other complications specific to multiple gestation & 14 \\
\hline O32.0 & Maternal care for unstable lie & 14 \\
\hline O32.1 & Maternal care for breech presentation & 14 \\
\hline O32.2 & Maternal care for transverse and oblique lie & 14 \\
\hline O32.3 & Maternal care for face, brow and chin presentation & 14 \\
\hline O32.4 & Maternal care for high head at term & 14 \\
\hline O32.5 & Maternal care for multiple gestation with malpresentation of one fetus or more & 14 \\
\hline O32.6 & Maternal care for compound presentation & 14 \\
\hline O32.8 & Maternal care for other malpresentation of fetus & 14 \\
\hline O32.9 & Maternal care for malpresentation of fetus, unspecified & 14 \\
\hline O33.0 & Maternal care for disproportion due to deformity of maternal pelvic bones & 14 \\
\hline O33.1 & Maternal care for disproportion due to generally contracted pelvis & 14 \\
\hline
\end{tabular}




\begin{tabular}{|c|c|c|}
\hline O33.2 & Maternal care for disproportion due to inlet contraction of pelvis & 14 \\
\hline O33.3 & Maternal care for disproportion due to outlet contraction of pelvis & 14 \\
\hline O33.4 & Maternal care for disproportion of mixed maternal and fetal origin & 14 \\
\hline O33.5 & Maternal care for disproportion due to unusually large fetus & 14 \\
\hline O33.6 & Maternal care for disproportion due to hydrocephalic fetus & 14 \\
\hline O33.7 & Maternal care for disproportion due to other fetal deformities & 14 \\
\hline O33.8 & Maternal care for disproportion of other origin & 14 \\
\hline O33.9 & Maternal care for disproportion, unspecified & 14 \\
\hline O34.0 & Maternal care for congenital malformation of uterus & 14 \\
\hline O34.1 & Maternal care for tumour of corpus uteri & 14 \\
\hline O34.2 & Maternal care due to uterine scar from previous surgery & 14 \\
\hline O34.3 & Maternal care for cervical incompetence & 14 \\
\hline O34.4 & Maternal care for other abnormalities of cervix & 14 \\
\hline O34.5 & Maternal care for other abnormalities of gravid uterus & 14 \\
\hline O34.6 & Maternal care for abnormality of vagina & 14 \\
\hline O34.7 & Maternal care for abnormality of vulva and perineum & 14 \\
\hline O34.8 & Maternal care for other abnormalities of pelvic organs & 14 \\
\hline O34.9 & Maternal care for abnormality of pelvic organ, unspecified & 14 \\
\hline O35.0 & Maternal care for (suspected) central nervous system malformation in fetus & 14 \\
\hline O35.1 & Maternal care for (suspected) chromosomal abnormality in fetus & 14 \\
\hline O35.2 & Maternal care for (suspected) hereditary disease in fetus & 14 \\
\hline O35.3 & Maternal care for (suspected) damage to fetus from viral disease in mother & 14 \\
\hline O35.4 & Maternal care for (suspected) damage to fetus from alcohol & 14 \\
\hline O35.5 & Maternal care for (suspected) damage to fetus by drugs & 14 \\
\hline O35.6 & Maternal care for (suspected) damage to fetus by radiation & 14 \\
\hline O35.7 & Maternal care for (suspected) damage to fetus by other medical procedures & 14 \\
\hline O35.8 & Maternal care for other (suspected) fetal abnormality and damage & 14 \\
\hline O35.9 & Maternal care for (suspected) fetal abnormality and damage, unspecified & 14 \\
\hline O36.0 & Maternal care for rhesus isoimmunization & 14 \\
\hline O36.1 & Maternal care for other isoimmunization & 14 \\
\hline O36.2 & Maternal care for hydrops fetalis & 14 \\
\hline O36.3 & Maternal care for signs of fetal hypoxia & 14 \\
\hline O36.4 & Maternal care for intrauterine death & 14 \\
\hline O36.5 & Maternal care for poor fetal growth & 14 \\
\hline O36.6 & Maternal care for excessive fetal growth & 14 \\
\hline O36.7 & Maternal care for viable fetus in abdominal pregnancy & 14 \\
\hline O36.8 & Maternal care for other specified fetal problems & 14 \\
\hline O36.9 & Maternal care for fetal problem, unspecified & 14 \\
\hline $\mathrm{O} 40$ & Polyhydramnios & 14 \\
\hline O41.0 & Oligohydramnios & 14 \\
\hline O41.1 & Infection of amniotic sac and membranes & 14 \\
\hline O41.8 & Other specified disorders of amniotic fluid and membranes & 14 \\
\hline O41.9 & Disorder of amniotic fluid and membranes, unspecified & 14 \\
\hline O42.0 & Premature rupture of membranes, onset of labour within 24 hours & 14 \\
\hline O42.1 & Premature rupture of membranes, onset of labour after 24 hours & 14 \\
\hline O42.2 & Premature rupture of membranes, labour delayed by therapy & 14 \\
\hline O42.9 & Premature rupture of membranes, unspecified & 14 \\
\hline O43.0 & Placental transfusion syndromes & 14 \\
\hline O43.1 & Malformation of placenta & 14 \\
\hline O43.8 & Other placental disorders & 14 \\
\hline
\end{tabular}


DELSA/HEA/WD/HWP(2009)5/ANN

\begin{tabular}{|c|c|c|}
\hline O43.9 & Placental disorder, unspecified & 14 \\
\hline O44.0 & Placenta praevia specified as without haemorrhage & 14 \\
\hline O44.1 & Placenta praevia with haemorrhage & 14 \\
\hline O45.0 & Premature separation of placenta with coagulation defect & 14 \\
\hline O45.8 & Other premature separation of placenta & 14 \\
\hline O45.9 & Premature separation of placenta, unspecified & 14 \\
\hline O46.0 & Antepartum haemorrhage with coagulation defect & 14 \\
\hline O46.8 & Other antepartum haemorrhage & 14 \\
\hline O46.9 & Antepartum haemorrhage, unspecified & 14 \\
\hline O47.0 & False labour before 37 completed weeks of gestation & 14 \\
\hline O47.1 & False labour at or after 37 completed weeks of gestation & 14 \\
\hline O47.9 & False labour, unspecified & 14 \\
\hline $\mathrm{O} 48$ & Prolonged pregnancy & 14 \\
\hline O60.0 & Preterm labour without delivery & 14 \\
\hline O60.1 & Preterm labour with preterm delivery & 14 \\
\hline O60.2 & Preterm labour with term delivery & 14 \\
\hline O61.0 & Failed medical induction of labour & 14 \\
\hline O61.1 & Failed instrumental induction of labour & 14 \\
\hline O61.8 & Other failed induction of labour & 14 \\
\hline O61.9 & Failed induction of labour, unspecified & 14 \\
\hline O62.0 & Primary inadequate contractions & 14 \\
\hline O62.1 & Secondary uterine inertia & 14 \\
\hline O62.2 & Other uterine inertia & 14 \\
\hline O62.3 & Precipitate labour & 14 \\
\hline O62.4 & Hypertonic, incoordinate, and prolonged uterine contractions & 14 \\
\hline O62.8 & Other abnormalities of forces of labour & 14 \\
\hline O62.9 & Abnormality of forces of labour, unspecified & 14 \\
\hline O63.0 & Prolonged first stage (of labour) & 14 \\
\hline O63.1 & Prolonged second stage (of labour) & 14 \\
\hline O63.2 & Delayed delivery of second twin, triplet, etc. & 14 \\
\hline O63.9 & Long labour, unspecified & 14 \\
\hline O64.0 & Obstructed labour due to incomplete rotation of fetal head & 14 \\
\hline O64.1 & Obstructed labour due to breech presentation & 14 \\
\hline O64.2 & Obstructed labour due to face presentation & 14 \\
\hline O64.3 & Obstructed labour due to brow presentation & 14 \\
\hline O64.4 & Obstructed labour due to shoulder presentation & 14 \\
\hline O64.5 & Obstructed labour due to compound presentation & 14 \\
\hline O64.8 & Obstructed labour due to other malposition and malpresentation & 14 \\
\hline O64.9 & Obstructed labour due to malposition and malpresentation, unspecified & 14 \\
\hline O65.0 & Obstructed labour due to deformed pelvis & 14 \\
\hline O65.1 & Obstructed labour due to generally contracted pelvis & 14 \\
\hline O65.2 & Obstructed labour due to pelvic inlet contraction & 14 \\
\hline O65.3 & Obstructed labour due to pelvic outlet and mid-cavity contraction & 14 \\
\hline O65.4 & Obstructed labour due to fetopelvic disproportion, unspecified & 14 \\
\hline O65.5 & Obstructed labour due to abnormality of maternal pelvic organs & 14 \\
\hline O65.8 & Obstructed labour due to other maternal pelvic abnormalities & 14 \\
\hline O65.9 & Obstructed labour due to maternal pelvic abnormality, unspecified & 14 \\
\hline O66.0 & Obstructed labour due to shoulder dystocia & 14 \\
\hline O66.1 & Obstructed labour due to locked twins & 14 \\
\hline O66.2 & Obstructed labour due to unusually large fetus & 14 \\
\hline
\end{tabular}




\begin{tabular}{|c|c|c|}
\hline O66.3 & Obstructed labour due to other abnormalities of fetus & 14 \\
\hline O66.4 & Failed trial of labour, unspecified & 14 \\
\hline O66.5 & Failed application of vacuum extractor and forceps, unspecified & 14 \\
\hline O66.8 & Other specified obstructed labour & 14 \\
\hline O66.9 & Obstructed labour, unspecified & 14 \\
\hline O67.0 & Intrapartum haemorrhage with coagulation defect & 14 \\
\hline O67.8 & Other intrapartum haemorrhage & 14 \\
\hline O67.9 & Intrapartum haemorrhage, unspecified & 14 \\
\hline O68.0 & Labour and delivery complicated by fetal heart rate anomaly & 14 \\
\hline O68.1 & Labour and delivery complicated by meconium in amniotic fluid & 14 \\
\hline O68.2 & $\begin{array}{l}\text { Labour and delivery complicated by fetal heart rate anomaly with meconium in } \\
\text { amniotic fluid }\end{array}$ & 14 \\
\hline O68.3 & Labour and delivery complicated by biochemical evidence of fetal stress & 14 \\
\hline O68.8 & Labour and delivery complicated by other evidence of fetal stress & 14 \\
\hline O68.9 & Labour and delivery complicated by fetal stress, unspecified & 14 \\
\hline O69.0 & Labour and delivery complicated by prolapse of cord & 14 \\
\hline O69.1 & Labour and delivery complicated by cord around neck, with compression & 14 \\
\hline O69.2 & Labour and delivery complicated by other cord entanglement & 14 \\
\hline O69.3 & Labour and delivery complicated by short cord & 14 \\
\hline O69.4 & Labour and delivery complicated by vasa praevia & 14 \\
\hline O69.5 & Labour and delivery complicated by vascular lesion of cord & 14 \\
\hline O69.8 & Labour and delivery complicated by other cord complications & 14 \\
\hline O69.9 & Labour and delivery complicated by cord complication, unspecified & 14 \\
\hline O70.0 & First degree perineal laceration during delivery & 14 \\
\hline O70.1 & Second degree perineal laceration during delivery & 14 \\
\hline O70.2 & Third degree perineal laceration during delivery & 14 \\
\hline O70.3 & Fourth degree perineal laceration during delivery & 14 \\
\hline O70.9 & Perineal laceration during delivery, unspecified & 14 \\
\hline O71.0 & Rupture of uterus before onset of labour & 14 \\
\hline O71.1 & Rupture of uterus during labour & 14 \\
\hline O71.2 & Postpartum inversion of uterus & 14 \\
\hline O71.3 & Obstetric laceration of cervix & 14 \\
\hline O71.4 & Obstetric high vaginal laceration alone & 14 \\
\hline O71.5 & Other obstetric injury to pelvic organs & 14 \\
\hline O71.6 & Obstetric damage to pelvic joints and ligaments & 14 \\
\hline O71.7 & Obstetric haematoma of pelvis & 14 \\
\hline O71.8 & Other specified obstetric trauma & 14 \\
\hline O71.9 & Obstetric trauma, unspecified & 14 \\
\hline O72.0 & Third-stage haemorrhage & 14 \\
\hline O72.1 & Other immediate postpartum haemorrhage & 14 \\
\hline O72.2 & Delayed and secondary postpartum haemorrhage & 14 \\
\hline O72.3 & Postpartum coagulation defects & 14 \\
\hline O73.0 & Retained placenta without haemorrhage & 14 \\
\hline O73.1 & Retained portions of placenta and membranes, without haemorrhage & 14 \\
\hline O74.0 & Aspiration pneumonitis due to anaesthesia during labour and delivery & 14 \\
\hline O74.1 & Other pulmonary complications of anaesthesia during labour and delivery & 14 \\
\hline O74.2 & Cardiac complications of anaesthesia during labour and delivery & 14 \\
\hline O74.3 & Central nervous system complications of anaesthesia during labour and delivery & 14 \\
\hline O74.4 & Toxic reaction to local anaesthesia during labour and delivery & 14 \\
\hline O74.5 & Spinal and epidural anaesthesia-induced headache during labour and delivery & 14 \\
\hline
\end{tabular}




\begin{tabular}{|c|c|c|}
\hline O74.6 & Other complications of spinal and epidural anaesthesia during labour and delivery & 14 \\
\hline O74.7 & Failed or difficult intubation during labour and delivery & 14 \\
\hline O74.8 & Other complications of anaesthesia during labour and delivery & 14 \\
\hline O74.9 & Complication of anaesthesia during labour and delivery, unspecified & 14 \\
\hline O75.0 & Maternal distress during labour and delivery & 14 \\
\hline O75.1 & Shock during or following labour and delivery & 14 \\
\hline O75.2 & Pyrexia during labour, not elsewhere classified & 14 \\
\hline O75.3 & Other infection during labour & 14 \\
\hline O75.4 & Other complications of obstetric surgery and procedures & 14 \\
\hline O75.5 & Delayed delivery after artificial rupture of membranes & 14 \\
\hline O75.6 & Delayed delivery after spontaneous or unspecified rupture of membranes & 14 \\
\hline O75.7 & Vaginal delivery following previous caesarean section & 14 \\
\hline O75.8 & Other specified complications of labour and delivery & 14 \\
\hline O75.9 & Complication of labour and delivery, unspecified & 14 \\
\hline O80.0 & Spontaneous vertex delivery & 14 \\
\hline O80.1 & Spontaneous breech delivery & 14 \\
\hline O80.8 & Other single spontaneous delivery & 14 \\
\hline O80.9 & Single spontaneous delivery, unspecified & 14 \\
\hline O81.0 & Low forceps delivery & 14 \\
\hline O81.1 & Mid-cavity forceps delivery & 14 \\
\hline O81.2 & Mid-cavity forceps with rotation & 14 \\
\hline O81.3 & Other and unspecified forceps delivery & 14 \\
\hline O81.4 & Vacuum extractor delivery & 14 \\
\hline O81.5 & Delivery by combination of forceps and vacuum extractor & 14 \\
\hline O82.0 & Delivery by elective caesarean section & 14 \\
\hline O82.1 & Delivery by emergency caesarean section & 14 \\
\hline O82.2 & Delivery by caesarean hysterectomy & 14 \\
\hline O82.8 & Other single delivery by caesarean section & 14 \\
\hline O82.9 & Delivery by caesarean section, unspecified & 14 \\
\hline O85 & Puerperal sepsis & 14 \\
\hline O86.0 & Infection of obstetric surgical wound & 14 \\
\hline O86.1 & Other infection of genital tract following delivery & 14 \\
\hline O86.2 & Urinary tract infection following delivery & 14 \\
\hline O86.3 & Other genitourinary tract infections following delivery & 14 \\
\hline O86.4 & Pyrexia of unknown origin following delivery & 14 \\
\hline O86.8 & Other specified puerperal infections & 14 \\
\hline O87.0 & Superficial thrombophlebitis in the puerperium & 14 \\
\hline O87.1 & Deep phlebothrombosis in the puerperium & 14 \\
\hline O87.2 & Haemorrhoids in the puerperium & 14 \\
\hline O87.3 & Cerebral venous thrombosis in the puerperium & 14 \\
\hline O87.8 & Other venous complications in the puerperium & 14 \\
\hline O87.9 & Venous complication in the puerperium, unspecified & 14 \\
\hline O88.0 & Obstetric air embolism & 14 \\
\hline O88.1 & Amniotic fluid embolism & 14 \\
\hline O88.2 & Obstetric blood-clot embolism & 14 \\
\hline O88.3 & Obstetric pyaemic and septic embolism & 14 \\
\hline O88.8 & Other obstetric embolism & 14 \\
\hline O89.0 & Pulmonary complications of anaesthesia during the puerperium & 14 \\
\hline O89.1 & Cardiac complications of anaesthesia during the puerperium & 14 \\
\hline O89.2 & Central nervous system complications of anaesthesia during the puerperium & 14 \\
\hline
\end{tabular}




\begin{tabular}{|c|c|c|}
\hline O89.3 & Toxic reaction to local anaesthesia during the puerperium & 14 \\
\hline O89.4 & Spinal and epidural anaesthesia-induced headache during the puerperium & 14 \\
\hline O89.5 & Other complications of spinal and epidural anaesthesia during the puerperium & 14 \\
\hline O89.6 & Failed or difficult intubation during the puerperium & 14 \\
\hline O89.8 & Other complications of anaesthesia during the puerperium & 14 \\
\hline O89.9 & Complication of anaesthesia during the puerperium, unspecified & 14 \\
\hline O90.0 & Disruption of caesarean section wound & 14 \\
\hline O90.1 & Disruption of perineal obstetric wound & 14 \\
\hline O90.2 & Haematoma of obstetric wound & 14 \\
\hline O90.3 & Cardiomyopathy in the puerperium & 14 \\
\hline O90.4 & Postpartum acute renal failure & 14 \\
\hline O90.5 & Postpartum thyroiditis & 14 \\
\hline O90.8 & Other complications of the puerperium, not elsewhere classified & 14 \\
\hline O90.9 & Complication of the puerperium, unspecified & 14 \\
\hline O91.0 & Infection of nipple associated with childbirth & 14 \\
\hline O91.1 & Abscess of breast associated with childbirth & 14 \\
\hline O91.2 & Nonpurulent mastitis associated with childbirth & 14 \\
\hline O92.0 & Retracted nipple associated with childbirth & 14 \\
\hline O92.1 & Cracked nipple associated with childbirth & 14 \\
\hline O92.2 & Other and unspecified disorders of breast associated with childbirth & 14 \\
\hline O92.3 & Agalactia & 14 \\
\hline O92.4 & Hypogalactia & 14 \\
\hline O92.5 & Suppressed lactation & 14 \\
\hline O92.6 & Galactorrhoea & 14 \\
\hline O92.7 & Other and unspecified disorders of lactation & 14 \\
\hline O94 & Sequelae of complication of pregnancy, childbirth and the puerperium & 14 \\
\hline O95 & Obstetric death of unspecified cause & 14 \\
\hline O96 & $\begin{array}{l}\text { Death from any obstetric cause occurring more than } 42 \text { days but less than one year } \\
\text { after delivery }\end{array}$ & 14 \\
\hline O97 & Death from sequelae of direct obstetric causes & 14 \\
\hline O98.0 & Tuberculosis complicating pregnancy, childbirth and the puerperium & 14 \\
\hline O98.1 & Syphilis complicating pregnancy, childbirth and the puerperium & 14 \\
\hline O98.2 & Gonorrhoea complicating pregnancy, childbirth and the puerperium & 14 \\
\hline O98.3 & $\begin{array}{l}\text { Other infections with a predominantly sexual mode of transmission complicating } \\
\text { pregnancy, childbirth and the puerperium }\end{array}$ & 14 \\
\hline O98.4 & Viral hepatitis complicating pregnancy, childbirth and the puerperium & 14 \\
\hline O98.5 & Other viral diseases complicating pregnancy, childbirth and the puerperium & 14 \\
\hline O98.6 & Protozoal diseases complicating pregnancy, childbirth and the puerperium & 14 \\
\hline O98.8 & $\begin{array}{l}\text { Other maternal infectious and parasitic diseases complicating pregnancy, childbirth } \\
\text { and the puerperium }\end{array}$ & 14 \\
\hline O98.9 & $\begin{array}{l}\text { Unspecified maternal infectious or parasitic disease complicating pregnancy, } \\
\text { childbirth and the puerperium }\end{array}$ & 14 \\
\hline O99.0 & Anaemia complicating pregnancy, childbirth and the puerperium & 14 \\
\hline O99.1 & $\begin{array}{l}\text { Other diseases of the blood and blood-forming organs and certain disorders involving } \\
\text { the immune mechanism complicating pregnancy, childbirth and the puerperium }\end{array}$ & 14 \\
\hline O99.2 & $\begin{array}{l}\text { Endocrine, nutritional and metabolic diseases complicating pregnancy, childbirth and } \\
\text { the puerperium }\end{array}$ & 14 \\
\hline O99.3 & $\begin{array}{l}\text { Mental disorders and diseases of the nervous system complicating pregnancy, } \\
\text { childbirth and the puerperium }\end{array}$ & 14 \\
\hline
\end{tabular}




\begin{tabular}{|c|c|c|}
\hline O99.4 & $\begin{array}{l}\text { Diseases of the circulatory system complicating pregnancy, childbirth and the } \\
\text { puerperium }\end{array}$ & 14 \\
\hline O99.5 & $\begin{array}{l}\text { Diseases of the respiratory system complicating pregnancy, childbirth and the } \\
\text { puerperium }\end{array}$ & 14 \\
\hline O99.6 & $\begin{array}{l}\text { Diseases of the digestive system complicating pregnancy, childbirth and the } \\
\text { puerperium }\end{array}$ & 14 \\
\hline O99.7 & $\begin{array}{l}\text { Diseases of the skin and subcutaneous tissue complicating pregnancy, childbirth and } \\
\text { the puerperium }\end{array}$ & 14 \\
\hline O99.8 & $\begin{array}{l}\text { Other specified diseases and conditions complicating pregnancy, childbirth and the } \\
\text { puerperium }\end{array}$ & 14 \\
\hline Z32.0 & Pregnancy, not (yet) confirmed & 14 \\
\hline Z32.1 & Pregnancy confirmed & 14 \\
\hline Z33 & Pregnant state, incidental & 14 \\
\hline Z34.0 & Supervision of normal first pregnancy & 14 \\
\hline Z34.8 & Supervision of other normal pregnancy & 14 \\
\hline Z34.9 & Supervision of normal pregnancy, unspecified & 14 \\
\hline Z35.0 & Supervision of pregnancy with history of infertility & 14 \\
\hline Z35.1 & Supervision of pregnancy with history of abortive outcome & 14 \\
\hline Z35.2 & Supervision of pregnancy with other poor reproductive or obstetric history & 14 \\
\hline Z35.3 & Supervision of pregnancy with history of insufficient antenatal care & 14 \\
\hline Z35.4 & Supervision of pregnancy with grand multiparity & 14 \\
\hline Z35.5 & Supervision of elderly primigravida & 14 \\
\hline Z35.6 & Supervision of very young primigravida & 14 \\
\hline Z35.8 & Supervision of other high-risk pregnancies & 14 \\
\hline Z35.9 & Supervision of high-risk pregnancy, unspecified & 14 \\
\hline Z36.0 & Antenatal screening for chromosomal anomalies & 14 \\
\hline Z36.1 & Antenatal screening for raised alphafetoprotein level & 14 \\
\hline Z36.2 & Other antenatal screening based on amniocentesis & 14 \\
\hline Z36.3 & Antenatal screening for malformations using ultrasound and other physical methods & 14 \\
\hline Z36.4 & $\begin{array}{l}\text { Antenatal screening for fetal growth retardation using ultrasound and other physical } \\
\text { methods }\end{array}$ & 14 \\
\hline Z36.5 & Antenatal screening for isoimmunization & 14 \\
\hline Z36.8 & Other antenatal screening & 14 \\
\hline Z36.9 & Antenatal screening, unspecified & 14 \\
\hline Z37.0 & Single live birth & 14 \\
\hline Z37.1 & Single stillbirth & 14 \\
\hline Z37.2 & Twins, both liveborn & 14 \\
\hline Z37.3 & Twins, one liveborn and one stillborn & 14 \\
\hline Z37.4 & Twins, both stillborn & 14 \\
\hline Z37.5 & Other multiple births, all liveborn & 14 \\
\hline Z37.6 & Other multiple births, some liveborn & 14 \\
\hline Z37.7 & Other multiple births, all stillborn & 14 \\
\hline Z37.9 & Outcome of delivery, unspecified & 14 \\
\hline Z39.0 & Care and examination immediately after delivery & 14 \\
\hline Z39.1 & Care and examination of lactating mother & 14 \\
\hline Z39.2 & Routine postpartum follow-up & 14 \\
\hline Z64.0 & Problems related to unwanted pregnancy & 14 \\
\hline
\end{tabular}




\section{SUMMARY OF REVISIONS}

The following revisions to the former version (OECD Technical Paper 19) of this manual were introduced subsequent to an initial pilot calculation of the indicators by several participating countries:

\section{Manual}

The list of Patient Safety Indicators specified has been reduced to the 7 indicators endorsed by the OECD HCQI Expert Group in Paris on October 232008.

The title of PSI 7 ("Selected infections due to medical care") is changed to "Catheter-Related Bloodstream Infection". The title of PSI 15 ("Technical difficulty with procedure") is changed to "Accidential Puncture or Laceration"

For PSIs 5 and 15 a note was added that hospital discharges with a length of stay less than 24 hours (or 0 days if timestamps are not available) shall be excluded from the denominator population.

For PSI 12 a note was added that hospital discharges with a length of stay less than 2 days shall be excluded from the denominator population.

\section{Appendices}

- Code Lists:

- Code lists are limited to those needed for calculation of the PSIs listed in this manual

- In Appendix 1 a code list with operation room procedures in ICD-9 CM is added

- Questionnaire:

- Use of electronic list functions to facilitate answers in the section referring to administrative databases.

- After the experiences of the 2008 pilot calculation supplementary questions have been included in relation to:

- denominator population related numbers of average length of stay for all indicators

- denominator-related average number of secondary diagnoses for all indicators

- optional: distribution of the coded numerator events in relation to their position in the database

All countries were asked to provide age (5 year age cohorts) and/or sex stratified data for each of the indicators. 


\section{REFERENCES}

AHRQ (2003) "Quality Indicators Patient Safety Indicators: Technical Specifications - March 2003 Version 3.1” Agency for Healthcare Research and Quality, Rockville, MD, AHRC website http://www.qualityindicators.ahrq.gov/downloads/psi/psi_technical_specs_v31.pdf (accessed $01 / 11 / 2008)$

AHRQ (2006) “Patient Safety Indicators Overview: AHRQ Quality Indicators - February 2006” Agency for Healthcare Research and Quality, Rockville, MD, AHRC website

http://www.qualityindicators.ahrq.gov/psi_overview.htm (accessed 11/13/2008).

Commonwealth of Australia (1998) “Australian Refined Diagnosis Related Groups V 4.1. Definitions Manual, Vol. 1-3”, Commonwealth of Australia, Canberra, Australia.

CIHI (Canadian Institute for Health Information) (2004) "Diagnosis Typing: Current Canadian and International Practices Background Paper for the Development of the ICD-10-CA/CCI Acute Care Inpatient Grouping Methodology” CIHI website, http://www.cihi.ca/cihiweb/en/downloads/Diagnosis_Typing_Background_v1.pdf (accessed 11/13/2008).

Department of Health and Human Services (2005) "ICD-9-CM Official Guidelines for Coding and Reporting”, Centers for Disease Control and Prevention website, http://www.cdc.gov/nchs/data/icd9/icdguide.pdf (accessed 11/13/2008)

Department of Health and Human Services (2007) “ICD-9-CM Tabular List of Diseases (FY07)”, Centers for Disease Control and Prevention website, http://www.cdc.gov/nchs/icd9.htm\#RTF. (accessed 11/13/2008).

DIMDI (German Institute of Medical Documentation and Information) (2007) DIMDI website, http://www.dimdi.de/static/en/klassi/diagnosen/ueberl/index.htm (accessed 11/13/2008).

Drösler S E, Cools A, Köpfer T, Stausberg J. (2007) “Are Quality Indicators Derived from Routine Data Suitable for Evaluation Hospital Performance? First Results Using the AHRQ Patient Safety Indicators in Germany”, ZaeFQ 2007; 101(1):35-42.

Drösler S E (2008) "Facilitating Cross National Comparisons of Indicators for Patient Safety at the HealthSytem Level in the OECD Countries” Health Technical Paper No 19, OECD, Paris

INEK (Institute for the Hospital Remuneration System) (2006) “German Diagnosis Related Groups, Version 2006. Definitionshandbuch, Vol. 1-5”, Institut für das Entgeltsystem im Krankenhaus gGmbH (InEK), Siegburg, Germany.

Millar J, S Mattke and the Members of the OECD Patient Safety Panel (2004) "Selecting Indicators for Patient Safety at the Health System Level in OECD Countries” Health Technical Paper No 18, OECD, Paris.

Mattke S, E Kelley, P Scherer, J Hurst, M L Gil Lapetra and the HCQI Expert Group Members (2006) "Health Care Quality Indicators Project Initial Indicators Report: Initial Indicators Report OECD” Health Working Paper No 22 OECD, Paris. 
OECD (2007) "Patient Safety Data Systems in the OECD: A Report of a Joint Irish Department of Health OECD Conference” OECD, Paris.

Quan H, Drösler S, Sundararajan V, Wen E, Burnand B, Couris C, et al. (2008) Adaptation of AHRQ Patient Safety Indicators for Use in ICD-10 Administrative Data by an International Consortium. http://www.ahrq.gov/downloads/pub/advances2/vol1/Advances-Quan_52.pdf (accessed $11 / 13 / 2008)$.

WHO (2006) "World Health Organization: International Statistical Classification of Diseases and Related Health Problems 10th Revision Version for 2006”, WHO website, http://www.who.int/classifications/apps/icd/icd10online2006/ (accessed 11/13/2008). 


\section{OECD HEALTH WORKING PAPERS}

A full list of the papers in this series can be found on the OECD website: www.oecd.org/els/health/workingpapers

No. 47 HEALTH CARE QUALITY INDICATORS PROJECT: PATIENT SAFETY INDICATORS REPORT 2009 (2009) Saskia Drösler, Patrick Romano, Lihan Wei

No. 46 EDUCATION AND OBESITY IN FOUR OECD COUNTRIES (2009) Franco Sassi, Marion Devaux, Jody Church, Michele Cecchini and Francesca Borgonovi

No. 45 THE OBESITY EPIDEMIC: ANALYSIS OF PAST AND PROJECTED FUTURE TRENDS IN SELECTED OECD COUNTRIES (2009) Franco Sassi, Marion Devaux, Michele Cecchini and Elena Rusticelli

No. 44 THE LONG-TERM CARE WORKFORCE: OVERVIEW AND STRATEGIES TO ADAPT SUPPLY TO A GROWING DEMAND (2009) Rie Fujisawa and Francesca Colombo

No. 43 MEASURING DISPARITIES IN HEALTH STATUS AND IN ACCESS AND USE OF HEALTH CARE IN OECD COUNTRIES (2009) Michael de Looper and Gaetan Lafortune

No. 42 POLICIES FOR HEALTHY AGEING: AN OVERVIEW (2009) Howard Oxley

No. 41 THE REMUNERATION OF GENERAL PRACTITIONERS AND SPECIALISTS IN 14 OECD COUNTRIES: WHAT ARE THE FACTORS EXPLAINING VARIATIONS ACROSS COUNTRIES? (2008) Rie Fujisawa and Gaetan Lafortune

No. 40 INTERNATIONAL MOBILITY OF HEALTH PROFESSIONALS AND HEALTH WORKFORCE MANAGEMENT IN CANADA: MYTHS AND REALITIES (2008) Jean-Christophe Dumont, Pascal Zurn, Jody Church and Christine Le Thi

No. 39 PHARMACEUTICAL PRICING \& REIMBURSEMENT POLICIES IN GERMANY (2008) Valérie Paris and Elizabeth Docteur

No. 38 MIGRATION OF HEALTH WORKERS: THE UK PERSPECTIVE TO 2006 (2008) James Buchan, Susanna Baldwin and Miranda Munro

No. 37 THE US PHYSICIAN WORKFORCE: WHERE DO WE STAND? (2008) Richard A. Cooper

No. 36 MIGRATION POLICIES OF HEALTH PROFESSIONALS IN FRANCE (2008) Roland Cash and Philippe Ulmann

No. 35 NURSE WORKFORCE CHALLENGES IN THE UNITED STATES: IMPLICATIONS FOR POLICY (2008) Linda H. Aiken and Robyn Cheung

No. 34 MISMATCHES IN THE FORMAL SECTOR, EXPANSION OF THE INFORMAL SECTOR: IMMIGRATION OF HEALTH PROFESSIONALS TO ITALY (2008) Jonathan Chaloff

No. 33 HEALTH WORKFORCE AND INTERNATIONAL MIGRATION: CAN NEW ZEALAND COMPETE? (2008) Pascal Zurn and Jean-Christophe Dumont

No. 32 THE PREVENTION OF LIFESTYLE-RELATED CHRONIC DISEASES: AN ECONOMIC FRAMEWORK (2008) Franco Sassi and Jeremy Hurst 
DELSA/HEA/WD/HWP(2009)5/ANN

\section{RECENT RELATED OECD PUBLICATIONS}

HEALTH AT A GLANCE 2009: OECD INDICATORS (2009).

See http://www. oecd.org/health/healthataglance for more information

ACHIEVING BETTER VALUE FOR MONEY IN HEALTH CARE (2009), OECD HEALTH POLICY STUDIES

OECD HEALTH DATA 2009 (2009), available on CD-ROM (in single-user or network installations). The database can be queried in English, French, German, Spanish and Italian. Japanese and Russian are also available but exclusively in the online version. www. oecd.org/health/healthdata

OECD REVIEWS OF HEALTH SYSTEMS - TURKEY (2009)

THE LOOMING CRISIS IN THE HEALTH WORKFORCE: CAN OECD COUNTRIES RESPOND? (2008)

PHARMACEUTICAL PRICING POLICIES IN A GLOBAL MARKET (2008)

OECD REVIEWS OF HEALTH SYSTEMS - SWITZERLAND (2006)

LONG-TERM CARE FOR OLDER PEOPLE (2005), OECD HEALTH PROJECT SERIES

HEALTH TECHNOLOGIES AND DECISION MAKING (2005), OECD HEALTH PROJECT SERIES

OECD REVIEWS OF HEALTH CARE SYSTEMS - FINLAND (2005)

OECD REVIEWS OF HEALTH CARE SYSTEMS - MEXICO (2005)

PRIVATE HEALTH INSURANCE IN OECD COUNTRIES (2004), OECD HEALTH PROJECT SERIES

TOWARDS HIGH-PERFORMING HEALTH SYSTEMS - POLICY STUDIES (2004), OECD HEALTH PROJECT SERIES

TOWARDS HIGH-PERFORMING HEALTH SYSTEMS (2004), OECD HEALTH PROJECT SERIES

OECD REVIEWS OF HEALTH CARE SYSTEMS - KOREA (2003)

A DISEASE-BASED COMPARISON OF HEALTH SYSTEMS: WHAT IS BEST AND AT WHAT COST? (2003)

MEASURING UP: IMPROVING HEALTH SYSTEMS PERFORMANCE IN OECD COUNTRIES (2002)

A SYSTEM OF HEALTH ACCOUNTS (2000)

SHA Revision information and proposals at http://www.oecd.org/health/sha/revision

For a full list, consult the OECD On-Line Bookstore at www.oecd.org, or write for a free written catalogue to the following address:

OECD Publications Service

2, rue André-Pascal, 75775 PARIS CEDEX 16 